
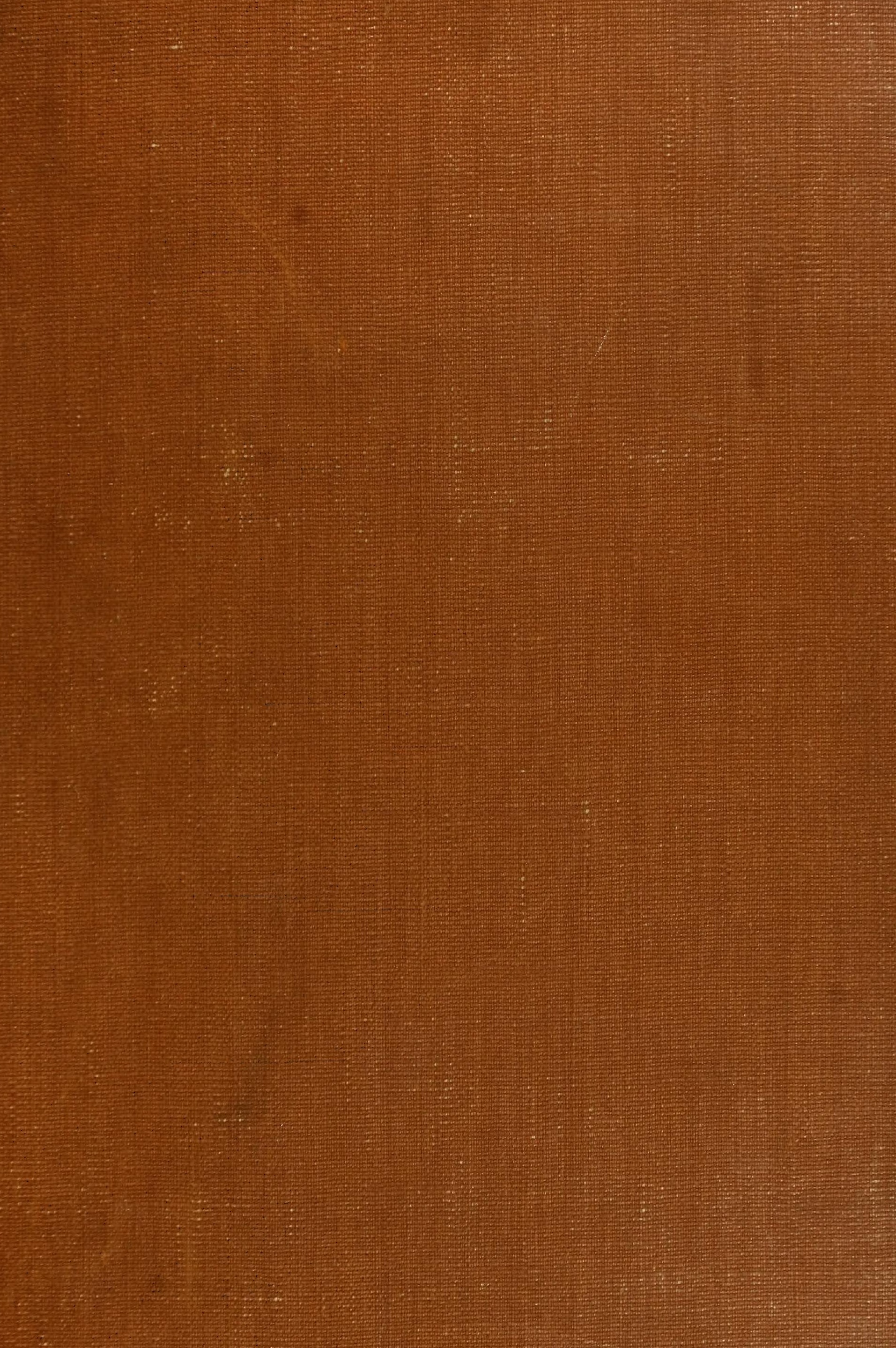


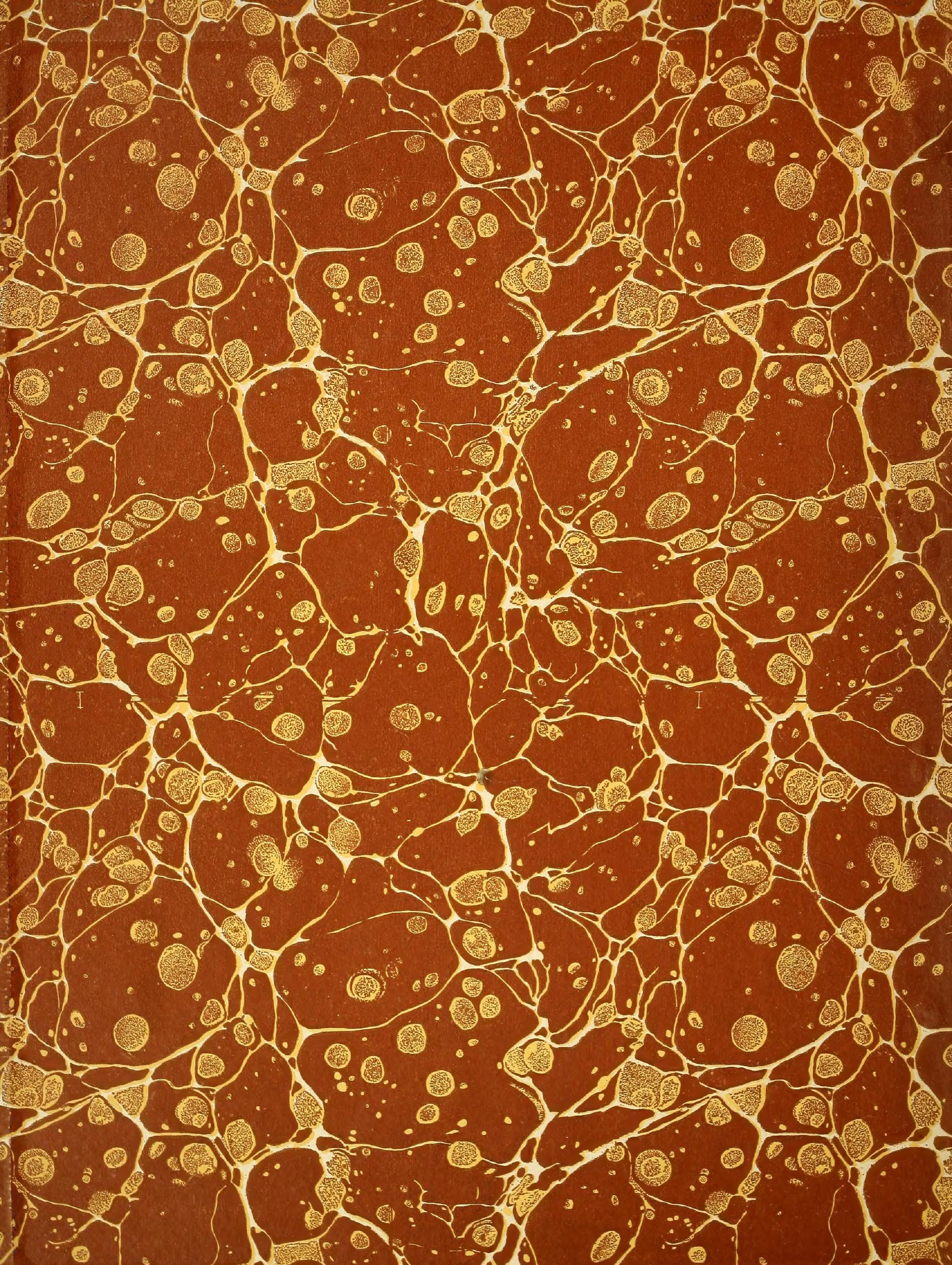




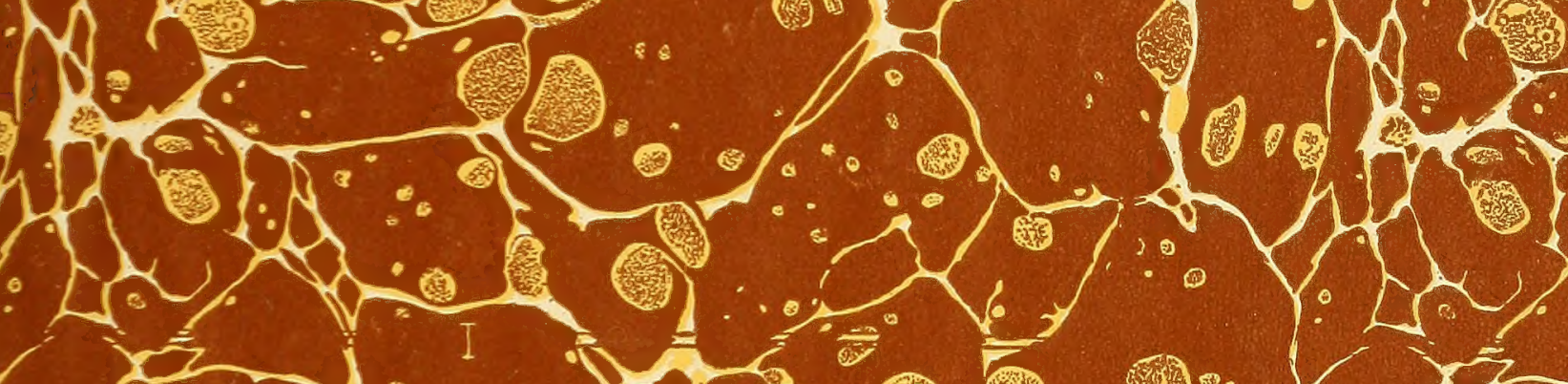
(1)

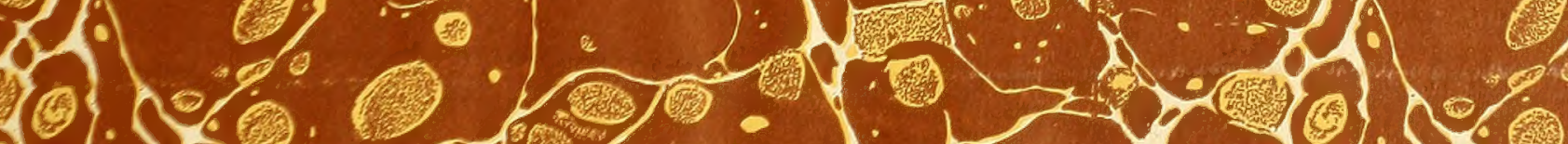

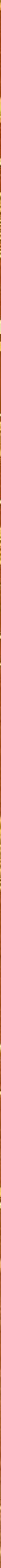






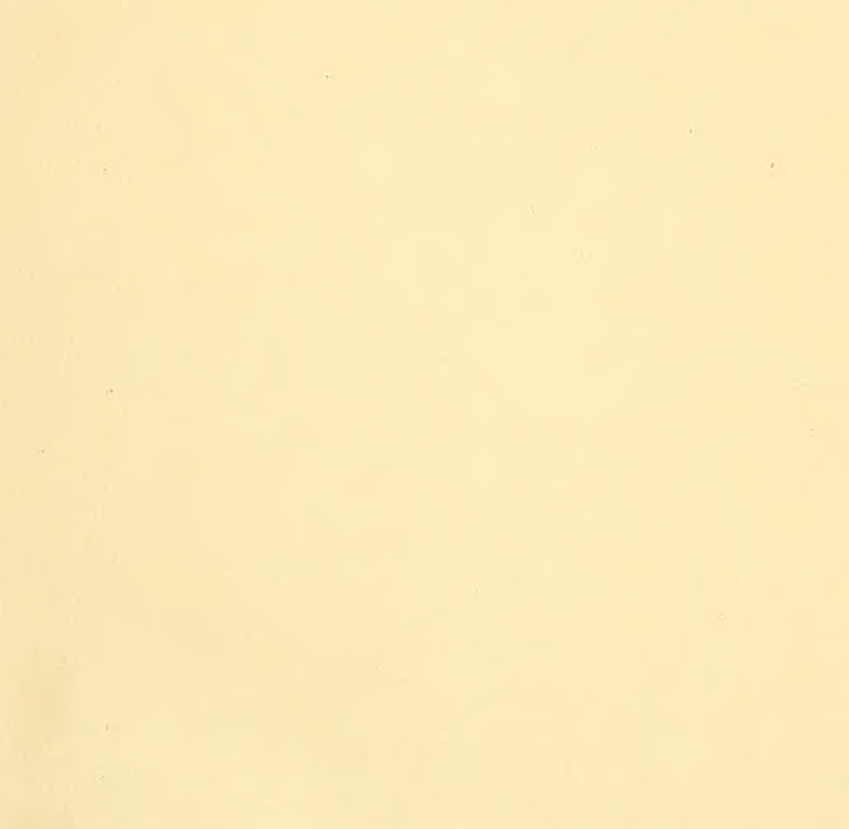





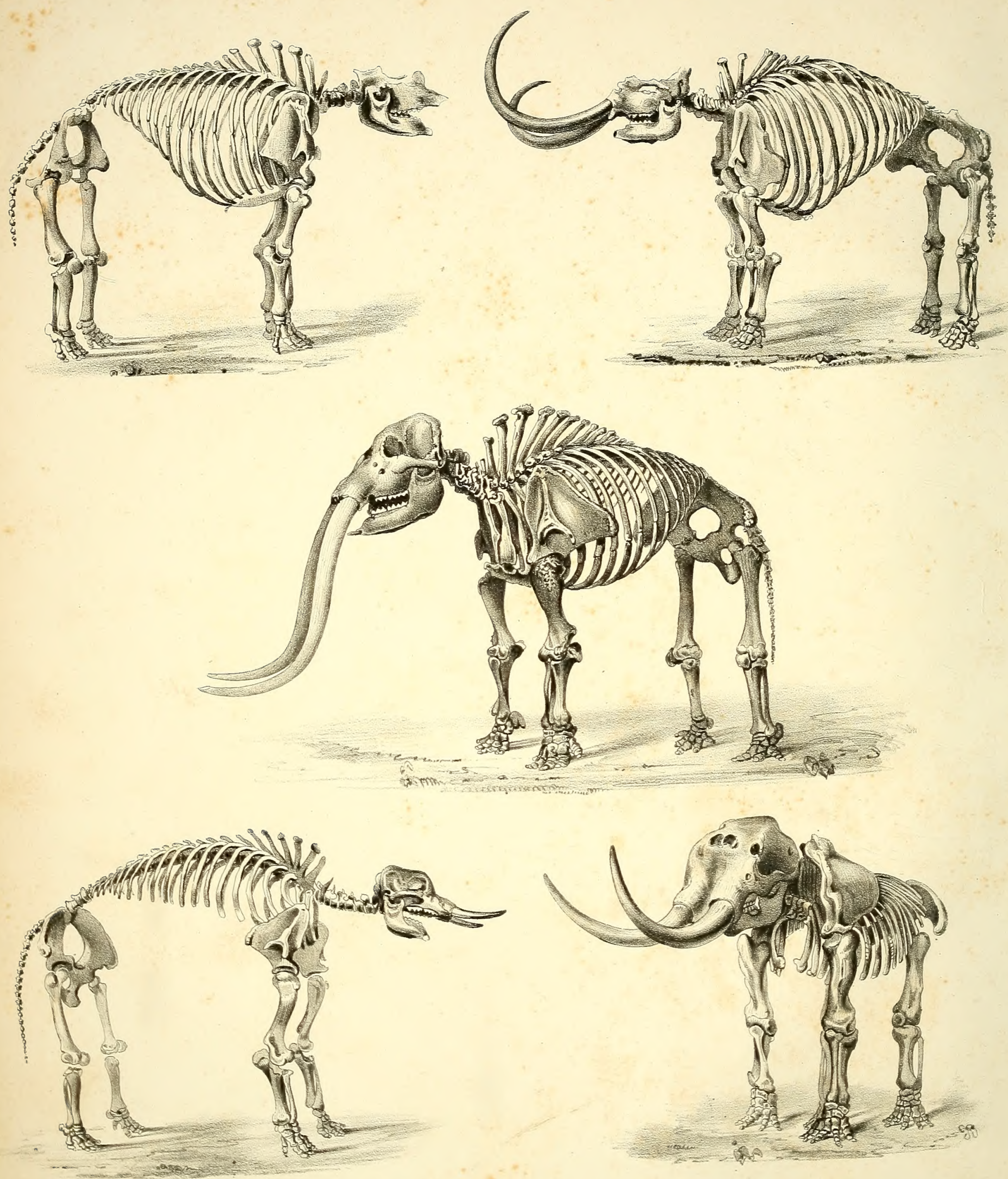


$$
\begin{aligned}
& \text { DES }
\end{aligned}
$$

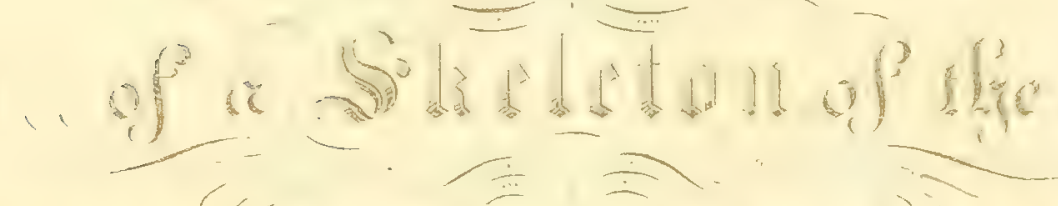

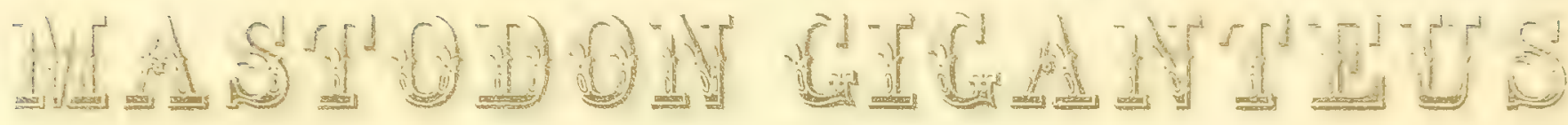
는

19* 9 .
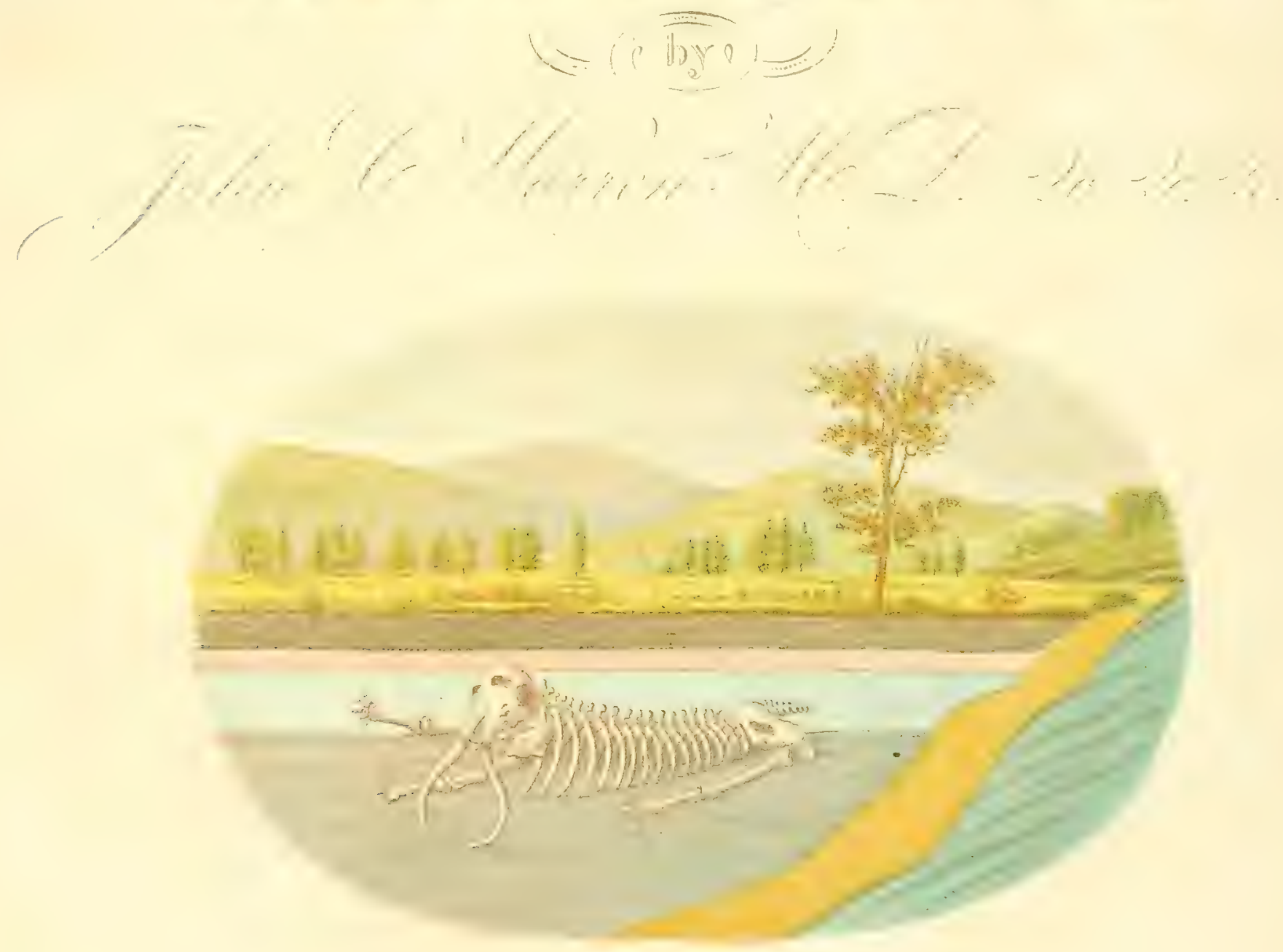

Botiston:

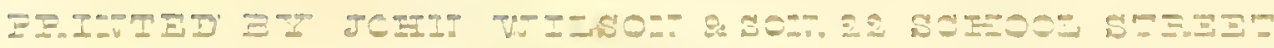

( 



\title{
MASTODON GIGANTEUS
}

OF

\author{
NORTH AMERICA.
}

B Y J O H N C. W A R R E N, M. D.

LATE PROFTSSOR OF ANATONY IX THE EXIVERSITY AT CAMBRIDGE; PRESIDENT OF THE BOSTON SOCTETY OF NATURAL HISTORY;

HEMBER OF THE AMERICAY PHILOSOPHCAL SOCIETY; OF THE AMERTCAN ACADEMY OF ARTS AND SCIENCES; OF THE PHLADELPHA ACIDEMY OF YATURAL SCIENCES; OF THE ACADEMT OF NAPLES, AND MEDICAL SOCIETY

OF PLOREXCE; WOYORARY MEMBER OF THE MEDICO-CHIRURGTCAL SOCIETY OF LONDON;

CORRESPOXDIYG BEMBER OF THE ACADEMIX OF MEDICINE AT PARIS;

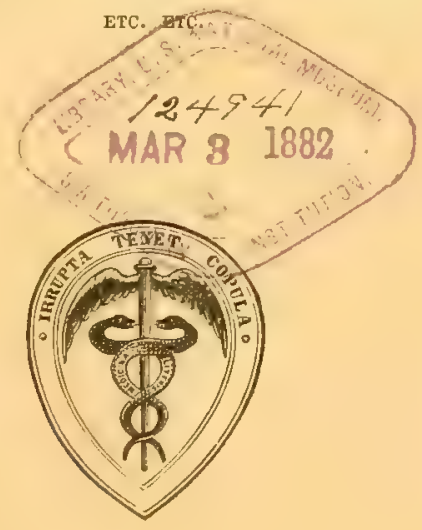

B OSTON:

PRINTED BY JOHN WLSON AND SON,

22, SCHOOL STREET.

1852. 



\section{PROFESSOR RICHARD OWEN,}

OF THE ROYAL COLLEGE OF SURGEONS,

Loxpox,

\section{T̃lis Work is Innscilbe}

\section{AS A TESTIMONY OF RESPECT FOR THE IMPULSE HE HAS GIVEN \\ AND THE}

ADDITIONS HE HAS MADE

To

NAT UR A L S IE N E E. 



\section{PREFATORY REMARKS.}

THE object of this publication is to describe the Mastodon Giganteus of North America. To this task the writer has been led by the possession of an almost perfect skeleton, which seemed to demand of him a description. This description has naturally led to the notice of other subjects connected with the Mastodon history. It may therefore be proper to specify the other means of investigation enjoyed.

The description of the skeleton has been aided by a careful comparison with the Cambridge skeleton; by the bones of the Baltimore Mastodon, those of the skeleton formerly in the Museum of Mr. Peale at Philadelphia, and a complete set of the separate bones of a young Elephant in my collection; by the skeleton of a young Elephant in the Museum of the Boston Society of Natural History, and a noble one in that of Moses Kimbali, Esq. Finally, by a comparison with the skeleton of the Elephant Pizarro, - one of the largest animals brought to this country, - drowned in the Delaware, and the bones of which are placed by the side of the great Mastodon.

Repeated examinations have also been made of the specimens in the large collection at Philadelphia, belonging to the American Philosophical Society, and that of the Academy of Natural Sciences; also of those in the Cabinet of the Lyceum of Natural History, New York, and of the large collection at Washington belonging to Government.

Assistance has also been derived from the inspection of four perfect heads of different ages, and an additional mandible in our University; a large Mastodon head (equal in size and perfection to that of the skeleton), and various fragments of lower jaws belonging to myself; the separate head of an African Elephant in the collection of the Boston Society of Natural History, and Elephant heads of various ages in my own possession. An examination has been made of a number of jaws of Mastodon individuals of different ages, numerous Mastodon teeth, a collection of those of the Fossil Elephants, and many belonging to existing species. 
To those above enumerated must be added a number of casts of Mastodon and Elephant heads from the Himalaya Mountains, given to me by the Trustees of the British Museum; and casts of various heads and teeth of both presented to the Boston Society of Natural History by the Court of Directors of the British East India Company, on the application of his Excellency, Аввотт Lawrence, Ambassador from the United States to the Court of Great Britain.

Circumstances having compelled me to visit Europe, I obtained the great advantage of seeing the collections in the British Museum, Royal College of Surgeons, that of the East India Company and of Economical Geology, the private collection of Dr. MANTELL, the Great National Museum at Paris, the Museum at Hesse Darmstadt (from which, through the kindness of Professor $\mathrm{K}_{\mathrm{AUP}}$, I obtained casts of the principal part of the Eppelsheim fossils), and the beautiful collection at York, made by the labors of Professor Phillips, Mr. Charlesworth, and others.

In our own country, the Smithsonian Institution at Washington, under the management of Professor Henry, has given a new impulse to science by the introduction of foreign scientific works, to which free access has been granted me.

To these advantages I may add the benefit derived from personal conversation with many scientific men in Europe, particularly Professor Owen, Professor Kaup, Monsieur Lauriluard, and Dr. Carpenter. In this country I am indebted to Professor Agassiz for the loan of the engravings of Professor KAUP, till I could obtain them from Europe, and for many valuable suggestions occasionally received. To Professor Wyman I am under obligations for numerous friendly and scientific attentions; also to Professor Srlliman, of New Haven; Dr. Hays, of Philadelphia; Professor H. D. Rogers, of Boston; Professor Gray, of Cambridge; Dr. Gibbes, of South Carolina; and others.

Of these privileges I am conscious that I ought to have made a better use. My apology for not doing so, and for the many errors which may no doubt be discovered in these pages, must be found in the engrossing duties of a profession which has occupied my life. 


\section{0 N T E N T S.}

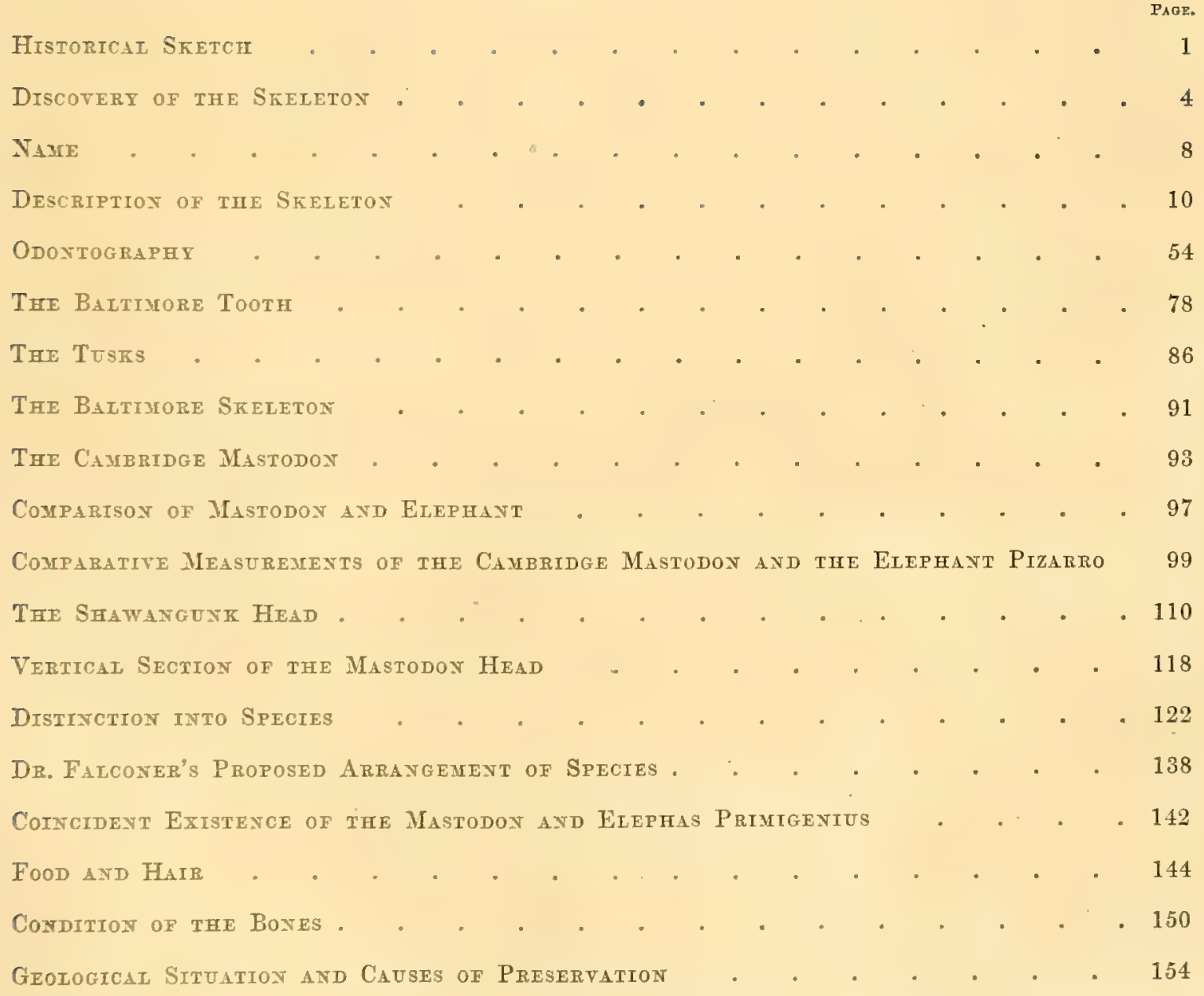




\section{APPENDIX.}

A. - Extract from a letter of Dr. Cotton Mather, of Boston, New England, to Dr. Woodward, S.R. Sec., A.D. 1712

B. - Account of the Exhumation of the Newburgh Mastodon, by J. Darrach, Esq. _ _ . . 172

C. - Mr. Charlesworth's Identification of the Baltimore Tooth . . . . . . 17

D. - Correspondence between Dr. Cohen and the Author in regard to the Baltimore Tooth . 177

E. - Situation in which the Cambridge Mastodon was discovered, being an Extract from the "Proceedings of the American Philosophical Society"
F. - Letter fiom Professor Silliman on Petrifaction . . . . 184

G. - Sir Charles Lyell's Views of the Deposit on the Mississippi containing Mastodon Remains . • • . . . . 186

H. - Specification of the Shells contained in the Marl in which the Newburgh Skeleton was found, by Dr. A. A. Gould . . . 187

Tb.-Microscopic Examination of the Marl, by Dr. John Bacon, jun. . . . . . 187

I. - Skull of an extinet Beaver, found in a Deposit corresponding with that of the Mastodon Giganteus . . . . . . 190

M. Pover's VIEWS OF THE SPEctes - . . . . . . . . . . . . . . 192

The Desiva Mastodon . . . . . . . . . . . . . . . 194

Measures * . . . . . . . . . . . . . . . . . . . 203

AUthorities . . . . . . . . . . . . . . . . . . . . . 204

Explanation of Vigxette axd Plites . . . . . . . . . . . . . . . . 211 


\section{A $\quad \mathrm{S}$ T $\mathrm{T}$ O}

HISTORICAL SKETCH.

THE first account re hare of the existence of Mastodon bones in this country is found in the rolume of the "Transactions of the Royal Society of London," for the year 1714. This volume contains a short article, in which it is said that a letter or letters had been written by Dr. Cotton Mather, of Boston, to Joln Woodward, M.D., and Richard Waller, Esq., S. R. Sec., in England, giring a description of some large bones discovered in 1705, at Claverack, about thirty miles south of Albany, in the State of New York. The bones were two large teeth (one of them weighing more than four pounds), and a thigh bone said to be seventeen feet long. One of the teeth was sent to the city of New York; the other specimens soon crumbled into pieces, and were probably never seen by any one capable of giving an exact account of them. - (A copy of this interesting article will be found in APPENDIX A.)

We hear nothing more on this subject till the year 1740 , when De Longueil, a French traveller, discovered bones at the Salt Lick in Ohio, 
which excited his curiosity so much, that he sent some of them to Paris, where they were subjected to the examination of scientific men. After him wrote Guettard in 1752, Gauthier, Daubenton in 1762, Buffon in 1765, Collinson in 1767, W. Hunter in 1768, P. Camper, Jefferson, Blumenbach, Vichaelis, Autenrieth, G. Cuvier, Humboldt, A. Camper, R. Peale, Wistar, Bonn, Domeier, Mitchell, Darwin, Godman, Hays, Horner, De Kay, W. Cooper, Harlan, Hermann De Meyer, Kaul, Owen, Silliman, Croizet and Jobert, Lartet, Laurillard, D’Orbigny, De Blainrille, J. B. S. Jackson, Falconer, and James Hall, nearly in the order of their names.

To Cuvier we are indebted for the first elaborate account of the bones of the Mastodon Giganteus. He had not, however, the advantage of a skeleton; nor, in truth, did any exist until the persevering labor of $\mathrm{Mr}$. Peale, of Philadelphia, produced one tolerably complete from the morasses of Orange County, New York, in 1801. Another, less perfect, obtained at nearly the same period by the labors of the Peales, existed in the Museum at Baltimore; and, the collection being remored, it was taken apart, and now belongs to me. About the year 1840, Mr. Koch obtained a skeleton and a rich collection of bones from the banks of the Missouri, which were mounted under the direction of Professor Oren, and have been deposited in the British Museum.

Bones, in greater or less numbers, have been found scattered over a large part of the territory of the United States and Canada. A rast number of these have been collected in the Salt Lieks of Kentucky, in Ohio, Virginia, the Carolinas, Alabama, Mississippi, the Arkansas Country; and lately by the exploring expedition on the banks of the Willamet, in Oregon. It is remarkable that scarcely any hare been knomn east of the Hudson River, and none east of the Connecticut. Professor Silliman, to whom we are 
indebted for many facts relating to this subject, and whose residence is situated in the region between these two rivers, informs us that a fine Mastodon rertebra, in perfect preservation, was found at New Britain, ten miles south of Hartford, in cutting a small mill-canal; also two fine teeth, white, dry, and crumbly, were tumed up in digging the Farmington Canal in Cheshire, about twelve or thirteen miles north of New Haven. These latter, so far as we know, are the only Mastodon bones which have been found in New England.

The great river which separates New York from New England might hare serred as a partial barrier to their passage into the Eastern States. The climate of the latter was perhaps less desirable to them than the milder regions of the South and West; yet as Canada, still further north, presents a number of their relics, climate alone could not have repelled them from the East. Some peculiarity in the soil, or productions of this section of the country, were probably uncongenial to the Mastodon constitution; or perhaps, at the period in which this race existed, the geographical relation of New England to the continent might have varied from the present, by the interposition of an arm of the sea too wide to be readily crossed. 


\section{DISCOVERT OF THE SKELETON.}

Newburgh, in the State of New York, is situated on the banks of the Hudson River, at the distance of about seventy miles from the city of New York, and one hundred and seventy-five miles from Boston. This place seems to have been a favorite resort of the Mastodon race. The country is fertile, undulating, well wooded, intersected with beautiful streams of water, and containing in its valleys small lacustrine deposits, favorable to the growth of such trees and shrubs as probably would afford the animal its subsistence.

In this town, and its neighborhood, Mr. Peale performed his laborious search in 1801.

The spot, where the skeleton to be described was found, is situated in a small valley of three or four hundred feet in length, now destitute of wood and shrubs. On the hills rising from each side are a fer trees, but none of great age. In the midst of this valley was a small piece of water, about thirty or forty feet in diameter, when I saw it. The ground immediately surrounding is wet and swampy, so that the cattle, as they wander about, are occasionally entrapped and mired. Under this watery collection lay the bones of the Mastodon, scarcely covered by the soil and a few feet of water; and there, almost on the surface of the earth, they had remained 
undisturbed for unknown ages. This spot belonged to the farm of Mr. N. Bretrster, whose house, as well as the public road, are at a very short distance.

The summer of 1845 had been unusually dry; many small lacustrine deposits $\pi$ rere exposed by the drought, and their contents removed to fertilize the neighboring fields. The spot above described, though usually covered by a small quantity of water, had been left dry (an occurrence never known before); and Mr. Brewster, wishing to avail himself of its contents, had emplored a number of laborers to remove them. The men had dug through a thickness of two feet of peat-bog, a layer of red moss about a foot thick, and then fell upon a bed of shell-marl (vide Vignette). After raising about a fout of this, they struck on something hard; and a question arose whether it was a rock, a bone, or some other substance. Night approaching, it was necessary to intermit their labor until the following day.

Mr. William C. Brewster, son of the proprietor, and Mr. Weeks, his sun-in-law, with assistants, in the presence of a large number of persons, neighbor's and travellers, proceeded to examine the object of their curiosity. The stroke of a spade brought up a portion of bone, and every one was then willing to believe they had discovered the last retreat of one of the ancient Mastodon inhabitants. The labor of exhumation then proceeded rapidly; and the part struck was ascertained to have been the summit of the head. This, being uncovered, disclosed to the eyes of the spectators the full extent of the cranium, which was four feet in length. The lower jaw was distorted a little towards the left side. The bones of the spine, tail, pclvis, and ribs, were successively found, for the most part in their natural relation to each other. The anterior extremities were extended under and in front of the head, as if the animal had stretched out its 
arms in a forward direction to extricate itself from a'morass, into which it had sunk. The posterior extremities were extended forwards under the body. The tusks lay with their convexities outwards; their anterior extremities opposed to each other nearly meeting; and thus the two tusks, taken together, described a large part of a circle. (Vide Vignette.)

At the end of the second day's labor, the whole of the skeleton had been obtained, with the exception of the posterior part of the sternum, a few bones of the feet, and a number of the caudal vertebræ, some of which were recovered afterwards. The bones were in an almost perfect state of preservation. They were not black, like most of the Mastodon bones, but of a brown color, like those of a recent human skeleton, which had been in use a considcrable time. It is morthy of remark, that no Mastodon bones but those belonging to this individual, and no other bones excepting two or three of animals recently entrapped in the mire, were found in this deposit. (Vide Appendix B.)

The skeleton, haring been extricated from its muddy bed, was deposited in the stable of $\mathrm{Mr}$. Brenster; and, after being cleaned and dried, the bones were ingeniously articulated by Dr. Prime, a scientific physician in the vicinity. They were then exhibited in the city of New York, and in a number of New England towns, for three or four months; after which they came into my possession.

When the skeleton was first seen by me, I perceived that some changes in its arrangement were necessary; and, being very much engaged in my course of anatomy, I requested the aid of my friend, Dr. N. B. Shurtleff, a gentleman equally remarkable for his knowledge of comparatice anatomy, and his mechanical ingenuity. He kindly and readily undertook the details of disarticulating, and re-arranging the bones, - a work which was 
happily and successfully completed after an unremitting labor of nearly four meeks. (Vide Large Plate.)

The principal changes were the depression of the head, in consequence of which the height of the skeleton was diminished, - an increase in the curve of the spine. so as to elevate the middle dorsal vertebræ much abore the anterior, and thus to give to the dorsal portion of the vertebral column the form of an arch, with an upward convexity and downward concavity, - a change in the position of the tusks, so that their convexity, instead of looking outrards, was directed downwards and backwards, their concavity forwards and upwards.

After the skeleton had been satisfactorily arranged; it was exposed for three days to scientific persons, and such other individuals as had the curiosity to examine it; then removed, to be again set up at the request of the distinguished geologist, Sir Charles Lyell, who happened to arrive in Boston at that time. Before being once more dismounted, it was examined by Professors Hornel and Wyman, and by the illustrious philosopher, Professor Agassiz. It has since been set up, under my direction, by Mr. Ogden, with important improvements, and is now deposited in a fireproof structure erected for its reception in Chestnut-street, Boston. 
N A M E.

WHEN the bones of the Mastodon were first discovered in quantity, they were supposed to belong to the same animal as those of the Fossil Elephant of Siberia ; and the name of Mammoth, meaning "of the earth," given to it by the Tartars, was applied to them, and generally used in this country. Cuvier, having satisfied himself that they differed in many respects from those of the elephant, designated the animal from the

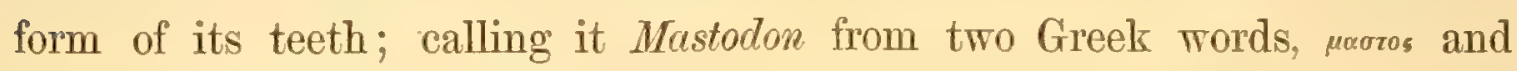
¿sovs, nipple-tooth, or tooth with mammillated eminences.

The great palaontologist of France added the specific term Giganteus; while others have employed, and sometimes he has himself, that of Ohioticus, as if this species belonged exclusively, or in a great measure, to the State of Ohio. As four out of five of the known skeletons were discorered in Orange County, Ner Tork, and the ricinity; and as great numbers of bones have been and still continue to be exhumed in the same district, it mould hare been quite as proper to hare used that of Aurantiacus or Eboracensis. Great numbers of Mastodon bones have been also found at Big Bone Lick in Kentucks, in the States of Alabama, Mississippi, and Missouri; and there would therefore be an equal or greater propriety in deriving a specific name from one of these States. But as 
the term Giganteus has been given and principally employed by Curier; as it has been adopted by Owen and others, and almost exclusively sanctioned by American palaontologists, we think it most convenient and judicious to adhere to this appellation.

"Pennant first ventured, in 1793 , to designate the American fossil animal, in a systematic work, as a species of elephant, by the name of $E$. Americanus; and Blumenbach, in 1797, erected it into a kind of genus, under the name of Mammut Ohioticum, which he briefly characterized by the form of the teeth. Cuvier, in his earliest memoir on the elephant, described it 'also as a species of this genus under the specific designation applied by Pennant of E. Americanus, for which Adrian Camper, entertaining the same opinion of its generic relations, proposed the substitution of E. macrocephalus. But in his second extended and elaborate memoir, published in 1805, which formed the groundwork of what he has written on the subject in the 'Ossemens Fossiles,' Cuvier separated the elephants with mammillated molars from the ordinary forms with lamelliform molars, and united the former into a genus which he designated Mastodon, taking the North American species, under the name of M. giganteum, as the type." Fauna Antiqua Sivalensis, by Hegr Falconer, M.D., F.R.S., and P. T. Cautley, F.G.S., pp. 17, 18.

Dr. Falconer has decided in favor of substituting the epithet Ohioticus for Giganteus, basing this conclusion upon priority of use. 


\section{DESCRIPTION OF THE SKELETON.}

$W_{E}$ feel much delicacy in attempting a description of the great American Mastodon, after it has been so well accomplished by Curier and De Blainville. The only apologg, I must repeat, for such an attempt will be found in the perfection of this specimen, and the advantage derired from a comparison with the skeleton at Cambridge, and the separated bones of the Baltimore Mastodon. Language is insufficient to gire an idea of the grandeur of this skeleton as a whole. Standing as it does in the midst of those of various large animals, - the horse, the cow, \&c., and tomering abore them, its massire limbs make them sink into insignificance. Even the elephant, although nearly as tall, has a frame which might be called delicate when compared with that of the Mastodon.

We shall now proceed to give a particular description of the bones, diriding them into those of the head, trunk, and extremities. We begin with the description of the HEAD.

\section{THE CRA NIU M.}

The cranium is of a flattened form; its longitudinal much exceeding the rertical diameter. We shall describe it as having five faces, viz. a superior, inferior, posterior, and two lateral. 
Stperion Face. - From the vertex of the superior ridge of the occipital superior bone to the anterior edge of the nasal bones, there is an obliquity forwards (Large Plate, and Plates I. and XVI.). From the latter to the anterior termination of the premaxillaries, the inclination is more considerable, being about fifty degrees. The cranium betreen the temporal fossæ is very much compressed. The face below the nasal opening is nearly double the width of the cranium. At the posterior termination of the vertex, we see the superior occipital ridge, which is very rough for the attachment of the cervical muscles. In front of this ridge is the smooth superior parietal surface, deeply indented laterally by the edges of the temporal fossæ. The parietofrontal surface is bounded anteriorly by the bifurcated extremities of the ossa nasi, and a ridge forming the posterior boundary of the nasal fossa.

Belor the nasal bones we perceive the nasal orifice, which is oblong in the transrerse direction: being twelve inches transversely, and six from above domntrards in the median line. The circumference of this orifice is of an oral form, flattened below. The nasal aperture leads into a fossa, which is twenty-four inches in depth from the edge of the ossa nasi to the posterior inferior edge of the pterygoid process of the sphenoid bone. On the superior face of the nasal fossa interiorly, we find two obliquely rounded apertures, each about two inches in their longest diameter, leading to the frontal sinuses. Below these is seen the nasal plate of the os ethmoides, which, united with the vomer, forms a partition between the right and left carities of the nostrils. These passages are five fingers wide from above downwards, and four from side to side, or across.

At the anterior part of the nasal orifice is a groove eight inches long, which, beginning at the vomer, terminates below the cavity of the nostrils in a free edge. Here the two premaxillary bones, uniting at the median 
line, form a bridge at its inferior anterior part; thus giving strength to that part of the carity which receives and supports the internal extremities of the tusks. The floor of the nasal orifice on each side of the median line forms the roof of that portion of the alveolus which lodges the base of the tusk. Hence the tusks, if driven through their sockets, would apparently pass into the cavity of the nostrils. Below this premaxillary bridge is a fossa two inches deep, which is the beginning of the great premaxillary fossa. This, commencing at the lower edge of the cavity just described, expands till it becomes thirteen inches wide at its middle; and, then narrowing, is, at its termination at the anterior edge of the mouth, nine inches. The outside of the premaxillary bone is rounded to correspond with the cavity for the tusks. Its anterior edge, which terminates the superior face of the head, is very thick and rough, and is divided in the median line by a fissure or gap between the anterior extremities of the premaxillary bones.

The sutures of the superior region are not visible on the cranium, but are seen on the face; especially the premaxillary, and those between the maxillary and premaxillary bones. The length of the superior face, from the vertex to the anterior edge of the premaxillary bones, is forty-eight inches; and the width across from one superior orbitar process to the other, twenty-eight inches.

INFERIOR FAcE (Plate XVIII.). - It is bounded posteriorly by the occipital foramen, occipital condyles, and a ridge extending from the condyles to the external auditory foramen. These form a strongly marked boundary between the posterior and the inferior face, as the occipital ridge does betreen the posterior and the superior. Anteriorly, the inferior face is bounded by the maxillary and premaxillary bones. At the posterior 
part is seen partially the occipital foramen, a considerable portion of the articular surface of the condyles, then a strong inferior occipital ridge terminating laterally in the external auditory foramen and the glenoid carity. The termination of this ridge occupies the situation of the mastoid process; but there is no real process existing here, only a thickened tip of the bone and a very rough edge.

Styloid Bones (Plate XX. Fig. 4). - The styloid processes are both perfect, measuring more than nine inches in length. They are attached Bones. at the base of the petrous portion of the temporal bones. This process is rarely seen in place; but in the head of a young elephant we find it connected with the temporal bone by a ligament. The cranial extremity of this bone, presenting the marks of the attachment of a fibro-cartilage, mhich intertened between it and the os temporis, is more than an inch across its longest diameter. From this end the bone tapers with some legree of regularity to its cervical extremity, which is pointed. The bone is curred at its upper part; and one side of the curved portion is fluted like the human claricle, where the subclavian muscle lies under it. The texture of the bone is quite dense; for which reason it has been preserved in a state of perfect integrity, notwithstanding the slenderness of its form.

In front of the occipital hole lies the basi-occipital process, which has a keel projecting downwards. On each side of this are the posterior foramina lacera, which are not large, and have an oblong fissural form, terminating posteriorly in a rounded cavity. These fissures probably give passage to the sublingual nerves, as there is certainly no foramen in the occipital condyle. Or these nerves may pass through apertures, which lie in the lateral direction towards the glenoid cavity. The same deficiency also exists in my heads of the Asiatic Elephant. 
The glenoid cavity is eight inches long, and very narrow; but the zygomatic ridge in front of it is smooth and very prominent, admitting the movement of the condyle of the lower jaw in an anterior direction. The pterygoid processes of the sphenoid are long, and have only an internal plate; but the pterygoid fossa is distinctly indicated. At the root of the strong pterygoid process is a very large Vidian canal, which has a common opening with the optic foramen. In the interval of the roots of the pterygoid processes exists a fossa about half an inch in diameter, through which a wire can be passed to the extent of four inches, where it is interrupted. Between the pterygoid processes is a large opening, leading to the posterior nares: this is four inches across at its lowest part, gradually narrowing and ascending. In the interior of this fossa is seen the septum narium, placed at about two inches from the posterior aperture (Plate XVII.). This extends forwards, and terminates in the large anterior nasal opening. On the outside of the pterygoid processes is the very large inferior opening of the zygomatic fossa, bounded externally by the sharp inferior edge of the zygomatic arch, which terminates posteriorly in a rough process. Anterior to the pterygoid processes is found the smooth, ill-defined posterior edge of the palatine fossa, only four inches wide at its extreme posterior termination, and very thick. This posterior part of the palatine fossa is roughened by a middle ridge, and two rough lateral ridges projecting from above downwards. From this part the palate widens, and, passing between the dental ridges, approaches the posterior molars; between these it narrows again, and is five inches broad. Thence it gradually widens to the anterior extremity of the molar teeth, where it is nine inches wide; then narrows between the sockets of the tusks; and finally expands at the termination of the sockets anteriorly, where it is ten inches broad (Plate IV. and VI.). 
The last portion is separated by a ridge from the swell of the premaxillary, by which ridge the buccal boundary is distinguished. The palatine fossa is remarkably narrow in the elephantine family.

The excaration of this fossa is generally very slight, not so great as in man or the elephant. It has three pairs of orifices for vessels and nerves.

On the inner and outer sides of the teeth are the alveolar ridges, sharp at their termination, soon becoming thick and strong. On the outside of the alreoli is a depression in the superior maxillary bone, bounded superiorly by the great infra-orbitar foramen. In front of the teeth are the rounded anterior extremities of the sockets of the tusks, which are much thinner here than at the superior part of the tusk-cavity. The anterior opening of this carity is eight inches in diameter. This opening is formed entirely by the premaxillary bone.

A particular description of the tusks of the upper and lower jaws will be found in a separate section.

Posterior Fice (Plate XIX.). - The posterior face of the cranium is Posterior nearly rertical, and composed by the occipital bone. It has generally a Face. flattened form, rendered irregular by various eminences. These are, 1st, a rertical crest, eight inches long by three and a quarter high, perforated at its base by a number of irregular holes; $2 d$, the projections of the occipital condyles; $3 d$, many irregularities, which occupy the whole surface of the bone, but are particularly distinct below the superior ridge, some of them eren being prolonged into remarkable processes, destined, no doubt, to give a stronger attachment to the muscles. There is also, on each side of this rertical crest, a deep depression, about eight inches long by three wide, for an attachment to the great ligament which supports the head. 
Above the occipital crest is a blind osseous cavity, uncovered by the breaking of the external table of bone into some of the numerous cells of the cranium. At the inferior part of this surface is the great occipital foramen, which looks from before backwards, and a little obliquely from above downwards. It is three inches and a half in the transverse, and four in the antero-posterior diameter. On each side are the occipital condyles, projecting two inches on their median limes, and presenting an articulating surface four inches broad and eight long. The posterior face of the head is twenty-two inches high by thirty-two wide. The condyloid portion of the occipital bone is separated in young animals from the supra-occipital by an angular suture, which crosses from the posterior angle of one temporal bone to the other.

In the young Mastodon head is seen the occipito-parietal suture. It lies midway between the inferior termination of the vertical ridge and the upper edge of the great occipital foramen, extending from this median point in a lateral direction more than half-way on the posterior face; then at an acute angle turning downwards, and with an inward curve terminating on the outside of the occipital condyle.

Lateral Faces (Large Plate, and Plate XVI.). - The lateral face is separated from the superior by a line which extends from the superior occipital ridge along the superior edge of the temporal fossa to the orbit, thence along the superior orbital ridge, and from the inferior anterior abrupt termination of this ridge forwards through the anterior infra-orbitar foramen to the edge of the tusk-socket. This line is strongly marked and rough at the upper edge of the temporal and of the orbitar fossæ, beyond which it is not indicated by any natural mark.

The temporal fossa is of rery great size. It is formed by the parietal, 
temporal, superior maxillary and sphenoid bones on its inner face. Its outer surface is constituted by the zygomatic process of the temporal bone, br the jugal bone, and the zygomatic process of the superior maxillary. The inner face is very much excavated; its superior extending laterally four inches more than its inferior edge. It measures from above downwards trenty-three inches; its width across is ten inches, and length from behind forwards, thirteen.

At the junction of the sphenoid with the upper maxillary bone is seen the long. spheno-maxillary fissure. At the anterior part of the zrgomatic fossa is the posterior oval opening of the infra-orbitar canal. This, at the inlet from the fossa, is large enough to receive the hand. The infra-orbitar canal is seven inches long. In front of the infra-orbitar formen is seen a small opening, which communicates with the great infraorbitar canal; an arrangement different from that in another Mastodon head of the same size, and also from that of two elephant heads. Between these holes and the anterior edge of the premaxillary bone we notice the suture of the maxillary and intermaxillary bones, which is very distinct at this part.

The zrgomatic arch, anteriorly and posteriorly, is very strong and thick. Its superior edge is fissured at the junction of the temporal and jugal bones. The inclination of the jugal bone is from before backwards, and from below upwards, when the cranium rests on its lower surface. The union of the jugal with the maxillary is close, but the suture is still persistent. The temporal hone is perforated by the external auditory foramen at a short ristance behind the union of its zygomatic process with the jugal bone. This canal measures two inches from above downwards, an inch and a half across, and is in depth twelve and a half inches. 
Orbitar

Fossa. at its posterior part. Near the junction of the jugal and maxillary bones is an eminence, which forms the infero-posterior part of the bony orbit. In front of this is a curve of the jugal bone, which, being continued by a curve in the maxillary bone, terminates at the inferior anterior orbitar process of the os frontis. A curved line extending first upwards, then backwards, forms the superior edge. The inferior anterior orbitar process above mentioned forms a projection an inch and a half high, dividing the anterior part of the orbit into two portions, as just stated. The bony circle terminates posteriorly in the superior orbitar process.

The bony orbit, then, is constituted in the following manner: - At its postero-superior part is the large, thick projection of the superior orbitar process; the bone then arches formards to a second remarkable projection, the inferior anterior orbitar process; thence, extending downwards and backwards, it terminates inferiorly and posteriorly in the jugal process of the orbit. The ridge thus described composes about two-thirds of a circle, flattened in its antero-posterior direction.

L O W ER JA W.

The outline of the lower jaw (Plates II. III. V.) has the form of a V, the anterior extremity being almost pointed. Te shall describe first the branches, and then the body of the bone, on their outer and inner faces, comprehending the description of the superior and inferior edges with that of the faces respectively.

External The external face is divided into two parts; the posterior of which, or articulating portion, has a quadrangular form. At the upper edge of the quadrangle, we see the narrow condrloid process, measuring six inches in 
length, and three in the transverse direction over the articulating surface. The sharp edge of the semi-lunar notch terminates anteriorly in the coronoid process, which is thin and pointed at its extremity, about three inches long, convex on the outside, concare on the inside. The condyloid and coronoid processes are nearly equally elerated; but the coronoid is in a slight degree lotrer than the other, in which it resembles that of the elephant, and differs remarkathly from that of the tapir, hippopotamus, fossil elk, and especially from the carnivora. The anterior edge of the quadrangle is thick at the root of the coronoid process, and afterwards divides into two ridges; one ruming inwards torrards the dental edge, the other outwards to the body of the jar. The inferior edge of the branch of the jaw is first smooth; then, as it approaches the angle, it becomes rough. The angle itself is rough. It rises with some obliquity to the condyloid process, at its junction with which there is a tubercle, while the neck above is very much flattened at its back part. On the outside, below the superior or semi-lunar edge, is a rleep fussil, extending from the root of the coronoid to that of the condyloid process, and serving to give attachment to the temporal muscle. The inferion prit of this external face of the branch is roughened by the attachments of the masseter muscle.

The external surface of the body of the inferior maxillary bone has a contex form. It presents two considerable apertures: one large, opposite tr, $i . r$ on the outside, and in the same perpendicular line with the middle rirlge of the anterior molar tooth; the other, near the anterior extremity of this face, is smaller; the first orifice being an inch in diameter, the second half an inch.

The internal face of the branch is excavated within the coronoid process for the attachment of the temporal muscle. Behind this fossa is the orifice 
of the infra-maxillary canal, which is twelve inches long, and one and three quarters in diameter. Below and behind the infra-maxillary orifice is an extremely rough surface, nearly fourteen inches in its longest diameter, for the attachment of the internal pterygoid muscle. On the inner surface below the neck is a rising for the attachment of the external pterygoid muscle.

The internal face of the body of the bone is oblique from above downwards, and from within outwards, except at its anterior part, where the direction of this face becomes perpendicular; and there it terminates in the infra-maxillary symphysis and gutter. The latter extends from the lower edge of the symphysis, first upwards, then forwards, and at last downwards, where it terminates in the anterior edge of the body of the bone. This groove, destined to receive the anterior extremity of the tongue, is about twelve inches long, and three and a half in its greatest width. The bone terminates anteriorly in a truncated manner; the truncated portion, having a circular form, is about three inches in diameter. In this portion we perceive on the left side the incisor tooth, or tusk (Large Plate); on the right side exists a depression an inch and a half deep, which had formerly contained a corresponding tusk. The depth of the carity on the left side is seven inches.

Edges.

The superior edge of the body of the bone behind, where it joins with the branch, has a slight fossa, the posterior part of which is a canal for the vessels and nerves. Immediately behind the molar teeth is a small ridge, which gradually separates into two, forming the external and internal alreolar ridges. In front of the molar teeth, these ridges unite together, and are tro inches thick at their point of union. They gradually coalesce into a single ridge, which extends fortrards to terminate orer the tusk- 
carity in a rounded form. The inferior edge of the body has a rounded form. On its left side is seen a considerable exostosis, quite rough and irregular, about the thickness of a man's wrist, and projecting from two to three inches.

T H E T E E T H.

The teeth are two on each side in each jaw, making in the whole eight teeth. The outer edge of those in the upper jaw projects beyond that of the lower; consequently, detrition has taken place on the outer edge of the lotrer dental surface, and inner edge of the upper. The direction of the teeth, and that of their alveoli, are obliquely forwards; all of them are tight in their sockets, and, of course, we are able only to examine their crowns. Those in the upper jaw, taken together, are eleven inches long on each side; those in the lower, rather more. They measure transversely nearly four inches.

The posterior tooth in the upper jaw has four ridges and a posterior eminence, or heel. The ridges are each subdivided into two mastoid processes, and a single posterior mastoid eminence terminates the longitudinal line of division separating the other processes.

The anterior tooth has two transverse furrows, making three ridges, which are subdivided by the longitudinal line into six nipples. Those of this tooth are very much worn, in some parts of them an inch being worn array, exhibiting the internal bone or dentine of the tooth. The thickness of the enamel is about the eighth of an inch.

The teeth of the lower jaw correspond nearly with those of the upper. A small part of the anterior tooth of the lower jaw has disappeared, apparently having been worn away. 


\section{T H E S P I N E.}

The head is set upon the atlas (Plate XXI. Figs. 3 and 4) by an articulation, which has so great an obliquity that the atlas seems to give to it very little mechanical support. This support depends almost wholly upon the great strength of the muscles arising from the dorsal spines, and the great power of the levers formed by the first six or seven dorsal vertebræ.

Cervical Vertebre. General Description. - The vertebræ of the neck are seven in number. They extend obliquely from above downwards, and from before backwards, so that the body of the seventh cervical is about eleven inches lower than that of the first. The inferior face of these vertebræ is convex in a direction downwards and forwards, but flattened. There is in the six superior a projecting ridge on the anterior part of the body, which divides this face into two parts: this ridge is largest in the upper, and diminishes in descending. The superior face of the whole cervical region, considered generally, is rery short, being about fourtcen inches only in length. Its anterior part is irregular, from the prominence of the spinous processes of the first and second rertebræ. The second spinous process, in consequence of the bend of the neck, approaches nearly to the serenth; the four intervening being very small. The lateral portions of these vertebræ present as a whole an inferior ridge, formed by the projection of the transrerse processes, and a superior ridge constituted by the upper extremities of the articulating processes. Betreen these two ridges is an excavation for lodging the cervical muscles.

Atlas.

Particular Description. - The atlas (Plate XXI.) resembles the human as to its general form. The body presents inferiorly a very remarkable projection at its middle for the common anterior rertebral ligament. The 
anterior face has the two articulating condyloid surfaces, six inches long and four across; the excaration is moderately deep.

The spinous process is short and notched; the transverse are very large, strong, and rough on their outer edges. The roots of the latter processes are perforated with holes, about an inch in diameter, for the passage of the rertebral arteries: these apertures open into a canal, which, after running three inches, terminates in another canal leading into the back part of the spinal carity, and giving passage to the artery already mentioned. The inferior articulating surface is excavated for the reception and interlocking of the superior surface of the second rertebra. The atlas measures eighteen inches across, and thirteen from above downwards; in circumference it is forty-four inches.

The sceond rertebre (Plate XXI. Figs. 5, 6, and 7 ) is of an oblong form, second and has its longest diameter in a direction from before backwards, and Vertebra. from below upwards. The body is flattened, and surmounted by the odontoid process. The transrerse processes are rery short and notched; the spinous process is rery large, thick, strong, and rough, affording space for the attachment of large and strong muscles. From the superior part of the body arises the odontoid process, which has not the form of that of the human slieleton, but is more prramidal, solid, and short, extending into the posterior face of the body of the atlas.

The bodies of the third, fourth, fifth, and sixth vertebroe present nothing Third, rery remarkable. The spinous processes of these four are very short, being Fourth, only from tro to three inches long; the transverse processes are also short, ${ }^{\text {and Sixth. }}$ and are all perforated by the vertebral arteries.

The secuth cervical vertebra measures fifteen inches across; the body seventh. is rounded, being seven inches in diameter, and presents on its sides quite 
large articulating surfaces for the first rib. The transverse processes of this vertebra are large, thick, and rough; they have no perforation for the vertebral artery. The spinous process is double the length of the sixth, being six and a half inches long. The spinal canal has an oval form in the cervical vertebræ, and is about four inches from above downwards, but less than that in the transverse direction.

Dorsal

Dorsal Vertebrix. - The dorsal vertebræ are twenty in number. They form a considerable concavity; for, springing from the base formed by the cervical vertebræ, they gradually ascend to about the twelfth, and then descend to the lumbar vertebræ, which are continued downwards to the pelvis; so that the dorsal and lumbar vertebræ, taken together, form an arch, the concavity of which is downwards. The central point of the segment of the circle thus formed is more than a foot higher than its extremities. The inferior surface of this part of the spinal column is generally rounded; but, as it approaches the lumbar vertebræ, it becomes less convex. The superior face of the column presents three lines; the middle formed by the projections of the spinous, and the two lateral by those of the transverse processes.

The first seven dorsal vertebræ are remarkable for very long spinous processes; from the fourth to the sixteenth, these diminish in length (Plate XXII.); the remaining four are equal. The extremities of the spinous processes of the anterior dorsal rertebræ are much enlarged and scabrous for muscular and ligamentous attachments; all of them lave a roughness at their extremities. The third of these measures eight inches from before backwards; and the fourth, seven inches transrersely. The longest spinous process, that of the third dorsal, is trenty-three and a half inches long; the last, which is the shortest, is only four inches in length. The tips of 
the longest spinous processes are not co-ossified with the shaft. All of them, on their anterior and posterior faces, are roughened at the insertion of the inter-spinal ligament.

The transverse processes are very thick in the first seven dorsal Transverse vertebræ, more prominent than in the others, and rough for muscular attachment: the extremities of all of them have a rough surface.

The articulating processes are not prominent in the sixteen anterior Articulatvertebræ, but, become so in the posterior on their anterior surface, the Processes. posterior surface not being so ; their surfaces generally affect the horizontal direction. The bodies (Plate XXII. Figs. 1, 2,. 3) have mostly a rounded form, but the last approximates to an oval; they are of about the same size in the different dorsal rertebræ. Their anterior and posterior surfaces are smooth, as is also the superior or medullary surface; the inferior is somewhat irregular, more flattened in the superior than in the inferior vertebræ, the last having this surface a little excavated anteriorly. The thirteen superior have a double articulating costal surface on each side, near the superior edge of the body (Plate XXII. Fig. 4). The first articulating surface is two inches and a half long, and two inches across.

Another surface for the tubercle of the rib is seen on the inferior face of the transterse processes of the thirteen superior bones. The medullary canal is of a triangular form in the uppermost dorsal vertebræ, and measures four inches on each side; inferiorly, it is flattened or elongated transversely.

Ltybar Vertebre. - These are three in number (Plate XXIII. Fig. 3). Lumbar Their spinous processes are short and oblique; in length they are the same Vertebræ. with that of the last dorsal. The transverse processes are very remarkable, particularly that of the first lumbar. This vertebra, measured across the 
transverse processes, is serenteen inches, nearly a foot and a half in length. While each of these processes is in this about six inches in length, that of the last dorsal is only three inches.

The bodies of these lumbar vertebræ have a more oval form than those of the dorsal generally. Like that of the posterior dorsal, they are much excavated on the lower surface. On the whole, these bones are more massive than the dorsal; but the difference in this respect is not so great as it is in man, in quadrumana, and in carnivora.

Os SACRUM (Plate XXIV.). - This bone is slightly excavated inferiorly. It consists of five pieces, presents four pairs of holes, and a pair of grooves below and behind. The excavation is of an oblong form, extending from the anterior or larger to the posterior or smaller extremity. The hollow of the sacrum, as seen in man, does not exist. The sides or edges are very thick, and are co-ossified mith the ossa innominata. The inferior face is trenty inches long; the upper articulation measures seven inches across; on each side of it is the iliac portion of this bone, four inches in extent.

The posterior face of the os sacrum is rough, from its numerous processes. Superiorly and anteriorly are the two long transverse processes of the first bone; below these are three other pairs of transrerse processes. The spinous processes are fire, the first and last of which are the most prominent. There are five pairs of holes on this face. The inferior extremity is nine inches across. The spinal canal is much flattened, and measures three inches across.

Catdal Vertebrex (Plate XXII. Figs. 6, 7, 8). - A number of these were not found with the skeleton, haring no doubt been decomposed; but those which exist appear to be of three classes: the first haring spinous and transrerse processes; the second haring transrerse with indistinct 
spinous processes; the third having indistinct spinous and transverse processes. The superior rertebræ hare a thick, oblong, solid spinous process; the middle hare this process bifid. The superior, to the number of seven, hare a regular spinal canal; the middle, an imperfect canal; the inferior, a mere groore on the dorsal surface. The five superior vertebræ measure one foot across the transverse processes; the body is oval, transversely oblong, with an articulating surface of three inches in diameter. The transterse processes are about three inches wide; the canal is an inch and a half in diameter.

The bifid vertebræ are slightly elongated. The largest measures about eight inches across the transverse processess.

The grooved vertebræ are more elongated. The smallest in this skeleton measures three inches in length. The front of the bodies of the rertebrie is generally slightly excavated, rough at the intervertebral connection.

\section{THE PEL VIS.}

The pelvis (Plate XXIV.), in consequence of the arched form of the vertebral colum and its obliquity, is placed rather behind than below this columm. Its anterior face is inclined a little downwards; the plane of the upper opening of the pelvic strait is nearly vertical; the lower is quite ollique, its inferior wall forming an inclined plane backwards and downwards.

It is an enormously massive structure; a part of the bones being very thick and strong. The upper portion of the pelvis, though less excavated, more nearly resembles the human than does that of most other animals, including the carnirora, ruminantia, and even the quadrumana. But the 
lower part differs in having no sub-pubic arch. The three great bones of the pelvis are co-ossified. The width across the anterior spinous processes is six feet two inches; the depth of the pelvis, from the summit of the symphysis pubis to the summit of the pubic arch, is thirty inches.

The foramen ovale is situated four inches below the superior opening of the pelvis. The surface in which this foramen is placed, represents an inclined plane, beginning with the postero-superior edge of the os pubis, and terminating in the inferior part of the os ischium. It measures nine inches in the vertical direction, and five in the transverse. The outlet measures across its brim trenty-two inches; frem the pubis to the sacrum, twenty-one inches.

Os Innominatum. - The supero-anterior edge is surmounted by a

very thick, rough crest, elevated near the sacrum, depressed at the spinous process, and exhibiting the state of epiphysis through the greater part of its course. Continued downwards and backwards from the thick anterior summit of the spinous process, this edge becomes thinner; then enlarges towards the pubes, where it is rery thick. The pubic bones are consolidated. Below the symphysis is a fissure extending nine inches downmards, where it terminates in a co-ossification of the ischiatic bones; and there they are massive. The posterior ascending edge of the ischium is of great thickness at the lower part, becomes thinner at the upper, terminating in the tuberosity, the thinnest part of this edge. Abore this tuberosity is the ischiatic notch, the edge of which is thin and rough, till it strikes that of the os sacrum; thence, arising to the superior anterior juncture of the sacrum with the os innominatum, it is rery thick, and co-ossified with this bone.

The anterior face of the os innominatum is moderately excavated, looking a little domnwards. Towards the pubic portion, it presents a 
process corresponding with the eminence on the human linea ileopectinea, from the intermal side of which extends a branch of the pubes and ischium, excarated in the middle, and separated from the branch of the ischium br the ischiatic ridge. This face terminates inferiorly and posteriorly in the areh of the pubes, which is distinctly seen within, although not visible on the outside of the pelvis. Just above the acetabula, near the union of the ilium and pubes, are two deep rascular depressions, passing outrards towards the anterior spinous processes.

The posterior superior face of the os innominatum is slightly excavated at its sacral portion: near the acetabulum it becomes rough; and inferiorly, smooth. The acetabulum is not of great depth; its diameter is nine inches; it has a deep groore on its anterior or pubic face, for the admission of bloodressels and nerres to the articulation. There is no depression for a round or inter-articular ligament.

The ischium has a very small spinous process. The spinous process of the pubes is represented by a roughness of the bone. The inferior anterior spinous jrocess of the ilium is continuous with the thick superior anterior syinons process. The posterior superior spinous process is prominent, and not thick. The posterior inferior spinous process has the same appearances.

THORAX AND RIBS.

The thorax (Large Plate) has a rounded, barrel-like form, flattened above at the rertebral column. Its anterior opening is two feet long from atrove domnmards, and one foot across; the posterior looks obliquely torrards the cavity of the abdomen. 
The Ster- The Sternum. - The sternum is a massive bone with a keel beneath, num. by which its inferior surface is divided into two faces. Anteriorly, the bone is pointed, or has a protuberance two inches thick. From this anterior extremity the sternum becomes wider to its anterior third, which is thirteen inches across. Its posterior part is narrowed, and the sides compressed; the anterior pieces are co-ossified. The anterior extremity of the bone is very rough and irregular for the reception of the inferior extremities of the first rib, with which it is partially co-ossified. The posterior extremity of the sternum is supplied.

The Ribs. - The ribs are twenty in number; thirteen true, and seven false. The first rib (Plate XXIII. Fig. 1) differs from all the others in form, having more the appearance of a clavicle than of a rib. It is situated in a vertical direction nearly; the superior extremities, however, of the two ribs being more distant from each other than are the two inferior. They are placed nearly on a line with the anterior edges of the scapula. This rib may be divided into three parts; a superior, middle, and inferior. The superior, connecting with the vertebral column, has nearly the form of the superior part of the human os femoris, and admits of three divisions, viz. 1st, the head, which is four inches thick, and presents a flat articulating surface to correspond with the first dorsal vertebra; $2 d$, the neck, in circumference six inches, presenting a prominence on its superior part; $3 d$, the great tuberosity, with an articulating surface on its rertebral extremity, where it comes in contact with the transverse process. The body of the bone is of a rounded form superiorly. The inferior extremity flattened is broad, massire, irregular, and co-ossified with the sternum; at its narrowest part it is six inches in circumference.

The length of the first rib is twenty-eight inches, from which the 
subsequent ribs increase in length to the ninth inclusively; and thence diminish to the lowest false rib, as will be seen by this table. The first rib measures 28 inches; second rib, $35^{\frac{1}{2}}$ in.; third rib, $39 \frac{1}{2}$ in. ; fourth rib, $44 \frac{1}{2}$ in.; fifth rib, $49 \frac{1}{2}$ in.; sixth rib, 52 in.; seventh rib, $53 \frac{3}{4}$ in.; eighth rib, $54 \frac{1}{2}$ in.; ninth rib, $54 \frac{3}{4}$ in.; tenth rib, $53 \frac{3}{2}$ in.; eleventh rib, $52 \frac{1}{4}$ in.; twelfth rib, $49 \mathrm{in.}$; thirteenth rib, $45 \mathrm{in.;} \mathrm{fourteenth} \mathrm{rib,} 42 \mathrm{in.}$; fifteenth rib, $37 \frac{1}{2}$ in.; sixteenth rib, $34^{\frac{1}{2}}$ in. ; seventeenth rib, 32 in.; eighteenth rib, $28 \frac{3}{2}$ in. ; ninteenth rib, 26 in. ; twentieth rib, 21 in.

From the second to the sixth rib inclusively, they are broad near the rertebral extremity; the broadest being the fifth, which measures four inches (Plate XXII. Fig. 4) ; after the seventh, they lose the flattened form at this extremity, and resemble the human ribs. The head, in each of the true ribs, presents an articular surface. The tubercle of each rib has also an articular surface, to correspond with that of the transverse process of the rertebra. The anterior edges of the ribs are sharpened; the posterior are rounded, and present a broad groove for the intercostal vessels, but this groove is less distinct in the anterior ribs. The sternal extremities are rough for the cartilaginous attachment.

The second rib on the right side (Plate XXIII. Figs. 1 and 2) has been broken six inches from the sternum, and reunited irregularly by osseous matter, which is perfectly smooth anteriorly, showing that the fracture had been of long standing. Near the sternum is a considerable irregularity, owing to uneven union.

The last two false ribs on the right side are co-0ssified for the space of eight inches; the result of a fracture near their vertebral attachments: the union of these ribs, at its broadest part, measures eight inches (Plate XXIII. Figs. 3 and 4 ). These bones are perfectly smooth within, and 
without are quite strong, at the place of union, and massive. This fracture is of great importance, as by the union is verified the remark of Cuvier, who found only nineteen ribs, but stated that there would, in his opinion, be hereafter found twenty, - a fact entirely established in this specimen, first, by the articular surface on the side of the twentieth dorsal vertebra; and, second, by the co-ossification of the nineteenth and twentieth ribs.

\section{A NTERIOR EXTREMITY.}

The Scapula.

The Scapula (Plate XXIII. Fig. 5). - The scapula is of a triangular form, nearly equilateral, and more closely resembling, in this respect, that of man than is that of the Asiatic Elephant. The curved process is also longer than that of the latter, and forms a large portion of a circle. The situation of the bone in this skeleton is such as to cover the six anterior ribs. Its superior part, or angle, corresponds with the bodies of three of the dorsal vertebre; and its inferior part, forming the glenoid carity, corresponds nearly with the anterior piece of the sternum.

The external face of the scapula (Plate XXV. Fig. 1) is divided very unequally by the spine; the anterior or supra-spinous fossa having less. extent than the posterior, or infra-spinous. The spine, arising from the rery thick rough superior angle, is thin at first; aftermards, the body of the spine being very thin, it becomes thicker and wider; and, where it divides into its processes, it is six inches broad. The anterior process, corresponding with the acromion, is short; smooth on the outer, and very rough on the anterior part. This process is ten inches long. The curved process, fourteen inches long, is rery rough on its outside, and smooth on the inside. It does not correspond with the human coracoid process, as 
it does not arise from the glenoid cavity, but is rather a division of the great spine of the scapula, which may be said to bifurcate at its inferior extremity; forming an anterior division, the acromion process; and a posterior, longer, rougher, and curved, thence called the curved process.

The supra or anterior spinous fossa is small, the posterior very ample: the former measures only six inches at its widest part; the latter, twentytwo. The first is a little excavated on its outer face; the latter, generally convex, but with a concarity near the spine.

The internal face or hollow of the scapula is subdivided into two unequal faces by an eminence corresponding with the spine of the scapula. It is smooth inferiorly, very rough superiorly, and terminates in the very rough thick superior angle.* The anterior division corresponds very nearly with the anterior spinal fossa; the posterior division is the real hollow of the scapula; it occupies the posterior two-thirds of the bone; the anterior is not excarated, and is very rough for muscular attachments. The anterior edge of the scapula is generally thin, except at its junction with the neck of the bone, where it becomes rery thick, terminating in the superior edge of the glenoid cavity.

The glenoid carity is regularly excavated, of an elongated oval form, and looks dornmards. Its articular surface is eleven inches long, and five wicle. Its circumference is not particularly rough, except near the external edge.

The posterior inferior edge of the scapula is thick near the articulation; then becomes thin; and afterwards thickens in the posterior angle, which is very thick, but not so much so as the anterior superior angle.

* It is stated by authors, that this eminence does not exist in the subscapular face of the Asiatic Elephant; but in our specimen it is very remarkable, as it is also in the Mastodon. 
The posterior superior edge, which corresponds with the base of the scapula in man, is thick and rough inferiorly; then becomes thinner; and terminates in the very thick massive superior angle, which does not, hotrever, correspond precisely with the same angle in the human bone. The whole of this edge, with seven inches of the angle, is in a state of epiphysis.

The scapula is very thin in the anterior and posterior spinate fossæ near the spine. The summit, or superior part, of the spinous process, the glenoid cavity, and the posterior angle, are massive. The length of the base is thirty-six inches; of the anterior edge, thirty-three; and of the posterior, thirty, including the glenoid carity. The circumference of the neck abore the glenoid carity is twenty-six inches.

Os Humeri (Plate XXV.). - The os humeri is massive; its superior extremity exhibits the articulating head and two tuberosities. The articulating surface is small compared to the human, and forms a small part of a globe. Where this surface is united to the tuberosities, there is an indentation or groove. The articulating surface is thirteen inches in length, and is surrounded by a ridge of moderate elevation. The great tuberosity is eighteen inches long, following its curre, and rery rough on the outside for muscular attachments. The small tuberosity is cuneiform; it is four inches broad at its base, and terminates in a sharp ridge. The groove for the biceps tendon, betreen these tuberosities, is large enough to receive a man's arm. Below the great tuberosity on the outside is a remarkable projection extending two-thirds down the limb, rery rough for the attachment of the deltoid muscle. The external condyle is prominent and rough, of great thickness. The internal condyle is broader, but less prominent, than the external; its internal surface is very extensice and rough for muscular attachments; externally and posteriorly, it presents a surface, 
which is articulated with the ulna. The condyles are separated by a groore, which corresponds anteriorly with the radius for a small extent; and the rest of the articulating surface with the upper extremity of the ulna (Plate XXV. Fig. 4).

The length of the humerus is thirty-nine inches; its greatest circumference, thirty-nine inches and one eighth; its smallest, eighteen inches.

The fossa for the reception of the olecranon process lies between and abore the condyles. It is a rery deep rounded indentation, passing gradually into a fossa, which extends one-third up the bone, and differs from that of the elephant in being pretty regularly continued from below upwards, while in the elephant the upper part is distinctly separated from the lower.

Fone-ARM. - The bones of the fore-arm do not correspond in the Fore-arm. direction of their perpendicular lines; for the radius does not lie on the outer edge of the limb, but is inclined across the ulna from without inward, so that its inferior extremity forms the inner portion of the wrist-articulation; while the superior extremity corresponds in part with the outer edge of the condyle of the humerus. About half of the radius lies on the inside of the ulna, and the other half on its anterior surface: this position represents the extremity in the liuman skeleton, when the hand is in its utmost pronation.

Radius (Plate XXV.). - The radius lies on the anterior part of the Radius. ulna abore, and, crossing to the inner part of the limb, forms a large tuberosity below. Its head corresponds, by its superior articulating surface, principally with the external condyle, as in man, but is situated on the anterior part of the articulation; the most external portion of which is formed by the ulna, and not by the radius. The anterior part of this head is flattened, and has nearly a triangular form. 
The body, or shaft, of the radius is slender and twisted. It has three edges. The anterior edge extends from the outer part of the upper, to the anterior part of the lomer extremity. The inner edge is rounded, and not well defined. The external edge is sharp, and corresponds with the inner edge of the ulna for a considerable extent. The interosseous space is scarcely sensible. The lowrer extremity of the radius is much larger than the upper; it has a considerable tuberosity on its inner edge (Plate XI. B), and is connected with the two internal carpal bones; which are the scaphoides and semi-lunare.

The length of the radius is twenty-nine inches; the breadth of its carpal extremity, six inches and a half. The entire circumference of the elbow-joint is forty-four inches.

tha. Ulda (Plate XXV.). - The ulna is much the largest of the two bones of the fore-arm, and is the great support of the limb. It has an immense olecranon, very long, thick, and rough, terminating in something like a neck; whence proceeds a process to the groore between the condyles, presenting an articulating surface for each of these, as before stated.

The body of the ulna has three edges and three faces. The posterior edge is a continuation of that from the olecranon process, and terminates in the back part of its inferior extremity. The external edge of the ulna, begimning at the external part of the head of the bone, continues regularly domnwards to the anterior part of the inferior condyle. The internal edge, proceeding from the internal part of the head of the bone, becomes less defined belor, and terminates near the lower extremity of the radius.

of the faces of the ulna the anterior is smooth and regular. It is corered in part superiorly by the radius; inferiorly it is uncorered and 
regular. The external face is a little excavated above, smooth at its middle, and below is divided into two parts by a deep groove, which bisects the external angle. The internal face has a somewhat posterior aspect, is excarated abore and flattened below. It terminates inferiorly in a rough surface for ligamentary attachment.

The inferior articulating surface of the ulna is connected with three bones of the superior range of the carpus (Plate XI. A), viz. principally below, with the cuneiforme, behind with the pisiforme, internally with the semi-lunare, with which it articulates to a very small extent.

The length of the ulna from the summit of the olecranon to the lowest point of the inferior extremity is thirty-four inches. The circumference of the neck of the inferior head is twenty inches; that of the head of the bone is thirty-eight inches, of the centre of the shaft fourteen.

The Hand. - The fore-foot, or hand (Plates XI. and XII.), is of great The Hand. size, the bones measuring nearly two feet across. Compared with that of the elephant, the hand is less perpendicular, presenting rather a superior and inferior than anterior and posterior surface. The superior surface is generally conrex, regularly so over the carpus, but less so over the fingers. The inferior surface is concave, very irregular, presenting a considerable number of eminences, formed by the bones of the carpus, metacarpus, and the sesamoids. The scaphoides, on the inner part of the wrist, and the pisiforme and unciforme, on the outer, form the most remarkable of these eminences.

The Wrist (Plates XI. and XII.) - The carpus has eight bones in two The Wrist. ranges. In the upper or proximal range are the scaphoides, semi-lunare, cuneiforme, and pisiforme; in the lower or distal range are the trapezium, trapezoides, os magnum, and unciforme. 
First

Range.

lunare.

like than a lunated form. It is large and flat anteriorly, small and rounded posteriorly. The superior face is slightly excarated, of a triangular form, for articulation principally with the radius. Its inferior face is also excavated, and of a triangular form; by this it is articulated principally with the os magnum, but partly with the trapezoides, and on the outside with the unciforme. Internally it is connected with the scaphoid, and externally with the cuneiform bones.

Cuneiforme. Cuneiforme (Plate XI. C). - It is properly so named, having a large internal edge connected with the lunare, and tapering to a rounded external tuberosity, behind which is situated the pisiforme. Its superior excarated face receives the lower extremity of the ulna; its inferior convex surface lies on the unciforme. In the elephant, the superior face is much more excarated than in the Mastodon.

Pisiforme. Pisiforme (Plate XII. F). - It bears no resemblance to that in the human subject. It is of an oblong form, lunated on its internal edge, conrex on its external. It is suspended, as it were, by a small superior anterior 
double articulating surface; the inferior part of which belongs to the cuneiforme, the superior to the lower extremity of the ulna. The postero-inferior face is quite rough and irregular, and presents a superior and inferior tuberosity, with an excaration between them.

Second Ravge. Traperium (Plates XI. and XII. K). - This bone lies at the internal side of the range, and might be mistaken for a metacarpal; but, on examination, it is found not to possess the enlarged extremities and contracted body of a metacarpal. It is situated between the trapezoides and first metacarpal bone. Its superior surface is oblique, descending from within outrards, corresponding to and articulating with the trapezoides. The inferior surface is flattened, to articulate with the upper surface of the first metacarpal. The internal face is rounded and very irregular; the external, somerthat flattened, but excavated in the middle for ligamentary attachments.

Trapezoides (Plate XI. I). - This bone is situated between the scaphoi- Trapezoides and trapezium on the inner side, and the os magnum on the outer. Its anterior face is quadrangular. The posterior face terminates in a tubercle; by the side of which is situated a large, deep excavation, which it forms, in common with the os magnum, for the reception of a strong ligament. It is articulated superiorly with the scaphoides and semi-lunare, inferiorly with the second metacarpal, internally with the trapezium, externally and principally with the os magnum, into which it is received, and with which it is firmly interlocked.

Os Magnum (Plate XI. H). - This bone has nearly a cubical form. Its anterior rough face is quadrangular; its superior wholly occupied by Magnum. an articulating surface for the semi-lunare; its posterior, large and irregular, presents various tubercles; its inferior has a double articulating surface 
for the second and third metacarpals, in which it differs, as all these bones do in some slight degree, from the carpals of the elephant. In the latter, this articulating surface is single, and connected with the middle metacarpal only. The external face corresponds exactly with that of the unciforme, having a superior and inferior articulating surface, and a large median excavation for the attachment of a very strong connecting ligament. The internal face articulates with the trapezoides.

Unciforme.

Unciforme (Plate XI. G). - This is the largest bone in the carpus, though the cuneiforme will bear comparison with it. It approaches to a cuboidal form, but is flattened from above downwards. Its anterior face forms a part of the carpal surface; the superior is smooth, to form an articulating surface, which connects it with the cuneiforme. The posterior rough face, of a triangular form, makes part of the carpal hollow. The inferior face is divided into two articulating surfaces; one for a part of the third, and the other for the fourth metacarpal. By its internal face, it is connected with the os magnum, and by its external with the fifth metacarpal. There does not appear to be any process analogous to the hook-like process of the human unciforme.

Metacar-
pus. and XII. L). The first metacarpal, or that which supports the thumb, is the smallest and shortest of the bones of this range. It has two-thirds the length of the corresponding bone of the next finger. Its superior face, articulating with the trapezium, is a little excarated, but not so much as in the human bone. Its infero-anterior face has an extensive articulating surface for the morement of the phalanx beyond. Its upper and lowrer extremities are decidedly enlarged, and its body contracted. Its length is more than four inches. 
The metacarpal bone of the second finger is smaller at its proximal extremity, where it is connected with the carpus, than at its distal, where connected with the phalanx. Its length is five inches. It is articulated superiorly mith the trapezoides and os magnum, internally with the middle metacarpal, inferiorly by an arched articulation with the first digital phalanx.

The metacarpal bone of the median or third finger is the largest, measuring six inches and a half in length, narrower at its proximal than at its distal extremity. The superior surface is comparatively smooth; the inferior, excarated, presents a great tuberosity, which is possessed in common by it and the two adjoining metacarpals; all of which are connected with the sesamoids, and serve with them to support the weight of the animal. It is articulated, by its proximal. extremity, with the os magnum and unciforme; by its distal, with the first phalanx.

The metacarpal bone of the fourth finger is shorter, being five inches long; and, like the last, is narrower at the proximal than at the distal extremity. It is articulated with the unciforme and first phalanx.

The metacarpal bone of the fifth finger is quite large and irregular; the outer edge is prominent, long, and rough; the inner edge is shorter and rougher; the superior surface is irregular, and indented at its lower part. The bone has a wedge-like form, the sharp part looking downwards.

Phalanges. - The phalanges of the thumb are two in number. The Phalanges. first plhalanx is of an irregular form, larger at its metacarpal than at its phalangeal extremity. It is excavated on its superior surface, as if bent upwards; its anterior extremity presents a convex articular pulley for the second phalanx. The principal support to the body of the animal in this finger is the inferior posterior extremity of the first phalanx. The bone is 
two inches and a lalf in length, and its anterior termination measures an inch and a half across.

The first phalanges of the second, third, fourth, and fifth fingers are much alike. They are quadrangular on their upper surfaces, and measure from three to four inches in length, and about the same in width. The second phalanges of these fingers are also very much alike. They are of a truncated, pyramidal form, about three inches across, and two from above downwards.

The sesamoid bones hare sometimes been mistaken, when discovered, for the terminal phalanges.

The third or ungueal phalanx appears to be wanting: we say appears, because the corresponding representative terminal bones do not seem to be the originals. They are not of a very oblong form, like the ungueal bones of the elephant, but mould be represented by one-half the length of this bone in the latter animal. We have, besides these, a portion of one of the toes, presenting a terminal bone, exactly like the factitious ones in the large skeleton: this is a real bone; but whether it be a real terminal is a question we are unable to answer, for its history is unknown. In order to settle this point, we have examined the terminal or ungueal phalanx of the elephant, and also the description of these bones by Curier and De Blainville.* From these descriptions, it appears that the bones of

* "Les premières phalanges de tous les pieds sont un peu plus longues que larges, un peu aplaties d'avant en arrière. Leur face supérieure est légèrement concave; l'inférieure en poulie peu prononcée. Les suivantes sont beaucoup plus larges que longues. Les dernières sont petites et en demi-cercles ou en ovales." - Ossemens Fossiles, Currer, tome i. p. 29.

"Il en est de même des phalanges onguéales, je n'en connais que deux, probablement des doigts intermédiaires, ce sont véritablement de très-petites phalanges à sabots, deux fois plus larges que longues, par le développement plus ou moins styloïde des angles de jonction du bord articulaire un peu avancé au milieu, avec le bord terminal plus ou moins arrondi et rugueux." - Ostéographie, Ducrotay DE BratrVIILE, p. 30. 
the ungueal phalanx, described by these celebrated authorities, were imperfect.

In our elephant skeleton, two of these bones have been preserved in the hand, and two in the foot, with great difficulty; for the three others (if we admit any for the thumb and great toe) could not be discovered and extricated from the firm elastic substance, which connected them with the skin and nails. The ungueal bones, then, in our skeleton of the elephant, are the following: one belonging to the middle and one to the fourth finger of the hands, and one to the third toe and fourth toe of each of the feet; so that exactly. the same bones are preserved in each of the four extremities. This fact shows that those belonging to the other fingers and toes were not lost by accident, but by the inherent difficulty of disengaging them from their natural connections. Mr. Ogden, the practical anatomist whom I emplored to dig out these bones from the skin, was fully impressed by me with the great importance of preserving them, especially that of the thumb; lut, with all his assiduity and skill, he was unable to preserve others than those mentioned. These bones we now proceed to describe.

The ungueal phalanx of the third or middle finger is three inches and a half long, and is divided into a body and two processes. The body, situated in the middle, is an inch and a half long, one inch and threeyuarters wide; its anterior face is rough and prominent; its posterior face is excavated to receive the smooth rounded articular surface of the second phalanx. The processes, or alæ, are an inch long, flattened in form, rough anteriorly and smooth posteriorly to conform to the condyles of the second fhalanx: these processes, or wings, are connected by movable articulations with the borly. The whole bone presents the form of the button used for fastening doors. 
The ungueal bone of the fourth finger, different from that just described, is composed of one piece only; the processes being consolidated with the body. Its length is nearly three inches; it is flattened on its anterior and posterior faces. The anterior is rather convex; the posterior smooth and concave, except at its middle, where it has a tubercle adapted to the carity of the articulating surface of the second phalanx.

From this description of the ungueal phalanges in the fore-feet of our elephant, we will pass to that in the middle toe of the hind-foot. This has nearly the same form as that of the anterior extremities, presenting a body and two processes or wings. The body is of an oval form, rough and prominent on its anterior face, smooth and excavated on the posterior. The processes are partially consolidated with the body; the point of union being, however, perfectly distinct. They resemble those of the fore-foot. The whole bone is three inches and a quarter in length; its width, at the middle of its body, an inch and a half.

The ungueal phalanx of the fourth toe, like the corresponding phalanx of the fore-foot, consists of a single piece. It is two inches and a quarter long, an inch wide at its middle part; the lateral extremities are of a styloid form. Its anterior surface is prominent and rough; the posterior concave and smooth, to conform to the articular surface of the second phalanx.

The ungueal phalanx of the Mastodon foot, the only one we hare, belongs to the middle toe of the right hind-foot. It is shorter and thicker than those of the elephant just described, being an inch and three-quarters in length, half an inch in thickness, rough on its anterior face, smooth and a little excavated on its posterior, conforming to the articular surface of the second phalanx. 
POSTERTOR EXTREMITY.

Os Femoris (Plate XXV.). - The os femoris is large, long, and heavy. os The upper end of it presents two large eminences; an internal, comprising the neck and head of the bone; an external, which is the trochanter. The internal consists of a semi-globular connected with a flattened cylindrical portion. The semi-globular is smooth: it contains the articular surface, in which there is no trace of a depression for an inter-articular ligament. On the outside of the smooth articulating surface is a rough portion of bone, corresponding with it, and contracted, so as to form a neck. The former of these surfaces is twenty-two inches in circumference, the neck twenty inches: the latter, at its upper part, is four inches long, flattened from before backwards, very thick and substantial.

The trochanter is constituted by a mass sixteen inches long, and twelve inches across; very rough and irregular, particularly at its upper part. This surface terminates superiorly and posteriorly in a ridge, which is strongly marked behind. Between this ridge and the body of the trochanter is the deep pit for the insertion of the rotating muscles. The trochanter minor is scarcely a sensible rising on the surface of the bone, but is indicated by a roughness for muscular insertion.

The shaft presents two faces; an anterior convex, and a posterior flattened. The anterior is divided into two parts by an oblique rough edge, running from mithin outwards; the posterior is uniformly flattened. There are also upon the shaft two lines, which divide these surfaces; one external, extending from the posterior edge of the trochanter major to the external condyle, the lower part of which is quite rough. The internal edge is not 
so well defined as the external: it extends from the neck of the bone to the internal condyle; it is rough at its upper part, where it may be said to constitute the trochanter minor.

The shaft of the bone measures seventeen inches around its smallest part; at the lowest, where it is the largest, thirty inches:

The condyles are each about eight inches in extent from above downwards, and are terminated inferiorly by a ridge, which is the external boundary of the articulation. On the forepart is the surface for the patella, deeply grooved in its middle, and surrounded by lateral ridges: it measures six inches across. The articulating surface of the condyles is flattened at the sides, and grooved in the middle for the spine of the tibia. The entire sweep of this articulating surface, from the superior extremity of the articulation of the patella to the extremity of the articulation posteriorly, is fifteen inches and a half. From side to side, it measures ten inches; the external condyle being lower than the internal.

Patella. The Leg. - The Patella (Plate XXV. Fig. 6) differs from that of most quadrupeds, in being nearly globular. Its anterior surface is excessively rough, and terminates inferiorly in a groove, three or four inches in length, and one inch across: something similar, but less defined, is seen at the upper extremity. The superior edge is prominent and well defined; the inferior has a projection or process for the ligament of the patella. The articulating surface is dirided almost equally by a rertical prominent ridge. This surface is seren inches long, and six transversely.

Tibid (Plate XXV. Fig. 5). - This bone has a general resemblance to the human. Its superior extremity is articulated with the os femoris to the exclusion of the fibula, and presents corresponding surfaces with the former bone, which measure fourteen inches across, and from before backwards 
seren and a half. The articulating surfaces are separated by a broad spine, which corresponds with the depression between the condyles.

The upper part of the body of the tibia is very rough near the articulation, especially at its outer part. In the midst of this roughness, posteriorly and externally, is the articulating surface of the fibula, nearly three inches long. The shaft of the bone presents three ridges: at the anterior is situated the tuberosity of the tibia, which is of a triangular form, and generally rough. On the inner part of this edge is an extensive rough surface. The external edge of the shaft is quite sharp: beginning at the external condyle, near the articulation of the fibula, it is rough; near to the middle of the bone, it becomes sharp and well defined, to terminate smooth inferiorly in a considerable prominence connected with the lower extremity of the fibula (Plates XIII. and XIV. A). The postero-internal edge is also sharp and well defined at its upper extremity, continues so to the middle, then becomes smooth, and terminates inferiorly in the malleolus internus. This is a short thick protuberance, presenting a prominence for the attachment of the great tibio-tarsal ligament.

The upper extremity is in circumference thirty inches. The entire length of the tibia is trenty-eight inches. The circumference of the middle of the shaft measures thirteen inches and a half. The lower articulating surface is about ten inches across.

Fibcld (Plate XXV. Fig. 5). - This bone occupies much the same rela- Fibula. tive situation as in man, and is rendered, by the pointed extremity of the external malleolus, of about the same length with the tibia. The upper extremity of this bone is placed on the back of the tibia; its posterior external surface is very rough. The articulating surface is from two to three inches in length. The body presents three ridges: an external, 
generally smooth, rounded, and not prominent; an anterior, rough abore, sharp and well defined in the middle, dividing into two lines below, to terminate in the malleolus externus; a posterior, rough and well defined, extending from the posterior face to the back part of the malleolus (Plates XIII. and XIV. B). The internal face of the bone is irregularly flattened; the posterior is narrow, of small extent, and ill defined; the external face is rounded above, flattened and somewhat excavated below.

The malleolus is grooved posteriorly: internally it presents an irregular surface, composed of three parts, viz. the first, anterior, rough for ligamentary attachment; the second, internal and superior, smooth for the tibial attachment; the third, below, excarated for the os calcis. The external surface of the malleolus is distinctly divided into two portions; the anterior most extensive, the posterior smooth and excavated for the passage of the peroneus longus muscle.

The whole length of the fibula is twenty-six inches; the circumference of the middle of the shaft, six inches and a quarter. The inferior extremity of the malleolus externus is much the broadest part of this bone, measuring seren inches in diameter.

The Foot. Tне Fоот. - The foot of the Mastodon is much depressed, compared with that of the elephant. It presents a superior regular conrex surface; and an inferior, irregularly excavated. Taking the tuberosity of the os calcis with the projection of the fire toes, the surface may be said to hare a radiated form.

Tarsus. TARsus. - It is composed of seven bones, placed in two ranges; all of them flatter than in the elephant.

First First Range. Astragahus (Plates XIII. and XIV. C). - The astragalus Range. is quite a flattened bone, compared with that of man, or eren with that of 
the elephant. It presents a superior rounded convex articulating surface, which is receired into a corresponding excavation of the tibia. Its inferior face is dirided into two articulating surfaces, by the anterior part of which it is connected with the naviculare, and by the posterior with the os calcis; the latter being divided into two surfaces by a deep fossa, which serves for ligamentary attachment. The anterior edge of the astragalus forms a part of the superior face of the foot: it is quite rough, and presents numerous orifices for ligamentary attachment. The posterior edge is compressed and sharp; being imbedded, as it were, between the tibia and os calcis. The internal edge is rough, and presents a remarkable tuberosity. The external edge is articulated anteriorly with the malleolus of the fibula, and has posteriorly a deep extensive excaration for the accommodation of that bone and its comnecting ligaments.

The astragalus is articulated superiorly with the tibia, inferiorly with the os calcis and naviculare, exteriorly with the fibula. It measures eight inches and a half transtersely.

The os calcis (Plates XIII. and XIV. D) is a very rough, irregular bone, composed of a large posterior rough tuberosity for the attachment of the wreat tendon, a short thick neck, and an irregular anterior body, articulating with the fibula above, the cuboides below and before, superiorly and internally with the astragalus, anteriorly with the naviculare. This bone is ten inches in length.

The naviculare (Plates XIII. and XIV. E) is a flattened bone, with a Naviculare. rough superior edge and an irregular inferior. It articulates with the astragalus above, below with the three cuneiform bones, and also with the cuboides, behind with the os calcis. The anterior face of this bone measures nine inches. 
Second

Range.

Internal Cuneiform Bone.

Cuneiform

Bone.

Cuneiform

Bone. cuboid bone. Its superior or anterior edge is rough, forming a part of the upper surface of the foot. Its infero-posterior part is compressed in a sharp edge. Its superior surface is smooth for extensive connection with the os calcis and nariculare. Its inferior face presents two articulating surfaces, 
which are connected with the fourth and fifth metatarsal bones. Its anterior face measures five inches by one and three-fourths in its widest part.

Metatarsts. - The bones of the metatarsus are five in number (Plates XIII. and XIV. K). Differing from the human, the middle metatarsal is the longest and thickest, next the fourth, then the second, the fifth, and lastly the first, which is the smallest of the five. These bones have nearly the same form, with the exception of the fifth, which has less of the characters of the metatarsal bones than the others. The first metatarsal bone is two inches and a half long; the second, four; the third, five and a half; the fourth, fire; and the fifth, three and a half. The circumference of the largest, or middle metatarsal, is eight inches. Their transverse diameters increase regularly from the first to the last.

The first metatarsal is articulated with the inner cuneiforme; the second with the middle; the third with the middle, to a very small extent, but chiefly with the external; the fourth with the external and cuboides; the fifth with the cuboides. All these connections are by flattened surfaces, the first being less so than the others. The phalangean extremities present a condyloid arrangement; having an eminence on each side, with an excavated surface for adaptation with the metatarsal surface of the first phalanx.

Phatanges. - The phalanges are supposed to be three in number in Phalanges. each toe, except the great. The first phalanx (Plates XIII. and XIV. L) is very thick, short, and irregular, in the second, third, fourth, and fifth toes. In the middle toe, this phalanx is of a quadrangular form; rough above, below, and at its edges. Posteriorly it is articulated with the middle metatarsal by an excavated surface; anteriorly with the second phalanx by 
two condyloid projections. It measures three inches in length, and eight in circumference. The corresponding phalanx of the second toe has much the same form; that of the fourth is more flattened. The fifth is smaller and less regular.

The second phalanges (Plates XIII. and XIV. M) in the second, third, fourth, and fifth toes, have about the same size and form with each other; they are all flattened at their proximal extremities, and hare faintly indicated condyloid surfaces at their distal. That of the middle toe measures two inches and a half across, six and a half in circumference, and one from behind forwards.

The great toe, it has already been said, has only one digital phalanx. This is a short bone, of a rounded.form, with an upper flat surface for the metatarsal bone, and a lower round surface for the terminal bone, or horns nail. The inferior surface is large, rounded, and smooth, as if adapted to another. The bone is an inch and a quarter long, and six and a half in circumference.

- The bones of the third range being altogether wanting, the existence of this phalanx can be established only by other considerations. These are, first, that some terminal platanges of the elephant are in our possession. Second, that the distal extremity of the second phalanx has the smoothness of an articulating surface in the second, third, fourth, and fifth toes. In the three latter, there has been undoubtedly a small third terminal bone, transversely oblong, as in the elephant. In the first toe, no second phalanx is admitted by Camper and other anatomists in the latter animal; nor have I erer seen one. Tet the appearance of the anterior extremity of this first hone of the great toe affords reason to beliere, that a second phalanx may exist in the elephant and in the Mastodon; that in the former it is 
remored with the skin and horny covering of the foot, and that in the latter it is lost. But this subject has already been dwelt upon in connection with the ungueal phalanges of the hand.

Sesamoid Bones (Plates XIII. and XIV. N). - At the junction of the sesamoid metacarpal and metatarsal bones with the first phalanges, there are two articulating surfaces on the lateral parts of these bones, particularly on the former; and on each of these is set a sesamoid bone, with an excavated articulating surface, corresponding with the prominence in the other. Tाँ sesamoids are found to belong to each of four toes. These bones measure from two to four inches transversely, and from one to two in thickness. Some of them present only one articulating surface; others two, one of which is smaller than the other.

ADDITIONAL DIMENSIONS OF THE SKELETON.

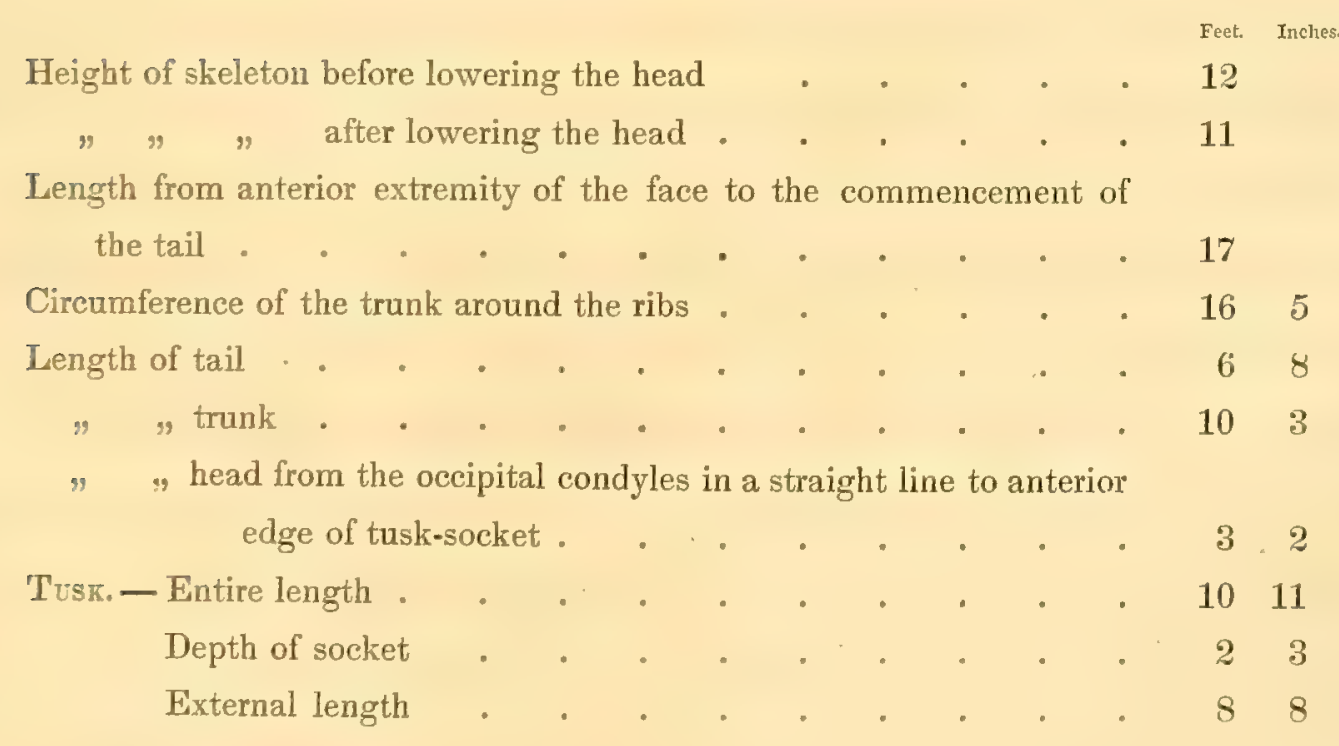




\section{O D O N T O G R A P H Y.} General Tre dental system of the Mastodon is a subject of much interest. The
Remarks. form, number, and structure of the teeth have materially aided in distinguishing the different members of the elephantine family. Hence it has happened, that these organs have receired an earlier, more full and exact investigation than any other parts of the skeleton; and this investigation has been favored by the great number of teeth which have been discovered, and their good state of preservation.

Elephant. Before describing the teeth of the Mastodon, it will be useful to take a transient view of those in another member of the proboscidian family, the only living one known to us, the elephant. As the teeth of the latter are composed of numerous lamella, this animal has been denominated by De Blainville, Elepleas Lamellidontos; while the Mastodon, from the nipple-shaped eminences of its teeth, has been denominated Elephas Mastodontos. The lamellated arrangement of the elephant is readily distinguished, Lamellx. on inspecting the cutting surface of the roru teeth, by the layers of the whiter substance, the enamel, which, in the Asiatic species, has the form of a flattened oral, and in the African a lozenge-like shape. This lamellated arrangement is most distinctly observed in the posterior part of the jaw 
of a young elephant. For, on opening into the cavity behind the teeth alreads formed, we discorer laminæ with double plates, of different size and thickness; some of them being about a line thick, and presenting, in our structure. specimens, a lateral surface of two and two-fifths inches by two and threefifths. They are composed of two layers, with fringed edges, and a cavity betreen. These laminæ are afterwards united, and thus a number of them are converted into a single tooth.

The matter by which this union is accomplished is a hard substance, Cement. called the cement or crusta petrosa. The cement also unites the different liamellix, when the tooth is completely formed, by extending from the base of one lamina to that of another, just as it is continued from one ridge to another of the tooth of the Mastodon. Besides the cement, the tooth of the elephant contains two other kinds of hard substance: one is called the Dentine. bone, ivory, or dentine, forming the basis of the tooth. The other constituent is the enamel, which, as before said, is seen to constitute the hard, Enamel. white, prominent ovals of the Asiatic Elephant, and the lozenge-like eminences of the African. These three parts are readily distinguished from each other. The enamel is the most prominent part of the cutting surface of the tooth; the cement coats the exterior of the body of the tooth, and glues together the laminæ; while the dentine forms the basis of the fangs and crown.

The whole number of teeth in the elephant, according to the best of Number. our present knowledge, is twenty-four, exclusive of the tusks. The existence of five of these teeth on each side of each jaw, their regular and successive derelopment, we have the means of indicating by a series of specimens in our possession and in other collections in this place. The sixth, probably the last tooth, belonging to advanced age, is not included in any of these, 
although two of the heads belonged to animals which must have been from thirty to forty years old.

We shall now examine the series of these teeth by means of different specimens.

Teeth of Calf Elephant.

There is in my possession the head of a calf-elephant, which died probably soon after birth. The teeth in this head are in the following condition: At the anterior part of the upper maxillary bone, behind the intermaxillary, a tooth, measuring six-eighths of an inch antero-posteriorly by five-eighths transversely, is discovered pressing hard upon the gum, as if ready to perforate it. Behind this is a second tooth, entirely buried in the bone, measuring two inches and three quarters in length, and consisting of seven plates partially cemented together, but not very firmly: the fangs are not formed. A considerable cavity exists posteriorly, containing a number of plates destined to form a third tooth.

Dr. Winslow Lewis, the first and second teeth have disappeared; and the third, measuring four inches and one quarter antero-posteriorly, is in place, rather worn, in which there are eleven plates. There is also, posterior to the last, a fourth tooth, destined apparently to be of greater size; for, though no part of the crown is fully formed, it is nearly an inch longer than the last named.

In the jaw of another animal, which I believe to have been about six years old, is a tooth from which the anterior part has been worn away, containing eleren perfect ridges, or laminæ, and two imperfect from having been worn, measuring five inches and three quarters antero-posteriorly. Fourth This is undoubtedly the tooth described as undereloped in the preceding Tooth. jaw. Behind this, principally imbedded in the bone, five of its anterior 
lamina only being - visible, lies the fifth tooth: in consequence of its Fifth situation, it cannot be exactly measured. The corresponding tooth in the upper jam measures seren inches in length, and contains fourteen plates; three of which, the posterior, are not cemented to the body of the tooth; and, no doubt, others would have been added as the tooth came into place. This tooth is peculiarly situated. The upper jaw not having sufficient space to accommodate it behind the rorking tooth, it is placed obliquely between a horizontal and a vertical line, and may be said to extend from below up rards, rather than from before backwards. When the working tooth is worn away, this comes into its place by a circular or curvilinear movement, and, from a perpendicular tooth, becomes horizontal. This is the mode in which the posterior molars are dereloped. The plate of bone investing the posterior and lateral parts of this undereloped tooth, which is the pterygoid process, is very thin, and may be readily broken away.

This succession of teeth is given altogether from specimens of the Asiatic Elephant.

In the collection of the Boston Society of Natural History, there is a Elephant of very jerfect skeleton of a young Asiatic Elephant, which died during its Nat. Hist. passage to this country, and was dissected here. The age of this animal, from its size and the state of its epiphyses, was supposed to be about ten years. Comparing it with a young living elephant, five years old, lately exhiljited in Boston, this skeleton might have a somewhat greater age than mas attributed to it. The appearances of the teeth in the head of this skeleton are as follows: One tooth in its place, on each side of the lower jaw, contains ten ridges, and measures six inches and a half antero-posteriorly, by three transversely. An undeveloped tooth, mostly imbedded in the bone, is situated behind the preceding. In the upper jaw, on each 
side, the anterior edge of the front tooth is greatly worn; and it has but eight perfect ridges remaining. Behind this is an undereloped tooth.

Elephant Pizarro.

The skeleton of the elephant Pizarro, supposed to have been from thirty to forty years old, drowned in crossing the Delaware during the spring of $\mathbf{1 8 4 7}$, is in my possession. The teeth in this head are eight in number, and arranged in the following order: In the lower jaw, on the right side, fully dereloped, in place, is a tooth measuring seven inches and three-fourths in length, and two inches and three-fourths in width, containing ten perfect ridges, and an anterior space from which others have been worn away. This constitutes the fourth tooth of the series. Behind it lies imbedded in its socket an undereloped tooth, exhibiting a surface of three inches and a quarter only. A large portion of the tooth is still imbedded in the base of the condyloid process, and presents eight risible ridges with a superficial concarity opposed to the convexity of the tooth in the upper jaw.

The teeth in the upper jaw correspond with those in the lower, being on each side one in place, and one undereloped; the former measuring eight inches in length by three inches and a quarter wide, and containing eleren ridges. Behind this lies another undereloped, and, in a great measure, buried in its bony socket.

In the Museum of Moses Kimball, Esq., of this city, there is a most perfect and beautiful skeleton, prepared and correctly set up by the ingenuity and skill of Dr. N. B. Shurtleff. The animal ras knotrn by the name of Siam. About two years since, it died on the banks of the Mississippi, was transported to and prepared in this place, and was thought to be of adranced age. I should judge, howerer, that it was between thirty and forty years old at the time of its death. In the head of this animal, there 
are existing seren teeth and one open socket, from which the tooth has been recently dismissed. Two teeth are in full operation on each side of the upper jaw; two on one side of the lower jaw, and one on the other. In the upper jar, the anterior tooth on the right side measures three inches and three quarters in length; its ridges are eight in number. The posterior tooth is partly in place, but principally included in the bony socket; the part in place is four inches long, and contains three ridges and a half; the remaining portion of the tooth is of great extent, and measures, with the preceding, fourteen inches.

On the right side of the lower jaw are two teeth: the anterior measures two inches only, and is, of course, near being shed; the posterior is nine inches long by three wide. A large part of the last tooth is undoubtedly concealed in the solid bone, by which it is covered. On the left side is a toothless socket, partly filled up by bone, and measuring two inches and it half square. Behind this is another tooth, of nearly the same dimensions with the corresponding one of the opposite side; sixteen ridges of it are visible, the remainder being concealed in the bone of the jaw.

The anterior portions, in each of the jaws of this elephant, are the remains of the fourth tooth, and are, in the lower jaw, nearly replaced by the fifth; but in the upper the change is less considerable, the useful part being rather greater in the anterior than in the posterior teeth. When, in the living animal, these anterior teeth are wholly displaced, and the posterior occupy their places fully developed, they constitute the great permanent adult teeth, which attend its middle age. The fact that the sixth tooth, which we know should follow, has not in any degree appeared, shorrs that this animal was not very old; and the state of the epiphyses, with that of the bones generally, confirms this opinion. 
Attention to the preceding statements will demonstrate the development of the first five teeth. The existence of a sixth tooth at a subsequent period, which is generally admitted, proves that the elephant is capable of attaining a very great age; and this would be extended much beyond any thing we are acquainted with at the present day, if we admit the opinion of some naturalists, that there may be a seventh and even an eighth tooth on each side.

The teeth of the elephant are, at first view, widely different from those of the Mastodon; but the organs, apparently so dissimilar to each other, are connected together by intervening links. First, we notice in some Asiatic elephants, that the oval projections of enamel, instead of forming a continuous ridge, are partially divided transversely, so as to form an incipient approximation to the mammellated arrangement of the Mastodon.

The teeth of the Elephas Primigenius, of Alabama, in the southern part of the United States, are vast compared with those of the modern elephants. Out of thirty in my possession, none of which are perfect, one, partially developed, is thirteen inches long, and six and a half in depth. It exhibits ten ridges and a posterior surface, from which others had been broken. The width of this tooth cannot be measured from its obliquity; but a portion of another, of about the same size, measures five inches in width. The laminæ are narrower, and are not so much separated from each other as in the Asiatic.

In the fossil jan first described by Mr. Clift, of the Hunterian Museum, and to which he gave the name of Mastodon Elephantoides, the ridges rise 
into numerous small mammillary processes, in number four, five, or six; presenting an appearance, when worn, like that in the Asiatic Elephant, and in their integrity representing distinetly the eminences of the true Mastodon. A fine mineralized specimen of part of a jaw, with an immense tooth of this description, exists in the Natural History collection in this place. Other links in the chain have been discovered by Dr. Falconer, who thinks he has established a connected series from the Elephas Primigenius through the Eleplhas Asiaticus and Africanus, Mastodon Latidens, Giganteus, and others, extended even to the Dinotherium.

The magnitude and beauty of the teeth of the Mastodon, while they excited the admiration of early observers, served for the construction of hrpotheses on the character and habits of this animal; and the knowledge General Remarks. of their derelopment has to modern naturalists been a source of pleasure and instruction. Dr. W. Hunter, misled by a partial view of their organization, and their apparent similarity to the teeth of the carnivora, was of opinion that the points of these massive organs were destined to crush the bones of smaller animals. A better knowledge of their structure, and their analogy to those of the regetable feeders, has entirely overthrown this theory.

While the teeth of the elephant are, as already said, composed of structure. three kinds of hard matter, dentine, enamel, and cement; those of the Mastodon Giganteus are constituted principally of two of these substances, dentine and enamel. Professor Owen has shown that a layer of cement incests the fangs, and is spread over the crown, but the basis of the crown and of the fangs is formed by the dentine; while in the teeth of the elephant, 
and some others of the Pachydermata, the cement, by its perpendicular interposed layers, constitutes a substantial part of the body of the tooth, as well as a protecting covering to its surface. A great portion of the Mastodon tooth (Plate XX. Fig. 1) is formed by dentine. The mammillary eminences or mastoid projections also have a basis of the same substance; but they are inrested with a corering of enamel, which, in molar teeth in my possession, measures from the sixth to the fourth of an inch in thickness. In teeth which have been worn, the enamel is ground down in various degrees; thus altering the surface of the cromn to an appearance approximating, in the Mastodon Giganteus, to the lozenge-shaped ridges of the African Elephant.

Wear. $\quad$ The worn surface or "usure," as denominated by the French writers, of the cusps of the mammille, is frequently employed to express specific characters. The form of these surfaces depends on the form of the eminences. If the latter are flattened, as in the mammillæ of Mastodon (riganteus (Plate $\mathrm{X}$.), the morn surfaces will be oblong; if rounded, as some of those in the Baltimore tooth (Plate XXYI.), they will be circular; if indented, the surface will be modulated according to the indentations; and, where these are numerous, it will be irregular. These irregularities are formed by the worn edge of the enamel, which is in some species, as the Mastodon Andium, fringed. The figure of the worn surface will also be varied by the depth of mear, as shomn of the Mastodon Giganteus in the plate already referred to. A slight mear will produce a linear form on the surface; a greater mear, a diamond-like or lozenge-form figure; and a very deep wear, an oval, circular, or triangular figure. In the narrow teeth, in consequence of the lateral sinuosities, the morn surface mill generally present a trifoliated figure, like a leaf of clover. 
The consideration of these facts will show the value of the figures formed by the enamel on the extremities of the cusps, as expressing specific character's.

The number of the teeth was long involved in mystery. The genius Number. of Curier opened the way to a knowledge of their number, differences, and derelopment. He adranced no farther in the path he had opened than to the fourth, or, at the utmost, fifth tooth; making the whole number to be from sixteen to twenty, exclusive of the great incisors or tusks.

In 1831, Dr. Hays, the distinguished editor of the "American Journal of the Medical Sciences," read a paper to the American Philosophical Societr, in which he described various jaws of the Mastodon Giganteus, and the teeth contained in them. He seems to have been the first writel who clearly pointed out the probability, that the number of these teeth was sir on each side of each jaw in the Mastodon Giganteus, and, of course, the whole number twenty-four. He says, "The whole number of teeth possessed by the animal described by $\mathrm{Dl}$. Godman (Tetracaulodon) is, then, at least trenty; and we think that it is at least probable, that the animal possessed an intermediate tooth between the second tooth with three denticules, and that with four denticules." "Should we be correct in our views, this animal possessed three tecth, with three denticules in each side of each jaw, making the whole number of teeth twenty-four; but to render this certain mould require specimens of intermediate ages to those hitherto described." These have since been obtained, and have fully confirmed the opinion suggested by the sagacity of Dr. Hays. In the collection of the Cambridge University, there is a series of jaws affording a perfect demonstration of this fact, and settling the number to be twenty-four. Professor Horner, in a paper read to the Philosophical Society, thought 
that there might be a greater number. De Blainville makes them twentyfour.

The specimens in the collection of the American Philosophical Society, those of Cambridge University, various others in New Tork, Albany, and in my prirate collection, support the opinion, that the number is twenty-four, and no more. These we shall endeavor to point out by drawings taken from my own specimens, and those of the University at Cambridge.

Professor De Blainville assigns to Kaup the merit of having first established the number of tecth in their normal succession of the Mastodon Longirostris, in consequence of the discorery of the celebrated deposit at Eppelsheim.

Develop. The teeth are not all developed at the same time, but in succession, in proportion to the waste of those which have preceded. At first appear two small deciduous teeth, or milk molars; next follows a third tooth, also deciduous, larger and more complicated than the former; then a fourth tooth, of the same form as the last, though greater in size. These four teeth sometimes co-exist, as in the Tetracaulodon's jaw, from the Museum in New York, originally described by Dr. Godman, and afterwards more particularly described and represented by Dr. Hays, in the "Transactions of the American Philosophical Society," vol. iv. To the teeth already mentioned succeeds a fifth tooth, of the same form as the last, but rather larger. Before the appearance of this, and even in most cases before the fourth tooth shows itself, one or more of the first teeth have disappeared. The sixth and last tooth is much larger, and formed in a mould different from any of the others.

It is well to state here, that, in the particular description of the teeth which follows, by ridge or lobe is meant an eminence extending transrersely 
across the tooth; but the term ridge is more strictly applicable to the teeth of Mastodon Giganteus, and that of lobe to the Mastodon Angustidens and its varieties; by mastoid, or mammillary eminence, a projection or division of one of these ridges; and by papillary eminence, a small pyramidal intervening cone. All Mastodon teeth are also traversed by a longitudinal furrow, separating the internal from the external mastoid eminences.

M. Laurillard makes an observation, in regard to the teeth, which is rerified by our specimens with singular exactness. The first three teeth are wider behind than in front, the two next square or parallelogramed; but the ultimate contracts gradually, so as to terminate in a blunt point. The upper teeth are a little wider than the lower.

Particular Description. - Eight anterior teeth, two on each side of each jarr, much smaller than the others, are developed soon after birth, shed at Particular Descripan early period, and have been called deciduous, or milk-teeth. Those of the luwer jaw are scen in perfection in the calf-jaw, as represented in Plate II. Fig. 1. The anterior, or first of these, is of small size; it has two bifid transterse ridges, slightly notched; an anterior small sharp projection in the centre of the front surface; and a posterior, more distinct. The height of the crown is seven-eighths of an inch; the width across, also seveneighths; from before backwards, an inch and a quarter; circumference of the neck, three inches and three-eighths. The fangs are two in number, widely projecting, much curred, smooth anteriorly and posteriorly, but hollowed in the interspace. The anterior fang, larger than the posterior, is an inch and a half long by three-fourths of an inch wide; the posterior fang measures an inch and five-eighths in length, by nine-sixteenths of an inch in width. The distance of the extreme tip of one fang from that of the other is, on the outer side, five-eighths of an inch; on the inner, three- 
fourths of an inch: a notch exists at the end of each fang. A separate drawing of this tooth is given in Plate VIII. Fig. 1.

Second

Tooth. same characters, but being larger. It has a small sharp anterior central crest, two transverse bifid ridges, and a prominent heel, the inner half of which forms a distinct ridge; but, towards the outer edge, it slopes downwards till it meets the neck of the tooth. The interspace of the transverse ridges is much greater on the outer than on the inner side, and has a slight triangular ridge in its interval. The height of the crown is an inch and one-eighth; the width across, an inch and a quarter; from before backwards, an inch and three quarters; cireumference of the neck, five inches. The fangs are two in number, an anterior and a posterior, extending the entire width of the tooth, slightly curved, with a deep groove on the anterior surface of the front fang, and the posterior surface of that behind. In the interspace, both fangs are deeply hollowed; the posterior is much larger than the anterior, the reverse of the former tooth. The anterior fang is two inches and one-eighth long, by an inch and one-sixteenth wide; the posterior is an inch and seven-eighths long, by one and a quarter wide. The distance of the extremities of the tips from each other, on the outer side, is one inch; on the inner, seven-eighths of an inch: the lower extremity of each fang is furnished with a deep notch. A separate drawing of this tooth is given in Plate VIII. Fig. 2, and its situation shown in Plate II. Fig. 1. six-pointed molar: smaller than the two other six-pointed molars, it is

* This is called the third deciduous tooth; but why it is more entitled to this epithet than the two which follow, it would be difficult to determine. Are not the first and second so-called permanent teeth equally deciduous, since they fall and leave the last permanent molar solitary? 
more than double the size of either of the two anterior four-pointed milk molars, behind which it is situated. It is the tooth of a young animal, and always has nearly the same size. It has, as before said, three ridges, each of which is divided into two mastoid eminences. Surrounding the base of the tooth, at its junction with the gum, is seen the prominent ridge which encircles the whole tooth. The fangs were originally six in number, but the two posterior are consolidated so as to form one. This tooth measures, from before backwards, three inches; transversely, two inches; height of the crown, an inch and a half; circumference of the neck, eight inches and a half; the anterior fang is two inches and sixeighths in length, the posterior two inches. A drawing of this tooth is given in Plate IX. Fig. 1 ; and its situation may be noticed in Plates II. III. and $V$.

The fourth tooth in the order of development, being the next six- Fourth pointed, and first permanent molar, is situated behind the last described, and has the same form, but is much larger. The crown bears three transverse ridges, each divided into two mastoid eminences; the inner eminence being notched. The base of the ridge is strongly marked at the anterior and posterior extremities of the tooth. Between the ridges on the outer side is a projecting tubercle not usually found. The fangs are two in number; an anterior, supporting the front ridge; and a large posterior, supporting the two remaining ridges. The measurements of this specimen are from before backwards, three and a quarter inches; transversely, two inches and a half; height of the crown, an inch and five-eighths; circumference of the neck, nine inches and a half. A drawing of this tooth is given in Plate IX. Fig. 2, and its situation shown in Plates IV. V. and VI. 
are notched. Is in the last tooth, the two posterior roots are consolidated, and support the two posterior ridges, while the anterior ridge is supported by the anterior fang; in every instance, each ridge has a corresponding fang, although in many cases tro or more of these become consolidated. The specimen from which this description is taken, is petrified. It measures four inches and a half antero-posteriorly; three inches transversely; circumference of the neck, eleven inches and a half. A draming of this tooth is given in Plate IX. Fig. 3, and its situation shown in Plates V. VI. and VII.

seen in place, but not well displayed, in Plate VII., and is figured separately in Plate $\mathbf{X}$. Both of these specimens are large and splendid teeth, the latter meighing 3 lb. $6 \mathrm{oz}$; being ten ounces less than another specimen. The crown of this tooth is dirided into four ridges, with a complex talon; and sometimes, as in the specimen before me, into fire ridges, of which the last, or posterior, is smaller than the other four. The furrows are more deeply cleft than in the other teeth, and the ridges, of course, are larger; each of them is divided into mastoid eminences, rather flattened than rounded. The inner eminences are notched, and more projecting than the outer. The comples talon, or fifth ridge, is of small size, haring only about half the eleration or breadth of the preceding ridges: like them it is divided into two mastoid eminences. There is a posterior tubercle. The two anterior ridges are worn at their extremities, the three posterior almost perfect; the basal cingulum or eminence, which encircles the base of the cromn, is more prominent on its outer than on its inner face. The anterior ridge of the crown is supported by a single fang: bearing some resemblance to the foliated 
fang of the elephant's tooth in its early development. The second, third, The Fangs. fourth, and fifth fangs are in a great measure consolidated into one; retaining, however, distinctly a partial division between them. The extremity of the three posterior consolidated fangs broken off exposes a cavity occupying the bodies of the four posterior, which, in the recent state, was filled with ressels and other soft textures. Each of the fangs is striated transrersely by depressions at the distance of an eighth of an inch apart, which extend across and disappear at the line of junction of the fangs. This beautiful striated appearance calls to mind the anterior face of the human trachea. It has been noticed, in regard to this tooth, that the crown and fang's were hollow. This appears to be generally true of teeth recently dereloped, while those which have been long used gradually become filled with osseous matter, so that when the anterior extremity of the tooth gives war, in the process of mastication, no cavity is opened and exposed, but a solid mass of dentine fills the corresponding part of the crown, and even of the fangs, so far as I have noticed.

The anterior extremity of the specimen before me is flattened, the posterior rounded; it measures antero-posteriorly, eight inches; transversely, three inches; in height, six inches and a half; around the neck, eighteen inches.

The teeth in the upper jaw of the Mastodon Giganteus have not yet Teeth of been fully described. Of these the first two are wanting; the third is found Jaw. in the Mastodon head represented in Plate IV.; the fourth in both the heads of Plate IV. and Plate VI. ; the fifth in that of Plate VI.; and the fourth, fifth, and sixth in the Shawangunk head, Plate XVI. The two anterior or milk molars have not, that I know of, been found in place; and, of course, any description of them is hypothetical. Fortunately we have 
very perfect specimens of those in the lower jaw : by the aid of these, and a comparison of the alveoli, we may presume that these two teeth in the upper resembled the corresponding teeth in the lower jaw.

The third deciduous molar has also never been described; and, as we have it in place in at least half a dozen instances, we shall be able to give a description of it. This tooth is larger than the two preceding, having three instead of two ridges, - those being bi-lobate, and this tri-lobate; thus resembling the second milk molar of the Mastodon Longirostris, and differing from the corresponding tooth in that species, because the latter has four lobes. Being always the tooth of a young animal, it is small ; in this specimen, two inches and a half in length, by two inches in breadth. (See Plate IV., where this tooth is represented in place.) It has, as already said, three ridges, each of which is partially divided into two principal tubercles; but, being rather serrated than notched, it presents four small tubercles. These are moderately worn, but not so much as those in the corresponding tooth of the lower jaw. The basal cingulum is more prominent on the outer than on the inner edge. The roots are firmly imbedded in their sockets.

The fourth, upper, and first permanent molar has also three ridges, like the last deciduous. It is smaller than the corresponding tooth of the lower jaw, represented Plates III. and $\mathrm{V}$., which belonged to a much older animal, but larger than the preceding tooth. It measures three inches in length, two inches and a half in breadth. The mammillary eminences are more distinctly notched than in the preceding tooth, being less worn. The basal cingulum is rather more prominent on the outer than on the inner edge of the tooth. In another head of much greater size, belonging to the University at Cambridge, the dimensions are larger. 
A partial description of this tooth has been given by Professor De Blaincille from an imperfect specimen belonging to the Ecole de Mines, in Paris.

The fifth tooth has been described by Professor De Blainville as being quadri-lobate, or having four ridges and a small talon; and he suggests Fifth that there should be also an enlargement of the inner side by the addition of two tubercles to the internal mammilla. I have never met with any instance of the existence of four lobes, or ridges, in the fifth upper molar of the Mastodon Giganteus, nor in any other tooth of that species, except the ultimate molar; and to this the description has not a resemblance; neither this nor the fifth haring any intermediate papille in the Mastodon Giganteus. But his description agrees well with the fifth molar of Mastodon Longirostris, and makes it probable that the tooth alluded to as the fifth of the Mastodon Giganteus should be referred to Mastodon Longirostris. Such a mistake of the great palæontologist would not be wonderful in the midst of the rast number of facts he was called by his researches to investigate.

The particular description of the sixth tooth may be left till after a consideration of the fourth and fifth teeth, as they exist in the Shawangunk head. In this head (Plate XVI.), the fourth tooth is in place, and measures Shawangunk Head. three inches in length by three and a quarter in breadth. It has three ridges, all very much morn, especially on the inner edge. In the first ridge, the internal cusp is nearly worn away, the second and third cusps are less worn; but the three are confluent at the inner edge, distinct at the outer. The internal cingulum is worn away; the external, not strongly developed. There is no talon, nor papillary eminence. The fangs, at their origin, are three in number; but the two posterior unite to form one. The correspond- 
ing tooth in the lower jaw has the same dimensions, and is like this, excepting that the outer edge is worn away.

Fifth

'looth of Shawangunk long and three broad. It has three ridges or lobes, each bearing two pairs Head.

of cusps: the anterior are worn into one, the middle are more distinct, and the third pair are but little worn. There is no additional or papillary eminence between the ridges, as supposed by De Blainrille. Both of these ridges are remarkably flattened on the anterior and posterior surfaces. There is a slight eminence at the posterior extremity, but no distinct talon : the cingulum is more developed on the outer edge than on the inner. The roots rise from three distinct origins corresponding with the ridges, and are then lost in their sockets. The tooth on the left side of the upper jaw corresponds with this on the right.

Sixth Tooth of Shawangun
IIead. specimen of the ultimate molar. It has four ridges, and a small talon at its posterior extremity. The points or summits of these ridges are in a number of instances bifurcated, particularly in the outer mammillæ. At their bases, the cusps run together, and are flattened on the anterior and posterior part. They incline forwards, as is most common in all the teeth. The valleys between the ridges are deep, and without papillary eminences. The basal cingulum is more marked on the inner than on the outer edge. This tooth measures six inches and a quarter in length, three inches in width orer the cusps.

The roots are concealed in their sockets; but we have preferred describing the cromn in this specimen, because it is in place, and there can be no doubt as to its true denomination. Haring many teeth of this 
character, we can describe the roots from some of these. I 'will, therefore, only remark further, that it corresponds with the tooth on the other side of the same jaw; and, like that, its cusps are very little worn. With the corresponding tooth in the lower jaw of the same head, it agrees in almost erery particular.

The fangs, in the most perfect of the specimens of this tooth in my possession, are fire in number. The anterior root inclines backwards; the posterior, which is the longest, bends forwards; the three intervening take a direction betreen that of the two others. The anterior root is separated from the rest, and supports the anterior ridge or lobe. The four posterior unite together, and support the corresponding ridges. Each of the roots has the form of a cone. These fangs are accompanied with a body, of the cellular bone of the upper jaw, which embraced them.

The finest ultimate lower molar I have met with, was brought from ultimate the banks of the Willamet river, in Oregon, by Captain Wilkes, of the Exploring Expedition, and is now deposited in the collection at Washington. Molar from Oregon. Through the kindness of the Honorable R. C. Winthrop, Speaker of the House of Representatives, I obtained a cast of this tooth, colored like the original. It has a peculiar interest in having been discovered beyond the Rocky Mountains, at the distance of thousands of miles from the great deposits on this side of the Mississippi, yet resembling the latter in every essential character, at least in my estimation; although, to those palæontologists who are disposed to increase the number of species in this family, it might perhaps afford distinctive characters sufficient to constitute a new species. The peculiarities are, 1 st, its greater size than that of the others; $2 d$, in addition to five regular ridges, it has a talon; $3 d$, it has a very light color; $4 t h$, the anterior fang is united with the mass of posterior fangs. 
The dimensions of the ultimate tooth in the great skeleton are: In the lower jaw, seven inches antero-posteriorly ; three inches and a half transversely; seventeen inches around the neck. In the upper jaw, seren inches antero-posteriorly; three inches and a half transversely; sixteen inches and three quarters around the neck.

Besides these specimens, two of the upper, and two belonging to the lower jaw, - making, in the whole, seven posterior molar teeth, gire the same measurements. The casts of three ultimate molars afford like results. Two others differed: one, having lost the anterior ridge by use, was six inches long; the second had the posterior ridge more developed than in the other specimens, and measured eight inches.

$\mathrm{Dr}_{4}$ Falconer says that the ultimate molar of the lower jaw is distinguished from the corresponding one of the upper, by possessing five ridges, instead of four. Not having noticed the existence of this distinction in so decided a manner as expressed by this learned palæontologist, we hare made a careful and repeated examination of many ultimate molars in our possession, and find the following results: The ultimate lower molar, in two entire full-grown heads, has four ridges and a talon; in one, five ridges and a talon. In every case, the same is true of both sides. In four portions of the lower jaw, it has four ridges and a talon. In the aged Baltimore jaw, the tooth of the right side has four ridges without the talon. In five casts of one ramus of the lower jar, there are four ridges and a talon to this tooth. In one cast, there are five ridges and a talon. In eight ultimate molars not in place, there exist four ridges and a talon; in two, five ridges and a talon; in one, five ridges without a talon. Thus we find, that, in thirty-two ultimate teeth of the lower jaw, less than a quarter have five distinct ridges. 
This concludes the description of all the teeth, so far as "we have had an opportunity of observing them.

Some authors have thought that there might be an additional premolar tooth, situated at the root of the second milk-tooth, in the Mastodon GiganAdditional teus, as was discorered by Curier in the Mastodon Angustidens, and by Kaup in the Mastodon Longirostris.

In some of the specimens of the Mastodon Giganteus within our knomledge, the lower jaw has been carefully examined, and the supposed locality of this tooth explored, without the discovery of any such vertically situated tooth, or any vestige of its former existence. An opening was made. by Prof. J. B. S. Jackson, in the jaw of a calf Mastodon, belonging to the collection at Cambridge, as represented in Plate II. The specimen container the milk molars, and the first small six-pointed molar; but there was not found the slightest appearance of an imbedded tooth between them.*

In the jaw of another young Mastodon, an examination was made for the purpose of determining the same question. This specimen consisted ut the right half of the lomer jaw, containing two developed teeth, a posterior wisket from which a tooth had fallen from decay of the bone, and an anterior socket from which a tooth had been shed in the process of dentition. The tro existing teeth were both three-ridged, the anterior of them being the first small three-ridged molar: the socket in front of this had contained the second two-ridged milk molar. An incision was made in the bone below the interstice of these teeth, the supposed situation of the vertical premolar; but no trace of any such tooth, or any socket that could have

* "Proceedings of Boston Society of Natural History," vol. ii. p. 140. 
contained it, was found to exist. In other lower jaws belonging to young animals, which were not opened, the form and capacity of the bone, in the situation of the supposed vertical tooth, did not favor the opinion that any such tooth was lodged in their interior. My impressions, therefore, are not favorable to the opinion, that a vertical premolar tooth, destined to occupy the situation of the second milk-tooth, is to be found in the lower jaw of the Mastodon Giganteus.

But no one of us has examined the space above the roots of the second milk molar in the upper jaw. We have, from the Eppelsheim fossils, a cast of the upper jaw of a calf Mastodon Longirostris, in which the vertical premolar exists. From the fact of an additional premolar tooth in the upper jaw of the Tapir, and in the Mastodon Angustidens and Mastodon Longirostris, we might analogically infer the possibility of the existence of this additional tooth in the upper jaw of the Mastodon Gigantens, without involving the necessity of its existence in the lower jaw.

ORDER OF THE APPEARANCE OF THE TEETH.

'The teeth of the Mastodon, taken collectively, are of such magnitude and weight, that the co-existence of the whole number, or even the greater part of them, would, it has been remarked, add much to the extension of the jaws, and require the emplorment of additional power to support and use them. The substances employed by these animals as food - branches of trees, sometimes of considerable size - must necessarily hare produced great detrition of these organs, and thus have rendered them useless before the expiration of the ordinary period of life. Nature has, in consequence, 
given to them a wonderful power of renovation of the masticating organs, by the successire derelopment of new teeth as they advance in age. The whole number, as before said, amounts to six on each side in each jaw, so far as can be proved by existing facts; and we have no reason to believe, that this number has ever been exceeded in the Mastodon Giganteus. If this were true, reasoning from the gradual increase of magnitude, which we hare had an opportunity to observe, we should expect to find occasionally some teeth larger than the sixth molar, and a greater number of ridges than fire. But eren if teeth were occasionally, though rarely, found exceeding in magnitude those we are acquainted with, we might fairly consider them as exceptions to the general law, from the fact that so large a proportion are of a different character.

In the youngest jaws of the Mastodon within our observation, we have been able to discover as many as four co-existent teeth, all of small size. In an older specimen, in the collection of the University at Cambridge, there is the largest six-pointed molar, with the two smaller of the same description, and the partially developed ultimate molar. The drawing of this jaw is given in Plate $V$.

The order, in which the teeth on each side of each jaw appear, seems, therefore, to be this: First and second, the two anterior milk molars, remarkably smaller than the other teeth; third, a small six-pointed molar; fourth, a larger six-pointed molar; fifth, at a much later period of life, the largest six-pointed molar, or penultimate; sixth, after the last, at an unknown interval, comes the great ultimate four or five-ridged tooth, with its eight or ten points, which takes the place of all the others, and remains the solitary tooth of its side, to be retained by the animal, so far as we know, during the remainder of its life. 


\section{THE BALTIMORE TOOTH.}

A veny interesting fossil tooth (Plate XXVI.) has been found in the United States, near Baltimore, an account of which may conveniently be placed here, its geological character and position not having yet been fully settled. the banks of a small river, where he thought some raluable fossils might be discovered. He pointed out the place to his assistant, Dr. Tilden; requesting him to examine it, and send to him at Baltimore the product of his examination. Dr. Tilden, his brother Mr. Tilden, and a negro boy, accordingly proceeded to dig into the side of the river-bank; when, a heavy substance falling out, Dr. T. directed the boy to wash it in the stream, and found it to be a tooth whose character was unknown to him. Suspecting that there might be some other bones, he followed up his researches, and exposed other fossil remains, but none of the Mastodon.

History. This tooth remained in the possession of Dr. Ducatel for some time, without attracting much attention. Mr. Charlesworth, a distinguished geologist, and now Secretary of the British Natural History Society, when travelling in this country pronounced it to be a grinder of the Mastodon 
Longirostris. Sometime after, being seen by Sir Charles Lyell, this great geologist gare for opinion that it was the tooth of a species "distinct from the Mastodon Giganteum:" Dr. Hars and Dr. Harlan, of Philadelphia, were of the same opinion.

The specimen belonged at the time to a collection in the Academy at Baltimore, where it was permanently deposited.

In the year 1843, a statement was made by Sir Charles Lyell on the Miocene deposits of the United States, in which he noticed this tooth. Haring a curiosity to see it, and being present at the great meeting of the American Medical Association at Baltimore in 1848, I applied to my Disappearfriend Dr. Cohen for an opportunity of examining this fossil. But, on inquiry, Dr. Cohen ascertained that the collection was dispersed, and the tooth had disappeared. Dr. Hays, of Philadelphia, being present in Baltimore at the time, joined in the search, and shared with me in the disappointment I experienced, as he had known the tooth.

On my return to Boston, passing through Philadelphia, I visited him; Re-appearand, on the same day, he accompanied me to the splendid collection of the ance. 'Academy of Natural Sciences. While examining the fine array of Mastodon teeth, Dr. Hays, fixing on one, immediately said, "This is the Baltimore tooth we rere looking for, or it is so like it as not to be distinguished from it; " and he further said, that it had been in his possession a considerable time (three months, I think). Of course he could not well be deceived. On inquiry of Dr. Thomas B. Wilson, who lad placed the article in the Academy, and to whose kindness I am much indebted for this and other valuable aids, he informed us that this same tooth was purchased in London, by his brother, of Mr. Charlesworth, who said it was an American fossil. (Vide Appendix C.) 
One fact, quite remarkable, serves to prove the identity of the tooth seen in Baltimore and that of Philadelphia. In his account of the tooth Fracture. to Dr. Ducatel, it was said by Dr. Tilden, that "it was broken by the men engaged in digging, and the fragments could not be recovered." Now, the tooth, as found in the Philadelphia Museum, has its anterior portion broken off, in consequence of which there is a deficiency of nearly:an inch of the inferior surface of the anterior extremity, and of perhaps a quarter of an inch of its superior face. This fracture is not represented in the engraving, because the inferior face of the anterior extremity is not shown. The fracture is oblique, and does not involve a considerable portion of the tooth.

As there is no other instance of the discovery, in the United States, of any tooth or any other bone of the narross-toothed group, and it is therefore the only relic which can serve to establish the fact of the existence of the remains of this species in this country, I have thought it proper to go into details of its history, and also to give a description and representation of it. (Plate XXVI.)

This tooth is of a dark color, silicified and moderately heavy. It is narrower in proportion to its length than any of the teeth of the Mastodon Giganteus, and resembles in this respect the teeth of the Mastodon Angustidens and Tapiroides, as described by Cuvier, De Blainville, Owen, and Kaup. In length it is five inches and a half, and its greatest breadth is two inches and a half. Its superior face is divided by a longitudinal furrow, as it usually is in Mastodon teeth, and by three transrerse furrows. It has two talons, the anterior of which is worn and broken; the posterior, very perfect and prominent. Each of the ridges and the posterior talon are divided into two principal mammillary eminences, which are very distinct in the fourth 
ridge and talon, but are much worn in the first, second, and third; each presenting; with different degrees of distinctness, a trifoliate appearance. The edges of the worn enamel exposed are between one and two lines in thickness. The unworn nipples, that is, of the fourth ridge and the talon, are remarkable for their mammillated and rounded form; while the unworn nipples of the Mastodon Giganteus have a flattened or wedge-like form.

Another point in which this tooth differs remarkably from those of the Mastodon Giganteus consists in certain minor eminences, situated betreen the ridges; two of these smaller eminences, or papillæ, lie between each of the ridges, though imperfectly dereloped betreen the last two. Those between the two anterior ridges are partially worn; those between the posterior, not being so prominent, have not been exposed to attrition. The basal ridge is less distinctly indicated than in the Mastodon Giganteus. The lateral surfaces have four clefts, corresponding with the depressions between the ridges. The fangs or roots of this tooth are broken off. The carities or hollows, with their septa, are very perfect. There are four pairs of the latter. corresponding with the four pairs of mammillary eminences; and a fifth pair, very small, in the posterior cavities of the fourth pair, answering to the cusps of the talon. These appearances show that the animal was young.

We perceive, then, that this tooth, like that of the Mastodon Angustidens represented and described by Cuvier, is long and narrow, with interrening papillie. One principal difference between it and the casts of the Distinct from Mastodon AngustiMastodon Angustidens tooth in my possession is in the division of this specimen into four ridges, and the others into three only; a point in which, if we consider it to be a penultimate, it approaches more nearly a tooth of Kaup's Mastodon Longirostris than one of the Mastodon Angustidens. 
Another difference is in the number of the small intervening papillæ; two of these existing betreen each of the ridges in the tooth under consideration, and one generally in my specimens of Angustidens. We may remark, in regard to the two mammillæ of the posterior talon in our tooth, that one of them is smaller than the other.

I described and also exhibited a cast of this tooth to the Geological Section of the American Association for the Advancement of Science, at their meeting in Cambridge, in August, 1849. The description elicited ingenious and valuable remarks from Professor Agassiz, Professor H. B. Rogers, and Professor Gibbes, of South Carolina. Some gentlemen questioned the probability of its having been actually found in the Western Hemisphere; believing it more probable that an insulated fossil should have accidentally made its way from Europe, than that it should have been found in this country; and I had the same incredulity myself, when I first knew of it. But a careful and repeated examination of all the facts connected with it, and the opinion of the geologists in Philadelphia and Baltimore who had seen the tooth and known its history, together with that of Mr. Charlesworth Corrospon. and Sir Charles Lyell, as well as a correspondence through Dr. Cohen with dence. Dr. Ducatel (vide ApPENDix D), have given to my mind the conviction that it is an American fossil of the narrow-toothed Mastodon, derived from the miocene deposit, as is the Angustidens of Europe.*

In 1850 I sent to Professor 0wen, by Dr. Boott, a copy of the engraving of this Baltimore tooth, and requested his opinion as to the species, to which he replied in the following terms :-

* This opinion receives some degree of support from the fragment of a tooth found on a wharf in the city of Baltimore, and sent to the distinguished geologist Professor Gibbes, of South Carolina, which he referred to the Mastodon Angustidens. 
"So far as I can judge from a figure which does not give a direct side-riew, or a direct view of the grinding surface, it appears to me to be Owen's identical with that of the penultimate molar of the Mastodon Angustidens given in M. De Blainville's great work, 'Ostéographie des Ongulogrades,' 'G. Elephas,' Plate XV. Fig. 5, d."

In 1851 I had an opportunity of delivering to him the cast furnished me by Dr. Wilson, of Philadelphia, and of conversing with him on the subject, though rery briefly. Not having had time to make a satisfactory examination, he did not express any further opinion as to the specific character. He did, however, say very decidedly, that the solitary existence of the fossil in North America could not be taken as a fact adverse to future discoreries of the same species.

This fossil mas, as we hare already seen, judged by Mr. Charlesworth to belong to the species Longirostris of Kaup. It has, in fact, the form of many Longirostris teeth; the principal divisions are very similar; the Distinet from M. Longirostris. mawmillary cminences resemble those of the Angustidens and Longirostris, heing rounded and conical; the union of the mammilla forms lobes as in Longirostris, and not ridges as in Mastodon Giganteus; the number of lobes agrees with Mastodon Longirostris, if re consider the broken anterior extremity to have been a lobe. Thus far we have reason to set it down as Longirostris. On a careful comparison, however, I can find no one of the Longirostris specimens, which has precisely the same divisions of the crownsurface; the clefts on the circumference of the tooth are deeper than in Mastodon Longirostris, extending even through the cingulum; and at the extremity of these clefts lies a set of small buttresses of a pyramidal form, about half an inch long, not existing in the Mastodon Longirostris, and very different from the interlobular eminences which we have called papillæ. 
These buttresses are not distinctly shown in the drawing. As to the interlobular papillæ, one in each cleft is larger than the other; and these are more numerous and more fully developed than in Mastodon Longirostris; the worn surfaces, both internal and external, present the trefoil form, and also the fringed appearance of the rorn enamel, more distinctly than any Longirostris I have seen.

After comparing this tooth carefully with M. Laurillard's description of the Humboldtian and Andium teeth, and with their figures represented by Cuvier and Dr. Falconer; after comparing it also with the excellent casts of Kaup's Longirostris, examining the Humboldtian teeth in the British Museum, and many beautiful and noble specimens of the same in the Paris collection, - we have come to the conclusion, that the tooth in question approaches nearer to the Humboldtian than to any other known tooth. The points of resemblance are in the form of the mammillæ, in the form and number of the papillæ, in the similarity of the worn surfaces of the cusps, i.e. in possessing the trefoil figure on the inner and outer cusps, and in the fringed appearance of the trefoil border as seen distinctly in Plate XXVI.

It is true that no other specimens from the same animal have yet been discovered; but this objection will lie to the first discovery of any other fossil; a marked illustration of which may be found in the latter part of Mr. Charlesworth's letter, Appendix C. Another objection is, that the great distance between the regions where the Baltimore tooth was found, and those which were inhabited by the animal bearing the Humboldtian teeth, renders it improbable that the latter should have strayed so far as the middle regions of North America; but a great number of similar cases may be adduced to show that such occurrences are not unusual. We have, for 
example, seen one or two bones of Mastodon Giganteus deeply buried in Comnecticut, and a number of bones of Elephas Primigenius in the hills of Termont.

While, howerer, the Baltimore tooth resembles in many respects the Humboldtian, it differs in size; some of those of the latter, which I have - seen, being very large. But my experience on this point is too limited to allow me to place much stress on it; and, moreover, difference in magnitude is not a safe ground for specific distinctions. Whether correct or not, this is the best opinion we are able to give in regard to the character of this tooth.

There are, therefore, objections to placing it in the species Humboldtius, New which may be removed by considering it a new species; and I leave the Species. learned to determine whether it deserves this distinction. 


\section{T H E T U S K $\mathrm{S}$.}

Tusks. The tusks, anatomically considered, are incisor teeth enormously dereloped. In the modern elephants, they attain the length of six feet or more; not being generally of such magnitude as those of the Mastodon.

Besides the regular intermaxillary tusks, there are two rery small ones which show themselres in the upper jaw at the earliest period of life, but Number. shortly disappear, and are succeeded by the permanent tusks. This is shown by cutting into the tusk-socket of our calf elephant head. The fact, well established in regard to the elephant, seems to afford presumption, that, besides the great intermaxillary tusks of the Mastodon, there may be others in the upper or lower jaw, which, appearing at an early period of life, are, in the greater number of instances, lost before the animal has advanced far in its existence.

In the present specimen of the Mastodon, there are two tusks in the upper, and one in the lower jan on the left side. Tro undoubtedly existed in the lower jaw at an early period of life, as the relic of the right cavity is perfectly distinct, retaining a depth of an inch and a half, and nearly its original diameter.

The Superior Tusks. - The tusks of the upper jaw were ten feet and 
eleren inches long; but, being broken soon after exhumation, the anterior Length of termination of each only, in length about four feet, and in diameter at the Superior truncated extremity fire inches, remains in a perfect condition. The middle portion, of rather more than two feet, has crumbled. The posterior portion, of about the same length with the anterior', is broken into laminæ; it is flattened at the base, so as to be half an inch longer in one diameter than in the other, making the largest seven inches and a half. The bases are surrounded externally by circular elevations, at first two inches distant from each other, but gradually increasing in distance, until, at about two feet from the extremities of the bases, they disappear entirely.

The tusk is composed of lamina, which, at the internal extremity of structure. the socket, are not more than a line in thickness. These laminæ increase in number as we advance from the butts, so that, where the tusk issues from its socket, at the distance of rather more than two feet from the posterior extremitr, the internal cavity has diminished from seven inches in diameter to two by two and a half. The plates into which the tusk has separated in drying are generally an eighth of an inch in thickness, some of them nearly an inch. The external surface has a brown appearance; the layers which have been recently uncovered are of a lighter color.

The following analysis of a portion of the tusk has been kindly furnished me by Dr. Charles T. Jackson :-

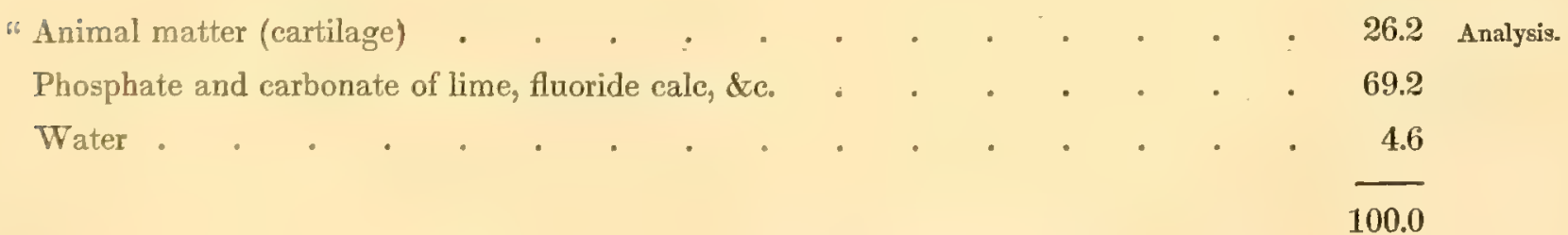

"Glass was etched with the fluorine. The constituents of the tusk are phosphate of lime, carbonate of lime, fluoride of calcium, phosphate of magnesia, soda, sulphur." 
The laminæ at the anterior part of one of the tusks, which is best preserved, are superficially not more than half a line in thickness; they are divided or split by longitudinal fissures, about three-fourths of an inch apart; they present none of the circular marks seen at the posterior extremity. The point anteriorly is worn away for the space of trro inches on one side (vide Large Plate), as is generally found to occur in the tusks of the Proboscidian family.

Direction. When the tusks were first discovered, they lay with their convexities outwards, their points approaching each other; laving turned apparently in their sockets after the soft parts, which retained them, were decomposed so as to loosen their attachments (as represented in Tignette on title-page). For the weight of the head inclined the butts downwards, while the resistance of the marl on their inferior and internal sides would give a rotatory motion outwards and upwards to a definite extent. In this direction they were placed by Dr. Prime, who had an opportunity of observing them in their original position in the imbedding marl. Although the extremities of the butts are somerthat oral, the greater size of their sockets, owing to the decomposition of the soft textures which lined them, would readily admit the butts of the tusks to be placed in any direction; and, considering the apparent inutility and the remarkitle anomaly of the position before mentioned, we thought it right to change their opposing aspect to one more consonant with the character and attitude of the skeleton.

The Inferior or Mandibular Tusk. - The small mandibular tusk has been brought into notice of late years by Dr. Godman, who considered it as characterizing a new species, to which he gave the name of Tetracaulodon, as will be shown hereafter. Professor Owen has attached a new importance to this tusk as one distinctive character between the genus Mastodon and 
the genus Elephas; a distinction which M. De Blainville, Dr. Falconer, A Distineand others, hare been willing to pass over. But hitherto, so far as we know, the existence of this part in the elephant has not been discovered; tion of Mastodon and while it is perfectly established in regard to the principal species of Mastodon, the Mastodon Giganteus, and Mastodon Angustidens. So long as this fact remains uncontroverted, we should consider it, taken in comnection with other facts, as forming an impassable boundary between the trro families.

This tusk (Plate $\mathrm{XX}$.) is eleven inches long, five and a half in circumLength. ference, and two in diameter at the base; being longer by an inch than the cast of a similar one in the collection of the American Philosophical Society, mhich was taken from the specimen originally described by Dr. Godman, and disinterred by Mr. Archibald Crawford, near Newburgh. The direction Direction. of our tusk is forwards and downwards, forming an angle with a horizontal line of about $45^{\circ}$. It has a cavity an inch and a half in diameter at the internal extremity, the thickness of the edge being one-fourth of an inch: this carity is of a conical form, and two inches deep. The rest of the tusk structure. aplear's to be solid. The anterior extremity is rounded, and about an inch in diameter; on one side it has been worn away to the extent of four inches. The worn surface is smooth at its extremity only, the rest being quite rough; the depth of the external layer is exposed in this abrasion, and exhibits the thickness of an eighth of an inch. Near the posterior or internal extremity are seen a number of circles to the amount of ten or eleven, extending from the base, two to three inches forward, and occupying that part which lay in the socket. The surface of the tusk generally exhibits longitudinal strix, in some of which cracks begin to appear from desiccation. These striæ are distant from each other from 
the fourth to the eighth of an inch. The color of the tusk is brown, excepting three inches of its anterior extremity, which is nearly black. At the fissures it is seen to be composed of lamina about the sixth of an inch in thickness. It is perfectly firm, and free from any marked evidence of decomposition. 
THE BALTIMORE SKELETON.

TrEe bones of this skeleton mere discovered by Mr. Peale, and exhibited in the Baltimore Anatomical Museum for some years. Having been disDiscovered mounted, I obtained them in 1848. I have not thought it necessary to remount them, as there were many deficiencies, and I had the use of two skeletons independent of this. The separate bones I have used for the purpose of comparison.

The lower jaw alone seems to deserve a distinct notice, on account Lower of its size, age, and the condition of its teeth; and therefore, although it has been already described by Dr. Hays in the "Transactions of the American Philosophical Society," vol. iv. New Series, I shall introduce some notice of it here.

This jaw is of great size, massive, and has the appearance of a bone of an old animal. It is remarkable in possessing only one tooth, and that the ultimate molar. The mandibular termination would lead us to believe that this bone belonged to a female, as there is no appearance of an excavation for an inferior tusk: possibly, however, the great age of the animal may have been the reason of this obliteration. 
MEASUREMENTS.

Length of the right ramus from the inferior angle to the rough edge of the mandible . $30 \frac{1}{2} \mathrm{in}$.

From the root of the condyloid process to the superior extremity of the rough edge

of the mandible . . . . . . . . . . . . . $31 \%$

From the last-named point backwards to the root of the coronoid process . . . 26 "

From the summit of the coronoid to that of the condyloid process . . . . $6 \frac{1}{2}$ "

Length of the condyloid process . . . . . . . . . $5 \frac{1}{2}$ "

Depth of the semi-lunar notch - . . . . . . . . $3 \frac{1}{2}$ "

Depth of the depression below this notch . . . . . . . . 1 "

Circumference of the bone in front of the root of the coronoid process ․ . $21 "$

The general form of this bone is rounded on its external surface; the inner face is convex. The inner face of the ramus is divided into two excavated surfaces.

Tooth. The tooth is solitary, and of the right side. The alveolar excavations before and behind, are filled by osseous deposit.

Length of the tooth . . . . . . . . . . $7_{\frac{1}{2}}$ in Width . . . . . . . . . . . . $3 \frac{1}{2} "$

Number of ridges . . . . . . . . . . . . . 4 4

Number of denticules (those in the front ridge not displayed, owing to use) . $\quad 8$

The anterior ridge is greatly worn, and the denticules on the outer side; those on the inner are not so much so, but the second and fourth are broken off, apparently from riolence. The talon is a sharp ridge, not divided, forming part of the cingulum. 


\section{THE CAMBRIDGE MASTODON.}

Ix the course of our description, reference has frequently been made to the Cambridge Mastodon. This noble skeleton, at the time of its discovery the most perfect, Tas obtained for the University by the liberal donations of gentlemen in Boston and vicinity, and set up in the mineralogical cabinet.

The State of New Jersey is rich in fossil remains. Among these are Tarions bones of the Mastodon, a multitude of fossil testacea, and the bones of the Mososaurus.*

In the autumn of 1844, as well as that of 1845, as before mentioned, Discovery. there was such a deficiency of rain in the Middle States, that many marshes and lacustrine deposits were dried, and thus afforded an opportunity of oltaining quantities of decomposed animal and vegetable matter for agricultural purposes. Among those who were occupied in this manner was a farmer, Mr. Ayers, of Hackettstown, Warren County, about twenty miles from Newark, and near the origin of the Mastodon Stream, the Waalkil. In a drained pond-hole, forty yards in length by twenty-five wide, an

* The distinguished geologist, Professor Henry D. Rogers, has labored successfully in this field; and to him I am indebted for one of the vertebræ of the Mososaurus, in a silicified state. 
excavation for the purpose above mentioned was undertaken, and resulted in the discovery of the skeleton and heads.

Nature of the Deposit

It is said, in a letter written by Mr. J. B. Maxwell to Professor Henry in October, 1814, and read before the American Philosophical Society at their semi-annual meeting in December following (APPENDIX $\mathrm{E}$ ), that the deposit in which they were found was thus composed:-

"On the top is about one foot of regetable deposit, formed of decayed leares, \&c.; then about six inches of whitish sand, mixed with regetable matter; and below this a deposit, which Mr. Ayers says, when first opened, was of a yellowish color, very much resembling in appearance the manure of a cow-yard when thrown up in heaps in the winter, and had a very strong smell of the same kind. Exposure to the reather has changed its color to the dull bluish black of swamp earth, which it seems to be mixed with; also great quantities of regetable remains, principally of marsh plants, with scattered fragments of branches of trees, \&c. In this deposit the remains were found, covered from four to six feet deep." "Between the ribs of two or three of them was a considerable quantity of what Mr. Ayers describes as resembling coarse chopped stran, mixed with fragments of sticks, - no doubt the contents of the stomach."

Some account of these remains has also been given by Professor J. B. S. Jackson in the "Proceedings of the Boston Society of Natural History" of Oct. 1, 1845 .

Re-articulation.

Haring been erroneously articulated in many respects, the skeleton was committed to me, by the government of the University, for the purpose of re-articulation; and it was therefore remored to the Hall containing my collection of comparative skeletons. There, being placed by the side of the large Mastodon skeleton and that of the elephant, an oppor- 
tunity was presented, which had not occurred before, of comparing two nearly perfect Mastodon skeletons with each other, and with that of the elephant. On this comparison it appeared that the head of the Cambridge skeleton was too low, and the spine too elevated, giving the grotesque appearance represented in the lowest figure on the left hand of Plate I. The spine had been elongated by placing very wide pieces of cork between the bodies of the rertebra, so as to render it nearly two feet longer than natural. In order to give it height, the scapula was placed obliquely under the body, . and considerable intervals left between the bones composing the articulations of the extremities. The bones of the hands and feet were supplied by pieces of cork, formed not in imitation of Mastodon bones, but rather on the model of the human, with the addition of a complete range of digital bones, making the phalanges four instead of three.

In order to restore the bones to their natural position, they were all taken apart, and placed as nearly as possible in their correct relations to each other previous to re-articulation. Then pieces of cork were fitted to the interstices of the bodies of the vertebræ, beginning with the spine, in thickness as near as possible to the intervertebral substance. The head was elevated, and the bones of the extremities also, raising the upper angle of the scapula so as to correspond with the spinous processes of the dorsal rertebræ. The bones of the articulations of the extremities were brought into contact with their correlative bones. The cartilages of the ribs were supplied by imitations in cork, and the bones of the feet ingeniously imitated in the same material by Mr. Ogden with the aid of those in 'the large skeleton. Numerous iron rods were removed, and replaced by two iron columns; one supporting the anterior, and the other the posterior part of the trunk. 
Appear-
ance. sents one of the most imposing and valuable specimens in existence. Its height, from the anterior dorsal spinous processes to the ground, is eight feet six inches; its length, from the anterior part of the muzzle to the first caudal vertebra, ten feet five inches; and, from this point to the extremity of the tail, four feet four inches.

The situation of the tusks was carefully examined; and they have been inserted, in relation to their sockets, with as much exactness as possible. They are both in a state of partial decomposition, and some portions have been displaced apparently; but I could not make the attempt to restore them, without danger of displacing them irrecoverably.

The skeleton thus restored was transferred to Cambridge; and, in the latter part of the autumn of 1850 , presented to the President of the University, the late Governor Everett, Professors Agassiz and Wyman, and the members of the Scientific School.

Besides the skeleton in question, there were obtained from the spot where it was exhumed, four very perfect heads, a number of fine teeth, and other bones sufficient to excite the hope that further investigation 'would produce abundant relics to complete another skeleton. 


\section{COMPARISON OF MASTODON AND ELEPHANT.}

Is making the comparison of the skeleton of an Elephant about ten feet high, with that of the Mastodon, as it now stands, eight feet six inches, rre find, among other differences, the following: The skeleton of the Elephant skeleton. presents a lighter and more slender aspect than that of the Mastodon. All the bones are less massive, and the gravigrade attitude is less strongly expressed than in the Mastodon. The trunk of the Elephant is more flattened laterally and less barrel-shaped. The spinous processes of the vertebræ are not so long. The bodies of the vertebræ are less heavy. The ribs are more slender. The pelvis is not so broad, and its aperture is Pelvis. smaller. The tail has trrenty-four bones, and that of the Mastodon twentyTail. two; but, in each of them, some have been replaced, and the whole number cannot be determined with accuracy.

The head of the Elephant is placed more vertically. This position Head. would, of course, be varied by the mode of articulation. In De Blainville's Elejhant, the head is raised much higher than the spinous processes of the rerterlic. In ours the vertex has the same height as the summit of these processes. The same is true of both the Mastodon skeletons, that is, the Cambridge skeleton and ours. The tusks of the Elephant are shorter Tusks. 
Lower and lighter. The lower jaw is shorter, and differs remarkably in its anterior Jaw. termination, which has some similarity to the shape of a ploughshare.

EXTREMITIES. - The scapula corresponds, at its superior angle, with the bases of the spinous processes more nearly than in the other skeletons; but this position depends on the mode of articulation. The head of the os humeri is much less massive. The anterior process is sharper, the posterior much blunter and shorter. The bone itself is also less massive. The radius and ulna are more crossed. The foot is more vertical and narrower.

Posterior Extremities. - The os femoris is long and slim. The tibia is more in front of the fibula. The patella is less prominent. The hind foot is narrower, more elevated, and less spread, than in the Mastodon.

On reviewing the skeletons, that of the Elephant appears, as before intimated, decidedly lighter and better calculated for motion than that of the Mastodon; while the latter presents, especially in its anterior parts, an arrangement adapted to sustain a rery great weight, and move a rery heavy mass. 
OF THE

\section{CAIBRIDGE MASTODON AND THE ELEPHANT PIZARRO.}

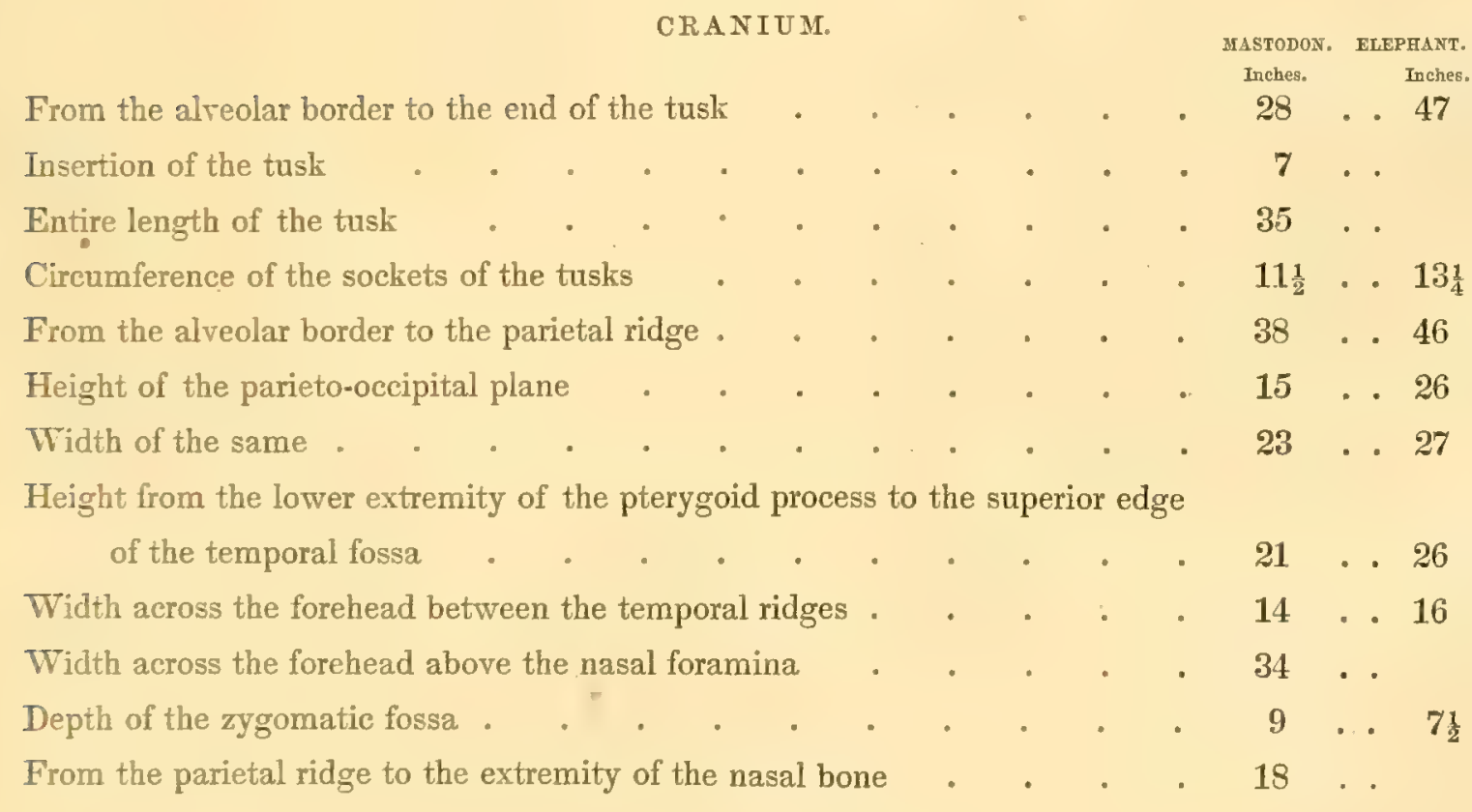

PALATINE PORTION.

Length of the bony palate . . . . . . . . . $21 \frac{1}{2}$. 19

Anterior diameter of the palatine fossa . . . . . . . 8 .

Middle diameter of the palatine fossa in front of the alveoli . . . . $6 \frac{1}{2} \ldots 2 \frac{3}{4}$

Posterior diameter of the palatine fossa behind the alveoli . . . . 4 . 5 
TEETH.

There are, in the jaws of this Mastodon, two teeth on each side of each jaw, making the whole number present to be eight. The anterior of these is the third six-pointed tooth, the fifth in the whole series, or the penultimate molar. The posterior tooth on each side is the five-ridged, ten-pointed, or ultimate molar. They correspond in number, form, and size with those in the large skeleton, with the following exceptions: The last molars are not so fully developed; the fifth transverse ridge is, howerer; larger; and the transverse furrow, between the fourth and fifth, is deeper. The anterior or penultimate molar is less used than in the large skeleton; the points being, in a great measure, preserved.

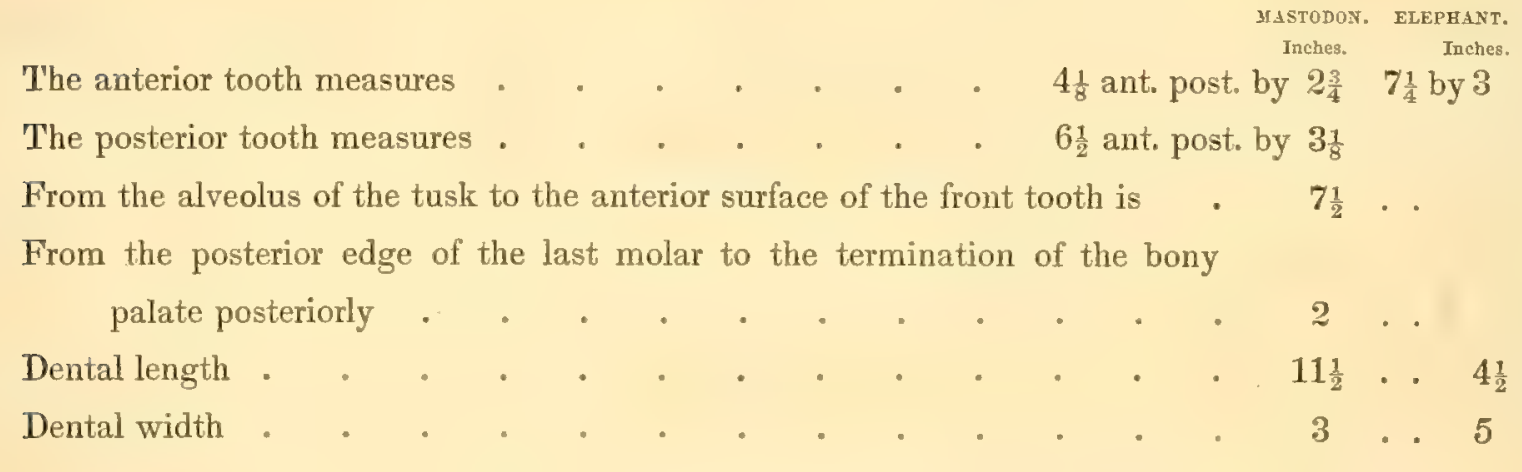
LOWER JAW.

This is about half the width of that in the large skeleton, but much broader than that in the Elephant, which terminates anteriorly in a long, pyramidal, smooth process, ending in a point. The rough extremity in the Cambridge Mastodon exhibits no appearance of an excaration for a mandibular tusk, in which it greatly differs from this part in the large skeleton.

The mandibular extremity is rough as if broken, and measures . . . $2 \frac{1}{2} \ldots 10$ Length of the horizontal branch . . . . . . . . 26 . 16 
Thickness of the same posteriorly

MASTODON. ELEPHANT. Inches. Inches

From the inferior border of the horizontal branch to the top of the condyloid and coronoid processes . . . . . . . . . . 14 . 16

From the condyloid to the coronoid process . . . . . . . . . $\quad$. $8 \frac{1}{4}$. 6

Width of the horizontal branch posteriorly _ . . . . . . 9 . .

Length of the condyloid articulating surface . . . . . . . . $4 \frac{1}{2}$. . $4 \frac{1}{2}$

Transverse width of the same . . . . . . . . . . $1 \frac{1}{2}$. 4

Width on the outside of the front teeth . . . . . . . . $8 \frac{3}{4}$. . 4

Width on the inside of the front teeth . . . . . . . . $44_{4}^{\frac{1}{4}}$. . $5 \frac{1}{2}$

Width on the outside of the back teeth . . . . . . 10 .

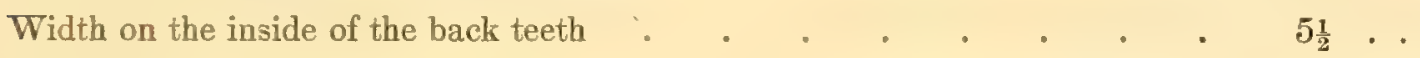

Length of the front tooth _ . . . . . $4 \frac{1}{2}$ ant. post. by $3 \frac{1}{8} \quad 7 \frac{1}{2}$ by $2 \frac{3}{4}$

Length of the back tooth . . . . . . 7 ant. post. by 35

Dental length

$11 \ldots$

Dental width

NASAL FOSSA.

Depth 。 . . . . . . . . . . . 19 . 21

From right to left . . . . . . . . . . 10 . . $13 \frac{1}{2}$

From above downwards . . . . . . . . . . 4 . 5

Below the nasal foramina lies the intermaxillary fossa - In width superiorly $\quad 2 \quad \ldots \quad 3$

In width inferiorly $\quad 6 \quad \ldots 8$

This fossa is very deep compared with that of the large skeleton, and terminates superiorly in a deep blind cavity situated immediately below the nasal fossæe, and which therefore may be considered as the Fossa Incisiva. This is a large cavity, measuring six inches in depth, three inches and a lalf in breadth, and five inches from above downwards. It has a fissure in its posterior part, which opens into the cavity of the nostrils and pharynx. In the great skeleton, this excavation, as well as the whole intermaxillary fossa, is comparatively superficial; and the same is true of the Elephant. 


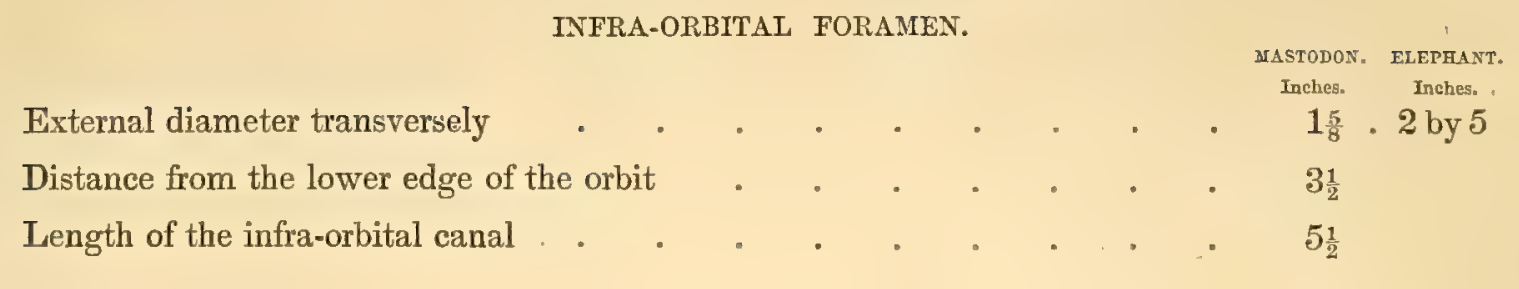

VERTEBRAL COLUMN.

The cervical vertebræ are, in the Mastodon, in number, seven; the dorsal, twenty; the lumbar, three; the caudal, twenty-two. In the Elephant the vertebræ are as follows: Seven cervical, nineteen dorsal, three lumbar, five sacral, twenty-four caudal.

The spinous processes of the cervical vertebræ are small, and the transverse processes quite indistinct. The spines of the first six dorsal vertebræ are very long; thence they gradually diminish in length, and increase in obliquity to the seventeenth.

The first cervical vertebra, or atlas, transversely . . . . . . 12 . 15

From above downwards . . . . . . . . . . $7 \frac{1}{2}$. 8

In circumference . . . . . . . . . . . 32 . . 34

The first dorsal. - Body including transverse processes \& . . . . 11 . 13

From above downwards . . . . . . . . 6 . 7

Spinous process . . . . . . . . . . 12 . 10

The first lumbar transversely . . . . . . . . 10 . . 7

From above downwards . . . . . . . . 7 . . $7 \frac{1}{2}$

Circumference . . . . . . . . 26 . $22 \frac{1}{2}$

The transverse processes of the lumbar vertebra are small, and hardly project beyond the bodies of the rertebra; while those of the large skeleton have a considerable projection.

TH ORAX.

The sternum of the Mastodon is wanting; the ribs are twenty in number; they are less massire than in the other skeleton in proportion to 
the height. In our Elephant the ribs are nineteen; in another specimen, trenty.

Length of the first rib

MASTODON. ELEPHANT.

Width of the first rib

Inches. Inches.

Length of the tubercles of the first rib

. 20

$4 \quad . \quad 4 \frac{1}{2}$

$4 \cdot 2$

Length of the twentieth rib

10

Width of the twentieth rib . . . . . . . . $1 \frac{1}{2}$. .

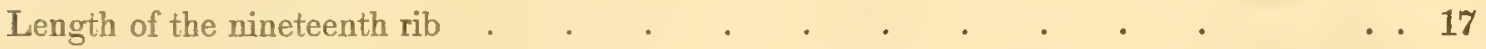

Width of the nineteenth rib

PELVIS.

The ossa innominata are not co-ossified with the sacrum.

The ossa pubis are co-ossified from the symphysis to the termination of the mper third; then occurs a slit between the rami, or branches, six inches in length. From the inferior termination of this slit to the inferior edge of the pelvis, they are consolidated. Nearly the same arrangement is seen in the large skeleton; but in the Elephant, there is no union, by bony matter, of the symphysis of the pubis.

The sacrum measures . . . . . . . . . . . 9 . $14 \frac{1}{2}$

From the top of the os sacrum to the inferior extremity of the ossa ischii . $36 \quad \ldots 30 \frac{1}{2}$

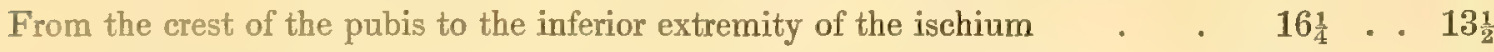

Transverse width between the two anterior superior spinous processes . . 58 . 43

Transverse diameter of the aperture _ . . . . . . . . 19 . 16

Vertical diameter of the aperture . . . . . . . . . $19 \frac{1}{2}$. . 15

Long diameter of the thyroid foramen . . . . . . . . 7 . $5 \frac{1}{2}$

Short diameter of the thyroid foramen . . . . . . . $4 \frac{1}{2}$. 3 .

Long diameter of the acetabulum . . . . . . . . . 6 . . 7

Short diameter of the acetabulum . . . . . . . . . . $5 \frac{1}{2}$. 7

Width between the tuberosities of the ischia . . . . . . . $15 \frac{1}{4} \ldots 11$

The direction of the ossa innominata is nearly vertical. The brim of 
the pelris is the same. That of the pubis and ischium is oblique, forming an angle of $45^{\circ}$. Compared with the large skeleton, the bones of the pelvis are less massive, and the apertures of the pelvis proportionally larger. In the skeleton of the Elephant, which is larger than this Mastodon, the pelvic aperture is decidedly smaller; and the transverse dimension of the pelvis, from one spinous process of the ilium to the other, is forty-three inches, not so great by fifteen inches, although the skeleton of the Elephant is, in every other respect, larger.

The result of these measurements of the pelvis leads to the conclusion, that our skeletons of the Elephant and Mastodon are males, and that of Cambridge is a female.

T A I L.

The vertebræ of the tail are, in the Mastodon, in number twenty-two; but some of them appear to be the bones of another individual, and therefore cannot be considered as affording accurate notions of these bones. Those of the Elephant are trenty-four' but the number probably varies in different animals.

EITREMITIES.

Anterior Extremity. Scapula. - The direction of this bone is nearly vertical. The external face is divided by the spine into an anterior third and posterior tro-thirds. The direction of the spine is oblique from abore dorruwards, and from before backiards. The inferior extremity is divided into tro processes, an anterior and a posterior; both of them sharp and pointed, compared with those of the large skeleton. The internal face is divided, like the external, into an anterior and posterior fossa, by a rounded internal ridge. 


\begin{tabular}{|c|c|c|c|c|c|c|c|c|c|c|c|c|}
\hline & & & & & & & & & & & $\begin{array}{l}\text { UASTRODON. } \\
\text { Incheg. }\end{array}$ & $\begin{array}{l}\text { ELEPHANT. } \\
\text { Inche. }\end{array}$ \\
\hline Spine to the bifurcation & - & - & - & - & - & . & - & - & - & - & 17 & .. 13 \\
\hline Length of anterior process & - & - & - & - & - & - & - & - & - & - & $7 \frac{1}{2}$ & - 13 \\
\hline Length of posterior process & . & . & . & . & • & . & $\cdot$ & . & . & • & 11 & 6 \\
\hline
\end{tabular}

In the Elephant the posterior process is many inches shorter, while the anterior is longer.

Width of the anterior spinal fossa . . . . . . . . . $4 \frac{1}{2}$. . $4 \frac{1}{2}$

Greatest width of the posterior fossa $\quad$. . . . . . . . 30 . . 14

Entire width of the inner face . . . . . . . . . . 24 . 19

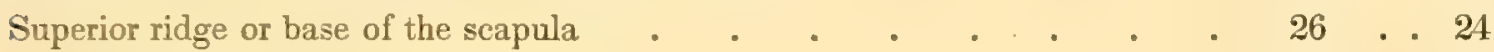

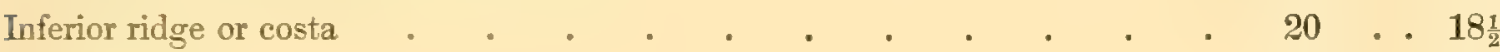

Anterior ridge . . . . . . . . . . . . 30 . 32

Length of the glenoid cavity . . . . . . . . . 7 . $10 \frac{1}{2}$

Width of the glenoid cavity . . . . . . . . 4 . 5

Except in size, all the parts of this bone correspond nearly with those of the large skeleton, but differ in many respects from the Elephant, particularly in the form and direction of the processes.

The glenoid cavity has the same semi-lunar form that it has in the great skeleton and in the Elephant.

\section{OS HUMERI.}

From the top of the great tuberosity to the lowest part of the external condyle $\quad 30 \frac{1}{2} \quad \cdot 34$

From the summit of the head of the bone to the lowest part of the internal

condyle . . . . . . . . . . . . . . . . . $28 \frac{1}{2}$. . $35 \frac{1}{2}$

The greatest circumference of the superior extremity of the bone . . . . $27 \quad$ - 29

Smallest circumference of the middle of the bone . . . . . . . $14 \quad$. 14

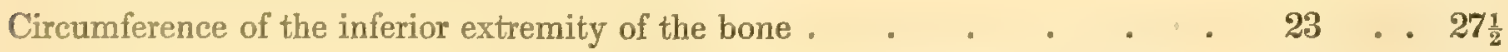

Length of the articulating surface of the head of the bone from front to rear.$\quad 10 \frac{1}{4} \cdot{ }^{-10 \frac{1}{2}}$

Greatest transverse width of the head of the bone from front to rear $\quad$. . $\quad 5 \frac{1}{2} \quad$. $9 \frac{1}{2}$

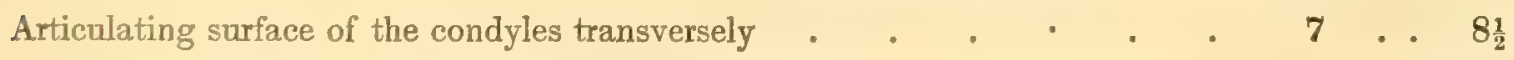

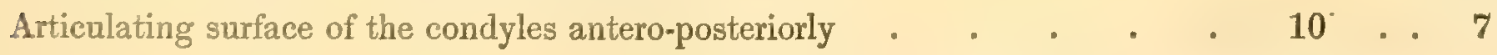


The great tuberosity terminates anteriorly in a large rough tubercle. The rough ridge for the insertion of the biceps muscle, the articular surface of the head of the bone, the groove of the biceps muscle, the condyles external and internal, their articulating surfaces, and other prominences and depressions of the bone, agree with those of the large skeleton, with the exception that the semi-lunar notch is deeper in proportion to its width.

ELBOW.

The elbow-joint exhibits two articulating surfaces belonging to the condyles, and three belonging to the bones of the fore-arm. The two first are prominent, semicircular; and of the three latter the internal is formed by the ulna in a great measure, and so is the external: the radius contributes to both of the surfaces, mostly to the external. The third inferior articulating surface, formed by the anterior superior part of the olecranon process, is divided into two surfaces corresponding with the opposite condyles by a middle ridge.

ULNA.

Length of the ulna.

MASTODON. ELEPHAXT

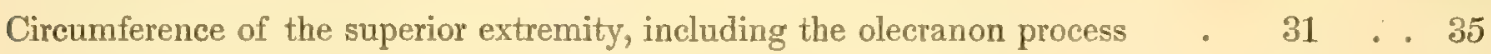

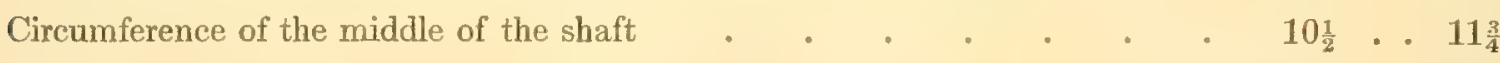

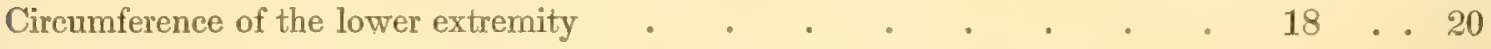

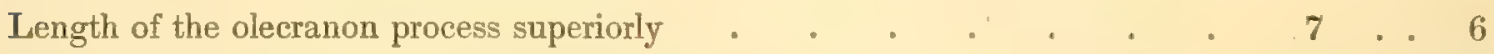

Greatest circumference of the olecranon process ․ . . . . . . $29 \frac{1}{2} .19 \frac{3}{4}$

Transverse dimensions of the superior articulating surface $. \quad . \quad . \quad . \quad 7 \frac{1}{4} \cdot 8_{\frac{1}{2}}$

Antero-posterior measurement of the superior articulating surface . . . . $\quad 3 \frac{3}{4} \quad$. $3 \frac{1}{2}$

Articulating surface of the olecranon process, from above downwards . . $\quad 3 \frac{1}{2} \cdot 4$

Inferior articulating surface - . . . . . . . . . $44 \frac{1}{4} \cdot 4 \frac{1}{2}$

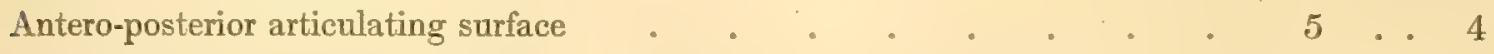


This bone has the same triangular form with that of the large skeleton. This form is very peculiar, its parts being defined by three ridges, and therefore more easily compared with the other, from which they do not differ, except in magnitude.

R A I U S.

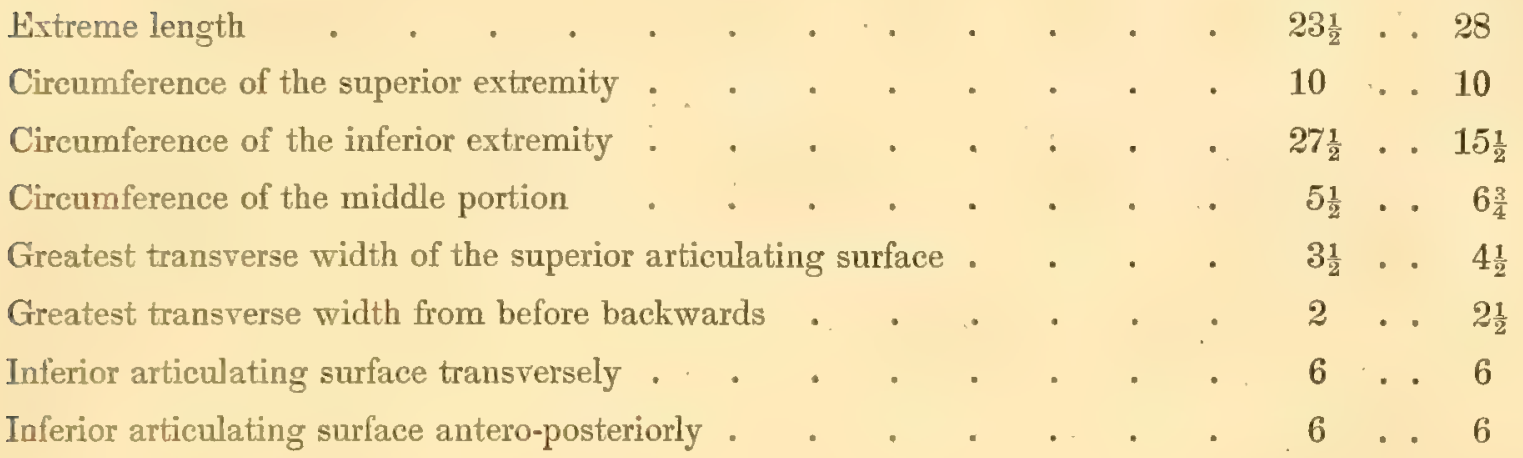

The radius has the same relation to the ulna as in the great skeleton, except that it is situated more in front, covering the ulna by its superior half, whereas in the former it covers only a third of that bone. It has the same form abore and below as in the other.

\section{H A N D.}

The bones of the hand in.this skeleton are imperfect, and do not admit of any comparison.

\section{POSTERIOR EXTREMITY. - OS FEMORIS.}

Greatest length

From the summit of the great trochanter to the lowest part of the external

$$
\text { condyle . . . . . . . . . . . . . . . . } 35
$$

Greatest circumference of the superior extremity of the bone below the head . $\quad 27 \quad$. $29 \frac{1}{2}$

Circumference of the shaft . . . . . . . . . . 13 . $13 \frac{1}{2}$

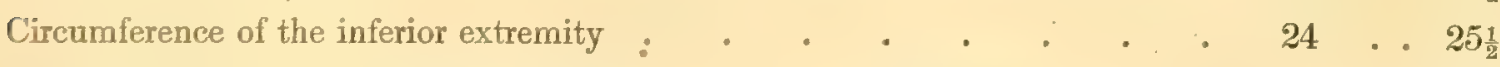

Circumference of the head of the bone . . . . . . . . 18 . 18 
Length of the great trochanter MASTODON, ELEPHANT Width of the great trochanter

(The small trochanter is faintly expressed.)

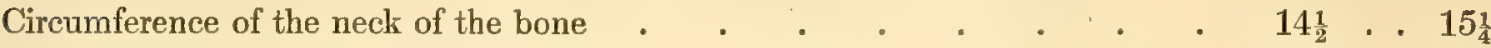

Superior line from the articulating surface to the trochanter . . . . $3 \frac{11}{4}$. 5

Inferior line of the neck, viz. from the articulating surface to the upper extremity of the trochanter minor

Articulating surface of the head of the bone transversely _ . . . $9 \frac{1}{2}$. .

Articulating surface of the head of the bone antero-posteriorly.$+ \quad 10 \ldots$

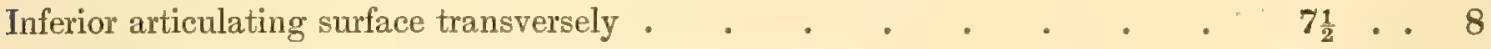

Transverse diameter of the articulating surface of the internal condyle . . $3 \frac{3}{4} \ldots 4 \frac{1}{2}$

Antero-posterior diameter of the articulating surface of the internal condyle . 8 . 8

Transverse diameter of the articulating surface of the external condyle . . $3 \frac{3}{4} \ldots 3_{4}^{\frac{3}{4}}$

Antero-posterior diameter of the articulating surface of the external condyle . $6 \frac{1}{2} \ldots \quad 5 \frac{3}{4}$

Patellar articulating surface transversely . . . . . . . . . . $5 \frac{1}{2} \ldots 4 \frac{1}{2}$

Patellar articulating surface, from above downwards . . . . . 6 . 4

The femur does not present any material difference in its form, excepting that the internal condyle is curved inwards towards the other knee more than in the large skeleton or the Elephant.

\section{PATELLA.}

Circumference outside of the articulation . . . . . . . . 14 . $14 \frac{1}{4}$

From above downwards, exterior to the articulation . . . . . 10 . $8 \frac{1}{2}$

The articulating surface, from the juxtaposition of the bones, could not be measured. The bone is prominent, and rounded as in the large skeleton.

TI B I A.

Length of the internal edge . . . . . . . : : $20 \frac{1}{2}$. . 25

Circumference above . . . . . . . . . . $20 \frac{1}{2}$. $22 \frac{1}{2}$

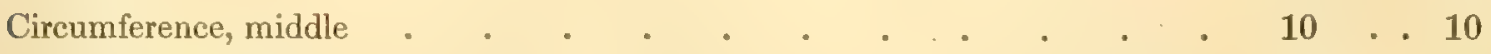

Circumference below . . . . . . . . . $16 \frac{1}{4}$. 18 
Its superior articulating surface is divided into two parts by the spine, both of which are a little excavated; the internal has nearly a circular form, and the external rather an oval. They measure as follows:-

The internal in diameter . MASTODON. ELEPHANT. The external transversely Inchess. Inehes. The external antero-posteriorly . . . . . . . . . . 3 . $3 \frac{3}{4}$ Transverse diameter of the lower articulating surface $\quad . \quad$. $\quad . \quad \ldots \quad \ldots \quad 4 \frac{1}{2} \quad \ldots \quad 5 \frac{1}{2}$ Antero-posterior diameter of the lower articulating surface . . . . $3 \frac{3}{4}$. 4

This surface is excavated for the reception of the astragalus, and surmounted by a large peripheral ridge, most prominent at the malleolus internus. It is interrupted externally by the inferior head of the fibula. The tuherosity of the tibia is less prominent than in the other specimens.

In comparing the articular surfaces of the Baltimore tibia, we find that they differ considerably. Instead of being divided into two nearly equal surfaces by the spine, the internal, in this specimen, has double the dimensions of the external; the internal condyle of the femur, as before mentioned, lrojects inward to occupy this surface. The articulating surface for the external condyle has not more than half the superficies of the internal; it is also very oblique, forming nearly an angle of $45^{\circ}$ at its internal edge.

\section{F I B U L A.}

It is situated exteriorly to the tibia, except at the superior extremity, which is a little behind.

It measures in length $18 \ldots 14$

Circumference above

$5 \frac{3}{4} \cdot 6 \frac{3}{4}$

Circumference below

Circumference, middle 


\title{
THE $\quad$ S H A W N G U N K H A D.
}

\author{
(See Prates XVI. XVIII. XIX.)
}

THE description of this rery fine head is given, though not so mimutely as that of the head of the great skeleton, with a view to some peculiarities, especially to the remarkable curve of the superior surface of the face, and Discovery, the distinction of the bones by sutures in some of its parts. It was found at a place called Scotchtomn, in Orange County, in the State of Ner Tork, a farorite habitation of the Mastodon. A few other bones were discovered in the same place, but none of any importance; and a search for the remainder of the skeleton was fruitless. The strata covering it were, 1st, gravel; 2d, marl; $3 d$, a layer of peat, "hard enough to be turned in a lathe."

Size. This magnificent head is remarkable for its size, whiteness, and the distinctness of its sutures. In size it is not exceeded by any Mastodon

condition. head with which we are acquainted, and its state of preservation is nearly as perfect as that of the head of an elephant recently prepared. It has the same length and about the same breadth as the Dinotherium head of Dr. Klipstein, a cast of mhich I measured in the collection at Darmstadt. But the head of the Dinotherium is flatter than that of the Mastodon, and 
therefore could not have contained the same amount of substance. Hence we might be led to doubt whether this species of Dinotherium was a larger animal than the Mastodon.

The elevation of the cranium exceeds that of the great skeleton. It Cranium. differs in the curre of the intermaxillary bones; for these are nearly straight in the one, while in the other they are curved from behind forwards, so that the anterior extremity of the tusk-socket is turned a little upwards. The sockets themselves contain the butts of the tusks projecting a few inches from the carities; the remainder, though perfect when found, having been since decomposed.

The mandibular extremity of the lower jaw is, in diameter, an inch Mandible. broader than in the great skeleton. It has no existing tetracaulodon tusks; but the tráces of their sockets are visible on both sides, especially on the right, from which the tusk had disappeared more recently than from the other. Both tusks, probably, were shed at an earlier period of life than in the great skeleton, which exhibits one tusk, and a deep depression originally occupied by the other.

Another peculiarity relating to this head regards the number of teeth, Number compared with its advanced growth. The head of an old Mastodon contains, of as we see in the Baltimore specimen, a single large terminal, five-ridged, ten-pointed molar on a side. In the heads of the great skeleton, and of that at Cambridge, we find two molars on each side in each jaw, making eight in the whole; while in this there are on the right side in both jaws three molars, on the left two, and an anterior socket partially filled. On the right side are anteriorly the second six-pointed molar, much worn, and nearly rearly to be shed, as the corresponding tooth on the other side had alrearly been; next, the largest six-pointed or penultimate molar; third, 
the great eight-pointed ultimate molar, with a distinct talon bearing two very small mammillary eminences.

This head differs, therefore, remarkably from the head of the skeleton, in having two more teeth on the right side, making in the whole, ten teeth ; while in ours and the Cambridge skeleton are only eight, and in the oldest heads only four (as in the elephant); whence we may conclude, that the individual to which this head belonged was young at the period of its death, and might, had it reached a great age, have attained an immense size. As it corresponds in magnitude and in many of its measurements with the great skeleton, we renture not to assume for it the claim of belonging to another species.

Particular Description

Particular Description. - The os frontis is co-ossified with the ossa parietalia anteriorly, and presents a rough space from two to three inches in width, of a semi-lunar form; constituting, with the ossa nasi, the superior boundary of the nasal aperture. On the sides of the head, and in a lateral direction, the ossa parietalia extend downmards about three-fourths of the zygomatic fossa, where they unite with the temporal bone.

Temporal Bone. thence extends backwards to form the inferior part of the occipital ridge. At this point it bifureates into the mastoid process on the back part, which is of a flattened form, and more distinct than in the elephant; and anteriorly into the zygomatic process, which, extending forwards, constitutes one-third of the posterior portion of the zrgomatic arch, being at this point united with the posterior third of the jugal bone. The external auditory foramen, situated at the root of these two processes, is of an oral form, and about three inches in diameter; its depth is, thirteen inches.

The jugal bone, narrow at its posterior part, where it unites with the 
zrgomatic process of the temporal, becomes broader anteriorly, where it unites with the os malæ. At the internal face of the zygomatic fossa is the spheno-maxillary fossa, of great length and curved form.

The ossa parietalia present a superior horizontal face, bounded anteriorly by an irregular curve, which separates it from the os frontis, and Parietal terminates externally in the superior posterior orbitar process. The posterior edge unites with the supra-occipital by a suture, which, in the Elephant and Mastodon, is ossified at an early period of life in order to afford a firm attachment for the temporal muscles in their action on the heavy lower jaw.

The os occipitis (Plate XIX.) constitutes the whole of the posterior surfice of the cranium, and a part of the inferior. Superiorly, the occipital face Occipital Bone. is very rough "for the attachment of muscles; and, in some places where the outer table is broken, an opening is made into numerous diploic cells. These apertures hare been caused by the separation of the rough processes near the superior edge of this surface, which have thus left openings into the cranial cells. In the midst of this posterior region of the occipital bone is a ridge or crest separating two deep fossæ, where the ligamentum nuchæ and muscles are attached. The inferior portion of the os occipitis to which the cerrico-dorsal muscles are attached, comprises a part of the occipital condrles, and the cuneiform process, which extends forwards, in a pointed form, to the posterior superior opening of the nasal cavities. The foramen magnum is about three inches in diameter, and looks obliquely backTrards.

Bones of the Face (Plates XVI. and XVII.). - The ossa nasi, of a ryramidal form, are partially co-ossified with the os frontis; they are short, separated at their extremities, joined at their bases. 
Inter-

maxillary

Bones.

On the lower part of the nasal opening, we see very distinctly indicated the intermaxillary or premaxillary bones, forming the lateral and inferior boundary of the great nasal carity. They widen below this foramen to the extent of ten inches; then, arching inwards to leave space for the maxillary bones, they narrow to seven inches, and, at their anterior extremities, again widen to sixteen inches to form the anterior exterior and a part of the inferior portion of the tusk-sockets. These bones are deeply indented across the middle of the face, differing in this respect from the elephant and from the other Mastodon heads. The intermaxillary fossa is of great depth. At its postero-superior extremity, it presents a fissure six inches long, and three or four inches deep; from the inferior angle of which it enlarges into a fossa nine inches across, and four or five deep; at its anterior termination again narrowing to the width of seven inches.

Upper

Maxillary

Bone.

The superior maxillary bone is of an irregular form. Superiorly, at the anterior part of the orbit, this bone rises into a pointed process, which separates the intermaxillary from the frontal bones; thence descending, it widens posteriorly to form the zygomatic process, at the root of which is the great infra-orbital foramen; below this it enlarges into the great alveolar ridge, and forms, on the fore part, the inferior wall of the tusksocket. Thence extending internally, it constitutes by its palatine plate a large part of the palatine, fossa, which is eleven inches broad at its anterior part, and narrows as it passes backwards.

The inferior face of the cranium (Plate XVIII.) measures anteroposteriorly, forty-six inches; and transtersely, thirty-one. It presents many irregularities from the prominences of the occipital condyles, posterior openings of the nasal fossa, the great zygomatic openings, the alveolar and dental prominences, and the palatine fossa, but may be said to have a form 
generally Alattened. At the posterior extremity of this face is situated the great occipital foramen; of a slightly rounded form, and looking rather backwards than dornmards; its anterior edge is distinctly notched. On each side are seen the rounded condyloid protuberances of the os occipitis, with an articulating surface arching fortrards.

From the condyle extends, in a lateral direction, an inferior, long, rough vccipital edge. terminating inmediately below the external auditory foramen. In front is the cuneiform process, presenting a strong ridge on its inferior face, a slight excaration on each side of this ridge, and on the external edges a long fissure terminated posteriorly and externally loy the internal extremity of the glenoid cavity of the temporal bone, and extending anteriorly as far forward as the junction of the cuneiform process with the body of the sphenoid. This fissure corresponds with the posterior foramen lacerum; two rounded holes are seen in its course, one near the middle, and another near its anterior termination. The glenoid cavity on each side is separated from this fissure by an inferior prominence of the temporal bone. It is long, and quite narrow; its length being about seven inches, and its width, from behind forwards, from two to three. Anterior to the eminence separating the jugular fissure from the glenoid cavity, lies the foramen ovale; and, about two inches in front of this, the foramen rotundum. The union of the cuneiform process with the sphenoid is complete. On the body of the sphenoid we see the posterior edge of the vomer separating the posterior nasal opening into two parts, whose edges are laterally surmounted by the pterygoid processes of the sphenoid. The mosterior nasal opening is smaller than might be expected, has a quadrangular form, and meastres six inches from behind forwards, three and a ruarter transtersely. In front of this opening lies the long palatine exca- 
ration: narrow at its posterior extremity, it widens gradually to its anterior termination in the edges of the premaxillary bones. The anterior part has about four times the width of the narrowest portion of the posterior. The palatine fossa is not much arched, but, compared with the human, approaches to a plane. On its posterior part is discerned the interpalatine suture, which forms a ridge through the posterior half, and a fissure through the anterior. Two pairs of foramina are visible in the posterior half, both of them small and narrow, having little more than the dianieter of a writing quill. The distinction between the palatine and maxillary bones is not visible.

\section{LOWER JAW.}

The lower jaw (Plate XVI.) has about the same size as that of the great skeleton, and does not differ from it in any remarkable way, except, as has been already indicated, that the restiges only of tusk-sockets are to be seen. The cavities are filled with osseous matter, not in a smooth and even way, but so as barely to indicate the situation of the original sockets on both sides. 


\section{MEASUREMENTS OF THE HEAD.}

Length from the ridge of the occipital plane to the extremity of the intermaxillary bones. Inches. Greatest breadth of the cranium . . . . . . . . . . . . . . 31

Least breadth of the cranium . . . . . . . . . . . . . . 15

Across the intermaxillary bones . . . . . . . . . . . . . $28 \frac{1}{4}$

Across the root of the ossa nasi . . . . . . . . . . . . . $28 \frac{1}{8}$

Across the nasal opening . . . . . . . . . . . . . . . . 10

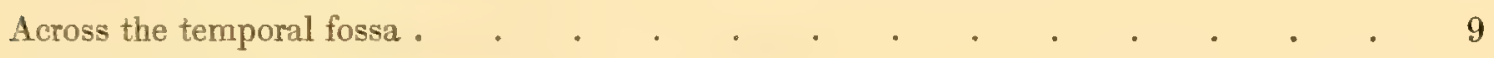

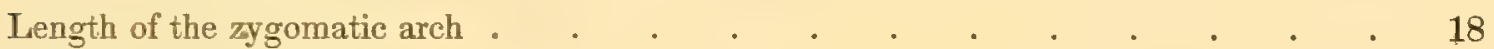

Length of the ossa nasi . . . . . . . . . . . . . . . . . . . $3 \frac{1}{2}$

Lerigth of the intermaxillary bones . . . . . . . . . . . . . 223

Vertical elevation of the cranium . . . . . . . . . . . . . . 22

Vertical diameter of the orbit . . . . . . . . . . . . . . . . $7 \frac{1}{2}$

Vertical diameter of the suborbitar fossa . . . . . . . . . . . . . . $3 \frac{1}{8}$

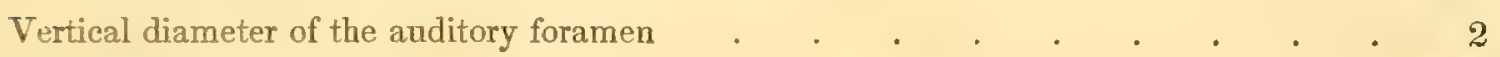

Diameter of the tusk-socket . . . . . . . . . . . . . 8

Depth of the occipital crest $\quad . \quad$. . . . . . . . . . . . . . . 25

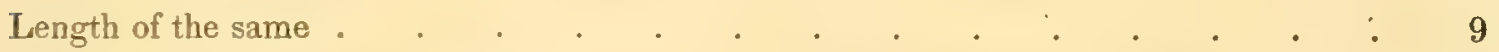

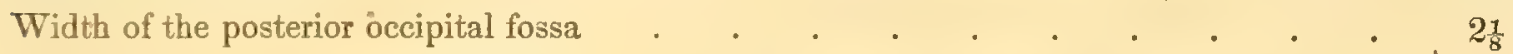

Length of the lower jaw

Width between the condyles . . . . . . . . . . . . . $22 \frac{1}{2}$

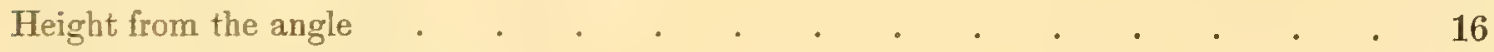

Height of the horizontal portion . . . . . . . . . . . $~ . ~ 7$

Width of the vertical part . . . . . . . . . . . . . . . 11

Width of the semi-lunar notch $. \quad . \quad$. . . . . . . . . . . 5

Length of the symphysial gutter . . . . . . . . . . . . . 7

Width of the same . .

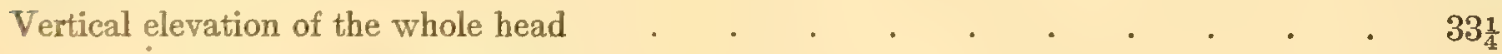




\title{
VERTICAL SECTION OF TIIE MASTODON HEAD.*
}

\author{
(RLate XVII.)
}

THIs head (the base of which is represented in Plate IV.) is a very perfect one, and appears to have belonged to an animal ten or twelve years old. The two small milk teeth, the third or three-ridged, are in place, and also the first permanent molar, a little worn.

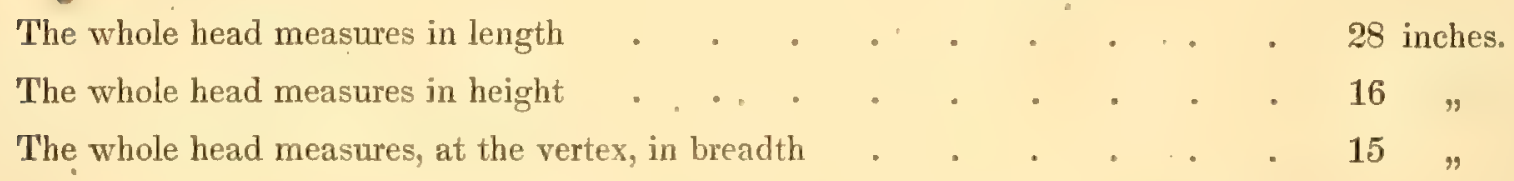

A vertical section, a little to the left of the median line, exhibits on the right side, the vomer; on the left, the nasal carity fully exposed. The Diploic first appearance that strikes us is the rast number and extent of the diploie Cells. cells; for they occupy two-thirds of the surface of the cranial section. Above, behind, and, in part, below, they surround the cerebral carity. The outer table of the bone which encloses them is about the eighth of an inch in thickness; the inner is rather more. The space betreen the tro tables, at its broadest part, is seven inches: this space gradually diminishes from the vertex backwards and downwards to the foramen magnum.

* For permission to make this rertical section, I am under obligations to President Sparks, and to Professors Agassiz and Wyman, of the University at Cambridge. 
The cells are of varions forms and sizes; they are generally oblong, and Form, Size, from half an inch to three inches in length; the diameter of the largest is nearly an inch. These cells appear to communicate with the nasal cavity. and There is one opening, quite at the anterior part, where the anterior cells terminate. The posterior cells open into a large canal. under the vertex; the partitions of the cells vary much in thickness, being thickest where they are connected with the tables of the cranium, and thinnest at the edges of their openings of communication. The cells which correspond with the inferior occipital region, where there is a great mass of flesh covering the bone, are very few in number. Those about the Sella Turcica are quite numerous, and open into the back part of the nasal cavity; one of these is very large, representing the sphenoidal sinus.

Cerebral Catity. - The cavity of the cranium is flattened from above downwards, so as to give its transverse diameter a greater extent than Cerebral Cavity. that from before backwards; its transverse measurement being twelve inches. while its greatest in the other direction is nine inches: its greatest depth from above downwards is five inches. The superior surface of this cavity is regularly vaulted; the inferior is irregular, presenting three different surfaces. The anterior or orbitar surface does not reach the orltitar fossa ; the middle surface, or petrosal division, has a deep excavation for lodging the middle lobes of the cerebrum; the posterior division is principally formed by the petrosal part of the os temporis in front, and gives support to the lobes of the cerebellum. In the middle of this inferior region we notice the projection of the Sella Turcica, with a slight excavation on the superior surface, but no appearance of clinoid processes. Below it are the diploic cells; in front, the cribriform plate of the os ethmoides; posteriorly, the openings for the nerves, of which the foramen ovale is most 
conspicuous. At the most posterior part of the cerebral cavity is seen the great occipital opening, the vertical diameter of which is just half that of the rertical diameter of the brain. This cavity for containing the cerebrum is remarkabjy protected by surrounding parts; superiorly it is guarded by the great number of diploic eells which occupy the vertical region; posteriorly, by a few cells, principally by the vast mass of cervical muscles; anteriorly and inferiorly; by the base of the cranium.

\section{. SECTION OF THE FACE.}

This section on the right side exhibits above and behind the septum narium; below, part of the nasal and the guttural surfaces. The upper part of the septum is formed by the nasal plate of the os ethmoides, which is five inches long above, and nearly six inches at the lower edge. This lower edge is curvilinear, and terminates in a posterior edge, which unites the posterior extremities of the two lines mentioned, and is itself three inches long. The inferior edge of the latter is united with the superior edge of the vomer by a suture, the relies of which are quite visible. 'The superior edge is attached to the base of the cranium; the posterior to the ethmoidal cells; the anterior is free, and corresponds with the cavity of the nostrils. Below and in front of the nasal plate of the os ethmoides is seen the vomer. This bone is of a triangular form. Of its three edges, the posterior superior corresponds with the inferior edge of the nasal plate. The anterior edge is connected with the intermaxillary bone, and the inferior edge is free between the guttural and nasal fossæ. Each of the edges measures about fire inches in length. The thickness of the vomer is about the twentieth of an inch; at its middle part, on removing the vomer, we 
sce the mhole extent of the nasal passage. The anterior external edge of this passage is transtersely oblong, and is about six inches in length. The extent from above downwards is three inches. This aperture opens into an enlarged sinuosity, in which are seen orifices leading to neighboring cells. The nasal tube contracts to about two inches in diameter; then expands into a broad surface a little excavated, which turns down behind the os palati, and opens, between this and the pterygoid process, into the pharynx. We see protruding into the passage, part of the crown of a molar tooth. At the anterior part of the nasal cavity is seen a canal running the whole length of the face, and terminating anteriorly and inferiorly in a fissure betmeen the premaxillary and palatine plate of the maxillary bone. This camal is fifteen inches long, half an inch in diameter, begins in the nasal fossa, and is about a line in diameter at its termination.

The remainder of the section of the face is occupied by cells lining the entrance to the nasal cavity, and below by other cells occupying the palatine portion of the maxillary and palatine bones. 


\section{DISTINCTION INTO SPECIES.}

Since the skeleton of the Mastodon Giganteus has become rwell known, the bones of other animals of the same race exhibiting some differences have been discovered in rarious countries; and, on the ground of these differences, the number of species has been increased to more than twenty.

The following is a list of the species of Mastodon as proposed by different authors:-

\begin{tabular}{|c|c|c|}
\hline \multicolumn{3}{|c|}{ 1. Mastodon Giganteus } \\
\hline 2. & $"$ & Tetracaulodon \\
\hline 3. & $"$ & Andium \\
\hline 4. & क & Humboldtius \\
\hline 5. & $"$ & Angustidens \\
\hline 6. & $"$ & Longirostris \\
\hline 7. & $"$ & Arvernensis \\
\hline 8. & 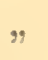 & Tapiroides \\
\hline 9. & $"$ & Minutus or Mino \\
\hline 10. & $n$ & Latidens \\
\hline 11. & $"$ & Elephantoides \\
\hline 12. & $"$ & Intermedius \\
\hline
\end{tabular}

13. Mastodon Dubius

14. " Sivalensis

15. " Perimensis

16.,$\quad$ Australis

17. $\quad$ Turicensis

18. " $"$ Cuvieri

19. " Jeffersonii

20. $\quad$ Borsonii

21. $\quad$ Godmani

22. $"$ Oollinsonii

23. $"$ Chapmani

To these must be added the subdivision of the species Tetracaulodon into - 
Tetracaulodon Tapiroides

$\left.\begin{array}{ll}\text { Osagii } \\ \text { Kochii } \\ \text { Haysii } \\ \text { Bucklandii }\end{array}\right\}$ Proposed by Professor Grant.

Many of these distinctions are founded, not on the comparison of skeletons, or of very considerable parts of skeletons, but on some slight variety in the size or form of a tooth.

The multiplication of species on doubtful grounds impedes the progress of natural science, and ought, of course, to be avoided where the lines of distinction are not strongly marked. For, in many instances, such divisions mar separate from each other those animals which have the closest resemblance except in a single point.*

The number of species of Mastodons which the present state of science has fully distinguished appears to us to be more limited than that enumerated. Of them, we shall notice, as distinct species, the Mastodon Giganteus, M. Andium, M. Humboldtius, M. Angustidens, M. Longirostris, M. Sivalensis, and M. Latidens; leaving to more able hands to trace the characteristics which may be found to designate a greater number. It will he seen, therefore, that it is not my intention to determine the actual number of species, but rather to mention those whose characters have been satisfactorily distinguished, without making any pretension to settle differences, which have been left in a state of uncertainty by the most able scientific men of the age.

* "It is true, indeed, that the most manifestly natural mammalian genera are those, the species of Which are provided with absolutely similar molar teeth; and that those genera which include species with molars of different forms do not present the same character of unity. But it does not follow, that, by combining species of mammals with similar molars, a group will be formed perfectly analogous to those which may be considered as the most natural or perfect. Neither the molar teeth nor any other solitary character will serve to establish a natural classification." - OWEN's Odontography, p. 70, Introd. 


\section{MASTODON TAPIROIDES.}

Mastodon Tapiroides.

A species called Mastodon Tapiroides from a supposed resemblance to the Tapir, and more nearly approximating to the Mastodon Giganteus than any other species, having been much noticed by palæontologists, we must mention in this place. It was based by Cuvier on a single tooth discovered near Orleans; other similar teeth have since been found in various places. Their peculiarities consist piincipally in the formation of the cusps of the mammilla, which, in a degree, resemble those of Mastodon Giganteus, but are less notched or crenated. This seems to be a very imperfect foundation for the support of a new species; and Professor De Blainville scarcely mentions it as such. Dr. Harlan at one time believed the Tapiroides to exist in North America; but he was probably deceived by some little variety in the form of a tooth of Mastodon Giganteus, and ultimately abandoned his opinion. The Tapiroid species is said to form a link in the chain connecting the Dinotherium and Mastodon Giganteus.

\section{SOUTH A MERICAN MASTODONS.}

Souţh American Mastodons.

Having already described the species of Mastodon we are most perfectly acquainted with, that of North America, we shall next say something of the South American, as most naturally following the former. Two species have (I speak with diffidence) been established, viz. the Mastodon Andium and Mastodon Humboldtius; between which, however, no distinction is made by M. Alcide D'Orbigny.

\section{MASTODON A NDIUM.}

In the British Museum, in July, 1851, I saw a very perfect head and 
tusks of this species. The head was very flat from before backwards, and the size of the cranium remarkably small. The jugal bone was long and Mastodon slender, and inclined forwards. The processes of the lower jaw were also inclined fortrards, the coronoid being lower than the condyloid. The teeth, two in number on each side of each jaw, resembled, as. well as I could ascertain from a distant view, some of those of the Himalaya Mountains; the mammillie being more rounded than in the Mastodon Giganteus, and slightly alternate. The middle molar teeth have the same form as in the Giganteus; they are quadrangular, and the crowns are also composed of three ridges. The figures developed on the crown of the worn molars resemble those of the Mastodon Longirostris; but the fissures dividing the cones from each other, and penetrating deeply between them, give an mndulating form to the enamel. These characters were afterwards distinctly pointed out to me by M. Laurillard, in specimens in the National Museum at Paris, and were typically represented by him as follows:-

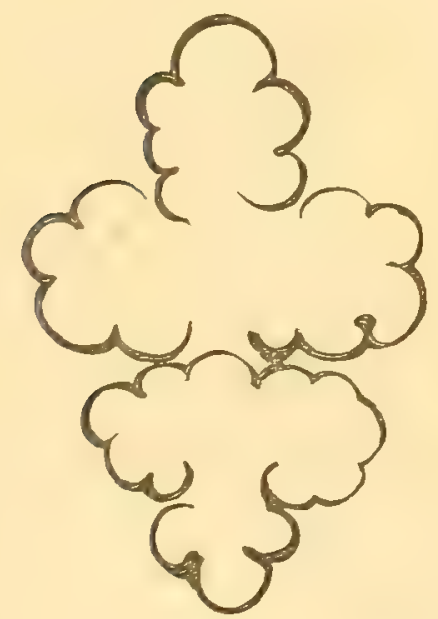

m. humboldtii

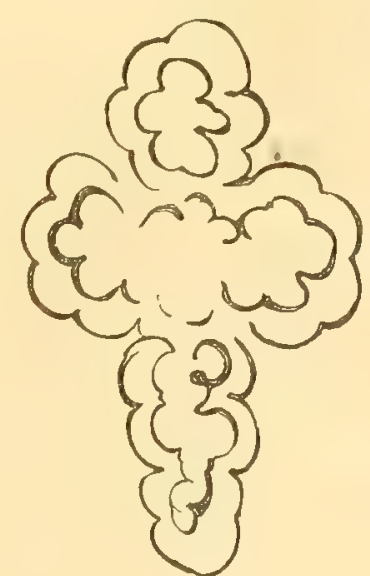

m. andium

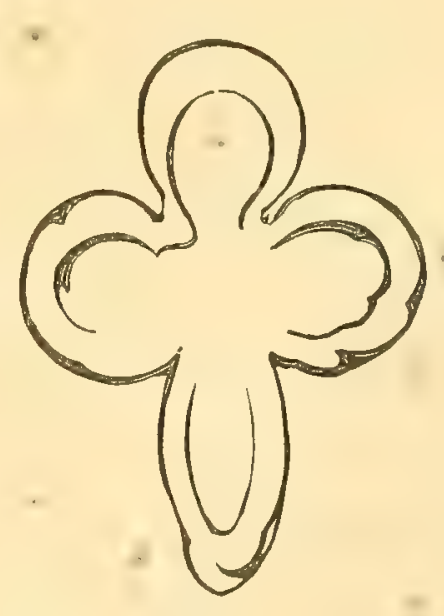

m. giganteum 
Mastodon Andium.

The representation given by the distinguished traveller, D'Orbigny, of the ultimate molar in Mastodon Andium, very closely resembles the Baltimore tooth. The number, direction, and form of the mammillæ are nearly the same. Both the teeth have an anterior and posterior talon: in both, the anterior talon is very small; and the posterior, consisting of two tubercles, considerable. The general form of the two teeth is quite similar; on the other hand they differ in that the Baltimore tooth has two papillæ between the ridges, while the Andium of D'Orbigny has three. The cusps in the former are inclined to the median groove; in the latter they are comparatively upright. If M. D'Orbigny is correct in the opinion that his four-ridged tooth is an ultimate, it would, in my opinion, determine the Baltimore tooth to be an ultimate, and not penultimate.

\section{MASTODON HUMBOLDTIUS.}

Mastodon

Humboldtius.

This species, named from the celebrated traveller who discovered it, has been considered by the highest authorities, viz. Cuvier, De Blainville, Owen, and I believe Darwin, to belong, equally with the Andium, to the species Angustidens. Since this opinion has receired the sanction of such authority, the number of specimens from South America has been greatly increased; and it remains to be seen whether the inspection of these fossils will lead to a change of opinion.

In the remarks already made on the subject of the Mastodon Andium, we hare shown, the difference between the worn surfaces of Mastodon Andium and Mastodon Humboldtius. To these we should add another difference in the rostrated extremity of the lower jaw being shorter in the Humboldtius. There were some other points which, at the time of my. 
obserrations, I could not examine so closely as to justify their insertion in this place. Both of the species, however, have the general aspect of the narrow-toothed group.

\section{MASTODON ANGUSTIDENS.}

The name of Angustidens was given by Cuvier to Mastodons having teeth different from those of Mastodon Giganteus in their comparative Mastodon Angustinarrowness. There have been, however, great differences of opinion in regard to the species for which this name has been reserved; some authors haring included under this appellation the whole group of narrow-toothed Mastodons, while others have divided them into a number of species.

Tithout entering into any minute description of the Mastodon Angustidens, of which, in fact, I have seen very fow remains, excepting the teeth, we will mention some of the peculiarities which European authors have noticed. According to De Blainville, the coronoid process of the lower jaw is lower than the condyle, and the horizontal branch is more rounded externally and inferiorly, - differences which approximate it slightly to the living elephants. But its chief distinction is, that this horizontal branch in front of the molars, instead of terminating in a short beak, more or Iess acute, or even in a sort of short and truncated gutter as in the Mastorlon Gigantens, forms a long horizontal semi-canal, slightly inclined domminards, and which, after boing dilated and flattened at its extremity, displays two alveoli empty, or occupied by inferior tusks. In the last particular it corresponds with the Mastodon Tetracaulodon, or male Mastodrin Ciganteus; and it is probable that the jaw, in which the mandibular tusks appeared, was that of a male Mastodon Angustidens: on this, 
Mastodon however, we have not a sufficient number of facts to warrant a decided Angusti-
dens. Conclusion.

The nineteenth dorsal vertebra is said to be the last rib-bearing, and in consequence there are four lumbar vertebræ, while in the Mastodon Giganteus there are three. The humerus is much shorter, more clumsy and twisted than in the Mastodon Giganteus. The femur has its third trochanter more prominent; the articulating surface for the patella is onethird smaller.

The bones of the Mastodon Angustidens, according to the same author, seem to hare a greater resemblance to those of the Asiatic Elephant than to those of the Mastodon Giganteus. The most important differences are in the teeth, on which, as already said, is founded the name Angustidens, or narrow tooth. Through the intervention of my friend Dr. Boott, I have received, by the politeness of Charles Stokes, Esq. of London, casts of two large molars, one of them said to belong to Mastodon Longirostris, the other to Mastodon Angustilens; and also, through that of the late Professor De Blainville, a complete set of all the teeth in the upper and lower jaw, marked Angustidens in the National Museum of Paris. Besides these, I have some Angustidens teeth which I purchased in Paris in 1851, and the cast of a beautiful ultimate molar given me by M. Laurillard as such.

The incisors are two in the upper, and two in the lower jaw. The first molar is similar to the small deciduous molar of the Mastodon Giganteus. The second molar has three instead of two ridges. The third is peculiar, being the rertical tooth in the upper jaw mentioned by Professor Owen. This rertical premolar has not been admitted by De Blainville. The three following teeth hare been variously riemed by different writers: some consider them as possessed of three ridges, and others assign to a part or the 
Thole of them foul. The ultimate tooth - the seventh or last molar — has Nastodon either four or five ridges.

Dr. Falconer is of opinion, that the distinction between the Mastodon Angustidens and Longirostris has been overlooked; that, in the former, no proof exists that the penultimate molar has more than three ridges; but in the Longirostris or Arvernensis, the penultimate and the two preceding molar's hare four ridges. On this ground, the Angustidens and Giganteus are, in his opinion, more nearly allied than the Angustidens and Arvernensis. He therefore would include in one section, which he calls Trilophodon, the Mastodon Andium, M. Angustidens, M. Giganteus, and perhaps, M. Tapiroides; and in another, Mastodon Longirostris or Arvernensis, M. Sivalensis, and M. Latidens rel Cliftii. On the supposition that Dr. Falconer is correct, we must change our views with regard to the relation of the Angustidens to the Giganteus, and say that, instead of differing in nearly all the teeth, it differs in the second milk molar, which has two ridges in the Giganteus, and three in the Angustidens, and in the vertical premolar, which is not found in the Giganteus.

Passing over other differences which are not settled, it appears from the abore account, that, besides some variation in the forms and size of a fer bones of the skeleton, peculiarities exist in the form of the second tooth, in the existence of an additional tooth, and in the comparative width of the teeth generally.

\section{MASTODON LONGIROSTRIS.}

This, according to some authors, is not to be distinguished from the Mastodon Angustidens; but, upon the authority of Professor Kaup, who has particularly investigated this subject, the Longirostris is distinguished, 
Mistodon Longirostris.

$1 s t$, by the length of the lower jaw ; $2 d$, by the existence of four ridges in the third, fourth, and fifth teeth; and by various other points. Professor Kaup has so well described what relates to the Mastodon Longirostris as to render it quite unnècessary for us to enter into any description or investigation in regard to it.

Were it admissible, we should have much to say on the Eppelsheim fossils. Having, through the aid of Professor Kaup, obtained beautiful casts of the collection, we have been enabled to use it with great advantage in the course of our necessary investigations, embracing, as it does, about fifty specimens belonging to Mastodon Longirostris, and thirty specimens of Dinotherium, as well as other fossils.

Under the head of Mastodon Longirostris may be placed, according to Professor Kaup, the Mastodon Arrernensis found in the south of France by Croizet and Jobert, in 1828. This supposed species is said by M. De Blainville to be characterized by a gireater number of mammillary eminences than other species, and by a talon in front as well as belind. Few authors, horrerer, admit it to be a distinct species; and Professor Kaup considered it to be the young of Mastodon Longirostris. M. Laurillard, on the other hand, believes it to be a Mastodon Angustidens.

\section{MASTODON SIVALENSIS.}

This is a new species from the sub-Himalara Mountains, established by Dr. Falconer and Captain Cautley. The teeth are of great size. An ultimate molar, belonging to the upper jaw, measures in length a little orer eight inches, and in midth three inches; another, belonging to the lorrer jar, measures nine inches and a half in length, br three inches and four- 
tenths in width. That of the upper jaw has six ridges, which are divided from each other by five transverse furrows; the sixth is less distinctly Mastodon separated than the others, and has behind it a trifid talon. The longitudinal furrow, separating the external and internal mammillæ, is less distinct than it commonly is in the Mastodon family, in consequence of the mammillie inclining towards the median line of the tooth in such a way that the mammilla of one side corresponds with a depression on the other, so as to incligitate. The sixth, not being fully developed, presents, instead of two mammillix, four small ones, which would undoubtedly have merged in two, had the animal lived longer. The mammillie are of a rounded form, as in the narrow-toothed Mastodons, and not flattened like those of the Mastodon Giganteus. The basal cingulum is remarkably prominent.

The corresponding tooth in the inferior jaw is, as already said, longer than that in the upper. The number of ridges or lobes is the same, i.e. six, and a talon with one eminence. The basal cingulum is less prominent. The mammilla are more inclined, both longitudinally and transversely. The extremities of the mammillæ of the three anterior ridges are worn away in the upper tooth, and of two in the lower, displaying, in the former, oval figures; in the latter, no distinct form.

In an excellent east of a large portion of the head, with the palate nearly entire, there are four teeth, two on each side. One of these is almost perfect: it is the left ultimate molar, and contains five ridges. They have the same form as those described above, but their direction is less oblique. This tooth, except as to the number of its ridges, has a general resemblance to the corresponding tooth of Mastodon Angustidens in the Paris Museum; but the clefts betrreen the ridges are not so deep as in the latter. It is not at all worn. In front of it is the penultimate molar, very much worn; 
Mastodon Sivalensis two present largely worn, and rather irregular terminations. Those of the corresponding tooth on the opposite side have a trifoliated shape. The enamel which surrounds the worn surfaces is a little irregular.

On the whole, these teeth present the characters of the narrow rather than the broad-toothed group, and are such as to entitle them fully to the distinction of a separate species. Dr. Falconer, however, places the Sivalensis in a section with the Mastodon Latidens and Mastodon Arvernensis, on the ground that they possess "the same numerical division of the crownridges in the last deciduous molar, and in the first and second true molars in both jars."

\section{MASTODON LATIDENS}

Mastodon Latidens. are found on the banks of the Iriwaddy. The teeth, for the most part impregnated with the carbonate of iron, are broader than those of other species. The last molar sometimes has as many as ten ridges and a talon: a cast of one of these teeth in my possession, from a Paris specimen, has six ridges of a serrated rather than tuberculated form, and a posterior talon. This tooth, and that called Mastodon Elephantoides, form, as was first noticed by Mr. Clift, two links connecting the Mastodon with the Elephant.

\section{MASTODON TETRACAULODON.}

Mastodon Tetracaulodon.
The existence of a tusk in the lower jaw has given origin to the distinction into another species; a distinction first proposed by Dr. Godman, an excellent naturalist and anatomist, mhose early loss the science of 
this country has deeply deplored. A great number of mandibles of the Mastodon Mastodon haring been found furnished with one or more tusks, it was Tetracaunatural to consider its occasional existence as a peculiarity sufficiently important to stamp it as a new species.

The remarkable skeleton described in this paper having a mandibular tusk on one side, and the remains of a very distinct fossa for the reception of a second on the other, we must, of course, inquire whether the existence of this part affords sufficient reasons for considering this specimen to have belonged to an animal specifically different from the Mastodon Giganteus, or whether it characterized the age or sex of the last-named species.

The specimen from which Dr. Godman made his description was the lower jaw of a young Mastodon, which he describes as being perfect on the right side, "with the exception of part of the condyloid, the whole of the coronoid, and a small part of the posterior alveolar processes" (Trans. Am. Phil. Soc. p. 488). This is obriously a mistake, as his plate shows that the greater part of the coronoid process is preserved, and none of the condyloid; and the cast of the same jaw in our possession agrees with the plate.* Of course, the obliquity of the condyloid process, described by him as peculiar to the Tetracaulodon, could not have been observed in this jar.

This mandibular tusk is represented to have been four inches long, and its socket an inch in diameter at its outlet. On the left side was a corresponding alreolar cavity without a tusk. These sockets are filled with osseous matter as the subject advances in age, so that in the adult they are generally obliterated, leaving restiges of their previous existence.

* Perhaps the terms condyloid and coronoid were accidentally transposed in printing. 
Mastodon Tetracaulodon.

An examination of sixteen jaws shows mandibular tusks or restiges of these tusks in nine instances, and an absence of them in seven; thus making the number of each not very different; - a fact which, as far as it goes, tends to prove that the Tetracaulodon was quite as likely to have been the original type, as to have been a different species or variety of the Mastodon Giganteus.

Other circumstances alleged in favor of the specific Tetracaulodon character are derived from the length of the rostrated or anterior portion of the lower jaw, as appears by the following quotation from Dr. Godman's description :-

"The great.peculiarity of this jaw, and that which separates this animal from every other genus hitherto established, is its elongated or rostrated extremity, containing the alveolar processes or sockets for two very remarkable tusks. The superior border of the jaw, from the situation of the anterior teeth, declines immediately, tapering towards the lerel of these sockets. Inferiorly, the outline of the jan does not so immediately change, until opposite the anterior mental foramina, whence it suddenly diminishes to the end. The rostrated portion of the jaw, anterior to the front teeth, is three inches and three-fourths long, and superiorly is regularly hollowed or grooved as for the reception of the tongue: this hollow is two inches wide, quite smooth, and bounded on each side by thin raised edges."

On comparing a number of Tetracaulodon jaws with those of the Mastodon Giganteus, we do not discover any difference of length in faror of the former. But for greater exactness a comparison has been made of a Tetracaulodon jaw with a Mastodon's of the same dimensions, by which it appears that the length of the rostrated portion is seren inches and one- 
fourth in this Tetracaulodon, and seren and a half in this Mastodon; thus showing that, in this instance at least, the part is not longer in the TetraMastodon caulodon, but shorter than in the Mastodon Giganteus. In the same jaws there is no difference in the declination of the condyloid process, and the semilunar notch is not deeper in the latter than in the former. The truncated appearance of the anterior or rostrated portion is, as Dr. Godman states, more frequently met with in the Mastodon Giganteus, but is sometimes seen in the Tetracaulodon.

This truncated portion deserves some particular notice, as it is the seat of the Tetracaulodon tusks, where they exist, and its appearance indicates whether they have existed or not. In the great Mastodon head, this rough surface, being of a somemlat circular form, is, as we have seen, about three inches in diameter. In jars in which both tusks exist, or from which they have recently fallen, this surface presents an oval form; the circle being flattened from above downwards, and divided into two parts by the ridge which separates the tusk-cavities. If the tusks originally existed, and have been shed for a length of time, the cavity which contained them is unore or less filled with osseous matter, which sometimes renders it difficult to decide whether they have existed or not; but, in the greater number of cases, a sufficient depth of cavity remains without osseous matter, to show that sockets have originally existed; and this fact is supported by another, riz. the transversely oval form it exhibits. Where there is, in this truncated extrenity, notbing to lead one to suspect the former existence of tusks, it is of a rounded form; being, in the Baltimore jar, about three inches in diameter.

In two young jars belonging to the Cambridge collection, and represented in Plates III. and V., the truncated extremity is two inches in 
Mastodon Tetracaulodon.

diameter, of a rounded form, without the least appearance of tusks having ever existed. In Plate II., which is still younger than either of these, we notice the tusk-sockets open and fairly displayed to view, showing the great difference in the anatomical character of the last jaw from the other two. On the other hand, in the great Shawangunk head (Plate XVI.), the tusks having existed and fallen have left a more extended, irregular, and oval surface, which, though the sockets may be said to be filled, give this an aspect very different from that in the two young jaws just mentioned. In regard to the rectangular outline of the jaw, it is found, on comparing a number of specimens, not to be more remarkable in our Tetracaulodons than in the Mastodons, so far as we can discern. Yet I must say, that an able palæontologist and anatomist maintained that there was no appearance of sockets ever having existed in the Shawangunk head.

The conclusions to be drawn from the facts above stated are the following: 1st, that the existence of tusks in the mandibular jaw does not indicate a peculiar species; $2 d$, that in most cases these tusks are found in young animals, though one tusk is occasionally seen in the adult skeleton.

We have had an opportunity, by placing them side by side, of perfectly comparing the Tetracaulodon skeleton here described with the Mastodon skeleton in the collection of the University at Cambridge, which has not the least appearance of a claim to the Tetracaulodon character. A comparison of the head, teeth, vertebræ, scapula, os humeri, bones of the fore leg, os femoris, and bones of the hind leg, presents no difference in any respect, except in magnitude.

The pelvis in the Cambridge skeleton exhibits an aperture much larger, in proportion to its width, than in the other. The whole width of the former 
is fiftr-eight inches; the entire width of the latter is seventy-four; making Mastodon a difference, in the whole width, of sixteen inches, while the difference in Tetracauthe apertures of the pelres is much less. The aperture in the Cambridge skeleton, in the transverse direction, is nineteen inches; in that of the other, twenty-one; making a difference of only two inches.

There is also a remarkable disproportion between the tusks of the two skeletons. The length of the tusk in the Cambridge skeleton is about thirty-six inches; and of the other, a hundred and twenty-six. The tusk of the former is nearly straight, and that of the latter much curved.

The comparison of the apertures of the pelves, and of the size of the tusks in the two specimens, has led to the opinion, that one of these was male, and the other female. In objection to this inference, it might be sugrested that one of these was the skeleton of a younger animal than the other. The state of the teeth, homerer (which are the same in number and form in both), makes it probable that the difference in age was not very great: and the condition of the epiphyses affords an additional though not so strong a support to this hypothesis. A comparison of the other bones has not afforded any important results tending either to strengthen or weaken it.

On the whole, it appears that there are no such differences in the jaws, the teeth, or any other part of the bony skeleton, as would call on us to separate the specimens containing mandibular tusks from those which are destitute of them. And we have no doubt that the acknowledged differences depend on the difference of sex; the Tetracaulodon being the male, and the Non-tetracaulodon the female; of the Mastodon Giganteus. 


\section{DR. FALCONER'S PROPOSED ARRANGEIENT OF SPECIES.}

Dr. Falco- The specific distinctions in the Mastodon family have been differently ner's Oppor'tunities. viewed by Dr. Falconer, excepting as to the Tetracaulodon. This gentleman, with Captain Cautley his coadjutor, has had great opportunities of inrestigating the fossils of the Himalaya Mountains; and the result has been displayed in the production of a magnificent collection, and series of representations, of Elephant, Mastodon, and other fossil bones.

Distinctions from Form and Structure of Teeth.
In the published part of this work, at least eleren species of Elephants and six of Mastedons hare been pointed out. Dr. Falconer has founded his distinctions on the structure and form of the teeth. We have already said that the teeth are composed of three kinds of substance, - dentine, enamel, and cement; and have also shown that the elephant's tooth is composed of thin plates of dentine, coated by enamel and united by cement. The Mastodon teeth are not foliated or laminated, but have a body of dentine, and a crown of dentine, enamel, and cement. This crown is divided into ridges, and these ridges are subdirided into mammilla; in some cases smaller nipples, or papillie, are, as before said, placed in the interstices of the ridges. The laminx of the teeth of the elephant, gradually becoming shorter, wider, and conical, may be traced mith a good degree of regularity, 
beginning - with the Elephantidx, through the Mastodon series to the Dinotherium; at one end of the line are placed the very long thin plates of the Elephas Primigenius; at the other, the gradually expanding cones of the Mastodon Giganteus. While the Elephantine teeth generally affect the laminated form, the Mastodon affect the conical. These forms, however, are not always distinctly expressed on the external part of the tooth. Another difference which may be considered general, though not without exceptions, is the longitudinal furrow which divides the whole crown of the Mastodon tooth into.two parts, and does not exist in the elephant.

The Mastodons are separated into two groups; one called Trilophodon, Triophodon and the other, not particularly named, which might be called Tetralophodon. - Group. The Trilophodon group contains M. Giganteus, M. Angustidens, and M. Andium. They are distinguished by possessing three transverse ridges in three of their teeth, viz. the third, or last deciduous molar; the fourth, or first permanent or antepenultimate molar; and the fifth, or second permanent or penultimate molar.

In the other group there are also three species, viz. M. Latidens, TetralophoII. Arrernensis, and M. Siralensis. This group is distinguished by the don Group. possession of four ridges in each of the three teeth above named, hence called Tetralophodon. The Mastodon Arvernensis is said to have been hitherto confounded with Mastodon Angustidens; but, according to Dr. Falconer, it has uniformly four ridges in the teeth alluded to, while the Angustidens has three, only.

Haring laid down the distinctive characters of the groups, we look next for differences between each of the species which constitute these groups. In the Trilophodon group the M. Giganteus is readily distinguished from I. Angustidens and M. Andium by the absence of papillæ - the small 
conical eminences - between its ridges; which papillæ exist in the other two species. Further, M. Andium is distinguished by the quantity of cement which fills the depressions between the ridges, and partly buries the papillæ.

In the Tetralophodon group, the M. Latidens, like the M. Giganteus in the other group, is distinguished from its two congener's by the absence of papillæ. The M. Arvernensis has papillæ; but the mammillæ are rertical compared with those of M. Sivalensis, which are so very oblique that they almost cross each other, the mammillæ on one side being actually received, in some cases, between those of the opposite side.

Thus we have pointed out, as well as we could, in a brief manner, the distinctive characters of the Mastodon teeth, according to Dr. Falconer, though too briefly to do justice to his descriptions; and, if these distinctions are not made sufficiently plain, the blame must be attributed to us, and not to him.

We shall not venture to give any opinion on the ingenious and valuable labors of this able palrontologist, as the greater number of the species of which he treats are not found in this country. When his great work is completed, the subject will be investigated by scientific men in Europe, who have much greater adrantages for determining these distinctions than we can have in this country. I will make only one remark. I should be very unwilling, without a fuller knowledge, to place M. Giganteus and M. Angustidens in the same group. The teeth of the tro species are rery different in form, size, and perhaps eren in number; and there are many differences in the skeleton. A fuller investigation of the distinctive characters of M. Arvernensis and M. Angustidens may lead to different conclusions on the last-named question, but cannot alter the comparative character of 
the whole skeleton; and, reverting to the opinions of Professor Owen, expressed at page 123 , we would not readily adopt a peculiarity in the teeth as a sufficient bond of union between species widely different in other respects. 


\section{COINCIDENT EXISTENCE OF THE MASTODON AND ELEPHAS} PRIMIGENIUS.

THE remains of Elephas Primigenius are abundantly found, both in this country and in Europe. In this country they are met with in company with those of the Mastodon Giganteus, in Ohio, South Carolina, \&c. Remains have been found in New England, where are also some, though very few, relics of the Mastodon Giganteus. In digging a railroad in Rutland, Vt., at an elevation of thirteen hundred and fifty feet above the level of Lake. Champlain, various bones of the Elephas Primigenius were discovered two years since; particularly a fine tooth, some vertebræ and ribs. A part of these are in the possession of Professor Agassiz, and a part in my hands, for which I am indebted to Samuel Henshaw, Esq., of Boston. On comparing a considerable number of these teeth from Alabama and other places in the southern part of the United States with those from different parts of Europe, I do not perceive any remarkable difference.

In Europe the bones of the Mastodon Angustidens and Longirostris are much earlier than those of Elephas Primigenius, the latter existing altogether in dilurial deposits. For example, in Auvergne the bones of the Mastodon Angustidens are found in pliocene; while, according to M. Pamel, as stated in a letter to me from the learned M. E. Desor, the Elephas exists in diluvium. 
The teeth of Elephas Primigenius of this country and of Europe are similar the one to the other, so far as I have had an opportunity of observing; and I have quite a large collection of these teeth, obtained principally from Alabama. We have, indeed, nothing like a complete skeleton in this country; but many separate bones have been discovered. The resemblance in the. structure of the teeth appears to be uniform, exact, and important, so that we hare no hesitation in considering it as characterizing a uniform species.

The Mastodon Angustidens of Europe occupies a geological position anterior to that of the Mastodon Giganteus of this country. The Mastodon period of Europe differs, therefore, from the Elephas period, and also from the Mastodon period of Imerica. But the Elephas period is the same in both continents; so that, while the Mastodon of Europe was separated by a long interval from the Elephant, the Mastodon of America might have been coeval. 
Found at FOoD. - When the lacustrine deposit at Newburgh, in which our Mastodon Newburgh. was found, was laid open, and part of its contents had been removed, a mass of substance resembling the crushed branches of trees ras noticed, though at first with little attention. Dr. Prime, who was present, describes its appearance as follows:-

"In the midst of the ribs, imbedded in the marl and unmixed with shells or carbonate of lime, was a mass of matter, composed principally of the twigs of trees broken into pieces of about two inches in length, and varying in size from very small twigs to half an inch in diameter. There was mixed with these a large quantity of finer regetable substance, like finely divided leaves; the whole amounting to from four to six bushels. From the appearance of this, and its situation, it mas supposed to be the contents of the stomach; and this opinion was confirmed on removing the pelris, underneath which, in the direction of the last of the intestines, was a train of the same material, about three feet in length and four inches in diameter."

Soon after, the side of the excaration fell in, and enveloped these substances in such a way that a small portion only of them could be pre- 
serred. On examination 'by the microscope, the fragments present the aspect of the terminal branches of coniferous trees. The observations of Dr. Carpenter, Professor Gray, and other gentlemen, support this opinion, so far as relates to the Mastodon food found at Newburgh in the great skeleton. The same is true of that found in Warren County, New Jersey, with the Cambridge Mastodon, in which also the supposed food appeared to be arranged in the form of intestinal convolutions.

In a letter to the author, Professor Gray gives the following account of the portion of substance examined by him :-

"As to the sticks found in the stomach of the Mastodon, I stated to the Academy that an examination with the microscope showed, from the Professor Gray's structure of the moody fibre, that they were boughs of pine or spruce of some sort, and that they minutely agreed with the wood of hemlock spruce; so that this is very probably the species they belonged to, but.there is no certainty of it." And in a subsequent letter he says:-

"The observations made with the microscope on the material supposed (1) hitre heen in the stomach of your great Mastodon, showed that the woody matter consisted of twigs of some coniferous tree or shrub, and probably. some kind of spruce or fir."

When in London in the summer of 1851, I submitted portions of the Dr. Carpenundicester and partially digested food to Dr. Carpenter, without informing ter's lim whether any opinion had been already expressed in regard to them, so that he mas entirely ignorant of the result of Professor Gray's examination, or that they had been examined by any other person. The following is his reply:-

"Although I have not had time to make as full an examination as I could have wished into the nature of your Mastodon's food, yet I think that 
the results I have obtained are of some interest, and that they will help you to a more complete investigation.

"The substance you placed in my hands contains two different sets of fragments of wood, readily distinguishable by their color, and by their different states of preservation.

"Those of a reddish hue are very little changed, and may be clearly made out to belong to the coniferous tribe. The transverse sections exhibit the structure as well as those of a recent wood would do. The longitudinal show the borders of the woody fibres less clearly defined, and the glandular markings are less obvious than in a fresh piece of wood; but still the structure is very well preserved, and I make little doubt that a similar examination of your existing conifers will serve to identify its nearest, if not its actual, representative.

"The blacker fragments are quite a different wood. They have undergone a greater change by decomposition, and are much infiltrated with carbonaceous matter. I have found it impossible, on account of their tendency to disintegration, to cut slices as thin as I could wish; and I am consequently unable to speak positively as to their origin. Moreover, the type of structure is one with which I am not familiar, though I have seen something like it in silicified woods. I hope that some of your own vegetable anatomists will be able to discover its representative among the American forests. The principal part of the black amorphous matter I believe to be the product of the more advanced decomposition of this wood."

Bishop Madison, in a letter to Dr. B. S. Barton, describes the appearance of what was considered to be food, such as "half-masticated reeds, twigs, and grass or leares," discorered in connection with the bones of a Mastodon, 
or, as it was called at the time, a Mammoth, in Wythe County, Virginia. Ind, although the Bishop did not examine the supposed food himself, yet, as its description accords with that found with the other skeletons, there seems to be ground for a presumption of their identity.

Professor Mitchell, in the Appendix to "Cuvier"s Theory," at page 376, speaking of another skeleton, says: "Beneath the bones, and immediately

Found in Goshen, N. Y. around them, was a stratum of coarse vegetable stems and films resembling chopped straw, or rather drift stuff of the sea; for it seemed to be mixed with broken fibres of conferva, like those of the Atlantic shore." This specimen was found in Chester, near Goshen, Orange County, N. Y.

The correspondence of these appearances, in at least four different conclusions. places, affords strong, we may say satisfactory, reasons for believing that the Mastodon was a regetable feeder, and subsisted, like the elephant, the hipsopotamus, and rhinoceros, on the tender branches of trees with their leaves, on rushes and other aquatic plants. This opinion is confirmed by tro facts: first, no substances having a similar appearance have been found in other bogs; second, there was no intermixture of gravel or any other foreign substances with the supposed alimentary matters.

Dr. William Hunter, as before said, noticing the points or mammillary eminences of the teeth, received the impression that this animal was carnirerous. This opinion of the distinguished British anatomist was corrected by Curier, who demonstrated that the nipple-shaped cones of the Mastodon tooth possessed a different character from the flat serrated grinders of the lion, tiger, and wolf. As the branches of most of the forest-trees would have been too dry and woody to serve the purpose of food, the animal was compelled to resort to the bogs, the rivers, and lakes, where it was frequently betrayed to enter so far as to become involved in the yielding 
mud. Hence it has happened, perhaps, that so many of the remains have been found imbedded in lacustrine deposits, where they have been preserved to the present time for the examination of the naturalist.

The Hair.

The Hatr. - Mr. Graham, in the "New York Medical Repository," vol. iv. page 414, says: "In Montgomery there was found hair of the Mastodon three inches long, and of a dun color." Judge Miller, in describing the discovery and appearance of a skeleton at Shawangunk, Ulster County, says that "around and in the immediate vicinity were locks and tufts of hair, of a dun brown, of an inch and a half to two ànd a half inches long, and, in some instances, from four to seven inches in length."

Professor De Blainville, in the "Geology of the Mastodon," page 340, records another instance in these words: "M. Lesueur, who lived for" several years at New Harmony, exhibited to me the drawings of an almost entire mandible, at least in its two horizontal branches, one of which contains the two last molars. It was found at White River, between Vincennes and Harmony, and presented to the library of the former of these cities by M. Badollet, one of its curators. He states that other bones - a fine rertebra, a femur, and epiphyses, the drawings of which M. Lesueur also showed me - are in the same library. They were found at the depth of more than sixty feet, in digging a well in another part of the same State, nearer the entrance of the Wabash into the Ohio; and, according to M. Badollet, in company with skin and hair."

Additional authority, in regard to the possible preservation of hair, may be found in the account by Mr. Adams of the condition of the fossil elephant discovered in Asiatic Russia, in 1801. He says, under date of 1806:-

"More than thirty pounds weight of the hair and bristles of this 
animal were gathered from the wet sand-bank; having been trampled into the mud by the white bears while devouring the carcass." "The hair consists of three distinct kinds. One of these is stiff black bristles, a foot or more in length; another is thinner bristles, or coarse flexible hair, of a reddish-brown color; and the third is a coarse reddish-brown wool, which grew among the roots of the long hair," \&c. 


\section{CONDITION OF THE BONES.}

THE bones of our skeleton differ from those of most others. In color they are of a light brown, not being darkened as much as usual by the oxide of iron. In specific gravity they are lighter than recent bones, being divested of a portion of their gelatine, but still retaining not an inconsiderable part, as appears by the following analysis of Dr. C. T. Jackson, who had the goodness to undertake it at my request, and repeated his experiments a number of times in order to be certain of their accuracy, viz. :"A portion of the epiphysis of a vertebral bone yielded, when dried by Dr。 c. T. Jack- at $300^{\circ}$ Fahrenheit, -

son.

Animal matter (bone cartilage) . . . . . . . . . . 27.73

Bone earth (phosphate and carbonate of lime) and phosphate of iron . . . . $\frac{72.27}{100.00}$

"A portion of the bone with cancelli yielded, by drying at a little above $212^{\circ}$ Fahrenheit, -

Water

Bone earth.(phosphate and carbonate of lime) and phosphate of iron _ . : . 64

Bone cartilage . . . . . . . . . . . . 30 
"On burning the bone, the ash which remains is of a beautiful blue color, otring to the presence of phosphate of iron, which appears to have been infiltrated into the bone from the marl surrounding the skeleton."

Dr. Jackson also gave me trro or three portions of the animal matter, which possesses the same degree of tenacity as that found in recent bones.

The preservation of Mastodon bones may be in many instances attributed to a ferrugineous impregnation; but the bones here described contain

Cąuses of Preservation. a smailler quantity of iron than other Mastodon bones not in so good a state of preservation. Whence we must infer that other circumstances were concerned in preventing their decomposition.

Bones of the Mastodon Giganteus are not usually found in a mineralized state. "There are, however, exceptions to the general fact. Mr. Conrad, in speaking of the bones found on the banks of the Neuse in North Carolina, says that they were in a mineralized condition.

There are in my possession a number of silicified teeth, and I have seen others in the collection of the Academy of Natural Sciences. The Shawangruk country has afforded me a very beautiful specimen of silicified os femoris, three feet and a half long. It was found in Orange County, N. Y., not far from Newburgh. It is almost as dark as ebony, has a brilliant exterior, and requires the full strength of a laboring man to lift it.

In order to form any opinion as to the causes of this difference, we ought to be acquainted with the situation of the petrified specimens in relation to surrounding minerals.

The most common of petrifying substances are solutions of lime, silex, and iron. Lime and iron are readily soluble in cold water; but silex is not, Theory of Petrifacalthough this fluid, in a heated state, is capable of taking up a considerable portion of it. Silex is quite abundant in a great number of soils; it enters 
into and constitutes a parit of many vegetables. It must, of course, enter . them in a liquid form, i.e. the form of a solution. If, then, we suppose the bone of an animal to be situated in the vicinity of siliceous rock, near others containing alkalies, — the latter, being dissolved, might unite with the silex to form silicates, which, as fast as the decomposable animal matter should be evolved, would readily penetrate the pores or cells left vacant by the decomposed substance; and the silicate, permeating the calcareous matter of the bone, would gradually take the place of the animal texture. Various experiments made by chemists and geologists demonstrate the possibility of such an interchange. (Vide Professor Silliman's letter in APPENDix F.)

The mineralization of organic substances contained in very ancient deposits may, no doubt, be accounted for in a more satisfactory manner; since, in many of these, the agency of heat may be supposed to have been introduced, and to have operated in the same ray as in the great petrifying hot springs in various parts of the earth. This process is perhaps one of the causes which have preserved to us some of the bones of the Mastodon Angustidens of the Old Continent; but, as to the petrified bones of the Mastodon Giganteus of the Ner, a different and more limited action secms to have been exerted.

A part of the latter, howerer, appear to have undergone a degree of mineralization without petrifaction. I refer to those we frequently meet mith of a dark color, dense texture, and comparatively high specific grarity, as is noticed in a number of the hones of the Baltimore skeleton, in those contained in the collection of the Lnirersity at Cambridge, and in others. These are impregnated with a ferrugineous solution, derired from the bogiron ore so abundant in various parts of the country. 
The property of iron to preserve animal and regetable substances is sufficiently knomn. I hare noticed instances of fragments of ships wrecked upon the sea-shore, in which the wood surrounding the iron spikes was preserved, while the rest had disappeared. A lady of my family picked up, on the shore of Rhode Island, a small mass of iron-colored substance, which, on examination, proved to consist of an iron spike as the nucleus, surrounded by a substance showing the fibres of woody texture, in which were imbedded, in the most solid manner, a multitude of minute pebbles and shells, forming a specimen entirely mineralized. 


\section{4}

\section{GEOLOGICAL SITUATION AND CAUSES OF}

\section{PRESERVATION.}

BEFORE entering upon this subject, we would embrace the opportunity to express our admiration for the sciences of Geology and Palrontology. Newly created, they have already produced a rich supply of objects, which serre to enlarge our riers of natural science, and afford fresh subjects of inquiry and of pleasure.

Comparative Antiquity of $\mathrm{M}$. Giganteus and $\mathbf{M}$. Angustidens.

Although bones of the Mastodon Giganteus were known at an earlier period than those of any other species, the existing relics of the Mastodon Angustidens generally hare claim, so far as me know, to a greater geological antiquity. Teeth of the Mastodon Angustidens hare been discorered in France "in calcareous rock, fifty feet from the surface of the earth;" and the greater part of the bones of a skeleton, were found in the south of France, "under two beds of calcareous rock, and from twèlve to thirteen fect of a compact mass, rery destitute of fossils." In other places in rarious parts of Europe, teeth and bones hare been met with imbedded in rocks of the same character, at some depth (ricte De Blainrille's "Geology of the Mastodon," p. 326). Thes are usually deposited in miocene formations; but there are exceptions to this general fact. 
The geological position of the Mastodon Giganteus, as above intimated, differs greatly from that of the Mastodon Angustidens. One of the deepest Position situations in which the bones of this species have been found, though of M. Giganteus. possibly not the most ancient, is, according to Sir Charles Lyell, the loam resting on the eocene or lower tertiary strata of the region of the Mississippi. In his address to the British Association at the meeting at Southampton in 1846, he says that there is a collection of megatheroid bones, mastodon, elephant, mylodon, tapir, \&c., in a deposit resembling the loess of the Rhine, in bluffs skirting the plains of the Mississippi, from fifty to two hundred and fifty feet high. (Vide Appendix G.)

Professor Gibbes, of Columbia College, South Carolina, informed me sometime since, that Mastodon bones had been found in miocene at no great distance from Charleston; but, at a subsequent period, in a letter he sars "that Mrr. Tuomey, having completed his geological survey of South Carolina, has been induced, from a careful comparison of the fossils for three rears considered miocene, to class them with the pliocene, there being fortysix per cent of living species among them."

Mr. Conrad has described a large number of fossil bones of the Mas"todon Giganteus, and other extinct animals, on the banks of the Neuse in North Carolina, fifteen miles below Nerwbern, rolled in an upper tertiary deposit, corered with the shells of oysters and balani. But he seems to be of opinion, that the Mastodon bones were generally of an earlier date than the upper tertiary; and that, together with the associated quadrupeds, "they belonged either to the medial tertiary, or to the older pliocene period."

An able geologist, Mr. Foster, who has made a great number of observations of the Mastodon localities, has assured me in the strongest terms 
that he has repeatedly seen collections of these bones in position, below the drift and boulder deposits.

Recent

- Discovery

of Elephant

Remains at

a great.

depth.

The newspapers of the early part of February, 1852, printed at Buffalo, N. Y., announced the discovery, by the laborers on the Great Western Railroad of Upper Canada, of "the tusks and jawbone of an elephant, buried to a depth of sixty feet in earth and gravel." The exhumation took place while they were engaged in an excaration throngh Burlington Heights, near Hamilton, C. W. The jawbone is said to be of enormous size, and one of the tusks, which is slightly decayed at one end, to measure six feet and nine inches. The other tusk is perfect.

The Elephas Primigenius, as shown in page 142, was contemporary with the M. Giganteus. The remains here found of the Elephas Primigenius render it probable that those of the M. Giganteus might have had a similar depth, and thus tend to confirm the belief of Mr. Foster, expressed above, that these relics were occasionally met with below the drift. Considering this to be an important fact, I immediately wrote to a friend in the West to obtain more exact information, and hope it may arrive early enough for me to make use of it.

Relics thus situated would have a much higher antiquity than those we have had an opportunity of observing: But, while relating these facts as I have received them, I do not pretend to say that the present state of observation affords satisfactory evidence of the relics having been found to any great extent below the drift and boulder deposits.

The bones of the Mastodon Giganteus, in the northern parts of our country, have generally been discovered in post-tertiary or alluvial formations, at the depth of from five to ten feet, in lacustrine deposits, in bogs, in beds of shell-marl, or overlaid by these beds. The marl contains the 
fresh-mater shells, limnea, planorbis, palludina, valvata, and cyclas imbedded in green clay. (Vide Appendix H.)

Sir Charles Lyell has observed the disposition of Mastodon relics in a great number of localitics in the Lnited States from North to South, and has come to the conclusion, as said by him in the "Annals of Natural History," rol. xii. p. 126, that these deposits are later than those of the drift and boulder; but that, "although the date of the imbedding of these mammalian fossil remains is so extremely modern, considered geologically, it is impossille to say how many thousand years may not have elapsed since the Mastodon and other lost species became extinct."

Although the facts in our possession do not warrant any exact division of the geolugical localities of Mastodon Giganteus, me find. some reason to distinguish them into deep or ancient, and superficial or modern; the former haring occurred before the present geological condition, the latter since.

Of the former we may adduce the following, some of which have already been mentioned, viz. : -

TE R T I A R.

1. "It is now elear that they existed anterior to the upper tertiary in this comntry, and that they belonged to the medial tertiary or older pliocene period." - F. A. Conrad: Fossits of the Medial Tertiary of the U. States, p. 10.

2. "The loam [with which these bones are found] rests, at Vicksburg. and other places, on eocene or lower tertiary strata." - C. Lyeli: Report on the Delta and Alluvial. Deposits of the Mississippi, before the British Association at Southampton, 1846.

3. "Sixty feet deep near the mouth of the Wabash in Ohio; also skin and hair in digging a well." -DE BLutnville: Ostéographie, p. 340. 
4. "Pliocene fossils of South Carolina; mammalia, Mastodon Maximus, Cuvier; Cervus." - M. Tuomer: Report of the Geology of South Carolina, p. 205.

5. "Not later than the 'Erratic Block Group' of De la Beche." HaRLAN : p. 254.

The modern deposits are much more numerous; and, in order to show satisfactorily their character, we have collected a number of instances from authorities to be relied on for their exactness.

"Account of the discovery of a skeleton of the Mastodon Giganteum, extracted from a report made to the Lyceum of Natural History, by Messrs. De Kay, Van Renselaer, and Cooper. Read May 10, 1824: - '1. The black earth, containing the remains of the Great Mastodon, about eight feet thick. 2. Silicious sand, with rolled pebbles. Thickness unequal, but generally greater than that of the black earth. 3. Marl formations, almost exclusirely composed of the relies of testaceous animals. These appear to have been principally bivalve shells, though a fer univalves are sometimes found. This formation appears to rary in thickness, at different places, from ten to thirty feet. Perhaps it should be considered as composed of several strata, characterized by different species or genera of shells. Thus we observed one stratum wholly composed of species of ostrea, mihich was constantly elevated sereral feet higher than another, which contained only the shells of a different species. A fossil elephant's tooth is likerrise stated to have been found in a marl pit in this county. We were not able to determine the character of the strata underlying the marl.' " - Annols of the Lyceum of Natural History of New York. 
D R I F T.

1. "These bones often occur imbedded in gravel and sand of the nature of ordinary drift; but in such instances it can usually be shown that they have been transported, and that the deposit in which they occur is one of very modern origin." - JaMes HaLL : Geology of New York, p. 36 .

2. "In the neighborhood of the Great Osage river, in swamps, erect." CLtier: Oss. Foss. "ed. alt. vol. i. p. 217.

3. "Many since in swamps." - DE $\mathrm{DAY}_{\mathrm{AY}}$ : Zoology of New York, p. 365.

4. "The marl beds and. muck-swamps, where these remains occur, are the most. recent of all superficial accumulations...... rest on the drift." - J. HALL: Ibid. p. 366.

5. "At Hinsdale, Catteraugus County, a tusk, with" some horns of deer, Tere found sisteen feet beneath the surface of gravel and sand " [at an elevation of fifteen hundred feet above the sea-level]. - Ibid. p. 364 .

6. Our Shatrangunk Head, as it is styled, was found under the following strata: 1 st, grarel and drift ; $2 d$, marl ; $3 d$, a layer of dry peat, hard enough to be turned in a lathe. - Present work, p. $\mathbf{1 1 0 .}$

7. In Albany and Greene Counties, in shell-marl four or five feet deep. "The strata in which they (the English remains) lie do not belong precisely, like those in Nerr Tork, to the most modern geographical condition of the country." - Sir Charles Ltell: Tour in North America.

8. "In low sunken places, very wet and miry, and lay buried about ten feet under the surface. The earth and marl appear to consist of four rlifferent strata: 1st, the common earth found in low meadows, which is very black and rich; $2 d$, a stratum of blue clay; $3 d$, a stratum of white marl; 
and, 4 th, a stratum of grey marl." - Dr. DAvid R. Arnewx: New York Medical Repository, vol. xii. p. 315.

9. The bones of our skeleton lay in a peat-bog imbedded principally in marl. (Vide p. 5, and Vignette.)

10. Those of the Cambridge specimen below whitish sand in a vegetable deposit; consisting of leaves and branches of trees. (Vide p. 94.)

11. R. Peale's skeleton was found in peat, turf, and shell-marl. Godman's Natural History, vol. ii.

12. At the Salt Licks they occur on the surface, and mixed with the common soil. - Many writers.

13. In the "London Quarterly Journal of the Geological Society for August, 1851," there is a notice of the work of Dr. C. Grewink on the Orography and Geognosy of the North-west Coast of North America, and the outlying Islands. This article gires an account of Mastodon relics recently discovered at Unal, \&c., on this coast, and is of great interest, as it serves to confirm the statement, long since made, that the relics have been found as far north as the sixty-fifth degree of latitude; a statement, the exactness of which has been doubted.

"Diluvial formations were recognized, by means of their Mastodon remains, at Lnalaschka, the Pribülow Islands, Norton Bar, Kotzebue Sound, and the coast further north of this; and indications of these deposits were observed at Cook's Inlet, and on the Aliaska Coast. The distribution, howerer, both of allurium and dilurium, can only be correctly defined when the country is better known."

The banks of the Shawangunk and Waalkil rivers in Orange County, Nert York, situated to the west of the Hudson river, as 'tre have elsewhere said, are the fertile beds of Mastodon skeletons. Three out of fire of the 
skeletons known to exist have been discovered in this region, - the two procured by Mr. Peale, and that here described; a fourth, that of the Unicersity at Cambridge, was buried near the sources of the Waalkil. Besides these skeletons, rarious deposits, in ten or twelve different localities, have been found scattered about a region in the vicinity of these streams.

In nearly all these different spots, the bones have lain at the depth of from five to ten feet below the surface. The same fact is true of deposits near Niagara, described by Sir Charles Lyell; of those in Virginia, Long Island, the salines of Ohio, Kentucky, and most other places in the Western and Southern country of the United States.

The overlying deposits are generally a foot or two of mud, the same thickness of clay, a layer of peat sometimes intervening, and below the clay Overlying Deposits. shell-marl containing everywhere the relics of fresh-water testacea of existing species; some of them perfect, others decomposing. Sir Charles Lyell, in his geological tour through the State of New York, found, at Genesee, the bones of the Mastodon in a bed of shell-marl below the peat, corresponding, he remarks, with the situation of the fossil elks of Ireland, Fossil Elk. generally considered to have been buried in bog-mud or peat-swamps, but which in fact lie in a stratum of shell-marl.

I have in my possession the head of a fossil elk in a silicified state; for which I am indebted, through the influence of the distinguished Dr. Houston, of Dublin, to the liberality of the Royal College of Surgeons, of that city. This head is decidedly silicified to a greater degree than bones of the Mastodon skeleton usually are; but it is not uncommon to find wellsilicified bones; and the femur, already alluded to, is more fully petrified than the head of the Irish elk. Probably the relics of these two animals 
have nearly the same antiquity. (For a more particular account of the strata in which these fossils are sometimes found, see APPENDIX I.)

This fact - the occurrence of the bones of the elk and Mastodon in shell-marl - may seem to afford a satisfactory reason for their preservation. A little attention, however, will show that this opinion is not so well founded as might at first appear.

In many of the marl deposits, the layer is not sufficiently thick to contain the whole of the Mastodon skeleton; some parts lying above, and some below, the marl. In the skeleton we have described, the vertex or summit of the head was near the surface of the marl; and, although a considerable part of the skeleton lay in this bed, yet, as this was only three feet thick, it could not envelop an animal whose height, in the recent state, was twelve feet or more; and, of consequence, part of the bones would be buried in the clay or mud, on which the marly layer was formed fvide Vignette). Now, the Mastodon bones which lay under the marl are equally well preserved with those in it.

In relation to the strata which imbed the Mastodon relics in South America, an important fact is mentioned by M. D'Orbigny. In his list of formations, he makes the Pampéen, in which these remains are found, to lie "between the tertiary and diluvial formations," - a situation corresponding with the geologieal position of the North American relics of the same family.

Causes of

What, then, are the causes to which we must attribute the remarkable tion. preservation of a few skeletons, while thousands scattered on the earth's surface hare disappeared? The decomposition of the latter is attributable to the combined action of air and water, aided by the frosts of winter and Dry Air. the suns of summer. Perfectly dry air does not faror the decomposition 
of the osseous texture; and we therefore see the bones of men and animals preserred in the catacombs of Egypt, and the subterranean vaults of Rome, Naples, and other places.

Again, an immersion in water, to such a depth as to prevent the Water. contact of air, preserves, not only bones, but the trunks and roots of trees, and eren regetables, from decomposition. It is well known that there is a bridge across the Danube, at Augsburg, in Germany, the wooden piers of which have lain under water for a number of centuries, and are still quite sound. It is not uncommon to find the trunks and roots of trees in lacustrine deposits, in rivers, and even in the ocean, covered by layers of other roots and other trees deposited long after them.

Animal substances, protected by superincumbent earth from the action of air, have been known to resist, for unknown ages, the tendency to decomposition.

The seeds of various plants, also, after having been buried in the earth for a great number of years, at the distance of some feet from the surface, have not only escaped decomposition, but have actually germinated when placed in farorable circumstances.

The great number of fossil bones found in the vicinity of the Salt Licks, salt Licks. proves, as may be readily believed, that the earth of these districts, impregnated with the chloride of sodium, has a greater power of preventing their decomposition than the common soil of the country. Mr. Ansted, an excellent writer on Geology and Palæontology, has said, in a recent work ("The Ancient Morld," p. 300), that "perfect skeletons of the Mastodon have been obtained from the great salt marshes in North America." This is a mistake: no perfect skeleton of Mastodon has been found in the salt marshes or Salt Licks of North Anerica. Of the five skeletons known at this time, 
three have been found in the fresh-mater marshes of Orange County, N. Y. ; a fourth, in an interior morass in New Jersey. The fifth was obtained from the banks of the Missouri, probably in a fresh-water deposit. Neither of the five, therefore, was found, so far as we know, in a saline soil. Separate bones in considerable numbers lave been extracted from the saline deposits of Kentucky and Ohio, but nothing like complete skeletons.

Time.

The length of time since the probable disappearance of the Mastodon race has been, and still is, buried in uncertainty. No history or tradition, either in the old Continent or the New, can be considered as referrible to any species of Mastodon. This could not have occurred in regard to so remarkable an animal, if it had really existed within the historical period of the Old World, or the traditionary of the New. There is, indeed, in Mr. Jefferson's "Notes on Virginia," an account of a poetical tradition of the Delarare Indians, relating to the ancient destruction of animals of great size in the Ohio country. This tradition, however, which Mr. Jefferson imputed to the Mastodon, was undoubtedly referred, by the Indians, to the gigantic bison or buffalo; and, of course, does not form an exception to the general fact.

The existence of beds of shell-marl over Mastodon bones must be conBeds of sidered as a ground for belicring in their antiquity; and the facts quoted from Sir Charles Lyell, Dr. Gibbes, Mr. Conrad, Mr. Foster, and others, tend to show that this antiquity would extend farther back than the present geological arrangement. It would be extremely desirable to ascertain by exact observations, whether, as marl-beds are composed of shells of existing species of mollusea, we mar not learn, by obserring the gradual increase of these beds, what length of time might be required to envelop, or cover, these and other fossil bones deposited in or under them. Sir Charles Lyell, 
the distinguished geologist, having lately visited a great number of fossil deposits in rarious parts of North America, and being able to bring to this subject a vast amount of geological and palæontological science, must be well qualified to throw light upon this interesting inquiry. So far as he has expressed any opinion, it accords with that of many other excellent palæontologists, who are in favor of the theory, that the disappearance of the Mastodon and many other megatheroid animals occurred at a period not rery long anterior to the introduction of man. After carefully investigating the facts which might serve to elucidate this interesting research, we find that the relative phenomena seem to support this doctrine. But it would be rather derogatory to the powers of the Author of nature to surmise, as some have done, that these large animals were struck from the surface of the earth to make room for the existence of the human race.

The cause of the disappearance of the Mastodon seems to be mysterious. The are naturally disposed to believe, that an animal of so large size, of so great strength, and such extensive distribution in various parts of the earth, must have required some great and general catastrophe to overwhelm and annihilate it. The mystery diminishes on noticing, that a great number of animals, scarcely less remarkable than the Mastodon, have also disappeared. Among them are the Elephas Primigenius, the Sivatherium, the great Samians, the Zeuglodon Cetoides, \&c. These, however, may be thought to have existed at a period so remote as to have been subject to other laws than those which now regulate the surface of our globe, and, of course, before the existence of man. Such a supposition may perhaps be admitted by some geologists, while others are of opinion that the causes now in constant operation are sufficient to explain the wonderful phenomena of Geology and Palæontology. 
Recent

Annibila-

tions. realize more fully the changes which are going on in the animal creation. For example, a considerable number of animals have been swept off from the British Isles during the historic period. Among these are the bear, the wolf, the elk, \&c. Even in America, during the comparatively short period of its history, species have vanished, and others are following them. The beaver, formerly so generally spread over the whole country, is now only to be found in remote regions. The deer and the moose are disappearing in the same manner. The buffalo is very much diminished in numbers, and must, ere long, be extirpated. In other parts the Dodo and the Dinormis have perished within the last two centuries, and the Apterix is undergoing the same fate. These animals have fallen by the hand of man. But many species are constantly perishing from natural and inevitable causes; such, for example, as extensire inundations, earthquakes, rolcanoes, and the action of the winds. Various species undergo a gradual extinction by changes which deprire them of their accustomed food; and, finally, others seem to die out from unknown causes.

have destroyed the North American Mastodon. Vegetation appears to be the same as when the latest of the Mastodons lived, since we find, with skeletons of these animals, evidences of food derived from plants which are still existing. Nor is there any reason to believe the climate may have undergone any remarkable alteration at the period of their destruction, or that the winds or floods have had an agency in accomplishing it.

Notwithstanding, therefore, the possibility of conceiving many causes which may partly account for the destruction of the Mastodon, we cannot point out any one adequate to the annihilation of the whole race. 
The period during which the study of the earth's interior has been successfully pursued is too limited, and the facts collected are too few, to enable us to come to any satisfactory conclusion on this subject; and we must content ourselves with the hope that those who follow us may gradually discover the secret springs which have regulated, and will continue to regulate, the extinction of ancient, and the production of new, species of the animal creation.

The subject is one of the highest interest, and is well calculated to elevate our ideas of the Almighty Being, who, as it were before our eyes, yet in a way unperceived by us, is able to accomplish incessant changes in the animal creation, by which countless individuals and species are disappearing, and others are rising to supply their places. 
A P P E N D I X. 



\section{A P P E N D I X.}

\section{A. - Page 1 .}

"The first letter directed to Dr. Woodward is dated at Boston, in New England, Nov. 17, 1712. In this the writer gives an account of a large work in manuscript, in two volumes, in folio; but does not name the author. This, according to the account of it, is a large commentary upon some passages in the Bible, interspersed with large philosophical remarks taken out of natural historians, and the observations of himself and others, more particularly as to matters observed in America, whence he entitles the work, 'Biblia Americana.' This work Dr. Mather recommends to the patronage of some generous Mrcenas, to promote the publication of. As a specimen of it, he transcribes a passage out of it, being a note on that passage in Gen. chap. vi. verse 4, relating to giants; and confirms the opinion of there having been, in the antediluvian world, men of very large and prodigious statures, by the bones and teeth of some large animals found lately in Albany, in New England, which for some reasons he judges to be human; particularly a tooth brought from the place where it was found to New York, 1705; being a very large grinder, weighing four pounds and three quarters; with a bone, supposed to be a thigh-bone, seventeen foot long. He also mentions another tooth, broad and flat like a fore-tooth, four fingers broad; the bones crumble to pieces in the air after they are dug up; they were found near a place called Claverack, about thirty miles on this side Albany. He then gives the description of one, which he resembles to the eye-tooth of a man; he says it has four prongs, or roots, flat and something worn on the top; it was six inches high lacking one eighth, as it stood upright on its root, and almost thirteen inches in circumference; it weighed two pounds four ounces, troy weight. There was another, near a pound heavier, found under the bank of Hudson's River, about fifty leagues from the sea, a great way below the surface of the earth, where the ground is of a different color and substance from the other ground, for seventy-five foot long; which they suppose to be from the rotting of the body to which these bones and teeth did, as he supposes, once belong. It were to be wished the writer had given an exact figure of these teeth and bones." - Philosophical Transactions for the year 1714, vol. xxix. p. 62. 


\section{B. - Page 6 .}

It may be useful to publish an account of the Mastodon exhumation communicated to the author by a scientific gentleman, who was present during a part of it, James Darrach, Esq., of Orange County.

"On the evening of the 12th day of August, 1845, the laborers, who had been occupied that day in digging marl upon the farm of Nathaniel Brewster, Esq., announced to him they had struck upon something hard. Some said, 'a rock;' others, 'a log;' others jestingly, 'a mammoth.'

"Early the next morning, Mr. Brewster, and his son-in-law George Clinton Weeks, examined the supposed rock, which was soon found to be bone. The latter seized a shovel, and, clearing the marl (he keeping next the bone) with the assistance of the laborers, exposed to the view of more than a hundred spectators the massive skull and long white tusks of a Mastodon. Soon shear-poles and tackles were obtained, arranged, and, amid excitement, cheerings, and many cautions, the skull and tusks were prepared for raising out of the ground. The top of the skull was about five feet below the surface. In the act of raising, one tusk broke about the middle of its length into two pieces; the butt remaining in the socket, the point in its marly bed. The other cracked at about the same point of its length, but did not part. The top of the skull was upward, while the line of direction of skull and tusks was westward and somewhat downward.

"These being removed, the lower jaw, twisted slightly from the above direction, and the atlas (or top bone of the neck), were developed. The condyles of the occiput (backbone of the head) sat upon their sockets in the atlas, which was turned upon the dentata (second bone of the neck). The dental process of the dentata was nearly vertical. Below the dentata, in juxtaposition, were found the other vertebræ of the neck, one above another in a nearly vertical direction, slightly inclined forward. Upon their removal appeared the vertebræ of the back. From first dorsal to last lumbar they lay in a natural succession, and in a direction nearly north and south, cutting the plane of the horizon at a small angle, the greatest elevation being at the first dorsal; the greatest depression, at the last lumbar vertebra. The spinous processes of the back were vertical, pointing backward.

"At an early period of the exhumation of these vertebræ, on the right side, were discovered, near the position of the right shoulder, on the outside of it, the bones of the right hind foot, which led to the discovery of the bones of that limb in natural order to the ossa innominata (or bones of the pelvis). They lay parallel with the back nearly, and downward toward the toes. 
"During the exhumation of the successive bones of the back, the heads of the ribs were developed opposite their proper points of articulation with the vertebræ. The shafts of the ribs, following their proper and natural curvature, extended horizontally and downwards. The scapulæ were also discovered and exhumed at an early point of these labors, and left exposed the heads of the humeri. By this lead were reached the two long bones of the fore-arms, those of the wrists, the feet, and the toes. The general direction of these limbs was outward and forward.

"At the close of the exhumation of the backbones, Mr. Weeks reached the sacral portions, but, finding them fast, prosecuted his careful labor easterly and westerly, uncovering the posterior surface of a broad and massive bone. The direction of the sacral vertebræ was a continuation of that of the dorsal and lumbar. These, being ossified with the iliac portions of the ossa innominata, controlled their direction and position. This bone was raised with much difficulty, owing to the suction of the concave lower surface lying in close contact with a mass of broken twigs, grass, and leaves. After several efforts, success rewarded their care and anxiety. Joyful was the sight of both iliacs, pubes, ischia, and sacral vertebræ, lying upon the banks of the pit one entire unbroken bone. Now was seen the head of the remaining femur.

"The evening of the second day closed upon these interesting labors.

"The scene lay but a few rods north and in full view of the Newburgh and Cochecton turnpike road. No one of hundreds who passed and repassed thought his business too urgent to forbid his becoming one of the animated, wondering, and delighted throng which crowded around the bank of that marl-pit.

"The mass of broken twigs, \&c., above alluded to as lying beneath the pelvic bones, was in quantity about five or six bushels; differed from the surrounding mass; towards the posterior portion presented traces of convolutions, passed in a straight column of four inches diameter through the pelvic orifice, and behind the ischium terminated in a homogeneous mass, evidently of fæcal character. Three or four similar masses were found in different parts of the pit. The constituents of this mass, significantly called by President Hitchcock "his last supper," were twigs, grass, and earthy matter. The largest twigs, in their wet and swollen state, were from one-fourth to three-eighths of an inch in diameter, and from an inch to an inch and a half in length. They presented no appearance of being ground during mastication, but rather as though crushed in a vice. Some pieces of twigs were entire; those which separated, parted in the direction of their longitudinal fibres. Their botanical characters have not been accurately ascertained, but are supposed to belong to the willow, linden, and maple trees.

"During the night of the $14 \mathrm{th}$, the banks of the pit caved in; this mass, with the unexhumed bones, was again buried. The track, so easily and accurately followed in previous labors, was now lost. The interesting contents of the stomach and intestines were mixed up with mud 
and marl. The search for the remaining bones was without a guide, but was not wholly in vain: it resulted in discovering the small tusk of the lower jaw, and all except the phalanges (toe-bones) of the left hind-foot. The skeleton is deficient in these bones; a portion of them have been since found by searching the field upon which the marl was spread. During the exhumation, the anterior portion of the sternum was discovered in its proper relative position."

A very recent instance of the discovery of Mastodon bones has occurred, which serves to confirm and illustrate the statements made in regard to the previous case, and in the course of our text. The deposit in which they were situated was near to that of the Cambridge Mastodon. The bones, so far as we can learn, are in a state of partial decomposition.

"A Mammoth exhumed in Sussex. - The fossil remains of one of those extinct animals which probably roamed through our wilds in the days of the patriarchs were discovered on Saturday last, imbedded in a bog-meadow, a short distance below Greensville, in this county, on the premises and near the residence of Timothy H. Cook, Esq. The development of these animal relics was singularly accidental. The bogs in the meadow had been cut off; and, in burning them, one of the stacks was made around and upon an old stump. When the bogs composing this stack were consumed, the stump and roots were likewise destroyed, and the ground penetrated several inches by the fire. Upon clearing away the ashes, Mr. Cook noticed a large bone, and undertook to pull it up. It proved a tough job; but it was at last partially extricated, when he perceived it to be the tusk of some animal of enormous size. Excavations were thereupon immediately commenced, and prosecuted in right good earnest, when a second huge tusk, the upper and lower jaws, with the teeth entire, portions of the vertebra, several ribs, a thigh-bone, and various other gigantic fragments of a buried Behemoth, were successively exhumed from the bed of muck and tertiary strata, in which, for thousands of years, they had profoundly reposed. The bones of the head must have been near the surface, judging from the position of the skeleton, yet but few of them were found; the skull, \&c., probably having been calcined and pulverized by the action of the fire kindled in the bogs, stump, and roots immediately above them. The teeth, of which there are eight or ten, have those conical projections upon their surface which warrant us in pronouncing the animal a Mastodon.

"The 'New York Tribune' describes the bones discorered, and presumes 'the remains to be those of some monster of the Mastodon genus; for it is well known that the valley of the Delaware, and the tributaries of that river, were frequented by these animals,' dce." - Sussex Register, Sept. 27, 1851. 


\section{C. - Page 79.}

The following extract is taken from a letter of Edward Charlesworth, Esq., editor of the "London Geological Journal," Secretary of the British Natural History Society, \&c., and was written by that gentleman in consequence of my showing to him in London, in September, 1851, a cast of the tooth in question. Whereon Mr. Charlesworth immediately declared, that this was the tooth he had seen in Baltimore, and pronounced to be a tooth of Mastodon Longirostris; and which he had purchased in London for Dr. Wilson, who deposited it in the Collection of the Academy of Natural Sciences in Philadelphia, where it had been seen by Dr. Hays and myself.

At the same time with Mr. Charlesworth, in London, the cast was unexpectedly exhibited to Sir Charles Lyell, who at once recognized the tooth, and expressed his astonishment to find it in my possession.

"Museu, York, Sept. 12, 1851.

"DEAR SIR, - I have great pleasure in replying to your inquiries respecting the Mastodon tooth from the tertiary deposits of Maryland, and giving you the substance of the statement which I have recently communicated to Dr. Wilson, of Philadelphia.

"During a visit to the United States in 1840, I endeavored to ascertain whether any traces of Mastodon had there been detected in deposits of the true tertiary epoch. Among various geologists, to whom I named the subject, was Dr. Duchatel; and this led him to tell me of a tooth in the Baltimore Museum, the finder of which, as I understood Dr. Duchatel, had given it to him with a positive assurance of its having occurred in a marl-pit, the marl in question being well known to be tertiary. Dr. Duchatel told me that he did not at all question the good faith in which this statement was made; but that he thought the tooth had probably fallen into the tertiary marl from some overlying, more recent, deposit. Subsequently to this conversation, when going over the Baltimore Museum, the first thing I thought of was this tooth; and, upon its being shown me, I was gratified beyond measure to find it exhibit the precise characters of the Mastodon teeth from the English crag, and which are referable to the Mastodon Angustidens or Mastodon Longirostris, species regarded by Professor Owen as synonymous. These characters escaped the notice of Dr. Duchatel; and, upon my pointing them out to him, all doubt as to the tooth being of tertiary origin was at once removed. As I named to Dr. Harlan, and other American naturalists, the important addition thus made to the fossil Fauna of the United States, I fully expected to see some account of it published; but, so far as I am aware, the 
only record of the fact in print is contained in a paper read by Sir Charles Lyell to the Geological Society of London, and printed in the proceedings for 1843. The tooth, it seems, was then in the Baltimore Museum, having a memorandum with it in my handwriting.

"Some time in 1847 or 8, I was passing through an obscure alley connecting Lincoln's Inn Fields with Temple Bar, when my attention was arrested by a Mastodon tooth in a shop-window, which seemed to me a fac-simile of the one I had examined with so much interest in the Baltimore Museum. The proprietor of the shop, Rogers (a picture and general dealer), in reply to my inquiries, told me he had bought the tooth as American, and I think he said at one of Steven's sales, the well-known natural history auctioneers in Covent Garden. We struck a bargain for the fossil; and I shortly afterwards sent it to Dr. Wilson, with a statement of its remarkable resemblance to the tooth which I supposed still to be safe in the Baltimore Museum. It now, however, appears that the Baltimore tooth, and that purchased by me in Bell Alley of Rogers, are one and the same.

"As it respects the origin of this fossil, I certainly cannot see the shadow of a reason for doubting the fact of its being American. It is impossible to attribute any intention to deceive on the part of Dr. Duchatel; for he had placed the specimen in the Museum as a tooth of the common Mastodon Giganteus, and had not even thought it worthy of a label until informed by me of its value. By what probable means could the person who gave it him have become possessed of so rare a fossil as a tooth of the M. Angustidens, unless by digging it up in the way related?

"For many years, the occurrence of the Mastodon in the crag of England rested solely on the discovery of the tooth figured by Smith in his 'Strata identified by their Fossils.' 'This tooth was bought by the British Museum; but Mr. Konig, (late) the keeper of the geological department, would not have it included in the exhibited collection, because he had doubts about its being a British fossil. Only within the last twelve months, however, more than a dozen of these very teeth have been discovered, in consequence of washing the crag to get out the phosphatic nodules. So much for the value of doubts based upon the mere fact of a specimen being unique." 


\section{D. - PAGE 82 .}

The following letters from Dr. Cohen, of Baltimore, are published in support of the text. They, with other evidence here adduced, seem to form a complete chain, going to show, first, that this tooth was actually exhumed in this country; and, second, that after it had disappeared it was recovered by a remarkable coincidence, and deposited in the Museum of the Academy of Sciences at Philadelphia. Dr. Cohen is well known for his scientific acquirements, and particularly for his knowledge of mineralogy. His accuracy and impartiality are unquestionable. I must therefore consider myself peculiarly fortunate in being able to apply to a friend who was so well adapted to the investigation of the subject, and so favorably disposed to undertake it.

There will be found some discrepancy in the two statements of Dr. Ducatel as to the expression of opinion by Mr. Charlesworth and Sir Charles Lyell. The declaration of the latter gentleman, however, published in the "Geological Journal," 1843, makes it clear that Mr. Charlesworth had characterized the tooth as belonging to Mastodon Longirostris. The discrepancy does not at all invalidate the account of the principal facts.

\section{DR. COHEN TO DR. WARREN.}

June 19, 1848. - "I did not wish to write until I could give you the information which you desired in regard to the fossil bone. But all my efforts, and they have been almost daily ones, have not enabled me to procure it from Dr. Ducatel, with whom I left your letter, and from whom I am still to hear. I will no longer delay my acknowledgments; assuring you, that, so soon as I can get Dr. Ducatel to give me the information sought, I will write you again. I have no knowledge of the matter myself."

Sept. 12, 1848. - " Since I had the pleasure of addressing you in reply to your letter on the subject of the fossil tooth, Dr. Ducatel had promised me, from day to day, to give me a memorandum to forward you in regard to it, and at the same time to send the original memorandum made by Mr. Charlesworth, who had examined the tooth. As he tells me to-day, he has in vain sought among his papers for this letter; he desires me to say now that the information you have on the subject, derived from Mr. Lyell, is correct; and that this is the history of the fossil:-

"When Dr. Ducatel was on the Eastern Shore of Maryland, engaged in his geological survey, and at Greensburg, Caroline County, he caused the marl-beds at this place to be opened, and requested Dr. Tilden on the spot to forward to him such specimens as might be thrown out. 
Some time afterwards, this fossil tooth was sent to him, with other specimens, all bearing the marks of the locality. It was set aside, and was supposed by Dr. Ducatel to be the Longirostris. Mr. Charlesworth, of London, Editor of the 'Magazine of Natural History,' came to Baltimore subsequently, and it was shown him. He pronounced it at once not to be the Longirostris, but identified it with the Mastodon of the crag of England, and wrote a memorandum expressing his opinion; and this was placed with the fossil. When Mr. Lyell came to our city, the tooth, with Charlesworth's memorandum, was shown him by Dr. Ducatel; but he expressed no opinion, and made no remark. This is its history. Dr. Ducatel says there is no mistake in regard to its locality; the external surface, \&c., bore all the marks of the formation from which it was said to have been taken.... I have felt mortified that I could not obtain the information from Dr. Ducatel a long time ago; he was desirous of sending you Mr. Charlesworth's memorandum, and regrets with myself that he cannot find it."

Jan. 21, 1849. — "The result of my present inquiries, I am sorry to inform you, is that Dr. Tilden, to whom you had written, died some three or four years ago; and we shall have therefore to abandon all expectation of further information in regard to this fossil tooth.

"Now, I can fully understand, from having been myself a student of natural history, and knowing how easily false facts are mingled with the true, your desire to have the whole subject re-investigated, and to have a renewed averment of the facts in connection with the fossil; but I fear we shall have to rest upon what is now stated; and I must confess, notwithstanding the anomaly of the matter, that I do not see how we can refrain from admitting them. Dr. Ducatel himself, with whom I have again conferred, has not the slightest doubt on the subject. Besides reiterating verbally all the circumstances, he writes me a note, stating: 'There can be no doubt but that the fragment of the tooth, declared to be of the Mastodon Longirostris by Mr. Charlesworth, of England, and afterwards recognized to be such by Sir Charles Lyell, was found in the fossil deposit referred to the miocene period. It was rescued from the laborers engaged in making diggings for marl in a locality which I had pointed out to them; and sent to me by Dr. Tilden, through his brother, Mr. Tilden, of Baltimore. Neither of them could have had any other desire in handing me over the specimen than to oblige me. I was not aware myself of the interest attached to the specimen, until Mr. Charlesworth pointed it out to me.'

"You will remember that Dr. Ducatel was making his geological survey, and was in the habit of indicating to the farmers and others such matters as would prove beneficial to them. When at Dr. Tilden's, he pointed out a marl deposit, and told him to make his 'diggings' at this spot, and he requested Dr. Tilden (as he was always in the habit of doing on such occasions) to send to him at Baltimore any large and perfect shells, fossils, or bones, \&c., which his men might turn up. The result was, as you have already been informed, that this tooth was sent to 
Dr. Ducatel, with other fossils, from the spot pointed out by him. It had all the external characters (the physiognomy) of the fossils from the locality. Moreover, it was broken by the men engaged in digging, and the fragments could not be recovered: this was so stated at the time by Dr. Tilden.

"Dear Sir, however anomalous the case may be, I do not see how we can set aside the facts. I regret that we have no means now of beginning the investigation de novo for your sake. I was in hopes I should have had the opportunity, as it would have been a pleasure to me, to answer all your queries explicitly from Dr. Tilden's own statements; his demise alone prevents it.

"I will, however, not lose sight of the matter, and may, in the course of the spring, have an opportunity of learning whether any thing else of the kind has been developed from the same locality."

Feb. 22, 1849. - "I had the pleasure of addressing you on the 21st ult, and inter alic stated that I feared all likelihood of obtaining further positive information in regard to the Fossil 1Iastodon tooth was now lost, in consequence of the death of Dr. Tilden. The brother of Dr. Tilden has heretofore resided in Baltimore, and, at the time I wrote you, was absent from the city. The death of Dr. Tilden I learned from an acquaintance of the family. On yesterday, however, I saw Mr. Tilden himself, and learned from him the following facts, of which he had a perfect and distinct recollection: That he was present on the spot at the time the digging for the marl was made; he describes the place as being between a bank of shell, \&c., about sixteen feet in height, and the river; that a black boy was set to work for the purpose of exposing the bed of marl, and, whilst so doing, this fossil tooth was turned up; it was taken from the ground by the boy, and brought to Mr. Tilden (then present), who directed him to take it to the water near by, and wash the dirt from it. This was done, and the tooth put into Mr. 'Tilden's hands; who stafes that he gave the boy some change from his pocket as a reward. Mr. Tilden and those who were with him, thinking that, as they had discovered a tooth, perhaps the head of the animal might be found, extended the digging with this hope and expectation; but they were unsuccessful. Some other interesting fossils were found; all of which were brought over to Baltimore by Mr. 'Tilden, and given to Dr. Ducatel.

"Mr. Tilden is so positive and clear in his statement, that I think no further doubt can be entertained in regard to the matter. He gave me his account without knowing. why I particularly desired it, detailing the search for the head, after finding the tooth, \&c. When I told him of the doubts that had been connected with it, he was desirous of writing to his friends on the Eastern Shore to corroborate his statement; but I did not deem it necessary, as Mr. Tilden saw (suis oculis!) the tooth exhumed, and remembers it so distinctly. 
"I believe this statement meets all your queries in your last letter, and I am pleased"that it has (so unexpectedly) occurred that I can give you the information sought."

June 12, 1849. - " The 'one link' in the chain of evidence in regard to the Mastodon tooth wanting, is easily supplied, I think; for both Dr. Griffith of Philadelphia, and the Rev. Dr. Morris of Baltimore, recognize the tooth in the Academy at Philadelphia as the one that was in the Academy at Baltimore (the same about which we have been corresponding). Both Dr. Griffith and the Rev. Dr. Morris are naturalists, accustomed to the scrutiny of objects of Natural History; and they have no doubt in regard to the matter. Their opinion would weigh more with me than that of Mr. Tilden, a person unaccustomed to such examination of objects; but, if you think it worth while to submit a cast of the tooth to him, I will cheerfully do so for you. I should have said that the above gentlemen were active members of the Academy at Baltimore; Dr. Griffith being then a resident of our city.

"I was not aware, until sometime after our correspondence, that the tooth was in the Academy at Philadelphia, nor was the late Professor Ducatel. A curious subject of inquiry would be, how it found its way, as is said, into the hands of a London dealer, and was purchased, \&c., \&c."

After the reception of the last letter, I met Dr. Griffith in the Academy of Natural Sciences at Philadelphia; Dr. Hays, Dr. Wilson, and a number of other gentlemen being present; when Dr. Griffith identified the tooth before us with the Longirostris tooth seen by him in the collection of the Academy at Baltimore. 


\section{E. - PAGE 94.}

The following is an extract from the "Proceedings of the American Philosophical Society," rol. iv., page 118:-

"Professor Frazer read a letter from Mr. J. B. Maxwell, one of the trustees of Princeton College, to Professor Henry, dated Belvidere, Oct.17, 1844, relating to the discovery of Mastodon bones on the farm of Mr. Abraham Ayers, near Hacketts Town, New Jersey.

"There are portions of the skeletons of five Mastodons; one pretty large, three of smaller size and a calf; of the largest, only the grinders, portions of the tusks (thirteen and a half inches in circumference), and some fragments of the larger bones, remain; the rest having fallen to pieces on being exposed to the air. The bones of the calf fell to pieces in like manner, and no parts have been preserved except the grinders and the tusks, which were five or six inches long, about three quarters of an inch in diameter, and seem to have projected more than an inch from the bone; of the other three, the skulls and most of the larger bones are in good preservation. We measured some parts of the largest of them as follows :-

SkUII, from top of head, at junction of the muscles of the neck, to end of bone between the tusks, three feet four inches.

SkULL, between the large cavities for the ears across the forehead, two feet.

SkULL. Orbit of the eye, vertical diameter, six inches,

SkJuL. Reniform orifice below the eyes (communication between trunk and brain, \&c.), ten inches across, by four inches vertically.

SKULL. Oval orifice below this (communication between trunk and throat), five inches and a half vertically, by three across.

SkJLL. Tusk, from insertion, two feet three inches; whole length, three feet one inch, and about three inches in diameter.

PELTIS, four feet ten inches across, by three feet eight inches.

Fevorax Bore, three feet long, one foot one inch and a half in circumference in the middle.

SCAPULA, two feet five inches long, two feet one inch wide (measuring over the projection).

"There were three grinders on each side above, and the same number below. The two others and the calf had four teeth on each side, both above and below; but the forward ones were evidently ' milk teeth,' which would have been shed at a more advanced age. In none of these four did the back grinders appear to have cut through the gum. The largest of the five had had three grinders on each side in each jaw. All the grinders were of the same character, having the projecting conical points which distinguish the Mastodon. In one of the skulls, the 
tusks projected outwards, and inclined upwards; while, in the other two, they were inclined downwards and nearly parallel. This difference, and that in the number of the teeth, had induced Mr. Ayers to believe that the remains belonged to more than one species. But Mr. Maxwell considered it to be evident that the only differences are those of age and sex. The bones which he measured he supposed to be those of a female. The other two were younger animals, as was evident both from the teeth and the sutures of the skull; and, as the skull with projecting tusks seemed to have a broader and rounder outline than the others, it probably belonged to a young male.

"Mr. Ayers walked with Mr. Maxwell to the spot where they were dug out, and described the position in which they were discovered. North-west of the Musconetcong Valley, in which Hacketts Town is situate, lies a range of highlands, about two miles wide, rising perhaps three hundred and fifty feet above the valley, and separating it from the valley of the Pequest. This ridge, which is of gneiss, and has, like all our mountains, a general course of about north-east, is cut into sections by transverse depressions, or hollows, running generally about south of east. Through one of these depressions, which is probably a hundred and fifty feet below the general level of the range, passes the road from Hacketts Town to Vienna. By looking at Gordon's Map of New Jersey, a small stream is found to cross the road nearly half-way to Vienna. Mr. Ayers's house is about a hundred yards beyond the stream, and the bones were found more than a quarter of a mile beyond his house in a northerly direction, and perhaps three hundred yards from the road. The map does not represent the face of the country correctly. The road runs along the northern side of the valley or depression, most of which is occupied by a swampy meadow, through which the stream flows. From the road the ground rises regularly, but pretty rapidly, - probably a hundred and twenty feet in two hundred yards, - and then descends more gradually twenty-five or thirty feet into a smaller depression, which, however, does not cut through the ridge like the larger one, but descends very gradually from the general level on the east, and at its western end opens on the brow of the ridge by a kind of ravine. Near this western end is a depression or basin, deeper thån the outlet, and forming in wet weather a pondhole. Mr. Ayers says that formerly the water in it was at times four or five feet deep; but some years ago he drained it in part by a ditch, four feet deep, so that now it is merely a wet, swampy place, about forty yards in length by twenty-five wide. During the drought last sum. mer, it became quite dry, and he took the opportunity to dig out a portion of the earth for manure. In doing this, he discovered the bones. The basin slopes gradually from the east to a depth of about twelve feet near the western side. On the top is about one foot of regetable deposit, formed of decayed leaves, \&c.; then about six inches of whitish sand, mixed with regetable matter; and below this a deposit, which, Mr. Ayers says, when first opened, was of a yellowish color, very much resembling in appearance the manure of a cow-yard, when thrown up 
in heaps in the winter, and had a very strong smell of the same kind. Exposure to the weather has changed its color to the dull bluish black of swamp-earth, which it seems to be mixed with, - great quantities of vegetable remains, principally of marsh plants, with scattered fragments of branches of trees, \&c. In this deposit the remains were found, covered from four to six feet deep, except the largest, which lay near the south-east side of the basin, and were but slightly covered. A few feet to the north of this lay the next in size, on its back; and a little to the north and west of this the other two, - both as if in a standing position; and the calf was found in a similar position, near the north side of the basin. From Mr. Ayers's description, the bones of the largest one must have been disturbed after its death, as the tusks were found reversed alongside of the neck. Between the ribs of two or three of them was a considerable quantity of what Mr. Ayers describes as resembling coarse chopped straw, mixed with fragments of sticks, no doubt the contents of the stomach.

"Not more than one-fourth of the basin has been examined. The openings in it have been made at random, and in each an animal has been found, so that there is probably a number more. 'The question,' says Mr. Maxwell, 'very naturally occurs, How and when did so many of these huge animals become imbedded in this narrow space? - questions more easily asked than answered. My first conjecture, before seeing the place, was that they had been mired in attempting to reach a spring or lick; but the small extent and shallowness of the basin, and the gradual descent and character of its bottom (which, as far as has been examined, is perfectly solid, and, like much of the ground around, closely paved with rolled stones of gneiss and limestone, generally six or eight inches in diameter), all forbid such a supposition. It is possible that they may have been swept there by a deluge, which, from the configuration of the surrounding country, would, as it subsided, sweep through the larger depression with a current to the east, and form an eddy through this one to the west. The whole depression has in form a close resemblance to such as we see formed on a smaller scale in the sand along the Delaware. But, on the other hand, the number found together, most of them in a standing position, would seem rather to indicate that they had been overwhelmed in one of their native haunts by some sudden catastrophe; and some circumstances seem to favor the supposition that this could not have been at a very remote period. This little basin receives the drainage of some fifteen acres of land, and seems to have had a considerable growth of grass and marsh plants around it. Under such circumstances, it would seem that the accumulation of vegetable matter indicates no very great antiquity. The holes were so filled with water, that I could not ascertain whether the deposit below the sand showed any thing like stratification; but, as far as I could judge from what was thrown out, its character was pretty uniform throughout, exhibiting the appearance of a marsh, much frequented by animals, "which had trampled fragments of its plants all through it. I regretted very much that my knowledge was not sufficient to determine the species of the plants, 
of which so many portions remain; but I thought I recognized some which are now growing in the neighboring marshes, such as flags, cattails, dc. I hope, however, that you, or some of your scientific friends, will visit the place, and obtain more accurate information than I am competent to give."

\section{F. - Page 152 .}

The following letter to the author presents the views of the distinguished Professor Silliman on the subject of Petrifaction :-

"In reply to your letter, I can very briefly state my views regarding petrifaction. It appears to me to arise from a gradual substitution of inorganic for organic matter, the tissues of the latter serving as moulds in which the former is cast by gradual percolation or infiltration; and it becomes firm by cohesion.

"Petrifactions being chiefly siliceous or calcareous or ferruginous, and all these matters being contained in natural waters, may therefore be introduced through their agency.

"It is very possible that the immense petrified forests - the siliceous, I mean - may have been lapidified by hot or tepid volcanic waters, holding silicates of alkalies in solution. The sites of such forests may, by subsidence, have been lowered down beneath the waves; and hot waters, charged with silicates, may have continued to flow from a focal point beneath, and thus the trees may have become stone. The geysers of Iceland and the hot silicated fountains of the Azores produce changes upon organic bodies analogous to petrifaction. Submersion by subsidence has been so frequent a geological phenomenon, that it is easy to extend this view to calcareous and ferruginous petrifactions, which may be produced in the same manner with or without the aid of heat. The soft parts of organic, and especially of animal bodies, are rarely petrified, and in general only the firm fabric, such as bones, crusts, and woody fibre, which appear to be sufficiently persistent to endure for the requisite period of time. Shells, being already chiefly mineral matter, are more rarely changed, except by a substitution of inorganic matter for the gelatine, or other animal matter, which they contain. Still, instances are not very uncommon of silicified shells, silicified sponges and corals, \&c.; and siliceous and calcareous casts frequently occupy the interior of shells, thus copying both their form, and that of the included animal.

"I have a portion of a dicotyledonous tree, obtained in a railway cut near Baltimore, which is perfect hæmatite; and still the fibre is as distinct as it was in the living tree. 
"My friend, Dr. Mantell, has presented very interesting and instructive views of petrifaction in his 'Wonders of Geology;' to which excellent work I beg leave to refer you to supply the deficiencies of this hasty letter. You will observe that he mentions instances of the petrifaction of soft animal and vegetable tissues. Should it be objected to the theory which I have suggested, that an incipient petrifying coat would invest the substance externally, and defend it from further impregnation, it should be remembered that fluids easily permeate all vascular carities and cellular tissies to the very centre, and carry with them whatever they hold in solution.

"In the living tree cut down, and the amputated end of its trunk instantly immersed in a colored fluid, the extreme twigs and leaves soon show that every part has been penetrated. The vegetables of the coal-formation and the lignite of the tertiary are not included in the view above presented, as they are not petrified, but are merely altered vegetable matter.

"Col. Wailes, of Washington, near Natchez, has succeeded in bringing back fossil Mas- todon bones to a firm and persistent state, simply by immersing them in a strong solution of glue; thus restoring the gelatine which the waters and time had taken away. At his house I have seen his specimens, now beautifully preserved: they were found there near the Mississippi. Now, had there been mineralized matter present to make its way in, as the gelatine went out, then these bones would have been mineralized; and such are the Mastodon bones of Ava, on the Irriwaddy. I have one which is heavy with iron.

"The phosphate of lime of bones, being already mineral matter, becomes petrified when the animal matter is removed, and inorganic material substituted. Still, it is possible that the phosphate of lime may itself be removed, as we do sometimes find bones silicified which would require either the removal of the bony matter, and the substitution of silex, or the combination of the latter with it.

"Your Mastodon skeleton is not in the least mineralized, but appears to retain its gelatine, which accounts for its firmness.

$$
\text { "Yours very respectfully, }
$$

"DR. J. C. W ARREV."

"B. SILLIMAN. 


\section{G. - PAge 155 .}

"The whole period during which the Mississippi has transported its earthy burthen to the ocean, though perhaps far exceeding a hundred thousand years, must be insignificant in a geological point of view, since the bluffs or cliffs bounding the great valley (and therefore older in date), and which are from fifty to two hundred and fifty feet in perpendicular height, consist in a great part of loam, containing land; fluviatile, and lacustrine shells of species still inhabiting the same country. These fossil shells, occurring in a deposit resembling the loess of the Rhine, are associated with the bones of the mastodon, elephant, tapir, mylodon, and other megatheroid animals; also a species of horse, ox, and other mammalia, most of them of extinct species. The loam rests, at Vicksburg and other places, on eocene or lower tertiary strata, which, in their turn, repose on cretaceous rocks. A section from Vicksburg to Darien, through the States of Mississippi, Alabama, and Georgia, exhibits this superposition, as well as that of the cretaceous strata, on carboniferous rocks at Tuscaloosa. Sir Charles Lyell ascertained, that the buge fossil cetacean, named Zeuglodon by Owen, is confined to the eocene deposits. In the cretaceous strata, the remains of the Mososaurus and other reptiles occur without any cetacea. The coal-fields of Alabama were next alluded to, from which fossil plants have been procured by Professor Brumby and Sir C. Lyell, of the genera Sphenopteris, Neuropteris, Calamites, Lepidodendron, Sigillaria, Stigmaria, and others, most of them identical in species, as determined by Mr. Charles Bunbury, with fossils of Northumberland. This fact is the more worthy of notice, because the coal of Tuscaloosa, situated in latitude $33^{\circ} 10^{\prime}$ north, is further south than any region in which this ancient fossil flora had previously been studied, whether in Europe or North America; and it affords, therefore, a new proof of the wide extension of a uniform flora in the carboniferous epoch. Sir Charles, adverting to the opinion recently adopted by several able botanists, that the climate of the coal period was remarkable for its moisture, equability, and freedom from cold, rather than the intensity of its tropical heat, stated that this conclusion, as well as the oscillations of temperature implied by the glacial period, is confirmatory of the theory first advanced by him in 1830, to explain the ancient geological changes of climate by geographical revolutions in the position of land and sea.

"The lapse of ages, implied by the distinctness of the fossils of the eocene, cretaceous, carboniferous, and other strata, is such, that, were we to endeavor to give an idea of it, we must estimate its duration, not by years, as in the case of the delta, but by such units as would be constituted by the interval between the beginning of the delta and our own times." - Report of the British Association, \&.c., for 1816; Appendix, p. 118. 


\section{H. - PAGE 157.}

SPECTFICATION OF THE SHELLS CONTATNED IN THE MARL IN WHTCH THE NEWBURGH SKELETON WAS FOUND, BY DR. A. A. GOULD.

"Limnea Galbana, say, Jour. Acad. Nat. Scien. V. 123; Haldeman, Monog. of Limniades, p. 51, pl. 13, f. 22, 23 - allied to L. humulis, say. "All the specimens known occur in a superficial deposit on the margins of a pond in Western New Jersey; and I believe the species to be extinct, with perhaps one or two others from the same locality, which will bring this deposit within the tertiary period of geologists.' - Haldeman.

"Planorbis parvis, say, Nicholson's Encycl. Amer. ed. pl. 1, f. 5; Gould, Inverteb. of Massachusetts, p. 209, f. 139; Haldeman, Monog. of Limn. p. 27, pl. 4, figs. 19-23.

"Talvata tricarinata, say, in Jour. Acad. Nat. Scien. I.; Gould, Inverteb. of Mass. p. 225, f. 156; Haldeman, Monog. of Limn. pl. 1, f. 1-4. Cyclostoma tricarinata, say, Nicholson's Encycl.

"Amnicola Galbana, Haldeman, Monog. of Limn. p. 15, pl. 1, f. 9. "Occurs fossil in the fresh-water newest tertiary deposit in Sussex County, N. Jersey.' - Haldeman.

"Cyclas Galbana, Gould, a small, inequilateral, inflated, obliquely oval species, with tumid beaks, and well-developed lateral teeth; about the size of a millet-seed; allied to Cyclas Dubia, say, and perhaps identical, but certainly as much entitled to a distinct name as Limnea Galbana, or Aimnicola Galbana.

"My own conviction is, that all the above-mentioned shells are identical with the recent species to which they are said to be allied."

\section{MICROSCOPIC EXAMINATION OF THE MARL, BY. DR. JOHN BACON, JUN.}

"The marl was prepared for the microscope by removing the large proportion of calcareous matter by hydrochloric acid, and subsequent washing. It was ascertained by comparative trials, that no organized bodies were removed in this way, except the calcareous shells and their fragments, while the remaining subtances were brought into a much better state for examination. 
The matter undissolved by the acid was diffused in water, or Canada balsam, on slips of glass, and covered by thin glass or mica. When subjected to the microscope, it was found to consist mainly of fragments of plants, too much disintegrated for determination.

"Among these fragments there occur various bodies of some interest, especially the siliceous" shells of several fresh-water species of infusoria, belonging the family Bacillaria. These are not abundant, forming but a small portion of the marl, which also contains quartzose sand. The species are not distinguishable from those which occur in the siliceous deposits now forming in our bogs, except that some of the predominant forms of the recent deposits are rare in this. specimen.

"In the figurễs accompanying this paper (vide Plate XV.) are represented the forms observed. They were drawn by the aid of the camera lncida eye-piece attached to one of Chevalier's horizonto-vertical microscopes. The figures are enlarged two hundred and sixty-eight diameters, and are all drawn to one scale, indicated by Fig. 19, which represent $\frac{10}{100}$ of a millimètre magnified equally with the sketches. Many of the infusoria exhibit entirely different appearances when their ventral or lateral faces are presented to view. These two positions are given in the figures; the letter $a$ indicating in each the ventral face, and the letter $b$ the lateral one. Those species which have but little thickness in proportion to their breadth, rarely present their lateral faces to view, except when turned on the side by means of the compressorium.

"The forms of most frequent occurrence are those represented in Figs. 1, 3, 4, and 10. Fig. 1 is a species of Eunotia, not distinguishable from the living $\mathrm{E}$. Westermanni. There are seven of the internal transverse cells in a length of $\frac{1}{50}$ of a millimètre. Of Fig.4 only an outline sketch is given in the position " $b$, no specimen being found with its lateral faces sufficiently entire to afford the details. This species has from five to eight transverse striæ in $\frac{1}{100}$ of a millimètre. Fig. 6 is a species of Cocconema, with eight striæ in $\frac{1}{100}$ of a millimètre. Fig. 8 is a species of Gallionella, nearly allied to, if not identical with, G. varians. The form represented in Fig. 11 belongs to the genus Gomphonema, and is perhaps G. acuminatum. The species represented in Fig. 10 is often connected by the lateral faces in short chains composed of two, three, or more. At $b$ are represented two individuals thus connected. The form given in Fig. 1 often presents two individuals united in the same manner. The species of Cocconema, Gomphonema, and various other genera, are attached to a pedicel in the living state. This character is lost in the fossil specimens, and it often becomes difficult to determine the genus; some of the forms, which in the living state are free, bearing a very close resemblance in other respects to the pedicelled species.

"A few specimens occur of the forms represented in Figs. 2 and 5. Fig. 5 cannot be" distinguished from Pinnularia (Navicula) viridis. It has six striæ in $\frac{1}{100}$ of a millimètre. Pinnularia viridis, Eunotia Westermanni, and Stauroneis Baileyei, are among the most abundant 
forms now living in our bogs, and constitute a large portion of the recent fresh-water deposits of infusorial shells.

"With the infusorial shells are found considerable numbers of Spongiolites, the siliceous spiculæ of fresh-wwater sponges. Several forms of these bodies are represented in the figures from 14 to 18 inclusive. They are cylindrical, generally tapering at both ends, and traversed by a central canal. Some present a smooth exterior, others are covered with numerous protuberances which are themselves hollow; such is the case in Fig. 18. Sometimes the central canal is very narrow, appearing like a mere line, as in Fig. 14; in others it is very wide, as in Fig. 15. These bodies are common in the recent infusorial deposits.

"In Fig. 9, $a$ and $b$ represent two positions of a minute spherical body, having a short neck. These appear to be hollow, and are present in considerable numbers. Similar forms occur abundantly in the recent deposits of our bogs; but their nature is unknown.

"In Figs. 12 and 13 are given outline sketches of two Pollen granules. These are of frequent occurrence in the marl, and have the characters of the pollen of the Coniferæ.

"Professor Bailey has given, in a paper on Infusoria (Silliman's Journal, vol. xlviii. p. 239), the results of a microscopic examination of the marl from Scotchtown, Orange County, N. Y., in which was found a fine head of the Mastodon [the Shawangunk Head. $-E d$.]. He states that the marl contains numerous fresh-water shells of recent species, among which are several common species of Planorbis, Cyclas, and Limnea; some still retaining the epidermis.

"He prepared the marl for the microscope by the same process which occurred to me, and detected several species of siliceous-shelled infusoria, among which he names some of those found in the present specimen. Besides these, he mentions at single membranaceous species (Closterium Crenulatum), Spongiolites Lacustris, pollen of pine, stellate hairs of Platanus (?), and seed-vessels of Nitella or Chara.

"He says, "These results are interesting, as they prove, first, that siliceous infusoria, identical with those now living, were contemporaneous with the Mastodon; second, that not only siliceous but membranaceous infusoria, hairs of plants, \&c., may be preserved for ages in calcareous marls, where they mąy be detected after the calcareous matter is dissolved by acids.'

"I have not attempted to name definitely the species of infusoria detected in the marl, as the present state of microscopic science does not allow of a settlement of the question with regard to the identity of living species with those of any past geological periad." 


\section{I. - Page 162.}

\section{SKULL OF AN EXTINCT BEAVER FOUND IN A DEPOSTT CORRESPONDTNG WITH} THAT OF THE MASTODON GIGANTEUS.

A very interesting head of an ancient extinct Beaver of large size was discovered in Clyde, New York. The situation and condition of this specimen correspond nearly, though not exactly, with those of our northern.Mastodon; and, as the deposits are very distinctly and scientifically. described, we shall state them in the words of the able geologist, James Hall, Esq.:-

"The situation in which it was found is an elevated platean, or level tract of land, a portion only of which would be denominated a sivamp, though the whole surface is covered with a peaty soil, which supports a heavy growth of elm, hemlock, and ash, with some maple and beach. This elevated' ground is the summit-level, from which the waters flow, in opposite directions, into Lake Ontario on the north, and into the Clyde River, and thence into the Cayuga and Seneca Lake outlets on the south. The precise locality of the fossil was near the termination of a shallow ravine, or the bed of a small stream, which flows into Lake Ontario in a northeasterly direction.

"The extent of this level tract is about five or six miles; while its width, in most parts, is much less. Along nearly its entire length, a canal of eight or ten feet deep has been excavated; and in this excavation, about eight feet below the surface, the skull was found, the lower jaw separated some little distance from the cranium.

"A section at this place, and at numerous others near the same spot, presents the following characters :-

"1. Muck, or vegetable soil, supporting a heavy growth of timber, two feet or more in thickness.

“2. Fine sand, with occasional thin bands of clay, often consisting of alternating layers of sand, twigs, leaves, and other fragments of vegetable matter, and much blackened thereby; two to three feet thick.

“ 3. Muck, or peaty soil, composed of decayed fragments of wood, bark, leaves, \&c., enclosing trunks of trees of large size, about four feet thick.

$$
\text { "SKULL OF CASTOROIDES OHIOENSIS. }
$$

"4. Fine sand, with shells of Planorbis, Valvata, Cyclas, \&c.; one to two or three feet thick. 
"5. Ancient drift, with northern bowlders, and fragments of the sandstones and limestones, which oceur in place a few miles further north; depth unknown.

"The thickness of 2,3 , and 4 , is variable, though the bottom of No. 3 usually varies little from the depth of eight feet from the surface. A glance at the section reveals the true period of - the deposit, showing conclusively that the whole is a lacustrine formation, made subsequent to the deposition of the ancient drift (No. 5), which is characterized by its foreign materials, while in the latter deposit not a pebble of the size of a pea can be found."

Dr. Wyman examined this skull, and gave a scientific description of it, which was published, in connection with that of Mr. Hall, in the "Jourual of Natural History." The bone was in perfect preservation, though not petrified, and belonged to an unknown species, which must have been of great antiquity. 


\section{POMEL'S VIEWS OF THE SPECIES.}

IN page 142 we have referred to the opinions of M. Pomel; his name in that place, owing to a peculiarity in the writing of the manuscript from which it was copied, being erroneously spelt Pamel. This excellent palæontologist, in a communication to the French Geological Society of March 20, 1848, says: "Taking into view the discovery of many extinct genera, we see plainly that the pachydermata and ruminantia of the existing fauna do not admit of separation." He therefore divides the ungulated mammalia into four great families, viz. the Proboscidians, the Perissodactyles, the Artiodactyles, and the Ruminants.

1st. The Proboscidians include the genera Elepbant, Mastodon. - Dinotherium.

2d. The Perissodactyles include the genera Daman, Acerotherium and Rhinoceros, Elasmotherium. - Hippotherium, Horse. — Paloplotherium, Plagiolophus, Anchitherium, Pălæotherium, Macrauchenia. - Tapirs, Coryphodon, Lophiodon, Hyracotherium. - Adapis, Microchœrus.

3d. The Artiodactyles comprise the genera Elotherium, Hippopotamus, with its sub-genus Hexaprotodon, the Phacochœrus, Sus, Babirussa, Pecari, Palæochœrus (Hippohyus ?).- - Chæropotamus, Anthracotherium, Ancodas, Syṇaphodus (Anthracoth-gergovianum).- Chalicotherium (or Anisodon), Anoplotherium, Xiphodon, Dichobunis, Cainotherium. - Dichodon, Merycopotamus, Chæromeryx.

14th. The Ruminants. Genera not enumerated.

It will be seen that M. Pomel, like M. De Blainville and some others, unites the Mastodon genus with that of the Elephant. He is of opinion that the Mastodon of Western Europe may be distinguished into five species:-

1st. M. Angustidens, the name originally given by Cuvier, is limited by M. Pomel to the Italian species, with four ridges in the three penultimate molars, but no beak.

2d. M. Longirostris, distinguished, as already stated in our text, by four ridges in the three penultimate molars, and a prolonged lower jaw, containing two incisor teeth, or inferior tusks.

- 3d. M. Cuvieri, from Gers and Orleans, possessing three ridges in the three penultimate molars, and a prolonged lower jaw.

4th. M. Tapiroides, a species with tapiroid teeth, said by him to accompany the preceding species, but we think not generally admitted.

5th. M. Buffonis, a species constituted by M. Pomel from specimens characterized by short, thick teeth. Tq this species he refers the Siberian teeth. 
As to the geological position, he states that the M. Angustidens and M. Buffonis are found together in pliocene; the M. Cuvieri and M. Tapiroides, in miocene deposits of a lacustrine nature.

To these geological statements the distinguished philosopher, M. Elie De Beaumont, expresses his assent.

"In America," M. Pomel says, "the Mastodon deposits are diluvial, and agree in position with the Elephas Primigenius," as already noticed at the place referred to in the text. He also says, that, while the Elephant is of the Primigenius species exclusively, the Mastodons are of various species. This is in part strictly true; but it must be understood that all the Mastodon relics found in the north, from the Isthmus of Darien to $65^{\circ}$ north latitude, belong to the M. Giganteus alone, - making an exception of the Baltimore tooth, if that should prove to be American. Remains are found in the Isthmus, and in South America; but whether of one or more species, is not yet settled. 


\section{THE DUSINA MASTODON.}

The scientific world will be gratified to learn, that the want of a skeleton of the Mastodon Angustidens has been partially supplied by the discovery of a large number of its bones in Piedmont, in Italy. From a work published at Turin, 1851, entitled "Osteografia di un Mastodonte Angustidente, illustrato dal Professore Eugenio Sismonda," we learn that the discovery took place in the following manner.

Discovery. - In the latter part of September, 1849, the laborers on the railroad between Dusina and Villa Franca, not far from Turin, came upon some fossil remains. The directors of the railroad, being forewarned of the probability of similar discoveries, sent word, through the superintendent-general of railroads, Chevalier Bona, to the directors of the Mineralogical Museum at Turin. They entrusted the delicate work of exhumation to Sig. Francis Comba, curator of the Zoological Museum, whose persevering industry and great personal attention in its removal to Turin are worthy of the highest praise. Four months more were devoted by him to the labor of restoration, in the way of cleansing, drying, and repairing the fragments by an aqueo-alcoholic solution of isinglass.

The name of the village in which this discovery was made was Solbrito. The remains were situated in a fluvio-lacustrine deposit, at the depth of about twenty-six feet from the surface, in company with other pachydermatous remains, and some invertebrated terrestrial fossils. They rested upon a layer of nearly plastic clay, covered by other layers of sand and gravel. Consequently, the water, after penetrating the superimposed layers, could not soak through the clay, and therefore hastened the destruction of the skeleton; rendering very difficult the extraction of even some of the most resisting parts, such as the tusks, femora, humeri, \&c.

The fossil shells found in comnection with this Mastodon were the Unio, closely allied to the Unio pictorum, LaM。; the Helix, if not the type, at least a variety, of the Helix lactea, MurL。 the Paludina, not specifically different from the Paludina lenta, Brander; and the Clausilia, a solitary specimen, and apparently a distinct species. At a short distance from the skeleton were found teeth of the elephant, horns of the cervus, the mandible of a rhinoceros, and, in the more superficial argillo-calcareous layers, the head of a marmot. In the same deposit, but more towards Ferrara, in company with Mastodon molars and a magnificent tusk, were found teeth of the Hippopotamus and Tapir. 
"In Piedmont the pachydermatous deposit occupies a zone limited by the right bank of the Po; the sub-appenine sands, so called, on the left bank of this river, are either naked or covered with beds of rolled flint, not channeled, collected by the waters from the melting of the alpine snows, - in a word, from the non-fossiliferous alpine diluvial deposit."

SKELETon. - We have thought it might be interesting to palæontologists in this country to have the means of forming some notions of the character of the skeleton. These we have endeavored to furnish as well as time would permit; but, of necessity, in a very limited degree. In fact we do not feel authorized to give more than an account of some of the measurements of the different bones, which are particularly and scientifically described by Professor Sismonda. We have therefore, to some extent, translated, and converted into English measures, the labors of the author; assuring, at the same time, those who feel an interest in the subject, that they will be much gratified in studying the researches, and examining the beautiful plates, of Professor Sismonda.

HEAD. - The present specimen is more complete in this respect than any known, except that of M. Lartet at Sansans, Department of Gers.

Occipital Vertebra.* - The best preserved part of the cranium is a large portion of the right occipito-temporal, which exhibits the condyle of the right side, the posterior foramen lacerum, the glenoid cavity, and the posterior zygomatic extremity. Length of the right occipital condyle . . . . . . . . . . . 4.3 Width of the right occipital condyle . . . . . . . . . . . 2.7 Cord of the glenoid fossa transversely . . . . . . . . . . 5.9

\section{Spheno-Parietal Vertebra. -}

A fragment only remains of the upper portion of the right parietal, in length $\quad . \quad$. $\quad . \quad 27.9$

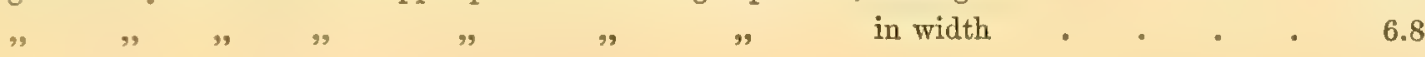

Stperior MLixilla. - The whole of the horizontal portion of the upper, and the entire lower jaw are in our possession.

MaXiLlaA. -

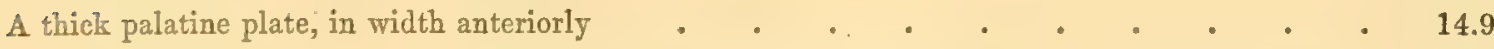

" " $" \quad$ " at the anterior margin of the molars . . . . . . . 11.4 Antero-posterior length . . . . . . . . . . . . . . . . . 20.5

* Professor Sismonda has employed the anatomical terms of the "homological system" in his description of the bones of the head.

Assenting, as we do, to the beauty and convenience of this system, we came, after much consideration, to the conclusion that in the present state of the reform the received appellations would be more generally understood than those proposed, and therefore adopted them in our own text. - Authon's Notr. 
At the anterior extremity of the left lateral margin is preserved the inferior part of the alveolus of the tusk of this side, with many fragments of its root. That of the right side is in a worse state of preservation, and presents no trace of the corresponding tusk-alveolus. Those of the molars are perfect on each side, and have the teeth implanted. The entire upper portion of the head is wanting. Taken as a whole, the palate is peculiar in its prolongation anteriorly; for, notwithstanding its incompleteness and the almost entire absence of intermaxillary bones, it attains -

The length anterior to the molars of The width between the two molars is only . . . . . . . . . . . . 4.3

Mandible. - It is very fine and massive, owing to the short and thick horizontal branches.

The length of the diagonal from the posterior maxillary angle to the symphysis at the beak is $\quad 26.7$

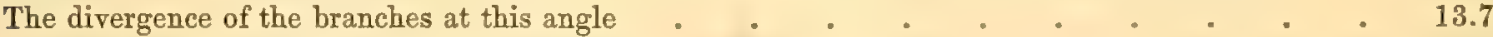

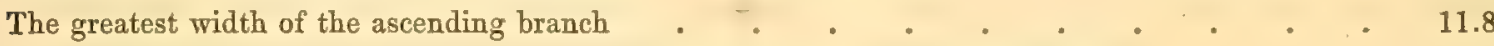

And its angle of junction with the horizontal branch is nearly a rectangle.

Length of the horizontal branch . . . . . . . . . . . 15.7 Length of the vertical branch . . . . . . . . . . . . . . . 16.1

The angle of junction at the symphysis is $65^{\circ}$; presenting no sign of suture, but forming a sort of short beak, obliquely cut off from above downwards, with margins rounded and turned outwards, "not unlike the mouth of a decanter." The masseteric depression, on the outer side of the ascending branch, below the sigmoid cavity, Professor Sismonda has not found so large and deep in the skeletons of the Indian Elephant as in this Mastodon.

Maxillary Tusks. - These are the finest ornaments of the fossil; and, thanks to the care bestowed in the exhumation and preservation, the right is entire.

The length, measuring according to the curve, is _ . . . . . . . . 102.4

The curvature of the tusk is from above downwards, from below upwards, and from without inwards. From their length Professor Sismonda pronounces the animal a male.

Mandibular Tusks. - The inferior tusks had fallen before the animal's decease, so that the mandibular symphysis presents no trace of alveoli; which is not to be wondered at when we consider the great age of the animal.

Molar Teeth. - "Those of the upper jaw with a. rectangular crown, rather smaller at the posterior extremity, which turns towards the fauces, are in length 6.7 , and formed of four very distinct ridges, each constituted by two large marginal tubercles, with some small intervening tubercles on the median line, and a posterior talon, which, seen from behind, almost rivals a fifth ridge. The mandibular or lower molars, somewhat larger than the upper, in length 7.5, of an irregular parallelogram form, larger in front than posteriorly, slightly concave on the external 
margin, and convex on the internal, present five very distinct ridges, composed as usual of a double series of large tubercles, in the midst of which rise others smaller, besides a large talon, which serves as a counterpoise to the last or fifth ridge." A rigorous application of the principles of Blainville induces Professor Sismonda to declare that the Dusina Mastodon has two sorts of molars ; referring to the two penultimate or fifth, those in the upper jaw, and to the two ultimate or sixth, those in the mandible.*

Vertebral Column. Cervical Vertebra. - In a note it is said: "A new species of elephant has recently been introduced to scientific men (Elephas Sumatranus, Teмn.), intermediate between the Indian and African. This new species, the original of which is in the Museum at Leyden, is characterized by fourteen pairs of false ribs; that is, one pair less than the African, and one pair more than the Indian Elephant. It has, moreover, twenty dorsal vertebræ, instead of nineteen as in the African, or twenty-one as in the Indian; while it possesses four sacral vertebræ as in the former, and thirty-four coccygeal as in the latter. When chance shall have revealed to naturalists a Mastodon skeleton really complete, and shall thus have put them in a situation to determine the precise number of vertebræ and ribs naturally belonging to it, then it may be known to which of the three existing species of Elephant the Mastodon had the greatest analogy." $\uparrow$

The vertebræ are not all in the best state of preservation, but sufficiently so to determine the series, and even their respective order in that series. Among the cervical are recognized the third, sixth, and seventh or last; all more or less fragmentary, and peculiar in the delicacy of the body; thus proving the neck of the Mastodon to have been short, as in the existing elephants.

Inches.

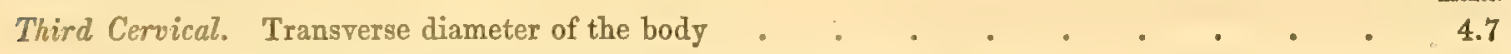

Transverse diameter of formen for vertebral artery . $\quad . \quad . \quad . \quad: 0.7$

Sixth Cervical. Vertical diameter of the body . . . . . . . . . . . 5.5

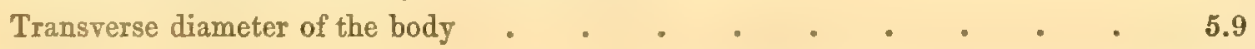

Dorsal Vertebra. - Fourteen are almost entire; and there are several separate spinous processes. Arranged in the natural order are the third, fourth, fifth, sixth, and seventh, with those from the ninth to the nineteenth inclusive. Their resemblance to each other is striking.

The third dorsal is remarkable for the extraordinary length of the spinous process. From

- The numerical position thus assigned the teeth admits of some discussion. From a careful examination of more than twenty jaws of the Mastodon Giganteus in our possession, we do not find a single instance of the solitary existence of a fifth tooth in the upper or lower jaw. It is usually, even when the preceding fourth tooth is in situ, accompanied by a more or less perfectly developed germ of the sixth tooth. - A Uxнов's Note.

+ The question proposed by Professor Sismonda is answered in indisputable form by the skeleton described in this work, all its ribs being perfect, and the twentieth consolidated by a united fracture, on one side, to the nineteenth (Plate XXIII. Figs. 3 and 4), while these two ribs are in their natural and perfect state on the other. - AurHon's NorE. 
the superior angle of the medullary foramen to the apex, it measures 15.5.* It terminates in a thick tubercle, for the support, in common with the other dorsal vertebræ, of the immense cervical ligament. The vertical diameter of the body is 4.7 ; the transverse diameter beneath the transverse processes is 4.3 ; the medullary foramen represents a triangle nearly equilateral, the median height of which is 2.4 , the width at the base 2.5 .

The fourth dorsal vertebra is reduced to the base of the spinqus process and a portion of the annular. The same is true of the fifth. The sixth is in rather a better state of preservation; its peculiar character being the position of the costal articulation, which is an excavation in the body, nearly on a level with the base of the medullary foramen, while in the preceding vertebræ this face is lower down, and in the succeeding more elevated, occupying, so to speak, the base of the annular portion.

The seventh vertebra consists of only a portion of the body, with the left transverse process annexed.

After this, with one exception, probably of the eighth vertebra, comes a consecutive series of eleven, for the most part united together, and forming a group from the ninth to the nineteenth inclusively. On the right side it seems quite perfect; but on the left there is a wide break from the ninth to the fifteenth, involving the transverse processes, and in some places the plate of the annular portion, thus exposing the medullary canal. At the sixteenth and seventeenth, the articular process becomes rudimental, subsequently increasing in size to equal the transverse.

The cavities for the articulation of the ribs result from the union of two demi-fossettes from the ninth to the fourteenth vertebra; the five following have each an entire fossette at the base of the annular portion, with a tendency to the centre of the plate, which is attained in the nineteenth.

Lumbar Vertebra. - Some authors allow only three vertebræ in this region : if it be so, the skeleton is complete in this respect. The body is not so thick as in the dorsal vertebræ, but the transverse diameter is greater.

The transverse diameter of the second is .

The sacral and coccygeal vertebræ are wanting.

RIBS. - Twenty-six discovered, and divided as follows:-

PIGHT SIDE.

1. The only one entire, length . . . . . . . . . . . . . . . . . . .

Width at the base . . . . . . . . . . 4.7

3. Wants only the vertebral extremity; the fragment measures . . . . . . 20.8

* This spinous process being the longest, its dimensions may be conveniently employed to give an idea of the magnitude of the Dusina Mastodon Angustidens and the North American Mastodon Giganteus. On referring to the latter, the length of the spinous process of the third dorsal rertebra is found to be twenty-three inches and a half. - AvTHor's Nore. 
4. The sternal half only remains, in length

5. About the same portion, length .

6. Only the inferior portion, length .

8. More than the superior half, including the head, length

9. A fragment with the head.

10. In three pieces; united they form an are, the cord of which measures

11. Only wants inferior extremity unbroken, length

11. Only wants inferior extremity unbroken, length • • • • • • • • • • 31.5

12. Very fine; a very small bit gone from the inferior part, length . . . . . . . . 36.2

13. In three pieces; wants the head; much injured inferiorly, length . . . . . . . 28.3

14. Without head; is a supra-median fragment, length . . . . . . . . 15.3

15. A flat fragment, with traces of the head . . . . . . . . . . 11.0

LEFT SIDE.

1. Wants the entire middle. From the dimensions of the head and base, thought to be broader than on the other side.

3. Intermediate portions .

4. Intermediate portions .

5. Wants the extremities

6. An inferior terminal portion

7. An inferior terminal portio

10. Wants the head and inferior extremity; the remainder forms an arc, the cord of which is

11. The most complete of this side, wanting only the head; cord of its arc

13. The head is decayed . . . . . . . . . . . . . . . 40.1

14. An inferior portion . . . . . . . . . . . . . . . . . . . . . . 16.9

15. An inferior portion . . . . . . . . . . . . . . . . . 18.1

16. An inferior portion . . . . . . . . . . . . . . . . . . 23.6

Sternum. - The most interesting portion of the skeleton. It consists of five distinct bones (sternebræ), which diminish in length from the first to the last, and increase in thickness in nearly the same proportion.

First Sternebra. - The most perfect of the five: it presents the length of 10.6 , by a width of 6.3 ; in comparison with these measurements, its depth cannot be said to be great.*

Second Sternebra. - It is of an imegular rectangular figure, -

In length

In width.

Thickness of the anterior margin

The body of this bone is rather thinner in the middle than the first, and the form of the keel more distinct on its inferior margin, with irregular depressions on the lateral margins for the cartilages of the second and third ribs.

- Like that of the Mastodon Gigantens, it may be likened in form to the ploughshare, and corresponds in description to that given on page 30. But the sternum, as a whole, is more perfect. - A tтrнor's NotE. 
Third Sternebra. - This closely resembles the second, except in having a more blunt superior margin, and the inferior not so distinctly keeled. Its dimensions are -

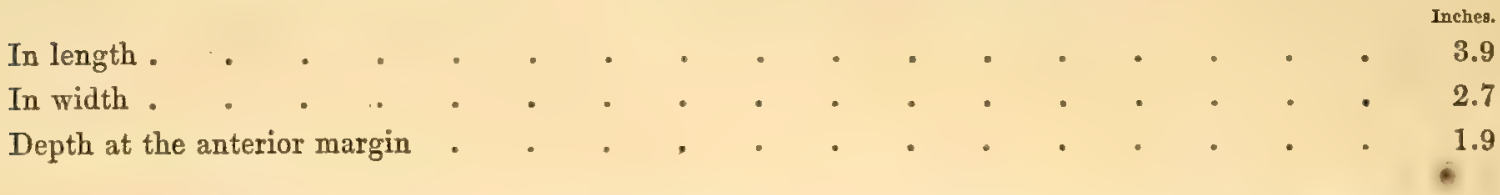

The fourth and fifth sternebra are in such a state of decay, that their true figures cannot be with certainty defined.

\section{ANTERIOR EXTREMITIES.}

SCaPUla, - A magnificent portion of the right remains, -

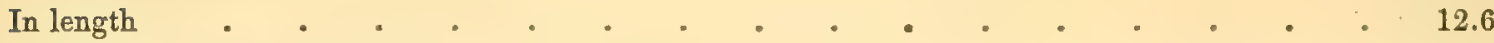

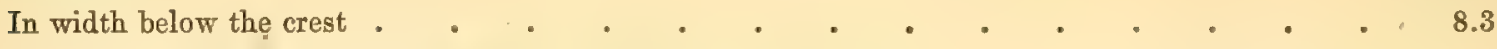

The antero-posterior diameter of the glenoid cavity measures about . . . . . . 7.5

The transverse diameter of the gfenoid cavity measures about . . . . . . 3.9

The acromion process only of the left is preserved, in length 11.4 , and in width at the base about 5.9; dimensions which, taken in connection with others of the right scapula, show the uncommon size of these bones in the Mastodon.

Humerus. - These bones display the same extraordinary proportions. The right humerus is as fresh as if from a recent animal. It measures from the top of the external tuberosity to the condyle, 31.5; antero-posterior extension of the external tuberosity, 9.4; transverse width at the origin of the condyloid crest, 10.2 ; elevation of the external fuberosity above the articulating head, 1.6.

The left humerus wants the lower extremity, with the exception of the anterior portion of the internal condyle.

UlNa. - The fore-arm constitutes a bony mass, about 3.5 shorter than the humerus. In very good condition are both the ulnæ, the entire left radius, and a portion of the right. 'The inferior articulation with the radius, 1.9. From the point of the olecranon to the margin of the inferior articulating surface of the ulna, 27.5.

Radius. -

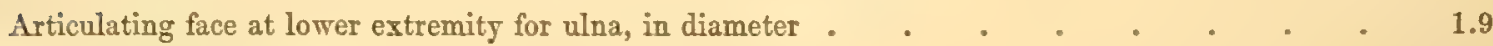

Left radio-carpal surface . . . . . . . . . . . . . . 24.4

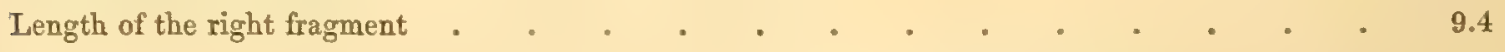

Carpus. - But few of the bones of the carpus remain uninjured; of these are the Pyramidale and Os Magnum, of each side. 
Os Pyramidale. - Transverse diameter, 5.5; greatest antero-posterior diameter, 4.7 ; vertical diameter, 2.3.

Os Mragmm. - Antero-posterior diameter, 3.5; vertical and transverse diameter, 2.7. The remaining five bones, although carpals, are too much injured to admit of a specific description.

Mietacarpals. - Of these we have the second and fourth of the right side.

Length of the second

Width of the second

Length of the fourth metacarpal

Width of the fourth metacarpal

Phalcnges. - These are the first of the index and of the ring finger of the right hand; each about 3.1 long by 2.7 broad. Transversely concave on the face of the metacarpal articulation, rounded on the opposite extremity.

\section{POSTERIOR EXTREMITIES.}

In contrast with the anterior, these are not so clumsy, owing to the delicacy and length of the feraur, as well as of the bones of the legs; for the great weight of the head, tusks, and thorax, required a more massive structure in the former.

Os Innominatum. - In consequence of the destructibility of the pelvic bones, we have to lament the loss of much of the pelvis; the only portions preserved are two large fragments of the right half, i.e. the middle inferior portion of the iliac, and of the ilio-ischiatic bones. The former piece, in length 13.4, contributed to form the great iliac fossa; the latter, in length 16.9, încludes in it the entire cotyloid cavity. This cavity is very large, its transverse diameter being 5.5 , the depth very slight in proportion, of a quadro-circular figure, limited by a periphery with a sharp, cutting margin, which is interrupted inferiorly by a canal soon lost in a fossa excavated at the base of this cotyloid cavity.

Femur. - The description is chiefly drawn from the left, which is in a rare state of preservation.

A diagonal from the head to the external condyle measures 37.0. Width of the neck from its internal margin to the extremity of the great trochanter, 9.4. Width of the tibial extremity between the two tuberosities, 9.1.

The head is constituted by an hemispherical eminence with smooth superficies, destitute of any sort of foramen for the round ligament.

The right femur is reduced to a piece 23.6 long, and consists of the upper half of the bone, in a fragmentary condition.

Tibia. - In the legs this skeleton has suffered the most injury. In fact, only a portion of the tibia, about 21.3 in length, and the fibula of the left side, remain. 
Fibula. - This bone is in rather better condition than the last, wanting only a small portion of its upper extremity. The width at the middle of the body, 2.5; the length of this particular specimen, minus a portion of its upper extremity, $\mathbf{1 8 . 5}$.

The lower extremity has three articulating surfaces: one for the external point of the inferior extremity of the tibia; a second for the articulation of the astragalus; a third for that of the os calcis.

Tarsus. - Only one bone of the tarsus has been lost, - the last cuneiform, or that of the thumb. They all belong to the left foot, as well as the metatarsals and phalanges. The loss of the right foot must be attributed to the same unknown cause which destroyed the leg, and injured the femur of that side.

Astragalus. - Thick and robust, it measures, in the transverse diameter, 5.1; antero-posteriorly, 4.3 ; the height of the internal side, 3.1.

Calcaneum. - Of all the bones of the tarsus, the most voluminous and irregular. Including the heel, it measures 7.5 in length, by 5.9 in width at the anterior part of the body.

Scaphoid. - This bone is rather an oval plane; its transverse diameter, 4.3 ; the vertical diameter, 0.3 ; antero-posterior diameter, 0.1 .

Cuboid. - In no respect deserving the name, its figure being very far from cubic. Distance between the two anterior angles or length, 3.9 ; greatest height, i.e., on interior side, 1.8.

Cuneiforms. - Only the second and third remain entire.

SECOND, THIRD, AND FOURTH METATARSALS.

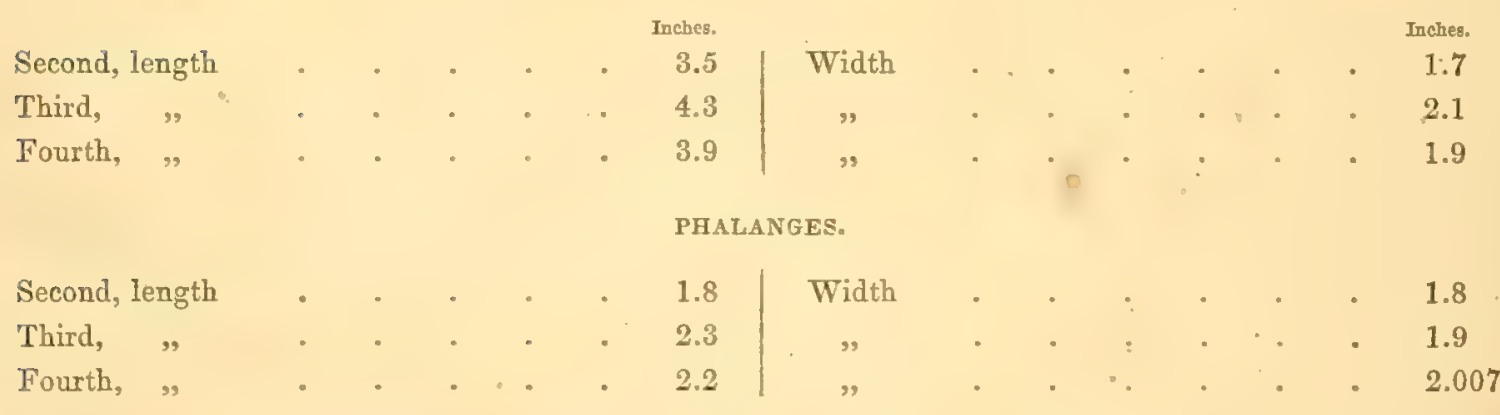

Patella. - Greatest diameter, 5.5 ; transverse diameter, 4.7. 


\section{E A S R E S,}

THE METRE BEING AT $32^{\circ}$, AND THE FOOT AT $62^{\circ}$.

The inch is between two and three centimetres, as appears from the following table:

\begin{tabular}{|c|c|c|c|c|c|c|c|c|c|c|c|c|c|c|}
\hline & & & & & & & & English Inches. & & & & Tarde. & Feet. & Incles. \\
\hline Millimetre & . & . & . & • & - & . & . & 0.03937 & - & & & & & \\
\hline Centimetre & & - & . & - & • & • & • & 0.39371 & - & • & 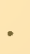 & & & \\
\hline Decimetre & c. & - & - & - & - & • & ${ }^{\circ}$ & 3.93710 & - & • & - & & & \\
\hline Meter & 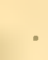 & - & . & - & $\bullet$ & - & - & 39.37100 & • & • & " & 1 & 0 & 3.371 \\
\hline Decametre & . & . & . & 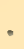 & • & - & . & 393.71000 & . & - & • & 10 & 2 & 9.710 \\
\hline
\end{tabular}




\section{A U T H 0 R I T I E S.}

1806. Ashe, T. Liverpool. Memoirs of Mammoth and other Extraordinary and Stupendous Bones.

1843. Annals of Natural History, vol. xii. p. 125.

". Agassiz and Gould. Principles of Zoology.

" Barton. Rhinoceros, Medical and Physical Journal, vol. ii. pp. 1, 158.

" Buckland, Rev. William. Bridgewater Treatise on Geology and Mineralogy, vol. i. p. 135.

1845. Boston Society of Natural History, Proceedings of.

1765. Buffon. Histoire Naturelle de, p. 86.

1778. " Article Supplementaire dans ses Epoques de la Nature.

" Bossu. Medical and Physical Journal, vol. i. p. 179.

1787. Camper, P. Nov. Acta. Academ. Scient. Imp. Petrop.

1777. " " " $" \quad " \quad$ " tom. i. cal. 2, pp. 219, 258.

1803. Camper A. Description of a Male Elephant.

" Conrad, F. A. On the Fossils of the Medial Tertiary of the United States.

"Collinson. American Museum, vol. v. p. 155; vol. viii. p. 284.

" Croizet and Jobert.

" Charlesworth.

1824. Cooper, S.; De Kay; Van Rensselaer. Account of the Discovery of a Skeleton of the Mastodon Giganteus. Extracted from a Report made to the Lyceum of New York. Annals of the Lyceum, vol. i. p. 143.

1798. Cuvier, G. Extrait d'un Memoire sur les Quadrupèdes Fossiles.

1801. " " " Ourrage sur les Esp. de Quadrupèdes Fossiles.

1806. " Annals of the Museum. 
1821, 1825. Cuvier, G. Recherches sui les Ossemens Fossiles.

1740. De Longueil.

1769. Daubenton. Actes de l'Académie des Sciences.

1765. $" \quad$ Histoire Naturelle de Buffon, Nos. 998, 1035.

1503. Domeier, Dr. Essay on the Mastodon of Ohio. Nouv. écrits des Amis des Sciences Nat. de Berlin, IV.p. 79.

. Ducrotay, H. M. De Blainville. Osteographie, \&c. p. 300, \&c.

". De Meyer, Hermann. Fossil Remains of the Grand Duchy of Hesse.

" Dudley. Massachusetts Historical Collection, second series, vol. ii. p. 263.

. Drayton. History of Carolina.

" D'Orbigny, Alcide. Voyage dans l'Amèrique Méridionale pendant les Années 1821 à 1834,4 to, 10 vol.

., De Kay, James E. New York Fauna, vol. i. p. 102.

" Emmons, Professor. American Quarterly Journal of Agriculture and Science.

. Falconer and Cautley. Fauna Antiqua Sivalensis.

1752. Guéttard. Memoires de l"Academie des Sciences, p. 359.

"Gauthier. " " $\quad$ " $\quad$ "

. Graham, Dr. New York Medical Repository, vol. iv. p. 211.

1345. Geological Society of London, Transactions of.

" Hall, James. Survey of the State of New York. "

" Hunter. American Museum, vol. v. p. 152.

1535. Harlan, Dr. Medical and Physical Researches, p. 252. Also, Fauna Americana.

" Jefferson's Notes on Virginia, p. 64. Medical and Physical Journal, vol. i. p. 64.

" Kaup. Fossil Remains of the Ducal Museum of Darmstadt.

" Klipstein and Kaup. Beschreibung und Abildungen von dem colossalen Schedel des Dinotherii Gigantei, \&c.

: Laurillard. Dictionnaire Universel d'Histoire Naturelle.

"Lartet. " $"$ "

. Lyell, Charles. Elements of Geology, pp. 268, 287.

" " $\quad$ Travels in North America, vol. i. and ii.

" Madison. Medical and Physical Journal, vol. ii. p. 58; vol. i. p. 156.

" Miller. New York Medical Repository, vol. iv. p. 308.

1818. Mitchell, Dr. New York Medical Repository, vol. ix. p. 322; vol. xi. p. 318.

"Nichælis. Gottingen Magazine, iv. An. 2, cah. n. 6 de Ossium Mammontei. 1801 to 1809. Medical Repository of New York.

" Mantell's, Dr., Wonders of Geology: Mammoth, vol. i. p. 139. 
1801. Mantell's, Dr., Medals of Creation.

" New York, Survey of the State of.

" Naturalist's Library.

" Pomel, A. Bulletin de la Sociêté Géologique de France, vól. v. p. 2506.

" Owen, R. Odontography.

$" \quad$ " History of British Fossils, Mammals, and Birds.

1802. Peale, R. Annals of the Museum, p. 250.

1803. " Essay on the Mastodon or Mammoth of Ohio; translated into Dutch, with an engraving, by Dr. Bonne. Amsterdam.

1845. Prime, Dr. American Quarterly Journal of Agriculture and Science for October.

" Quarterly Geological Journal.

"Rambles in the Mammoth Cave.

1851. Sismonda, Professore Eugenio. Osteografia di un Mastodonte Angustidente illustrato. Torino.

" Tuomey, M. Survey of the State of South Carolina.

From Siluiman's American Jourinal of Sciences and Arts:-

vor. PAGE.

i. 239. Short Notice of a Mammoth Tooth.

ii. 242. On some Ancient Bones, \&c., with a Notice of the Bones of the Mastodon or Mammoth, and the various Shells found in Ohio, by C. Atwater, Circleville, May 22, 1820.

vi. 199. Notice of Fossil Remains found in Albeville, France,

vi. 386. Skeletons of Mammoth and Elephant, found in Hortes, in Hungary.

x. 325. Article headed "Quadrupeds, Insects; or the Bones of the Animal called the Mammoth, or of any other unknown." - But in this article there is no mention made of the bones of the Mammoth.

x. 199. Proceedings of the New York Lyceum of Natural History, April 19th. - Mr. Cooper communicated a paper "On the Megatherium, recently discovered in Georgia." Inserted page $\mathbf{1 1 4}$ of the Annals.

xi. 246. Notice of a recent Discovery of the Fossil Remains of the Mastodon in New Jersey. By Jeremiah Van Rensselaer, M. D. Read before the New York Literary and Philosophical Society, June, 1824.

xii. 380. On the Fossil Remains of the Mastodon lately found in Ontario County, New York. By J. Van Rensselaer, M. D. March, 182\%. 
TCL. PAGE.

xiv. 31. On the Fossil Tooth of an Elephant found near Lake Erie, and on the Skeleton of a Mastodon lately discovered on the Delaware and Hudson Canal. By J. Van Rensselaer, M. D. Dec. 24, $182 \%$.

xiv. 1S6. Notice of R. Harlan, M. D., on the Examination of the Large Bones disinterred at the Mouth of the Mississippi, and exhibited at Baltimore, Jan. 22, 1828.

xir. 187. Notice of the Teeth of a Mastodon found near Cheshire, in Connecticut, Summer of 1827 .

xir. 1SS. Notice, by Thomas B. Stewart, of a Mammoth found near Schooley's Mountain, N. J., July 20, 1827.

xv. 191. Proceedings of the Lyceum of Natural History, New York. - De Kay read a paper on several Fossils from the Chesapeake and Delaware Canal. See An. Lec. vol. ii.

xv. 400. Plaster Casts of Fossil Bones of the Mastodon. - These specimens have been described in the Geological Transactions. Second Series, vol. ii. part 3.

xvi. 20S. Proceedings of the Lyceum of Natural History of New York.- Dr. Torry stated, that, having treated a portion of a fossil tusk (probably of a Mastodon) with dilute muriatic acid, the animal matter still remained, though somewhat modified.

xvi. 392. Remains of the Mastodon found near Bhering's Straits, at Escholz Bay.

xviii. 139. Notice of the Osseous Remains at Big Bone Lick, Kentucky.

six. 159. Proceedings of the Lyceum of Natural History of New York. - Mr. Cooper read a paper on Two Young Skulls of an Extinct Animal, resembling the Mastodon, found in Kentucky and New York.

vix. 355. Notice of a Mastodon found near Rochester, New York. Extract from a Letter from J. A. Guernsey to the Editor, dated Pittsford, Oct. 26, 1830.

xix. 388. Notice of the Mammoth.

xx. 370. Report of Messrs. Cooper, J. A. Smith, and De Kay, to the Lyceum of Natural History of New York, on a Collection of Bones disinterred at Big Bone Lick, Kentucky, in September, 1830, and recently brought to New York. Read May 30, 1831.

xxrii. 149. Proceedings of the Lyceum of Natural History of New York. Statement of Mr.

Cooper with regard to Bones disinterred at Big Bone Lick, Kentucky.

xxvii. 165. Vertebral Bone of a Mastodon found in the Town of Berlin, Parish of Britain, Connecticut.

xxvii. 166. Account of Fossil Teeth, found near Chautaque Lake, seven miles from Lake Erie, and about sixty miles above Buffalo. Aug. 4, 1834. 
TOI. PAGE.

xrvii. 168. Some Account of the Organic Remains found in the Marl-pits of Lucas Benners,

Esq., in Cravler County, North Carolina. By H. B. Croon, Esq.

xxvii. 251. Proceedings of the Geological Society of Pennsylvania. Fossil Zoology and Comparative Anatomy.

xxxi. 171. Retrospective Notice of the Discovery of Fossil Mastodon Bones in Orange County, New York. From a Letter addressed by S. Miller, Esq., to Hon. De Witt Clinton, in 1815.

xxxi. 339. Proceedings of the British Association, Section C. Geology and Geography in August, 1836.

xxxii. 377. Notice of Fossil Remains of an Elephant found near Rochester, New York, $183 \%$. xxxiii. 201. Bones of a Mammoth found August 19, at Rochester, New York.

xxxv. 307. British Association for the Advancement of Science. - A paper was read by Mr.

Owen on the Structure of Fossil Teeth, August, 1838.

xxxv. 380. Notice of Fossil Bones and Shells found near Savannah during the Spring of 1838.

xxxvi. 189. Head of the Mastodon Giganteus found near Bucyrus, Crawford County, Ohio, 1838. J. W. Foster, Esq. Ohio, February, 1839.

xuxvi. 198. Notice of a Mammoth found in Missouri, Jan. 12, 1839.

xxxvi. 385. Boston Society of Natural History, July 18, 1838. - Dr. Wyman reported upon a Collection of Fossil Bones.

xxxvii. 191. Remains of the Mastodon in Missouri. By A. Koch, Proprietor of St. Louis

Museum. June 25, 1839.

xxxriii. 381. On the Geognostic Position of the Zeuglodon. T. A. Conrad.

xxxir. 53. Notice of the Tooth of a Mastodon. By J. Wyman, M. D. Boston, May 2, 1840.

xl. 405. Fossil Remains in Lenoir County, North Carolina. J. Limbar. June 10, 1839.

xli. 178. Association of American Geologists. April 9, 1841. - Dr. Harlan exhibited models of the Dinotherium Giganteum.

xlii. 136. Notice of Fossil Bones from Oregon Territory, in a Letter to Dr. C. T. Jackson, by H. C. Perkins. June 2, 1811. With a Postscript to the Editors, Sept. 8, 1841.

xliii. 141. Notice of Two Fossil Mammals from Brunswick Canal, Georgia, with Observations on some of the Fossil Quadrupeds of the United States. By R. Harlan, M. D. May 15, 1842.

xliv. 69. Description of the Bones of a New Fossil, of the Order Edentata. By R. Harlan, M. D. \&c. With three Plates. Read before the American Philosophical Society of Philadelphia. Oct. 15, 1841. 
TOL. PAGE.

xliv. 341. Letter from R. Owen, Esq., on Dr. Harlan's Notice of New Fossil Mammalia. London, Dec. 10, 1842.

xliv. 370. Proceedings of the British Association. (Title only given.) Report on Fossil Mammalia. By Professor Owen. June, 1842.

xliv. 409. Notice of the Discovery of a nearly-complete Skeleton of the Zeuglodon of Owen, in Alabama. S. P. Buckley, A.M.

xlv. 208. Remarks on Dr. Owen's Letter to the Editor, on Dr. Harlan's New Fossil Mammalia. May 5, 1843.

xlv. 320. Association of American Geologists and Naturalists. April 29, 1843.- Mr. Buckley read a paper on the Zeuglodon of Owen (Basilosaurus of Harlan).

xlvi. 294. Notice of Remains of Megatherium, Mastodon, and Siluvian Fossils. Rufus Hayward, M. D. September, 1843.

xlvi. 320. On the Geological Position of the Mastodon, and associated Fossil Remains, at

Big Bone Lick, and other Localities in the United States and Canada. By Charles Lyell, Esq., V. P. G., \&c.

xlvii. 182. Proceedings of the British Association. Geology and Physical Geography. On

the Important Additions made to the Fossil Contents of the Tertiary Basin of the Middle Rhine. By R. J. Murchison, Esq.

xlviii. 105. Notice of Dr. Mantell's Medals of Creation. By the Senior Editor. Nov. 27, 1814. - Particularly, page 133.

xlix. 213. Fossil Remains from Algoa Bay, near the Cape of Good Hope. From Mr. Baynes.

xlix. 218. "Large Skeleton of the Zeuglodon of Alabama. May 23, 1845.

From the Second Series of Sildiman's American Journal of Sciences and Arts:-

i. 122. Mexican Fossils. - In a letter to Professor Browne, M. Claussen states that he has again found in Brazil a great many fossil bones, \&c. 1845.

1. 244. Remarks on some Fossil Bones recently brought to New Orleans from Tennesee and Texas. By W. M. Carpenter, M. D., Professor in the Medical College of Louisiana. Jan. 14, 1846.

i. 268. The Mastodon of Newberg, New York. Discovered in August, 1845. Editor.

ii. 231. The Mastodon Giganteus. Editor.

iii. 436. Food of the Mastodon. Professor A. Gray.

- iv. 13. General Geological Distribution, and probable Food and Climate of the Mammoth. Professor Owen. 
From the Philosophical Transactions of the Royal Society of London:-

1710. Patrick Blair. Dissection of the Elephant.

1714. Cotton Mather. Vol. xxix. p. 62. No. 339 for months April and June.

1767. Collinson. Vol. lvii. pp. 464, 468.

1768. William Hunter. Vol. lviii. p. 34.

1769. Dissertatio Epistolaris de Ossibus et Dentibus Elephantum, aliarumque Belluarum in America Septentrionali, aliisque Borealibus Regionibus obviis; qua indigenarum Belluarum esse ostenditur. R. E. Raspe.

1799. Observations on the Manners, Habits, and Natural History of the Elephant. John Corse.

1799. Observations on the Different Species of Asiatic Elephants, and their Mode of Dentition. John Corse.

1813. An Account of some Organic Remains found near Brentford, Middlesex. William K. Trimmer.

1822. Account of an Assemblage of Fossil Teeth, and Bones of Elephant, Rhinoceros, Hippopotamus, Bear, Tiger, and Hyena, and Sixteen other Animals; discovered in a Cave at Kirkdale, Yorkshire, in the Year 1821, \&c. By William Buckland.

From the Trainsactions of the American Philosophical Society:-

Vol. iv. 1799. Memoir on the Extraneous Fossils, denominated Mammoth Bones; principally designed to show that they are the Remains of more than one Species of non-descript Animals. George Turner.

" iv. New Ser. Descriptions of the Inferior Maxillary Bones of Mastodons in the Cabinet of the American Philosophical Society, with Remarks on the Genus Tetracaulodon, \&c. Isaac Hays, M. D.

" iv. Old Ser. Thomas Jefferson, Esq. pp. 246, $25 \%$.

" i. New Ser. Caspar Wistar, M. D. p. 375. No. xxxi.

" iii. " "Godman. Tetracaulodon. No. vi.

" iii. " " Dr. Hays. p. 471. No. xriii.

" iv. " " Dr. Hays. p. 317. No. ix.

" iv. " " Turner. p. 510. 


\section{VIG N E T T E A N D P L A T E S.}

VIGNETTE.

Turs representation is intended to show the strata in and under which were found the remains of the skeleton described in this work. It will also give a very clear notion of the geological position of the Mastodon Giganteus in the Northern parts of the United States. The view from which this is copied was of large size, and taken soon after the exhumation.

Under the immediate superficies we see, first, a layer of peat, indicated by the dark color, a foot or two in thickness; second, a layer of red moss, not so thick as the peat, of a pinkish color; third, shell-marl imbedding the head, right anterior extremity, spinal column, part of the ribs pelvis, and tail. The rest of the body and limbs lay in a muddy bottom, which inferiorly is bounded by a stratum of clay. The position of the extremities shows, that the animal, at the time of its destruction, was making strong efforts to extricate itself from the abyss into which it had unfortunately plunged.

It must be understood that all these strata were covered by a bed of water varying in thickness from one or two to six or eight feet, but not entirely disappearing, so as to leave the surface dry, until the time of the exhumation.

\section{PLATE 1 .}

This plate is a representation of the five skeletons of the Mastodon Giganteus, which have existed, without showing their comparative size or degree of completeness. In the references which follow, the skeletons are arranged in the order of their discovery.

The upper figure, on the left hand, is that of Mr. Peale, discovered in 1801, which was the first approach to a regular skeleton. In 1802 it was transported to London, but subsequently 
restored to America, where it reigned with scarcely a rival for nearly half a century. In Peale's Museum at Philadelphia, it occupied a prominent place, until, in the year 1849 or 50, it disappeared; and, since then, there is no authentic account of its history.

In the summer of 1851, being in Paris, I was told by M. Laurillard, of the Jardin des Plantes, that a Mastodon skeleton had been offered for sale in that city; but Professor De Blainville found it in so disordered a state, that he would not advise its purchase. Soon after, it disappeared, and he knew not in what place it then reposed.

- This skeleton was originally imperfect. It wanted a considerable part of the head, some of the vertebræ and ribs. Many of the bones of the extremities were represented in wood.

The upper figure, on the right hand, is that of the Baltimore skeleton, exhumed also by Mr. Peale in the year following the former, and from the same morasses in Orange County. It was very ingeniously articulated, but much of it was wood and plaster. Some years since, it was removed from the Baltimore Collection, and remained in a disarticulated state till I saw and purchased it in 1849. For the advantage of examining the separate bones, it has been preserved in this condition. The bones of this skeleton are large, and exhibit the marks of extreme age.

The lower figure, on the right hand, represents the Missourium, so called, taken by Dr. Koch to England in 1843, re-formed and set up in the British Museum under the direction of Professor Owen. Although imperfect in many respects, it has been of great use as the only representative of the Mastodon frame in Europe.

The lower figure, on the left hand, is that of the Cambridge skeleton. The drawing was made previous to its re-articulation: it now presents a very different appearance, and has quite an imposing aspect. The bones of the feet are supplied; the others are tolerably perfect.

The fifth, placed in the centre, is the figure of the skeleton we have described.

\section{PLATE II.}

This is intended to show the earliest stage of dentition in the Mastodon Giganteus. It is taken from a specimen in the Cambridge Collection, and confirmed by the cast of one belonging to the American Philosophical Society, which exhibits nearly the same teeth, and the two mandibular sockets of the tetracaulodon tusks. This plate is interesting, because it shows the first or milk teeth, the absence of the vertical premolar in the lower jaw, and the existence of both sockets of the mandibular or tetracaulodon tusks in a young subject.

The upper figure in this plate represents the earliest state of the teeth in the lower jaw of the Calf Mastodon. Three teeth are here seen on each side: first, the small deciduous tworidged milk molar; second, the larger two-ridged deciduous molar; third, the first and smallest 
three-ridged molar, also deciduous. On the left side of the same jaw, as appears by the figure, an opening has been made at the roots of the second and third teeth, to ascertain the existence of a vertical premolar; but none such was discovered.

The lower figure gives a front view of the same jaw, and exhibits the sockets of the two inferior or tetracaulodon tusks.

PLATE III.

In this are displayed the teeth in a continuation of the series. The first tooth in front is the tooth corresponding with the last in the preceding plate. The second tooth immediately follows the preceding, and is the fourth in the complete series, the second three-ridged molar, and first permanent. Behind it lies the partially developed fifth molar. At the anterior part is a good view of the lingual fossa, and truncated extremity of the jaw.

PLATE IV.

This is the upper jaw of a perfect cranium, to which belonged the lower jaw represented in Plate III. The reference to the teeth in the last plate applies to this also. The tooth in front is the first three-ridged molar, - the third tooth of the entire series. The next in order is the second of the three-ridged molars, the first permanent or fourth of the entire series; while the third three-ridged, or fifth in order of succession, is but partially developed.

We see also the palatine vault, narrow behind, and widening as it extends forwards to the anterior teeth, in front of which it again narrows. Behind the palatine vault are seen the posterior openings of the nostrils, and the pterygoid processes. Laterally are the zygomatic arches. Quite at the back part, or lower edge of the plate, are the great occipital foramen and the condyloid processes, more fully displayed than in the other plates.

PLATE V.

This jaw presents a greater number of teeth than any other. On the right side exist four; the two first have been seen in the former plates; the third on this side is the fifth in the dental series, the third three-ridged, the penultimate molar. Behind it lies the partially developed ultimate or sixth molar.

The three anterior teeth on the left side have been shed. In front is seen the lingual groove, and behind are the coronoid and condyloid processes of the lower jaw. 
PLATE VT.

The cranium connected with the lower jaw of Plate V. It exhibits the same teeth, with the exception of the anterior tooth existing on the right side of the former plate.

The anterior part of the palatine fossa, and of the intermaxillary bones, is more perfectly seen here than in the other plates.

PLATE VII.

This is intended to show the masticating surface of the sixth or ultimate molar, in place, with its ten points. In front-i.e. at the upper part of the plate - is the penultimate tooth, much worn. The anterior and posterior dental foramina are visible.

\section{PLATE VIII.}

This is the first of a series intended to show each of the six teeth separately, and of their natural size. They are all from the lower jaw. The two first were removed from their sockets in the jaw of the Calf Mastodon, represented Plate II.; the third, from another specimen of about the same age; the fourth, fifth, and sixth, are teeth found separate from the jaw.

The first tooth on the left hand in this plate is the first and smallest milk molar. That on the right is the second and larger.

The figure below is not one of the regular series, but is taken from the cranium in Plate IV. and placed here for convenience. It is intended to show the appearance of a molar tooth in the process of development. The crown is formed; the cavity below, or to the left of the crown, shows the situation of the undeveloped fangs.

- These germs are the crowns of teeth without the fangs. They bear their proper number of ridges and mammillæ, and, when viewed from without, appear to be quite perfect teeth; but, on examining their internal surface, there is found to be a large, regular cavity, containing a number of smooth projections, which correspond with the fissures or concavities on the outer side of the tooth. There are no fangs, and the edges of the shell-like hollow are very thin. Before this tooth can become useful, the fangs must be developed; whence it happens that the cusps of the mammillæ are not worn. In the growing animal one or more of these germs are usually found, and more commonly of the ultimate tooth than any other. 
PLATE IX.

This represents the third, fourth, and fifth molars. These three teeth have the same form, and have three ridges and six points; also three roots, two of which, the posterior, are cemented together.

The first tooth on the left, at the upper part of the plate, is the third in the order of succession. It is always smaller than the other two, but larger than the first and second two-ridged deciduous molars. The tooth on the right, above, is generally intermediate in size to the preceding and succeeding; approaching nearer, in this respect, to the latter than to the former. The roots of this are partially broken off.

The lower figure is the fifth tooth, - a beautifully-silicified molar; it is the penultimate. The basal ridge, which separates the crown from the fangs, is broader and more prominent than in the other two.

\section{PLATE X.}

This very fine and perfect tooth is one of the largest belonging to the Mastodon Giganteus we are acquainted with. It was found in Newburgh, about three miles from the great skeleton, and obtained for me by Mr. Brewster.

In the crown we notice five ridges, and ten pyramidal eminences, the posterior of which are smaller than the others; the four anterior points are moderately worn. From the base of the second ridge, the enamel is broken off, showing the bony base of the pyramid. The basal ridge or cingulum is less regular and continuous than in the fifth tooth. The fangs correspond in number with the ridges. The four posterior are united together; the anterior is separate.

PLATE XI.

This and the three following plates show the bones of the hand and foot: they are five-twelfths of the natural size. It was thought useful to represent these and other bones in their natural relations, since most of them have already been represented by Cuvier and others in an insulated state.

Left Hand or Anterior Foot. Front View. - Vide page 37. - A, Lower extremity of the radius. B, Lower extremity of the ulna. C, Scaphoides. D, Lunare. E, Cuneiforme. G, Trapezium. H, Trapezoides. I, Os magnum. K, Unciforme. L, The range of metacarpals, five in number. M, The first range of phalanges, five in number. N, The second range, four in number; there being none for the thumb. The third range, five in number, are not marked; being all artificial. 


\section{PLATE XII.}

Left Hand or Anterior Foot. Side View. - B, Lower extremity of the ulna. D, Lunare. E, Cuneiforme. F, Pisiforme. K, Unciforme. L, The three last metacarpals. $\mathrm{M}$, Those of the first range of phalangets. N, Those of the second range. $\mathrm{O}$, The sesamoids of the fourth and fifth metacarpals. The three last bones of the third range are artificial.

\section{PLATE XIII.}

Lefrt Posterior Extremity or Foot. Front View. - Vide page 48. - A, Lower extremity of the tibia. B, Lower extremity of the fibula. C, Astragalus. D, Os calcis. E, Naviculare. F, Cuboides. I, Internal cuneiform. H, Middle cuneiform. G, External cuneiform. $\mathrm{K}$, Range of metatarsals. L, The first range of phalanges, five in number. $M$, The second range of phalanges, four in number; there being none for the great toe. $\mathrm{N}$, The sesamoids. The third range, four in number, are all artificial.

PLATE XIV.

Left Posterior Extremity or Foot. Side View.-A, Lower extremity of the tibia. B, Lower extremity of the fibula. C, Astragalus. D, Os calcis. F, Cuboides. G, External cuneiform. K, The last three metatarsals. $\mathrm{L}$, The last three of the first range of phalanges. M, The last three of the second range of phalanges. N, The sesamoids. The last three bones of the third range are all artificial.

\section{PLATE XV.}

For a description of this plate, consult the "Microscopic Examination of the Marl, by Dr. John Bacon, jun.;" ApPendix, page 187.

PLATE XVI.

The Shawangunk Head. - Vide page 110.

PLATE XVI.

The Vertical Section of a Head. - Vide page 118. 
PLATE XVIIT.

The Base of the Shawangunk Cranium. - Pages 12, 114.

\section{PLATE XIX.}

The Occiput of the Shathangunk Head. - Pages $15 ; 113$.

\section{PLATE XX.}

Fig. 1. - Vertical section of a penultimate molar of Mastodon Giganteus. This tooth has lost its roots, and displays between their bases a portion of the cavity or hollow. The three textures belonging to the teeth of this species are distinctly shown. In the interior is the dentine or substantial texture, constituting the body of the crown; circumscribed internally by the hollow or cavity of the tooth, and externally by the enamel, which is very broad and distinct. The enamel invests the crown, and is a quarter of an inch in thickness. Under the cleft it presents two olive-like lobes, placed at the point of union between the ridges, where the greatest strength is required. On the outside of the enamel is seen the very thin line of cement which covers the enamel and descends to the roots. The part which invests the enamel of the crown is very thin, and only visible by the aid of a microscope in ordinary cases. This texture is not seen so distinctly in the Mastodon's tooth as in the Elephant's, where it constitutes a thick partition between the tranşverse ridges, and descends between them to cement together the plates forming the body of the tooth.

Fig. 2. - The mandibular tusk, belonging to the large skeleton, of its natural size. This is one of the largest and most perfect yet discovered. The worn part of its point is very conspicuous.

Fig. 3. - The large, conical cavity of this tusk, which terminates in a narrow cylindrical tube.

Fig. 4. - The styloid process.

\section{PLATE XXI.}

Fig. 1. - Anterior view of the atlas. (The dentata is seen behind it.)

Fig. 2. - Posterior view of the atlas.

Fig. 3. - Lateral view of the atlas and dentata articulated with the cranium.

Fig. 4. - Underneath view of the same. 
Figs. 5, 6, \%.-Anterior, posterior, and lateral views of a dentata, - not that of the great skeleton, but of a cast of this vertebra in the Darmstadt Collection, which is so fine a specimen that I thought best to represent it.

\section{PLATE XXT.}

Figs. 1, 2, 3. - Anterior, posterior, and lateral views of one of the middle dorsal vertebræ.

Fig. 4. - The fourth, fifth, sixth, seventh, and eighth dorsal vertebræ, showing the attachments of the ribs.

Fig. 5. - The fifteenth, sixteenth, and seventeenth dorsal vertebræ, with ribs attached.

Figs. 6, 7, 8. - Three views of two of the upper caudal vertebræ.

\section{PLATE XXIII.}

Fig. 1. - The second rib on the right side, showing the union of a fracture.

Fig. 2. - Interior view of the sternal end of the same. This fracture is perfectly consolidated, and had existed perhaps three or four years. The newly formed bone is not so exuberant as is sometimes seen in fractures.

Fig. 3. - A portion of the spinal column with the ribs attached, in connection with the pelvis; showing a fracture of the nineteenth and twentieth ribs, with exuberant new bone effused between, and cementing them firmly together. This fracture establishes with certainty the existence of a twentieth rib in Mastodon Giganteus; a fact which cannot be settled in the other Mastodon skeletons on account of their imperfection.

Fig. 4. - View of these two ribs from above.

Fig.5. - Interior view of the right scapula; the epiphysis wanting, but its situation indicated by a dotted line.

\section{PLATE XXT.}

Figs. 1, 2, 3. - Anterior, posteriol, and lateral views of the pelvis.

\section{PLATE XYT.}

Fig. 1. - Anterior view of the right fore-leg and scapula.

Fig. 2 - Posterior view of the same. 
Fig. 3. - Lateral (external) view of the same. In these three the joints are separated to show the articulations.

Fig. 4. - Upper extremities of the ulna and radius, forming the articulating surface for the reception of the humerus.

Fig. 5. - Posterior view of the hind-leg, also disarticulated to exhibit the articulation.

Fig. 6. - The patella.

\section{PLATE XIVI.}

T'he Batminore Tоотн. - A, The worn surface of the first, or perhaps the second, pair of lobes. B, A portion of another lobe, or of an anterior talon. C, Enamel border of a worn mammillary eminence, forming the trefoil or trifoliated figure, D. E, The bi-lobate talon, and posterior extremity. F, Papillary eminences, with their cusps not worn. G, Papillary eminences, with their cusps worn. H, Clefts between the mammillary eminences intersecting the basal cingulum. L, Small pyramidal buttresses supporting the bases of the mammillary eminences.

\section{LARGE PLATE.}

References: Pages 7, 11, 16, 18, 20, 29, \&c. - This lithograph shows most of the bones of the animal. The number of those deficient in the skeleton, and whose places are supplied, is very small, and I intended to have had them indicated in the engraving; but, owing to accidental circumstances, this was omitted. They are, however, mentioned in the text. 

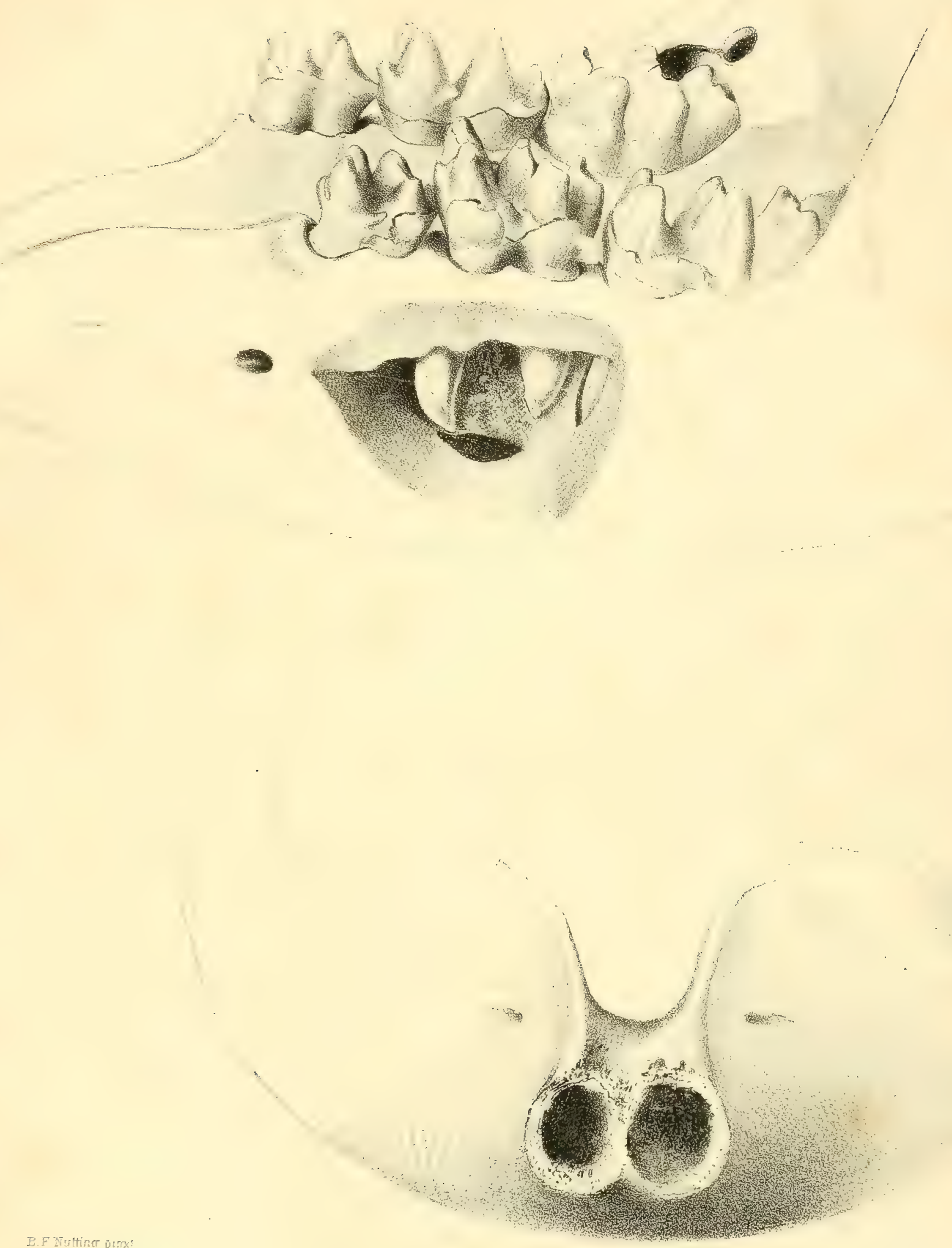

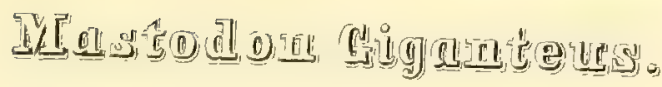




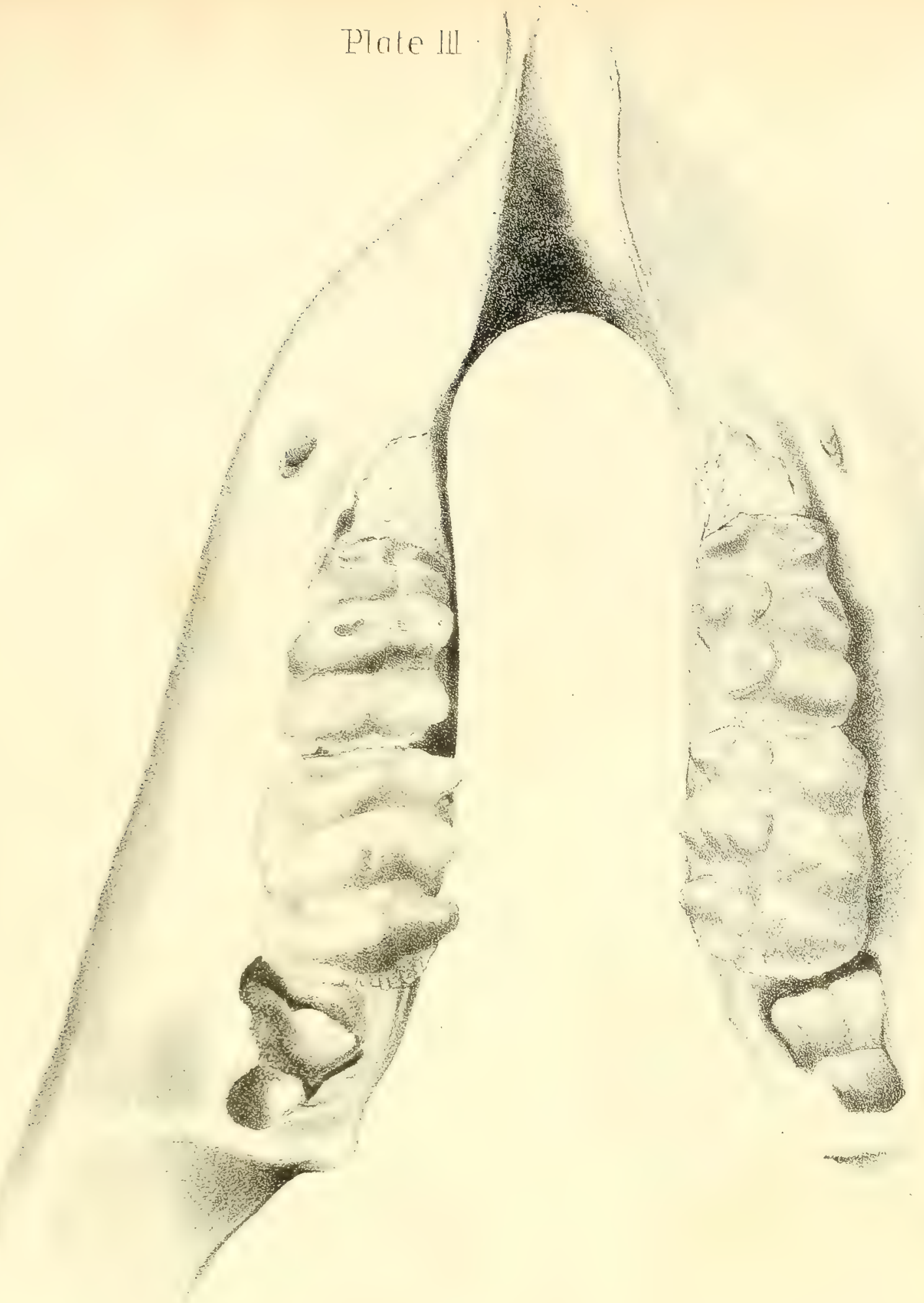



Plate V

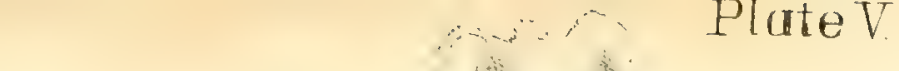





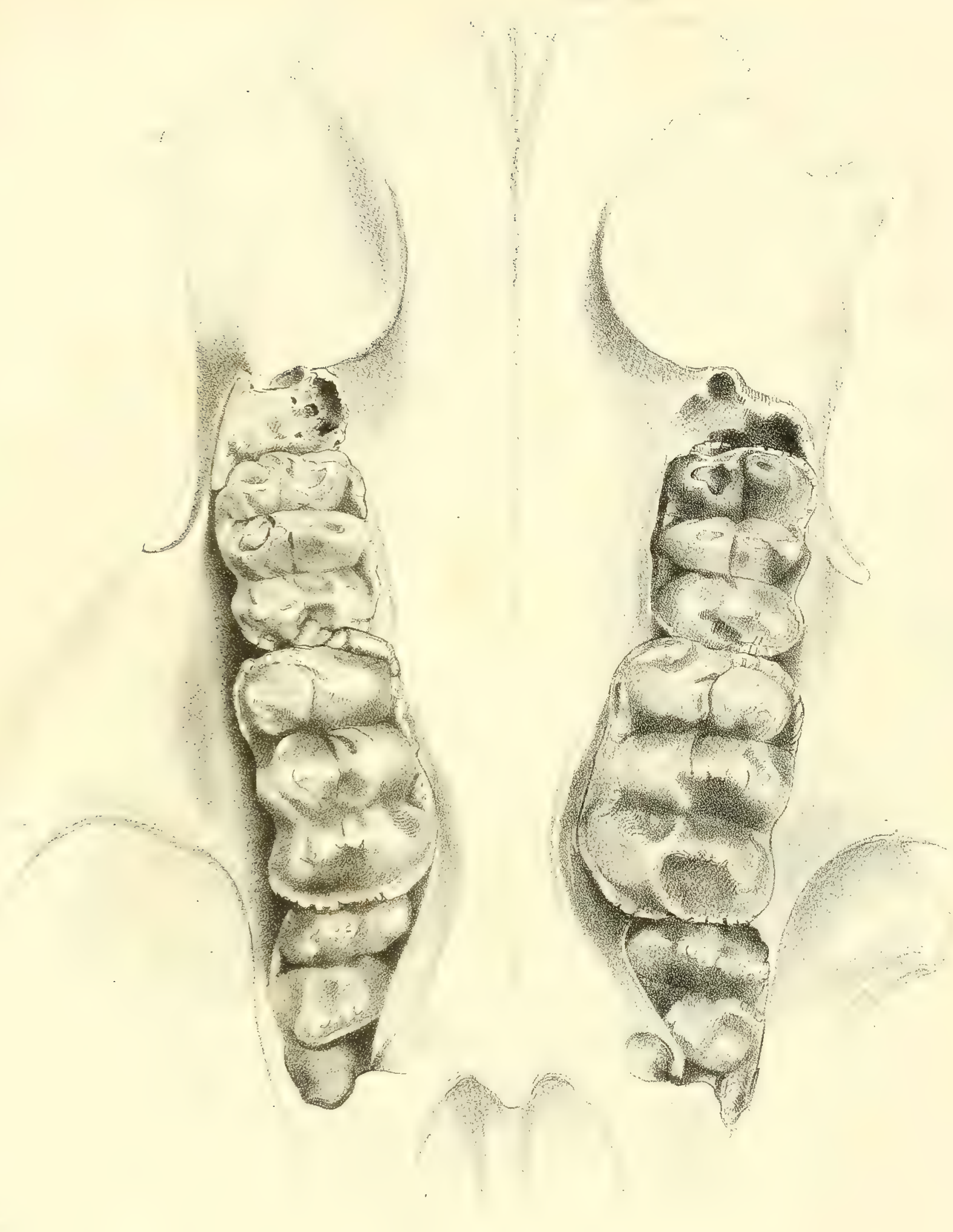

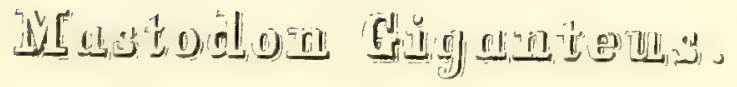



Plate VII

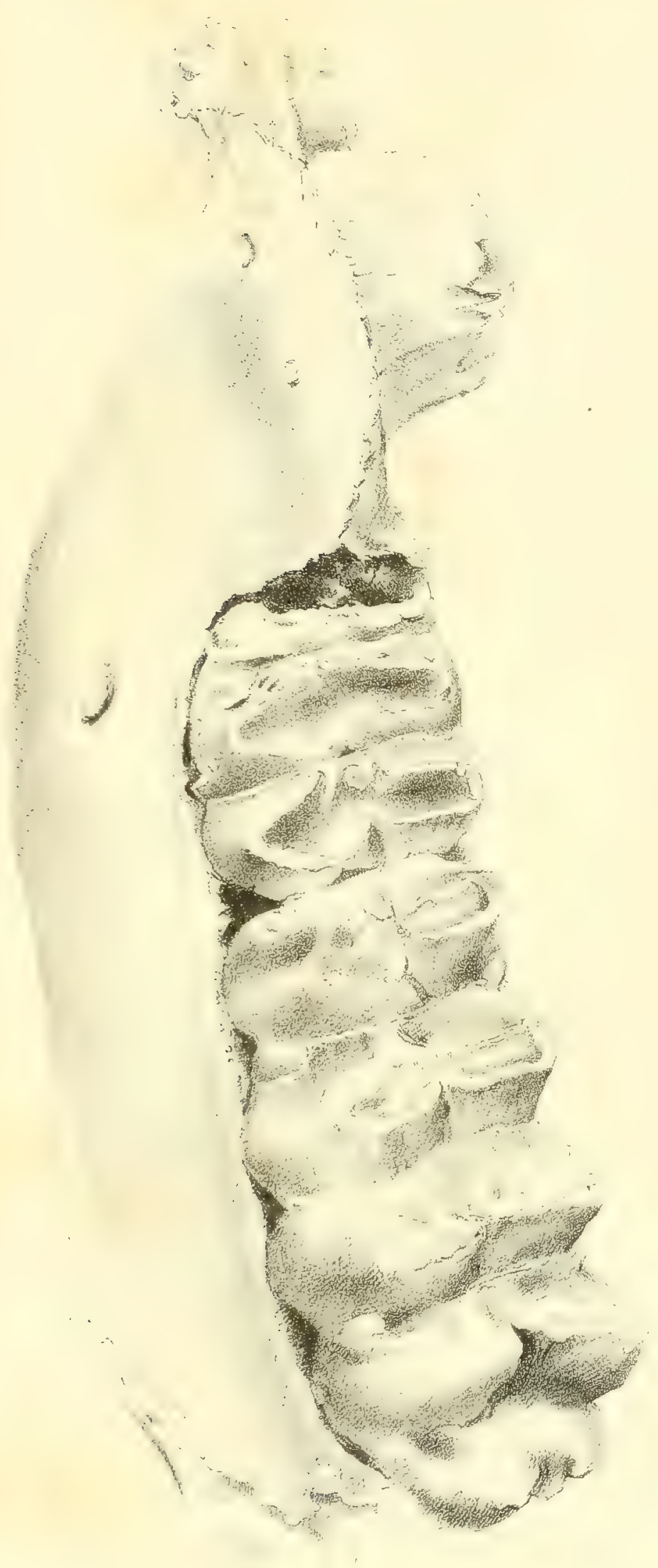

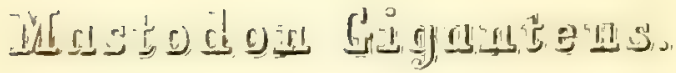



Plate VIII.
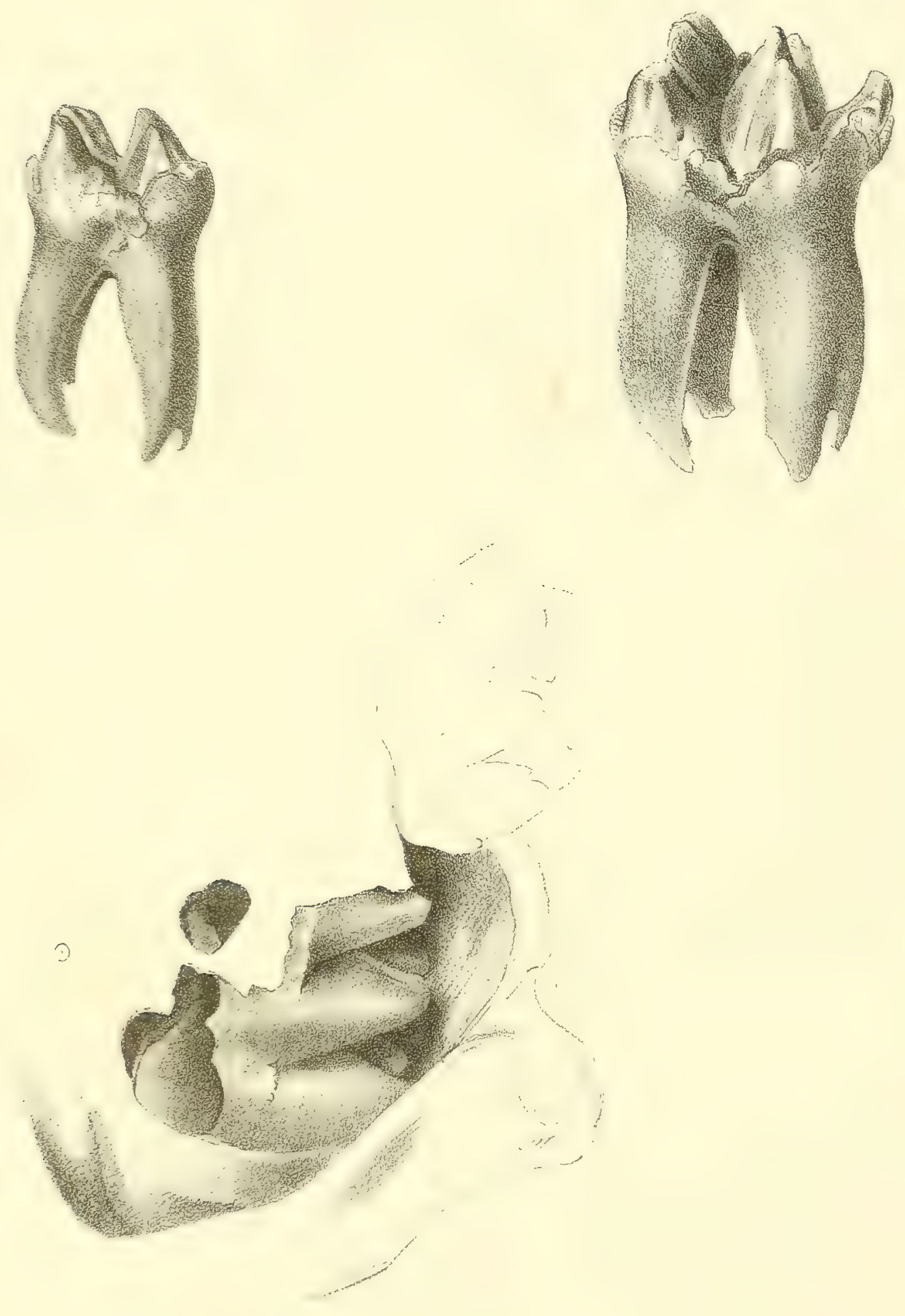

Bufflox d \& Co: . Tiplt

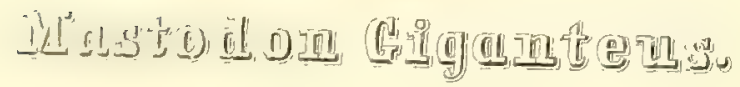


Plate IX
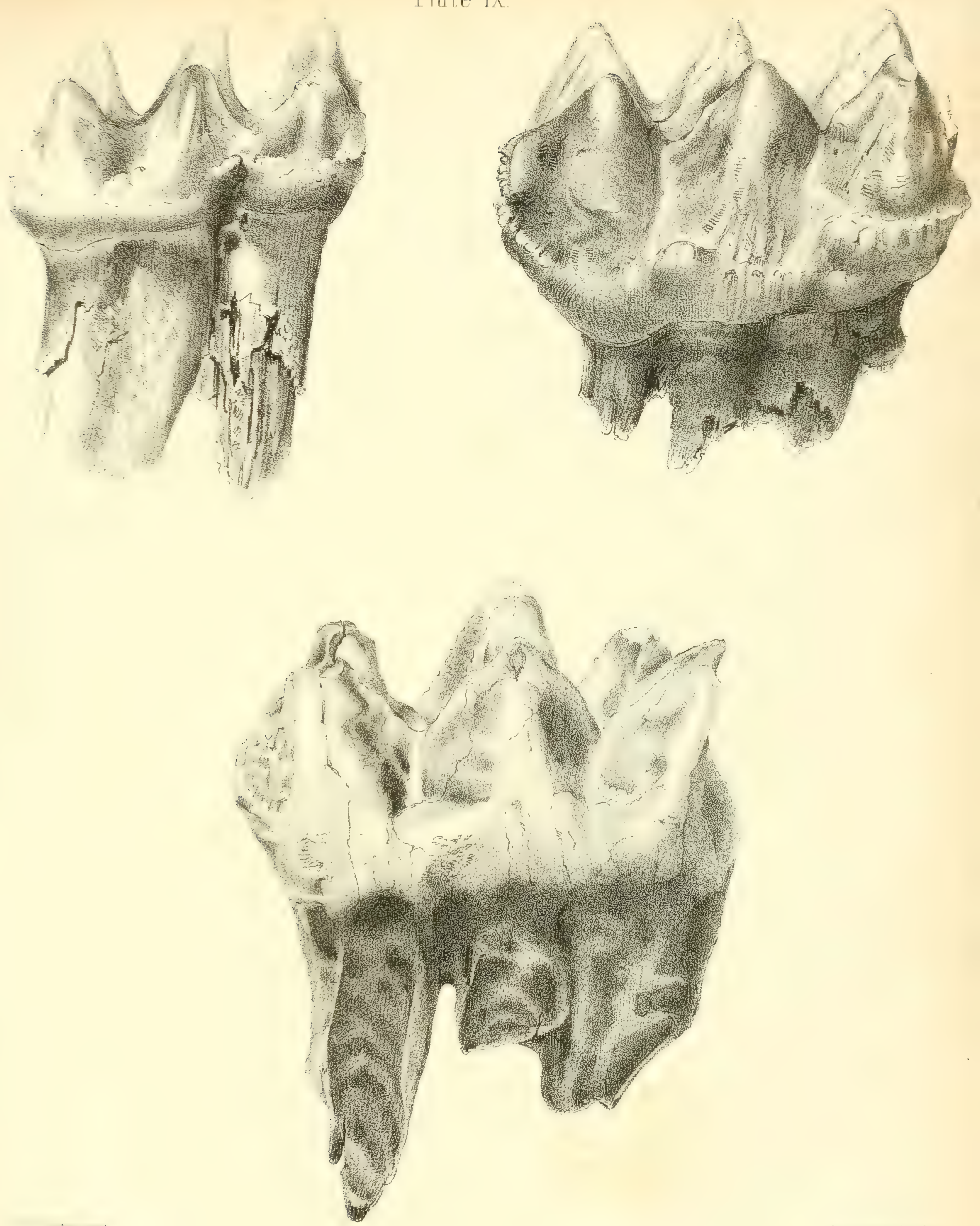

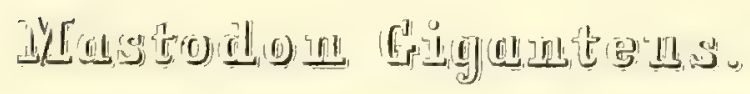





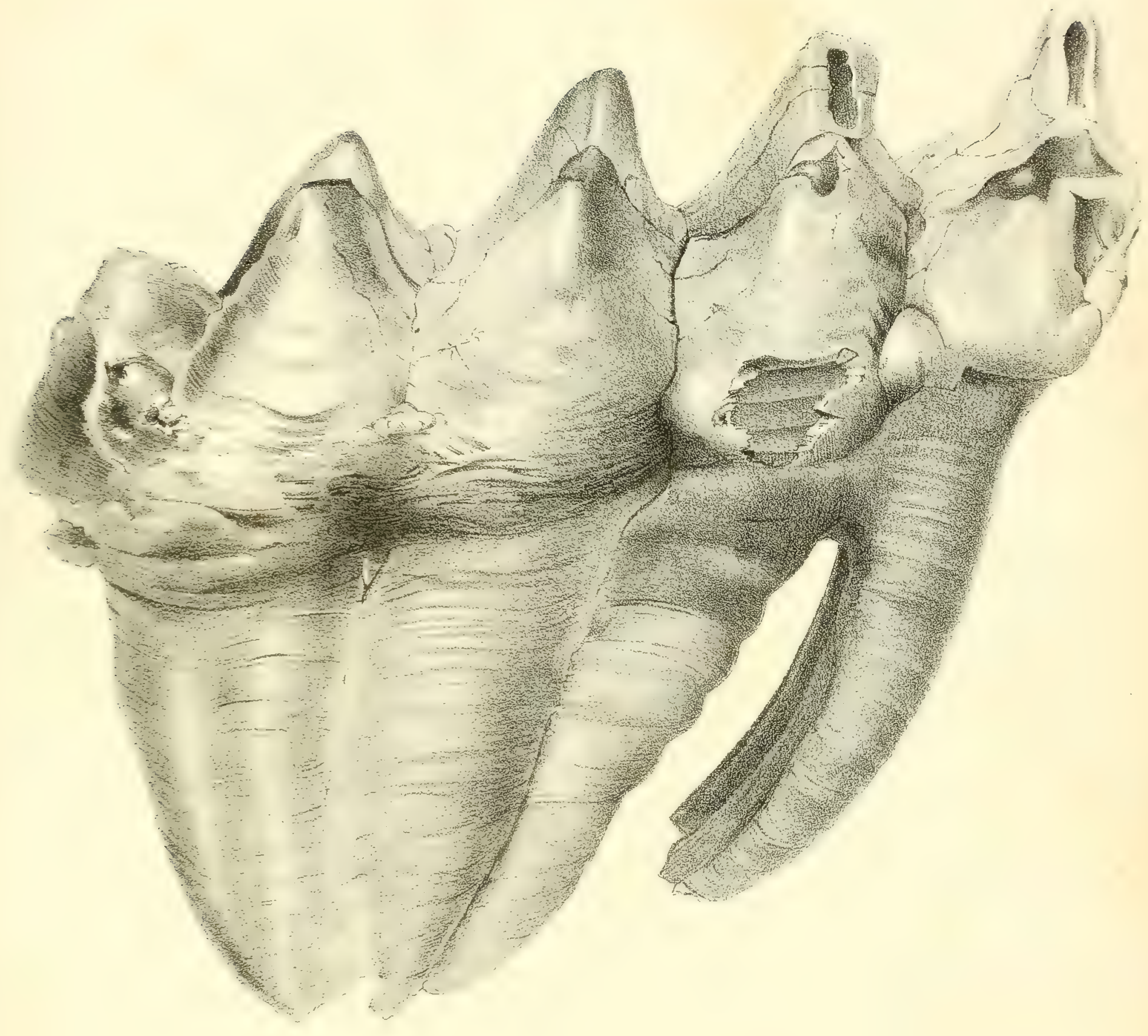

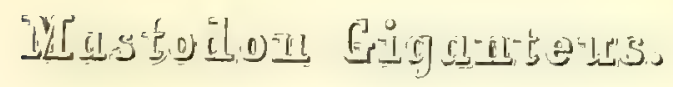





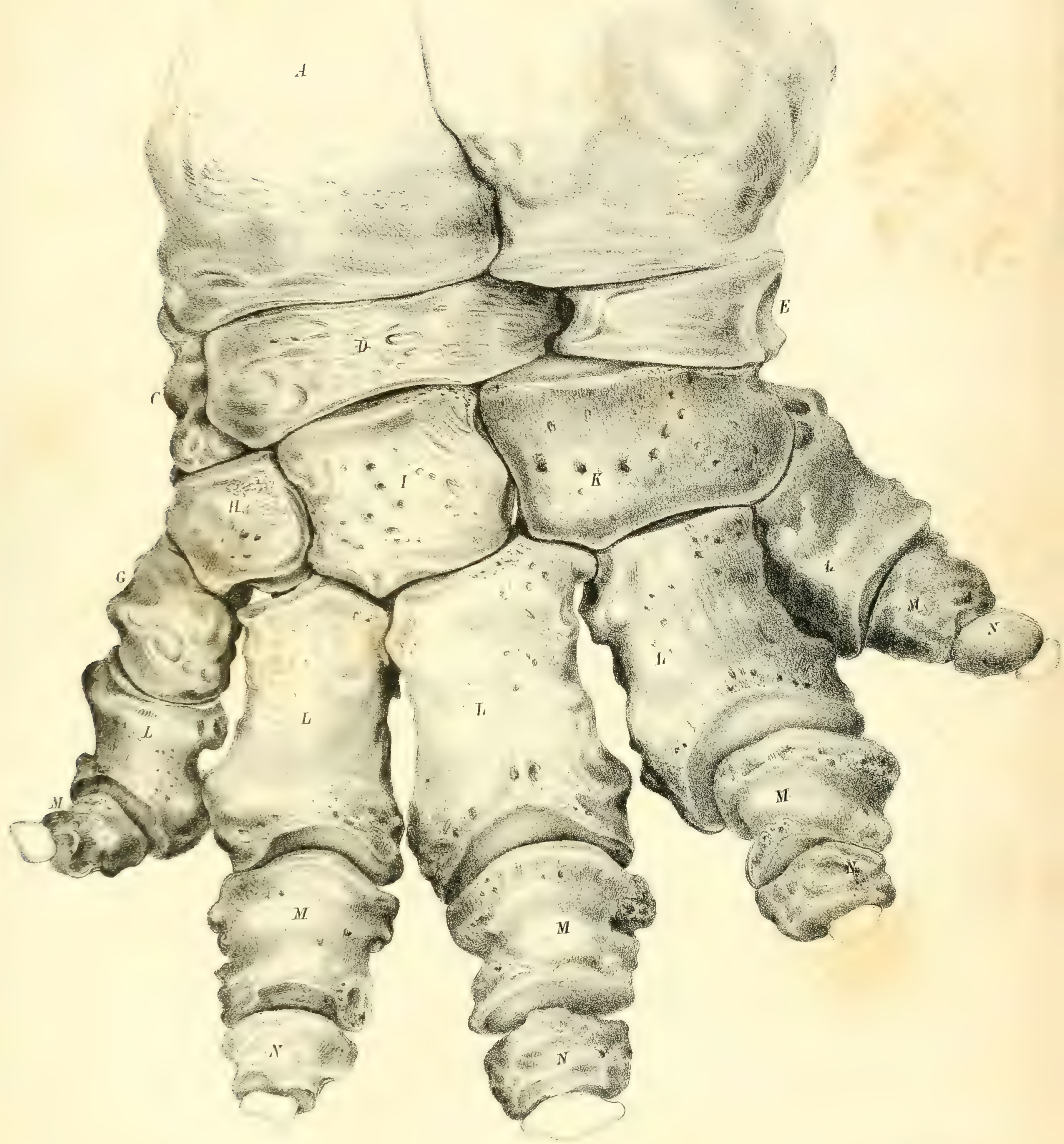

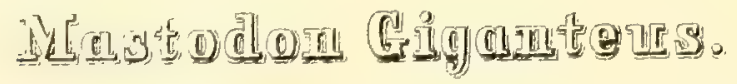





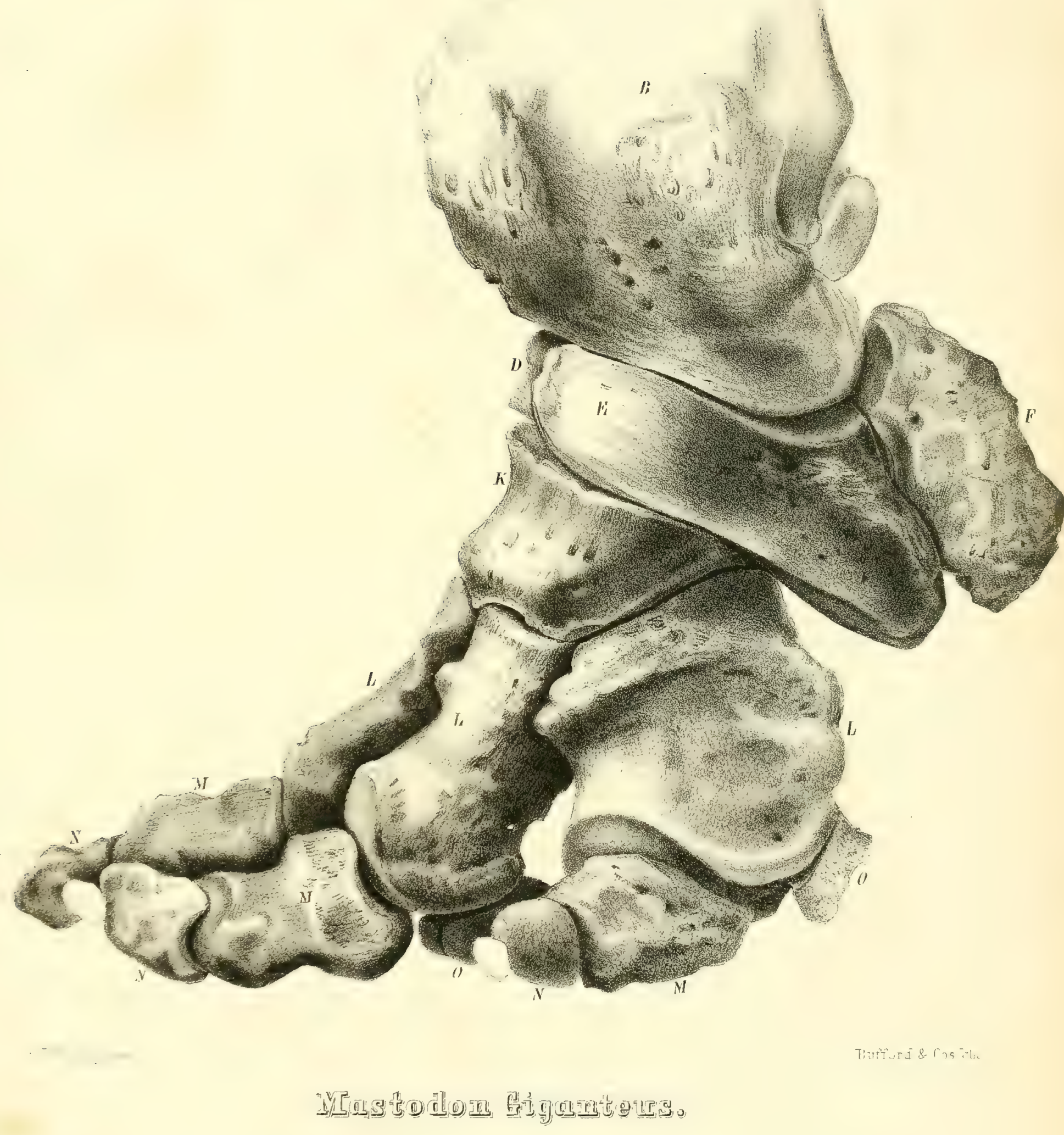




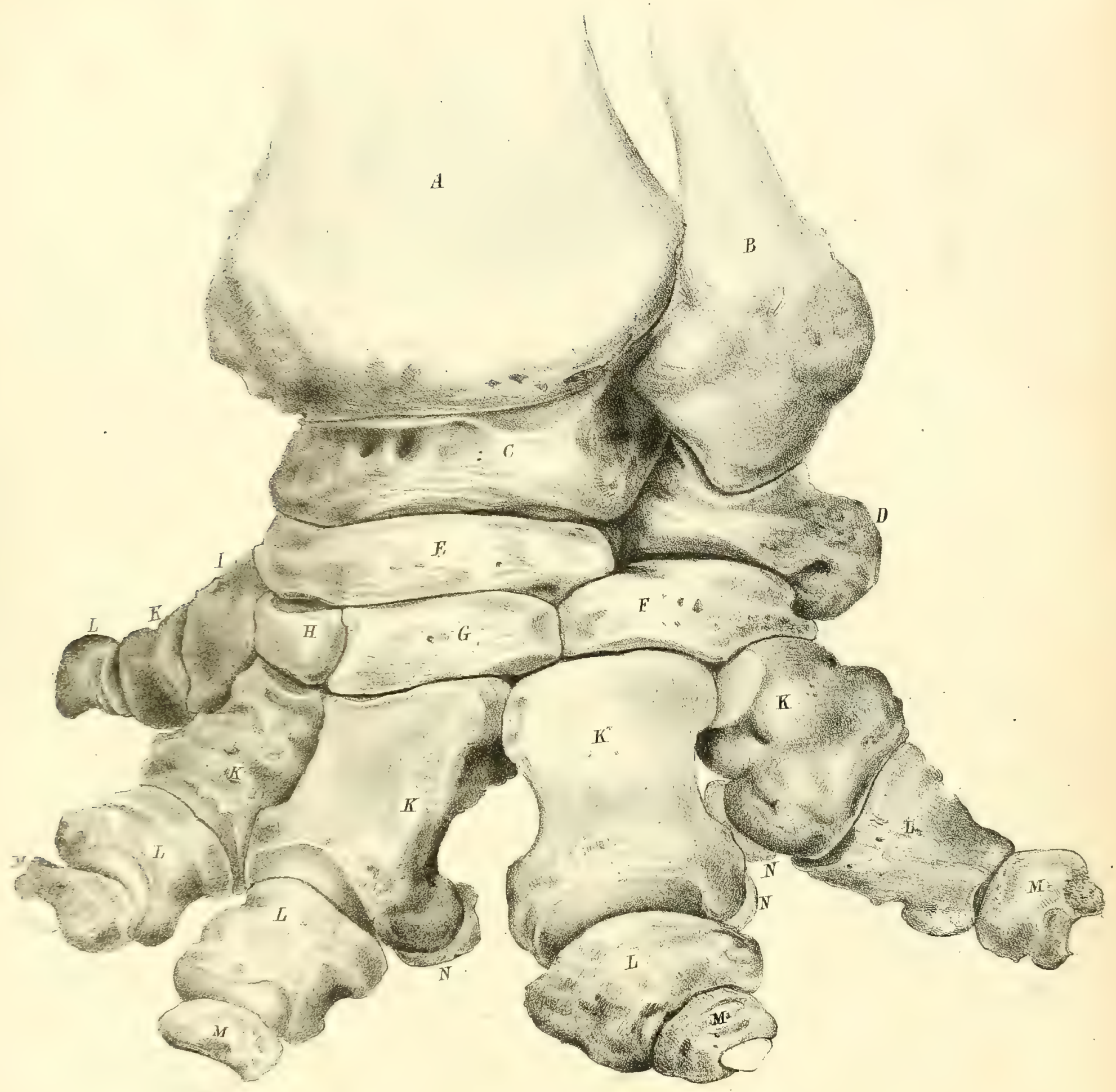

Bufforil \& Cos Tith

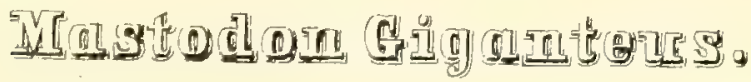


, 


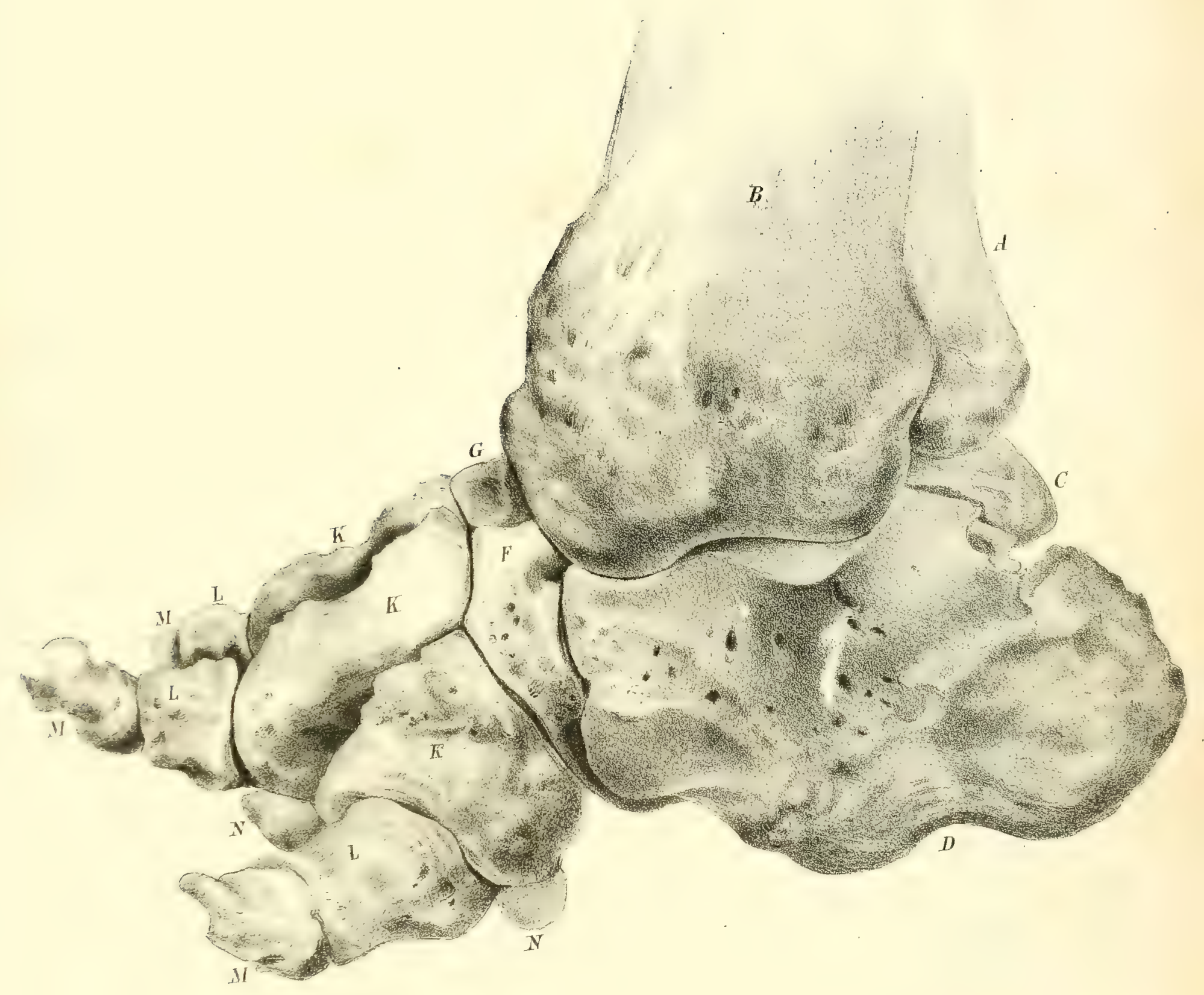

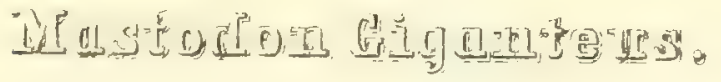


Plate XV.

Fig 3 .

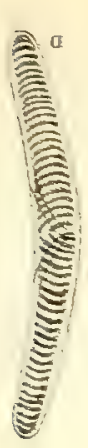

Fig 2.

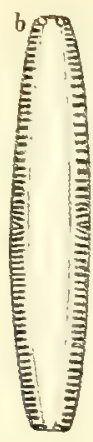

Pig. 3.

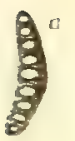

Fig. 10.

$\hat{V}^{\circ}$

Jig 11
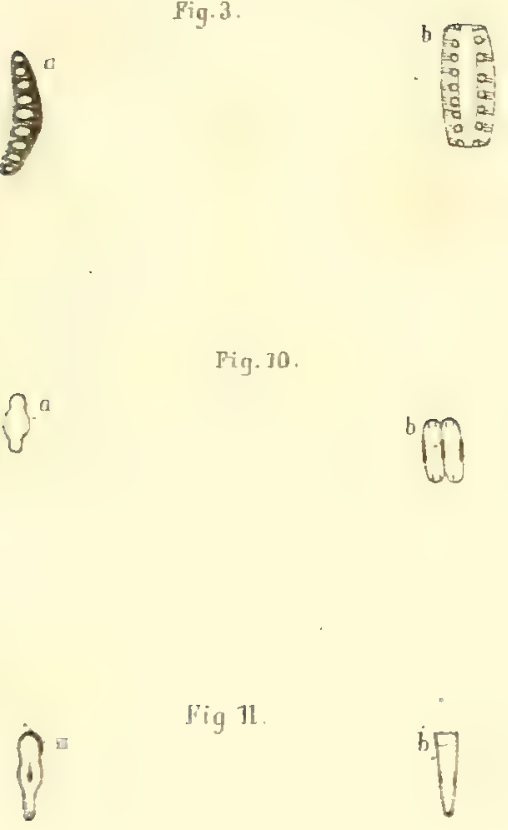

(ii

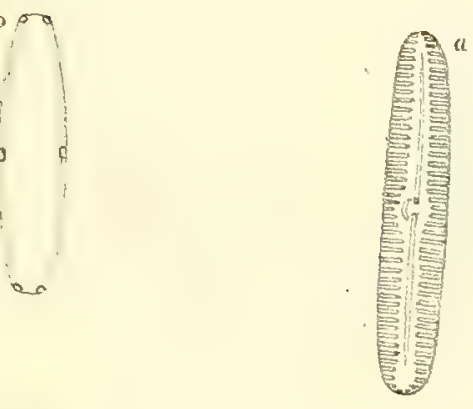

Fig 5 .
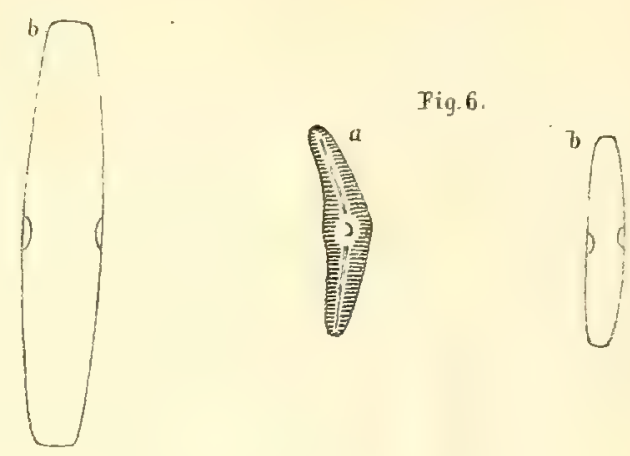

Fig. 4 .
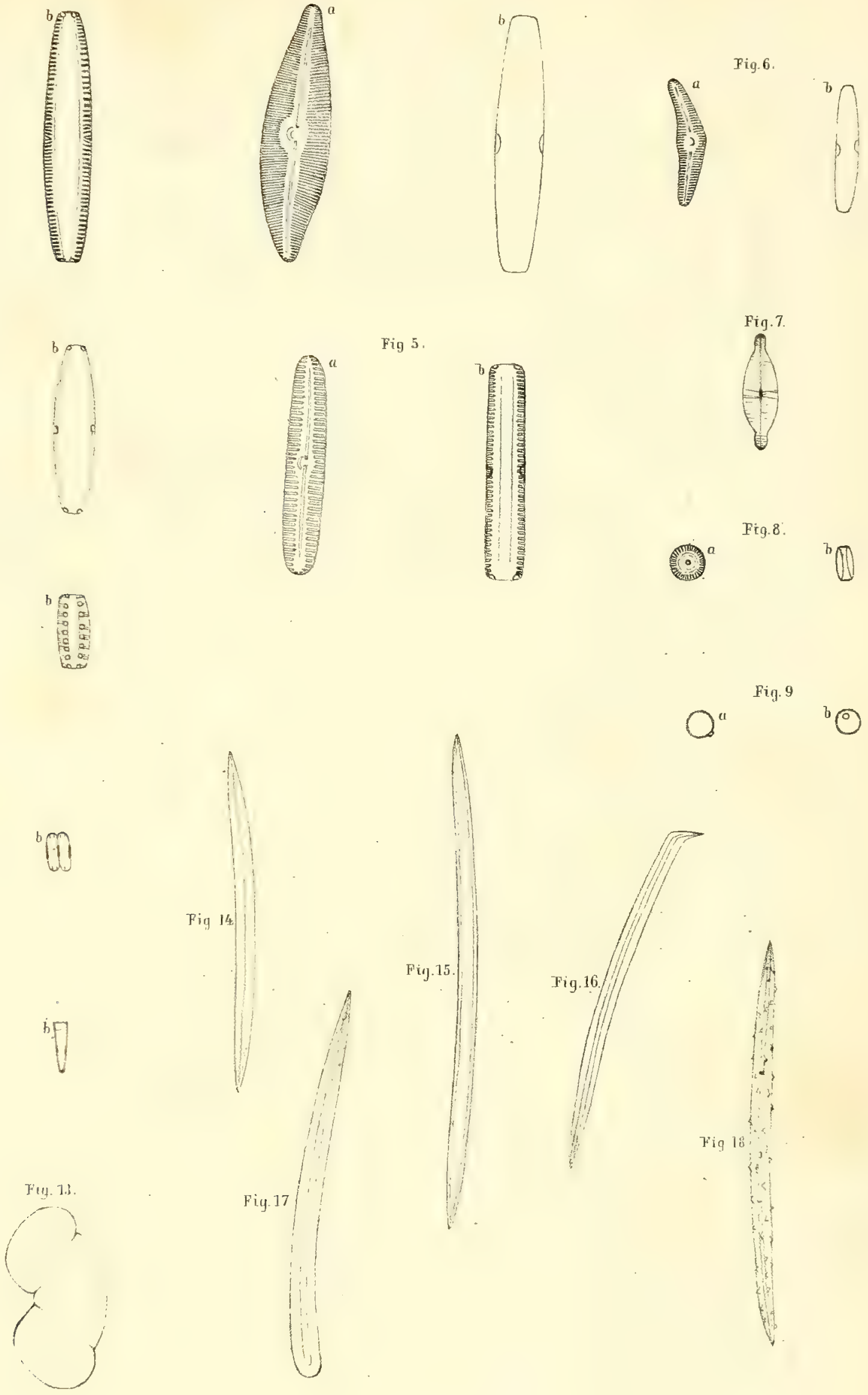

J.I Turf or th: 1 h th 


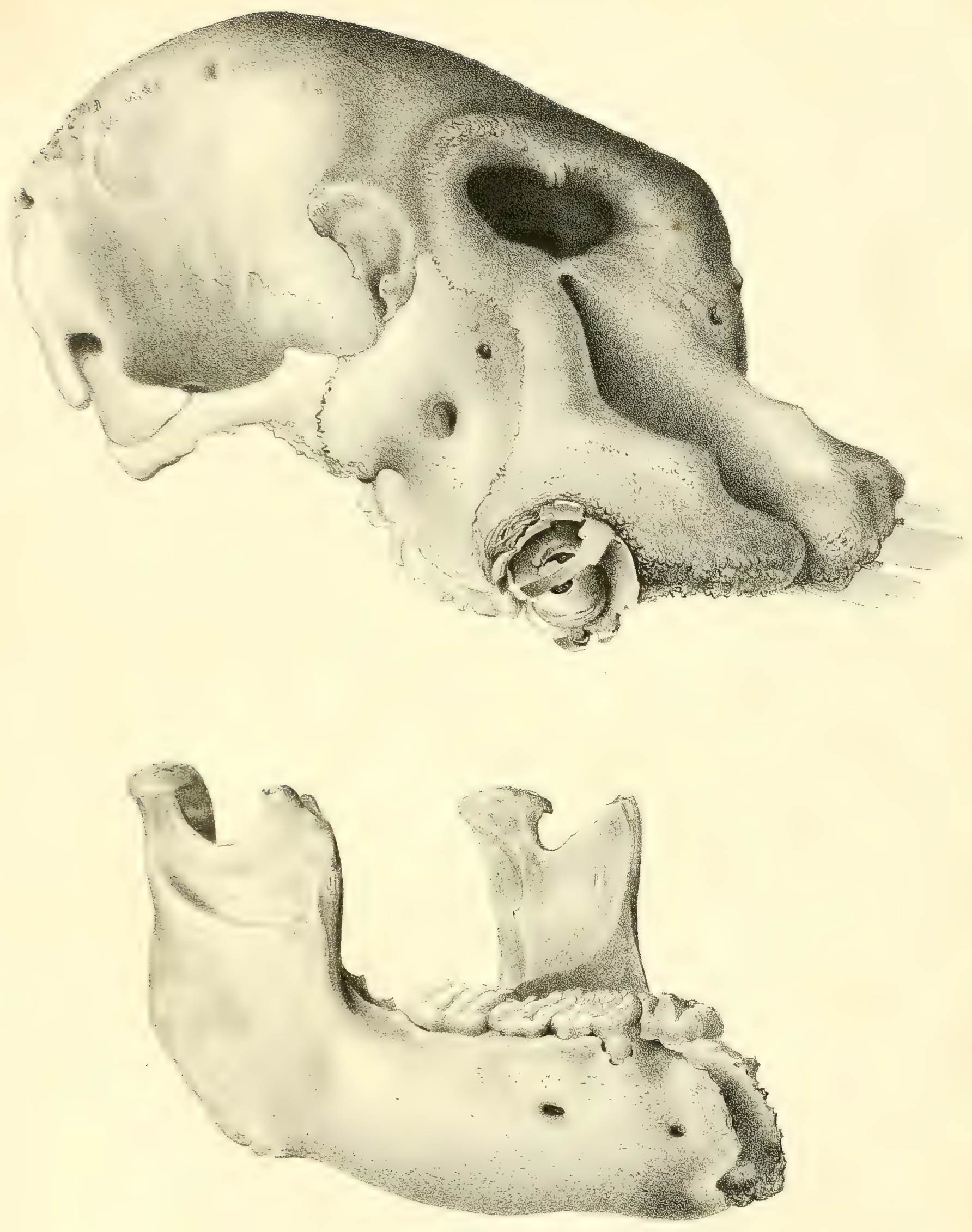
- 


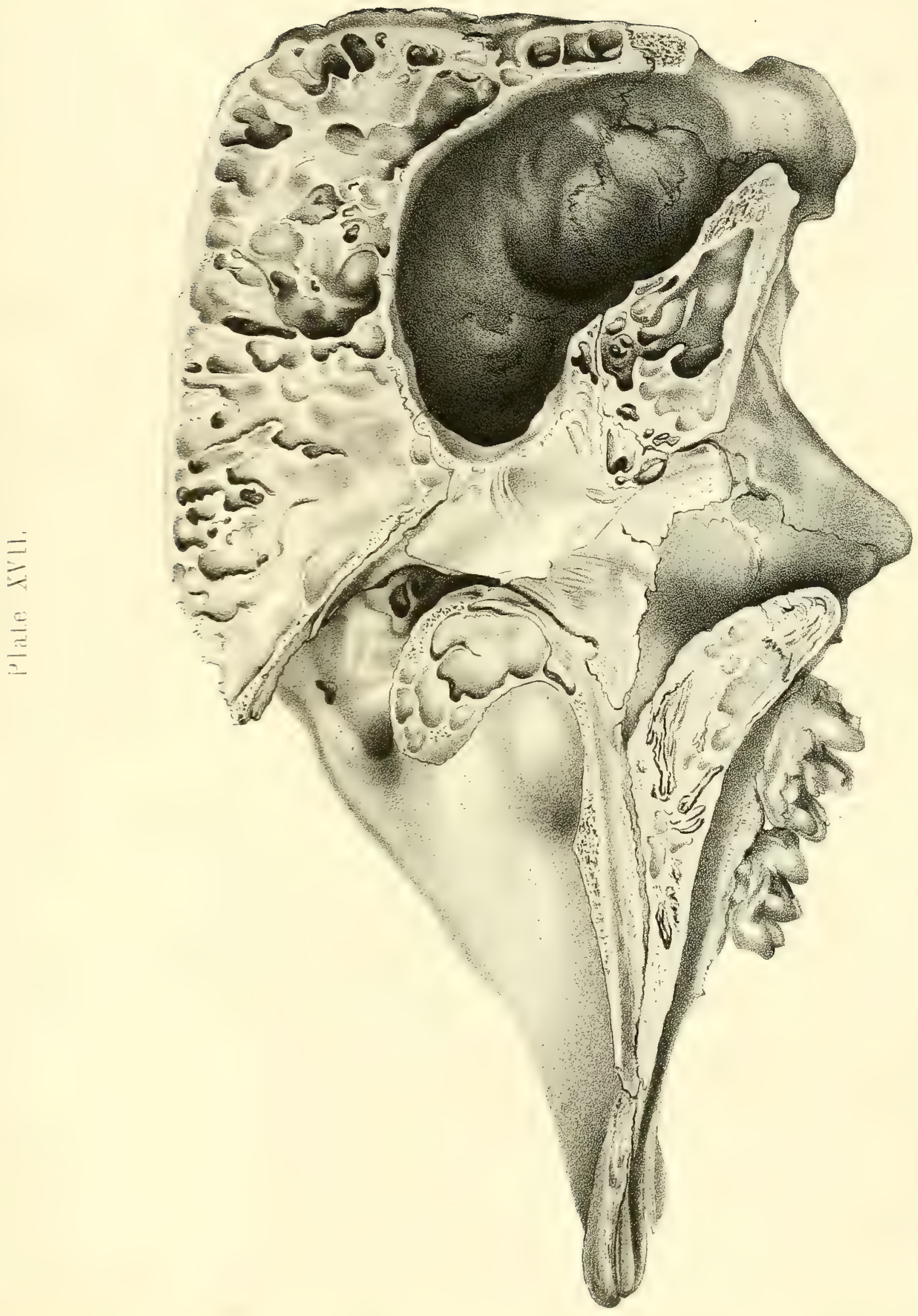

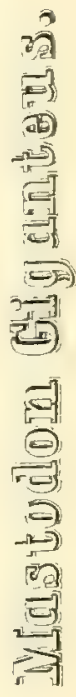




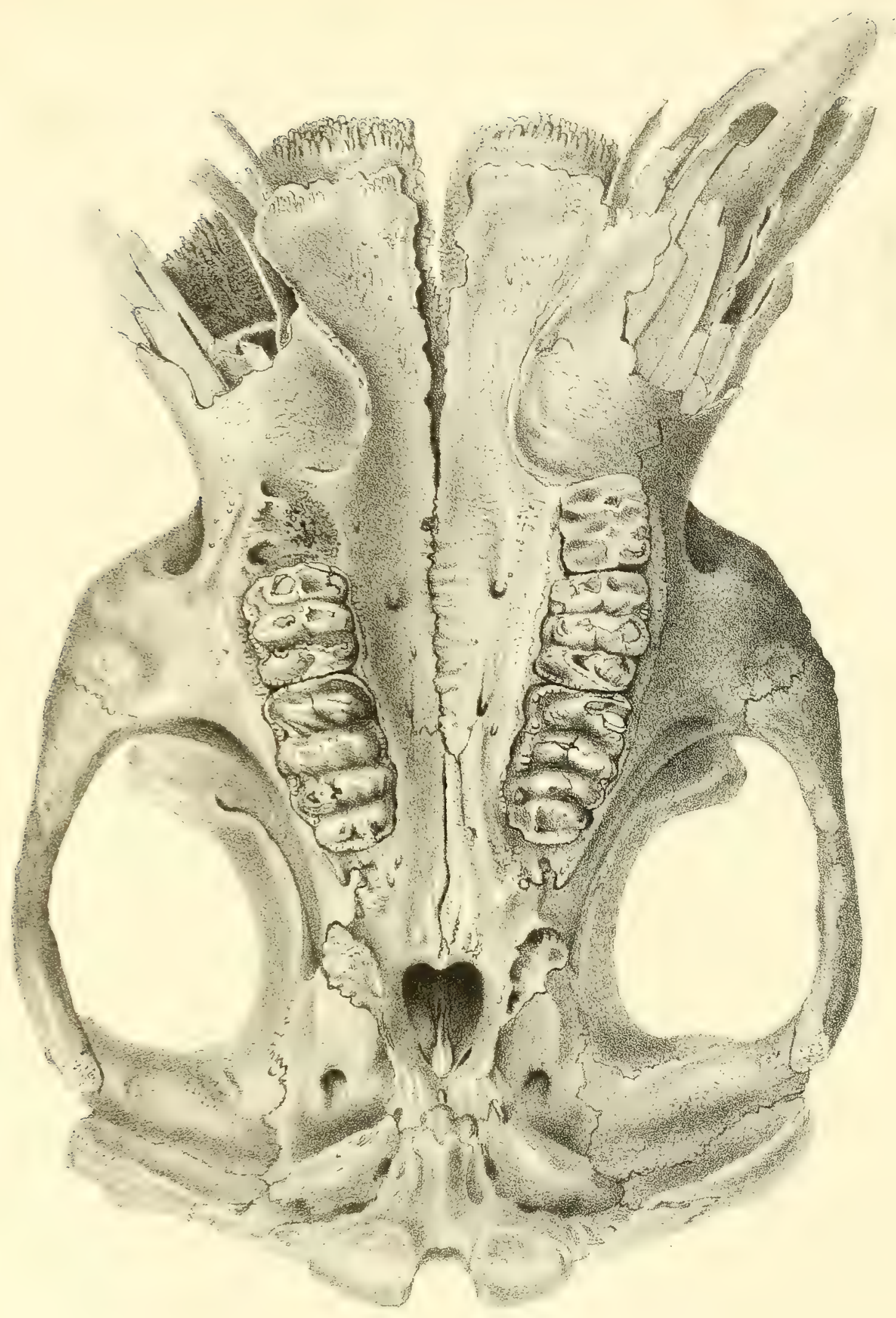

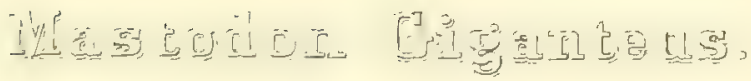





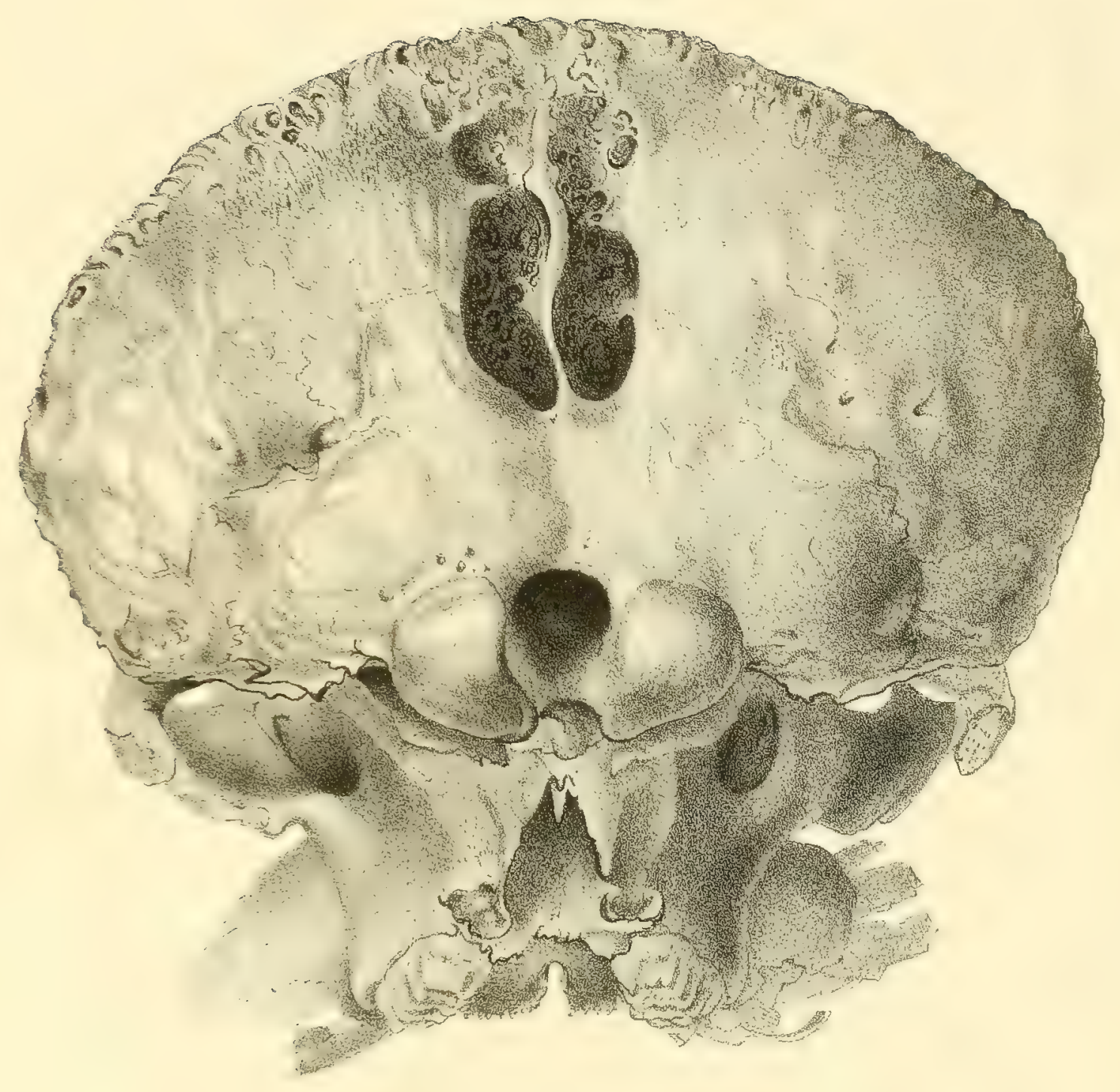

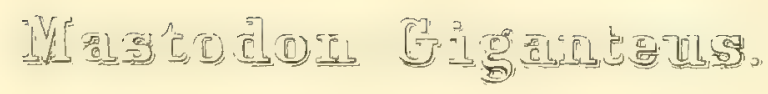





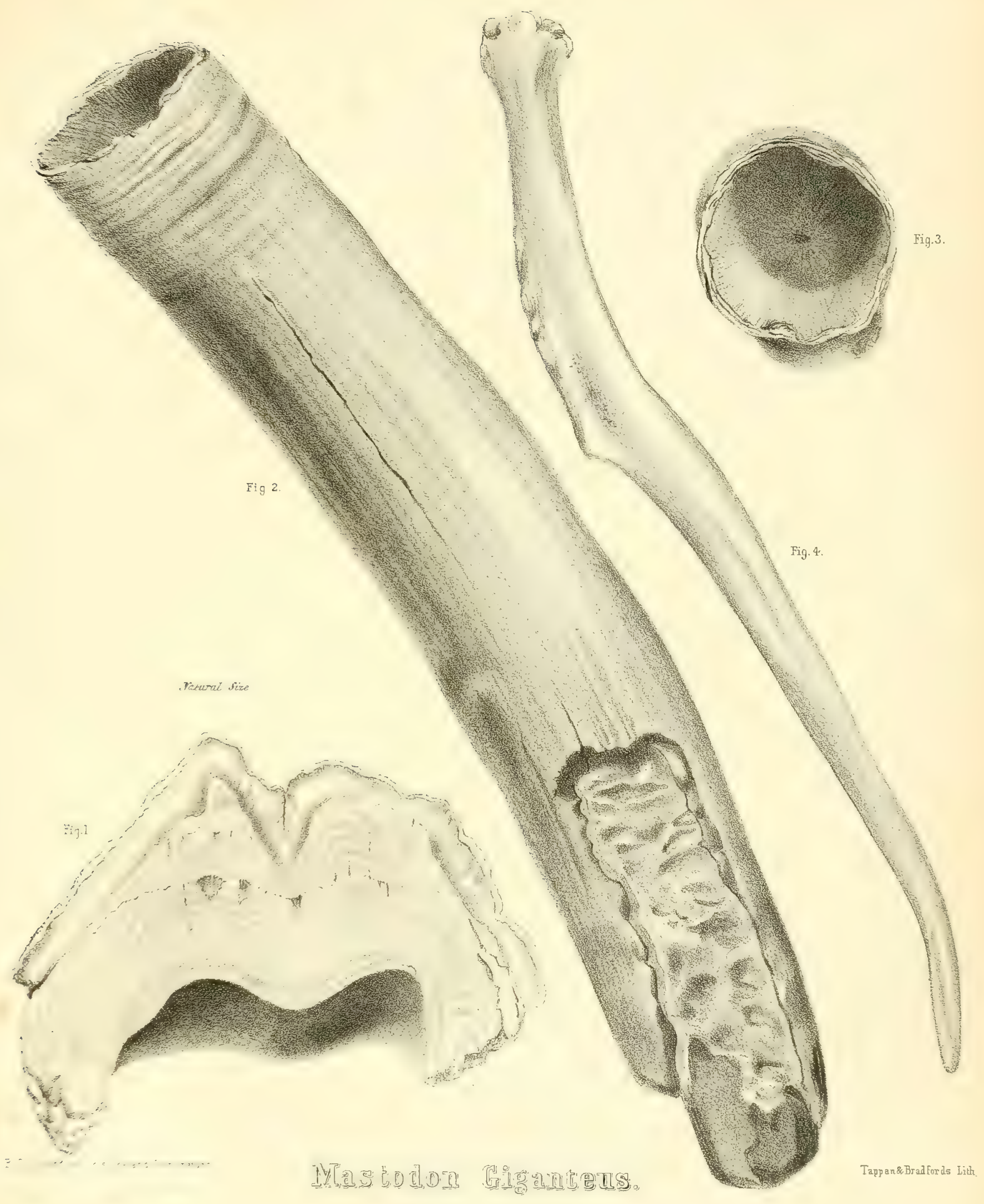




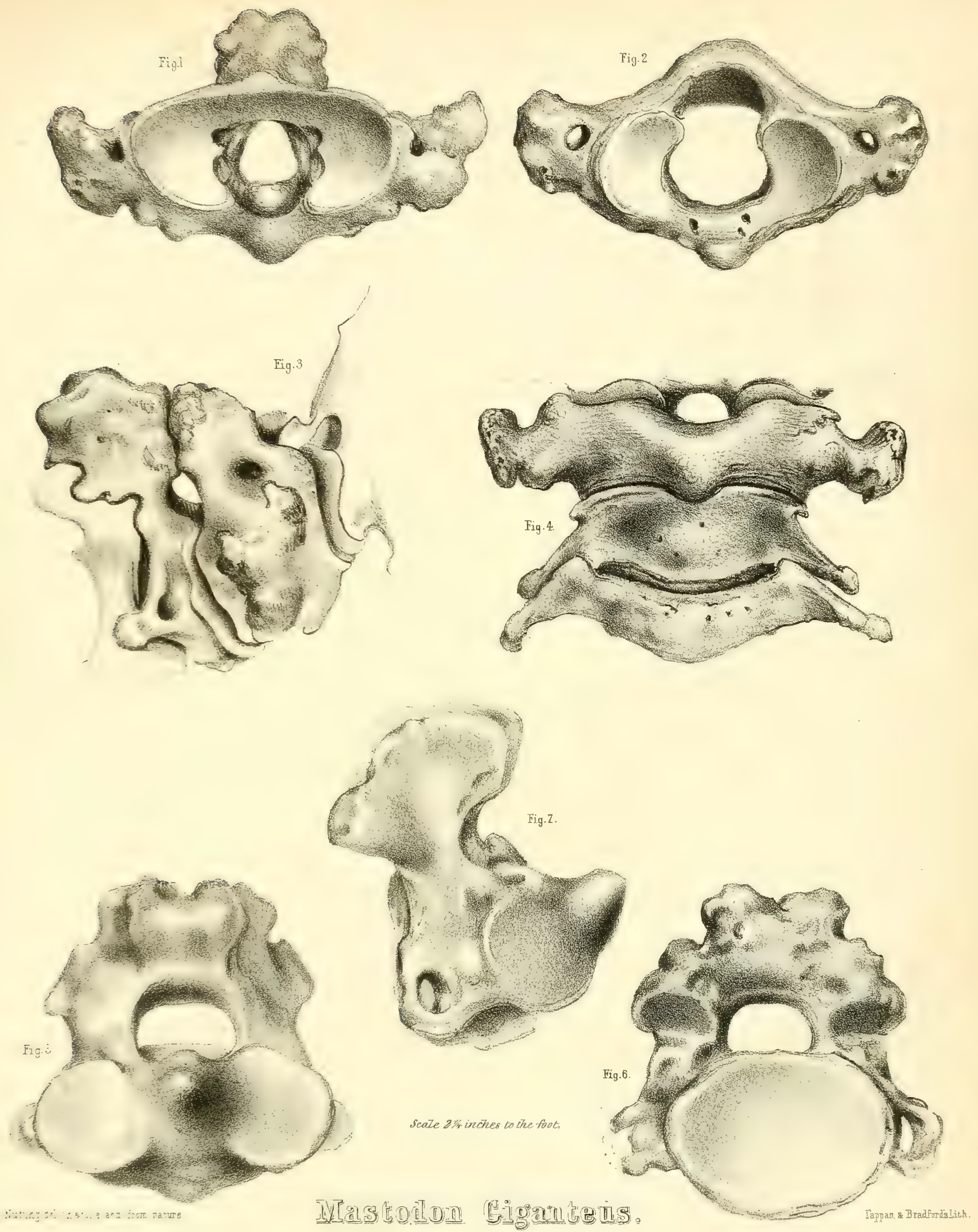
. 

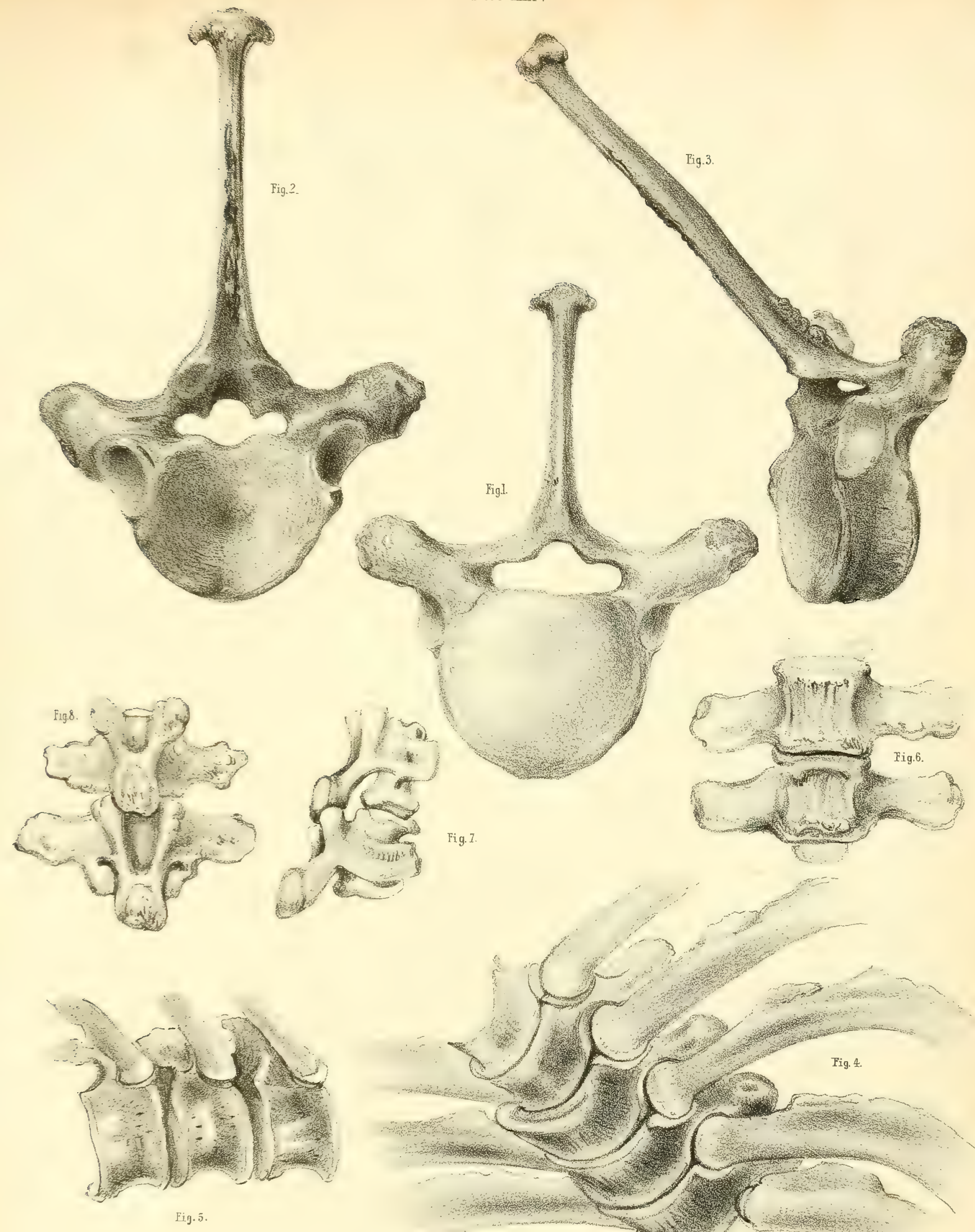


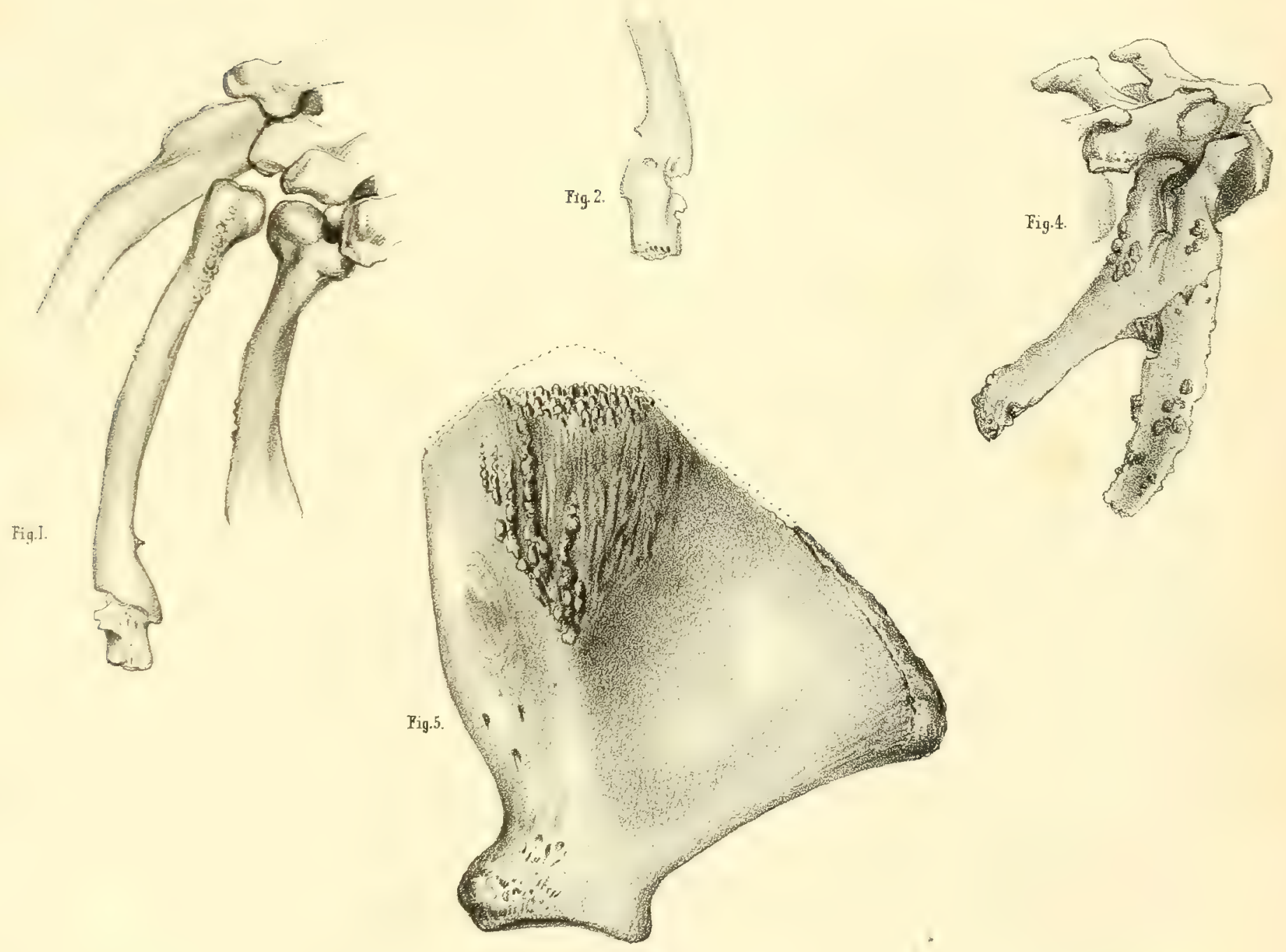

3. . . Natting delon stone and From nature. 


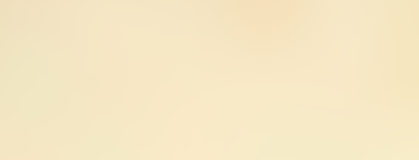

,

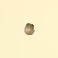




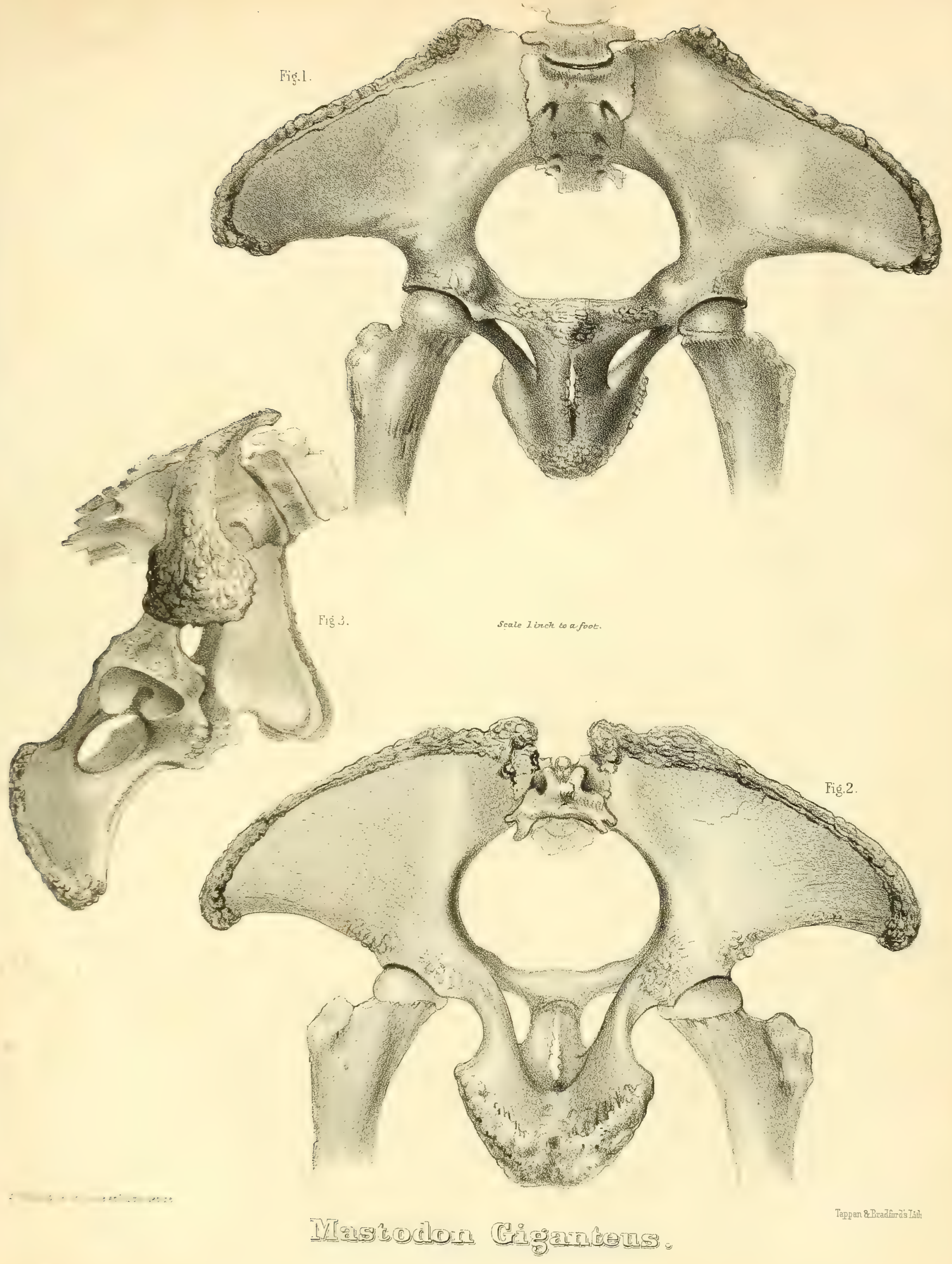





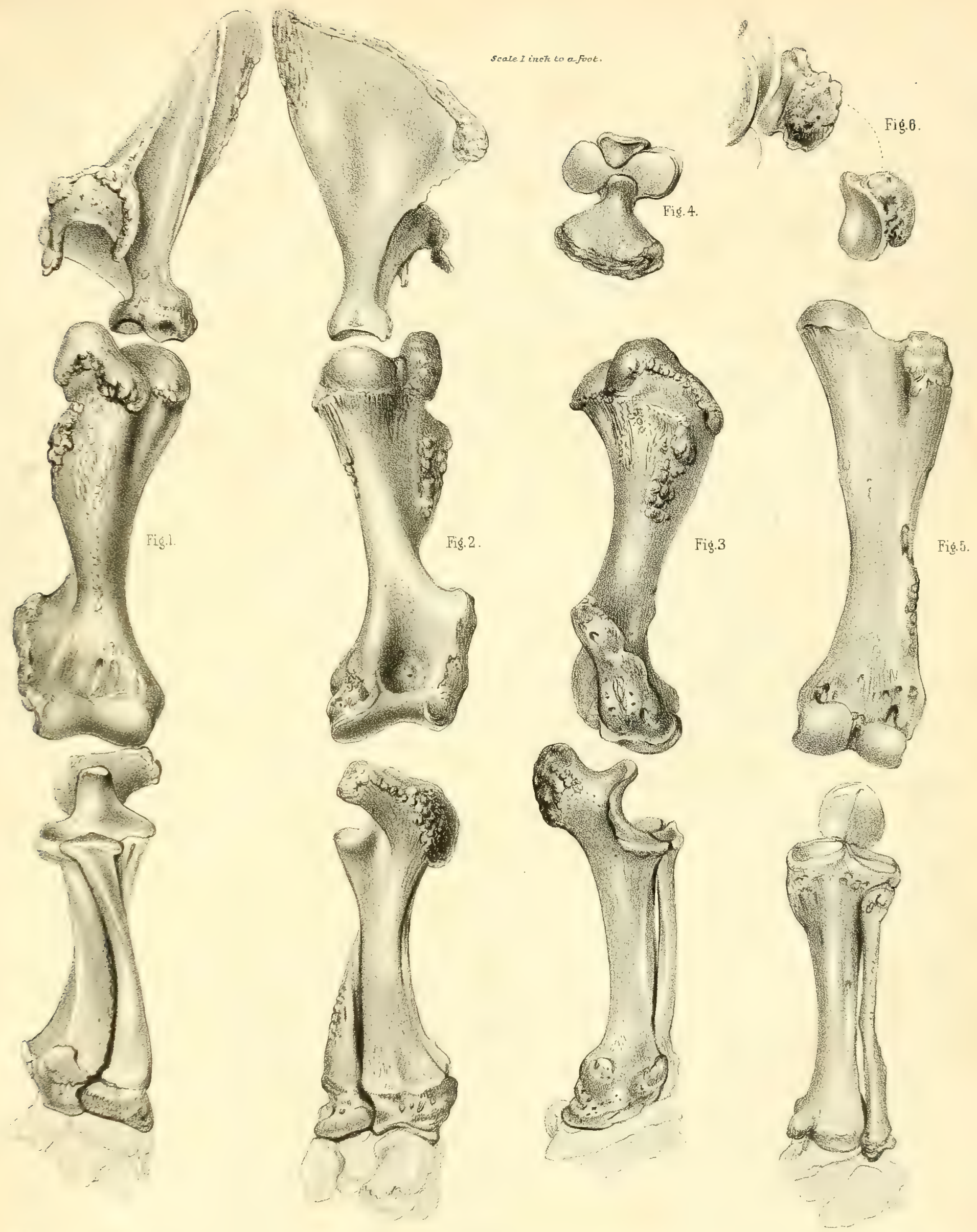

Vy 



\section{Plate XXVT}

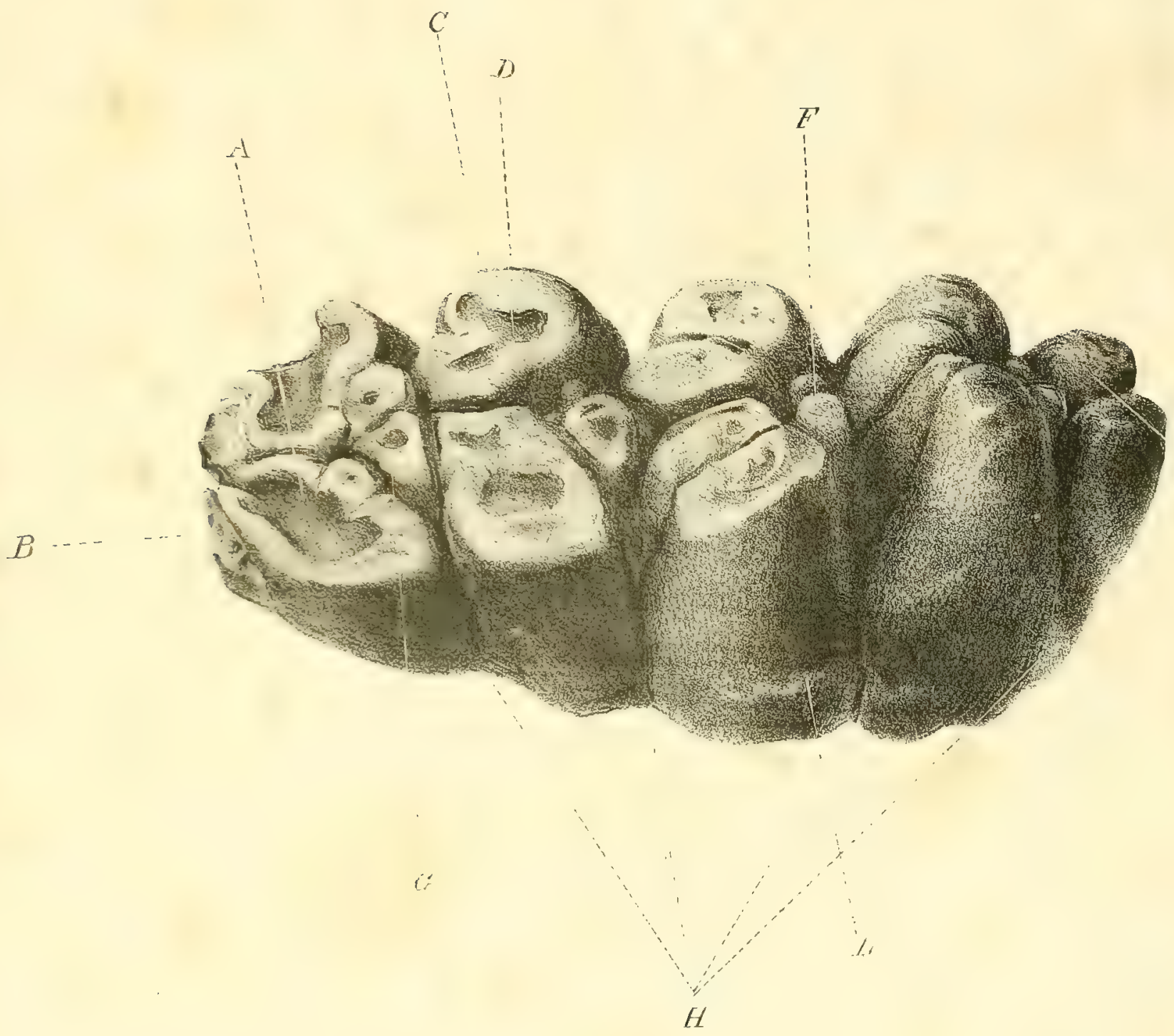

Z

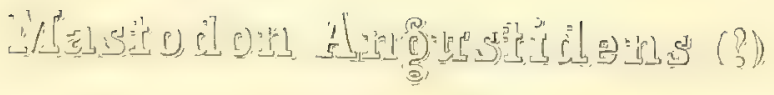



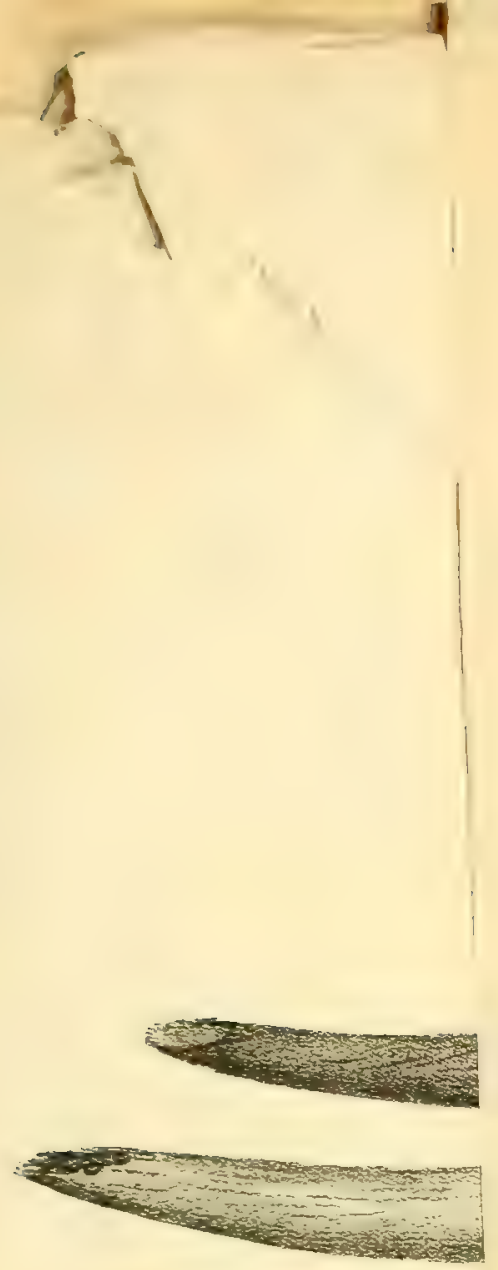


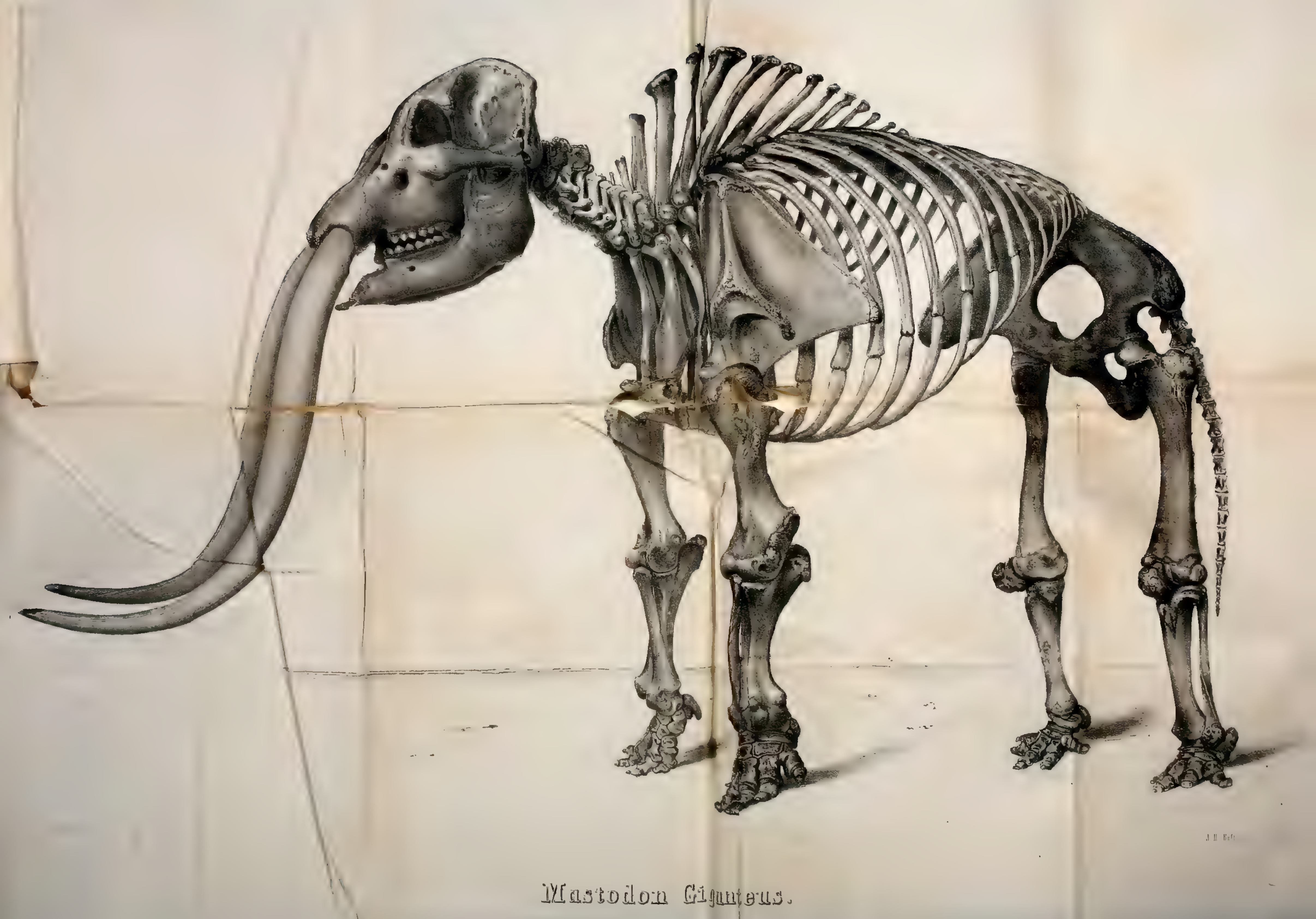




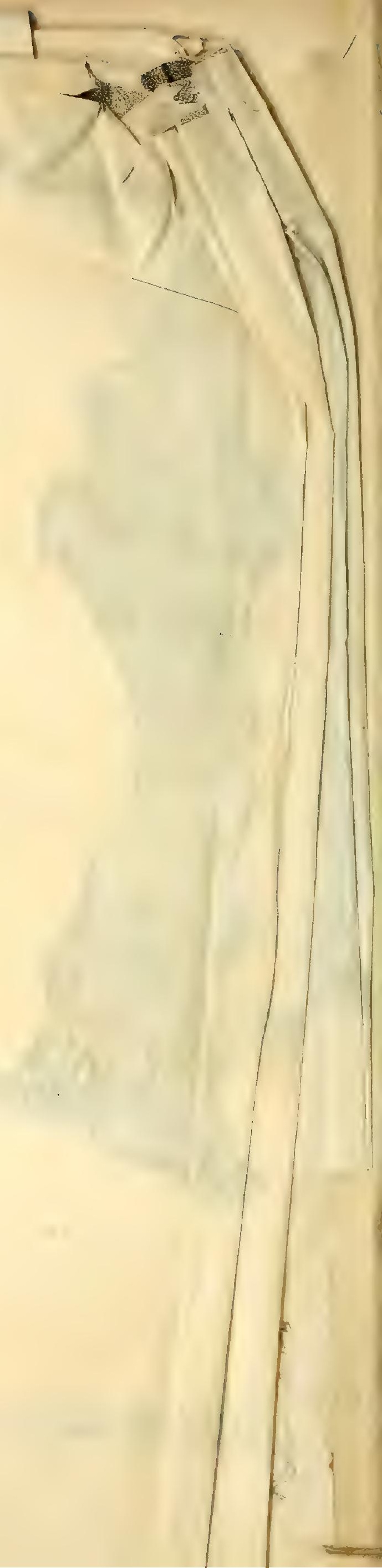








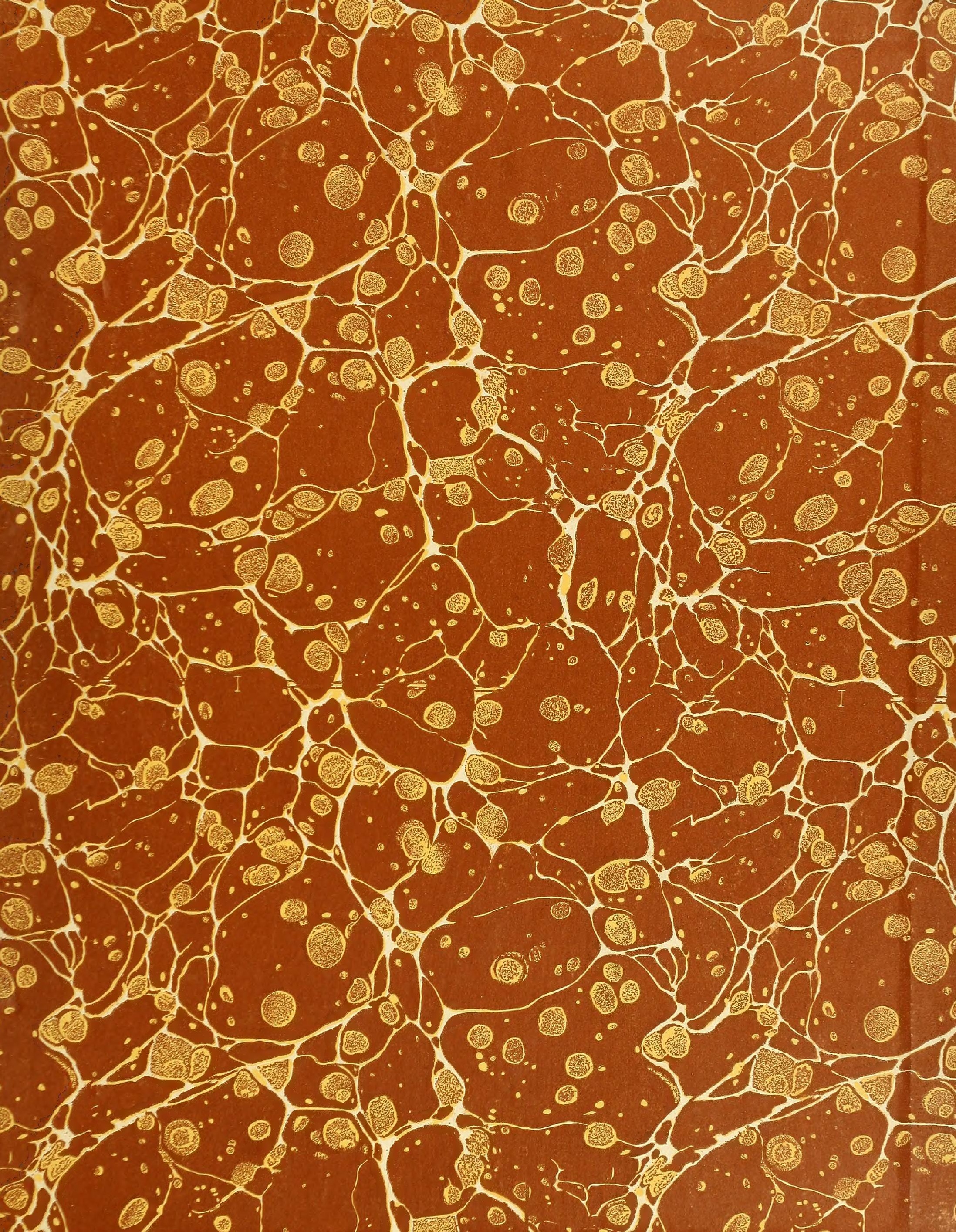


